\title{
Does Canada have a hidden 'wealthfare' system?: The policy history and household use of tax-preferred savings instruments in Canada.
}

\author{
by \\ Jennifer Robson
}

A thesis submitted to the Faculty of Graduate and Postdoctoral Affairs in partial fulfillment of the requirements for the degree of

Doctor of Philosophy

in

Public Policy

Carleton University

Ottawa, Ontario

(C) 2013, Jennifer Robson 


\begin{abstract}
Canada has account-based, tax-preferred savings instruments that are delivered through the financial services sector and that receive generous support through federal income tax incentives and direct transfers. These large tax and direct expenditures are all but are ignored in analysis of welfare policy. In this thesis, I ask whether there is adequate evidence to treat this set of tax-preferred savings instruments as a hidden welfare system, and whether the system is progressive or regressive in distributing public support for individual or household saving and accumulation of assets. I conclude that this set of policy instruments ought to be acknowledged as a welfare system and one that is largely regressive within an overall liberal welfare regime in Canada.
\end{abstract}

The thesis presents three different studies of the set of tax-preferred instruments: First, I present a history of each instrument in the set under examination. I conclude that each new instrument created is informed by past policy examples and replicates many of the same problems in the policy process and design. Second, I analyze data from the 1999 and 2005 Surveys of Financial Security, using a similar methodology to that used by Kerstetter (2002) and Morissette and Zhang (2006). Consistent with those earlier studies, I find that ownership of these tax-preferred savings vehicles, like all forms of assets, is more heavily concentrated among households in the top two quintiles of the distribution of net worth, and particularly in the top quintile. I also expand on these earlier studies noting, for example, that a non-trivial number of low-wealth households hold these taxpreferred forms of saving and, among those low-income users of the instruments, the 
savings amounts are higher than one might expect. The key finding of my analysis of the survey data is that half of the total assets of households in the top net worth quintile are in some combination of the tax-preferred savings instruments, with equity in their principal residence as the largest and most important. The third study is an exploratory qualitative study based on a series of focus groups with participants of different income levels. I find that, apart from constrained budgets and low marginal tax rates, the low-income participants face multiple barriers to using and benefitting from the selected instruments. 


\section{Acknowledgements}

Heartfelt thanks to the three members of my thesis committee, Professor Saul Schwartz, Distinguished Research Professor Allan Maslove (both of Carleton University) and Professor Elaine Kempson (of Bristol University). Your contributions to this thesis started well before you agreed to be on my committee since I have been fortunate to learn from each of you over several years of prior training and research. You each gave expert and constructive advice and feedback as this thesis progressed for which I am enormously grateful.

Sincere thanks also to the external members of the defense committee, Dr. Michael Prince, Lansdowne Professor of Social Policy at the University of Victoria and Professor Scott Bennett of Carleton University.

I would also like to acknowledge the support of the Director of Kroeger College, the Director of the School of Public Policy and the Dean of the Faculty of Public Affairs for giving me a chance to start my teaching career at Carleton University while conducting and completing the research for this thesis.

Thank you to a past employer, Peter Nares who first introduced me to the field of assetbased social policy. I am grateful for your wisdom, for our sometimes creatively conflicting views, but especially for your friendship. 
I'd also like to acknowledge the help in locating documents and answering specific questions that I received from federal public servants in the Canada Revenue Agency, the Department of Finance, Employment and Social Development and Library and Archives Canada. A similar thanks to Peter Lewis who agreed to share his organization's archival copies of public reports.

Thank you to the participants who took part in the series of focus groups that were the focus of the quantitative study. I am grateful for the time out of your own lives that you took for my research project and inspired by many of the personal stories and observations you shared with me.

Thank you to my extended family for asking (gently) how the thesis was coming and helping with occasional childcare.

Thank you to my partner, Mark, and our three children, Morgan, Isobel and Eloise. Mark even voluntarily proofread a penultimate draft. That is real love. You have been patient, encouraging and enthusiastic about my completing this thesis, even when I haven't been. I love you always and forever, no matter what. 


\section{Table of Contents}

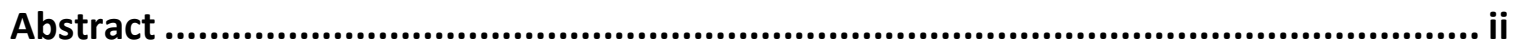

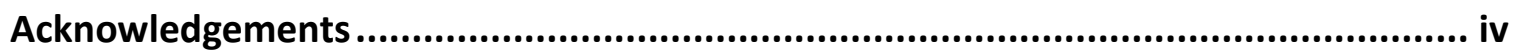

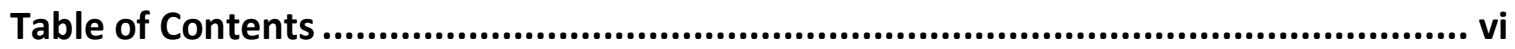

List of Tables .......................................................................................... ix

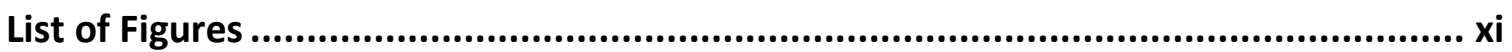

List of Appendices ...........................................................................................

Chapter 1: Introduction and aims of the thesis................................................ 1

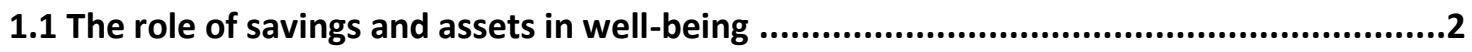

1.2 Choices in policy instruments: Tax-preferred, account-based instruments...................11

1.3 Prior research on tax-preferred savings and household assets in Canada ....................23

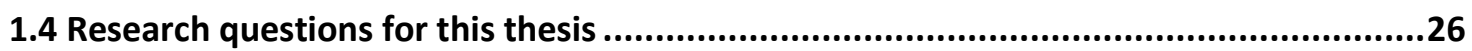

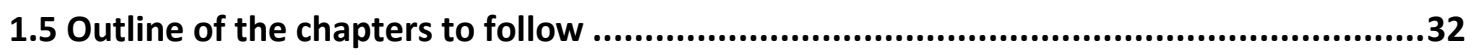

Chapter 2: Theory on personal savings and asset-accumulation ............................... 34

2.1 Historical ideas: Saving as moral act versus saving as macro-economic goal ................35

2.2 More current theoretical work on saving and assets.............................................47

2.3 Summarizing the individualist vs. institutionalist schools of thought...........................64

Chapter 3: Estimating public expenditures on tax-preferred savings instruments ...... 70

3.1 A brief description of the tax-preferred savings instruments.....................................72

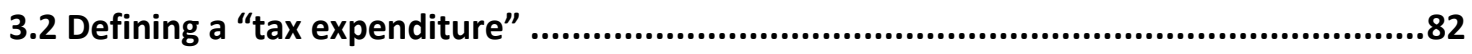




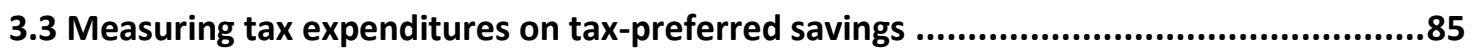

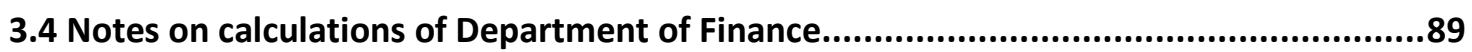

3.5 Estimates of tax and direct expenditures on tax-preferred account-based savings........95

3.6 Concluding thoughts regarding federal expenditures on tax-preferred savings...........104

Chapter 4: The start of tax-preferred savings: 1939-1971 ................................. 108

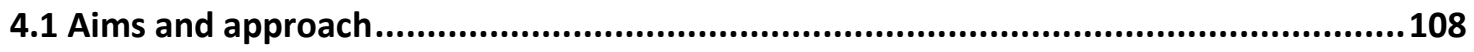

4.2 Contributions from the historical study and overview of key findings .......................113

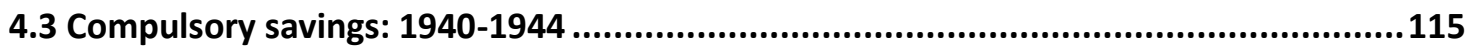

4.4 Registered Retirement Savings Plans: 1956-1971 .............................................135

Chapter 5: Relentless incrementalism: RRSPs and RHOSPs .............................. 160

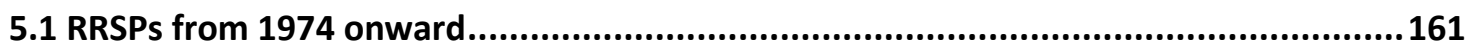

5.2 The Registered Homeownership Savings Plan 1974-1985 .......................................194

Chapter 6: Registered Education Savings Plans ............................................ 210

6.1 Launching a new private education savings plan ..................................................212

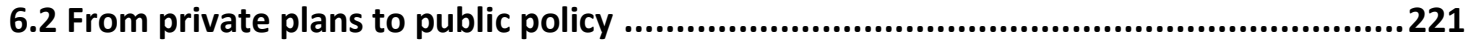

6.3 RESPs since 1996: Playing politics on private savings ...........................................233

Chapter 7: Completing the set: RDSPs and TFSAs ......................................... 266

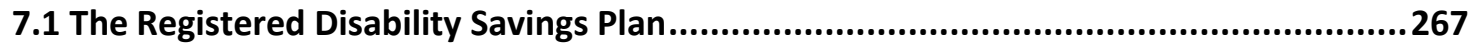

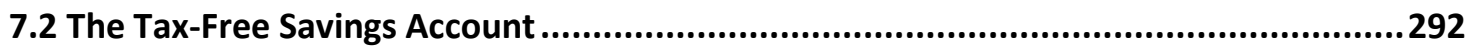

7.3 Overall conclusions from the retrospective analysis ..............................................311

Chapter 8: Survey data on household use of tax-preferred savings........................ 319

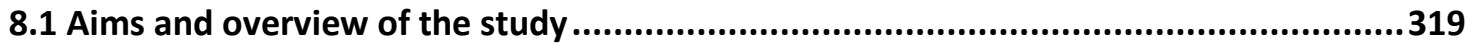

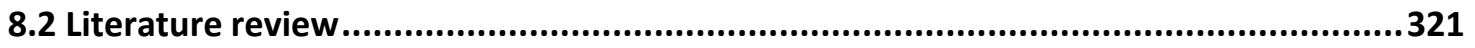




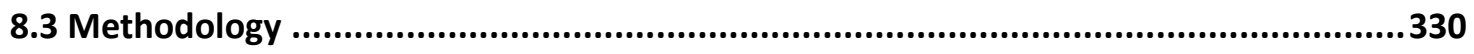

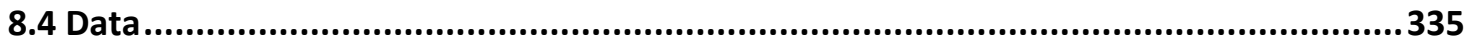

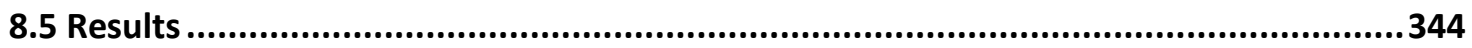

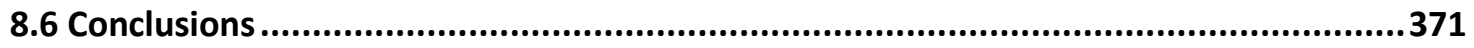

Chapter 9: Qualitative study on perceptions of, motivations for and policy impacts on

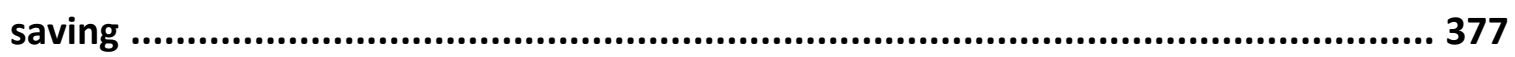

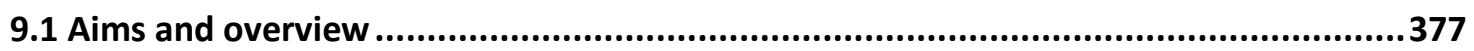

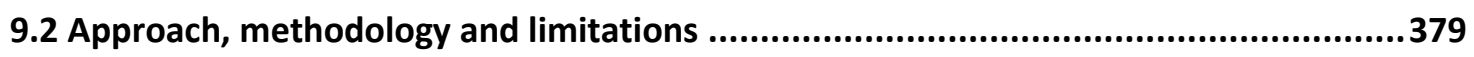

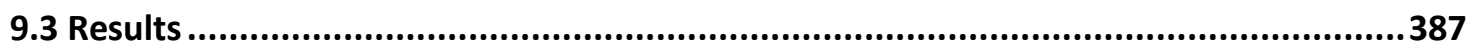

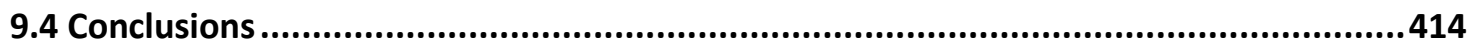

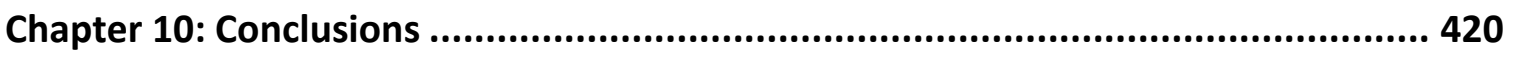

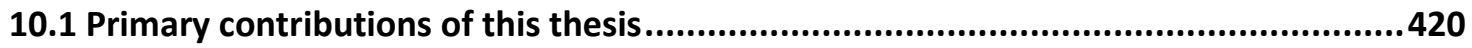

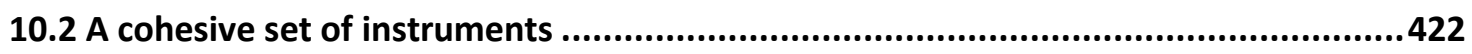

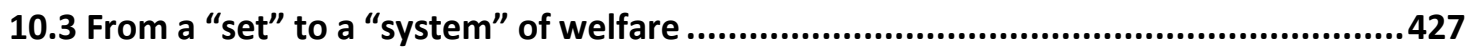

10.4 Does having a hidden welfare system matter? ..................................................442

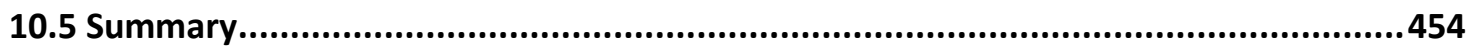

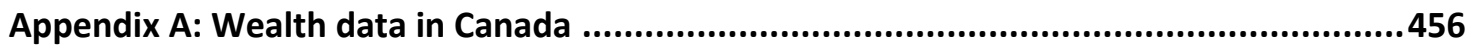

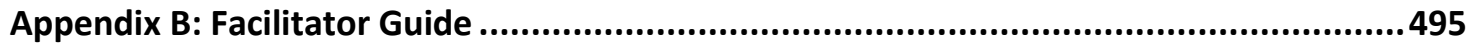

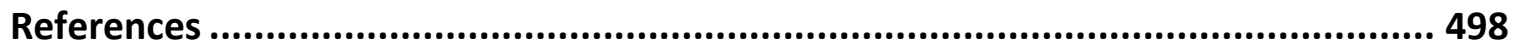




\section{List of Tables}

Table 1.1 Summary list of past and present tax-preferred and account-based instruments for individuals and households 18

Table 3.1a: Annual federal and tax and direct expenditures on tax-preferred account-

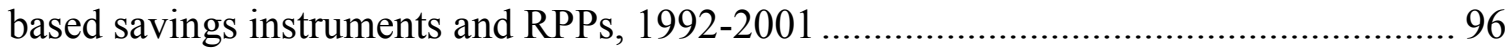

Table 3.1b: Annual federal and tax and direct expenditures on tax-preferred account-

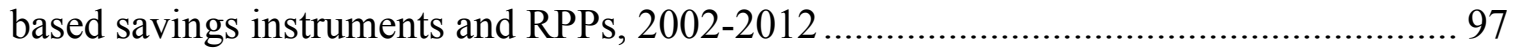

Table 4.1 Value of RRSP deductions (\$ millions), unadjusted .................................. 149

Table 5.1 Rates of self-reported RRSP withdrawals under the Lifelong Learning Plan as a percentage of all households with non-retirement RRSP withdrawal by household income quintile, 2008. 185

Table 5.2 Value of RRSP deductions, selected years and selected tax-filer characteristics (\$ millions, unadjusted)

Table 5.3 Data on RHOSP deductions selected years (\$ millions, unadjusted) 200

Table 6.1 Average annual education savings 1961-62, 1963, 2000 (unadjusted and adjusted, constant 2013 dollars) 218

Table 6.2 Ratio of median savings for a child's education outside vs inside of RESPs, 2001

Table 8.1 SFS sample size and response rates, 1999 and 2005 341

Table 8.2: Upper limits for net worth quintile, including pensions, median and mean net worth, 1999 (\$2005) 343

Table 8.3: Upper limits for net worth quintile, including pensions, median and mean net worth, 2005 (\$2005) 344 
Table 8.4: Incidence of RRSPs by net worth quintile, 1999 ..................................... 345

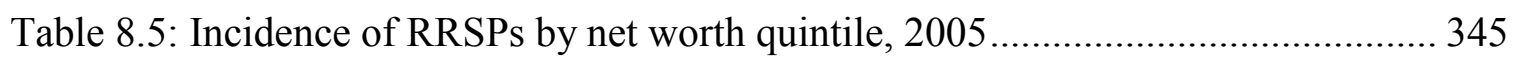

Table 8.6: Unconditional and conditional incidence of RESPs, 1999 and 2005 ........... 352

Table 8.7: Frequency, unconditional and conditional average values of RHOSPs, 1999

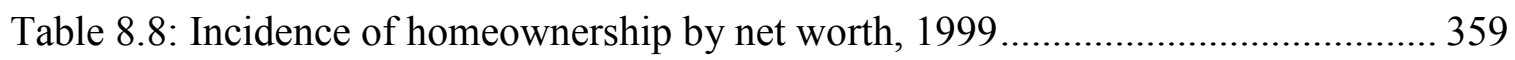

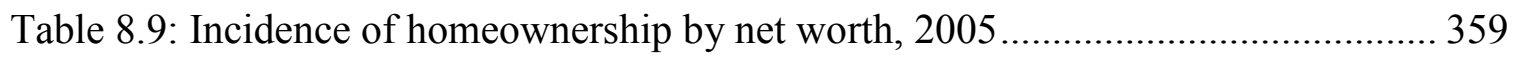

Table 8.10: Median portfolio shares in tax-preferred assets by net worth, 1999 and 2005

Table 9.1: Cross-tabulation of household income and net worth in Canada (2005) ...... 383

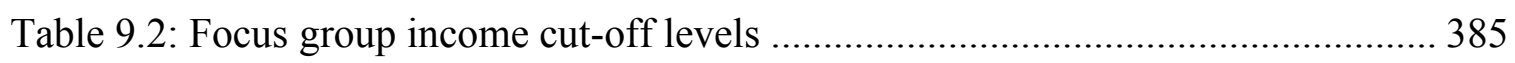

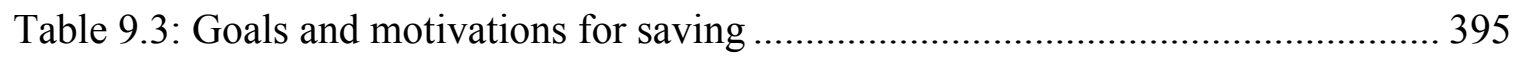

Table 9.4 Public programs for saving named by participants.................................. 401

Table A.1: Components of net worth for SFS 1999 and 2005, with variable names from

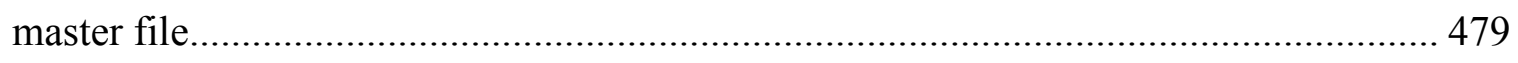

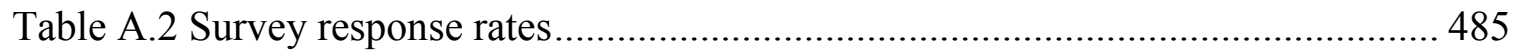

Table A.3: Imputation in 1999 and 2005 SFS master files (Statistics Canada 1999 and

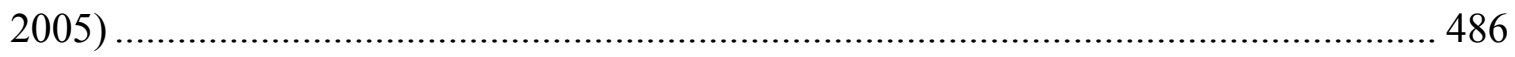

Table A.4: Median net worth by decile for 1999 using Morissette and Zhang (2007)

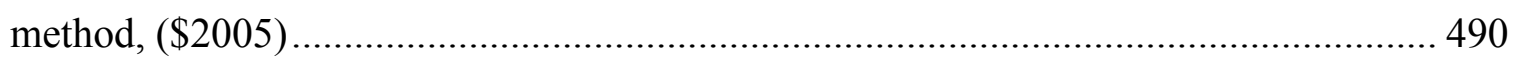

Table A.5: Median net worth by decile for 2005 using Morissette and Zhang (2007)

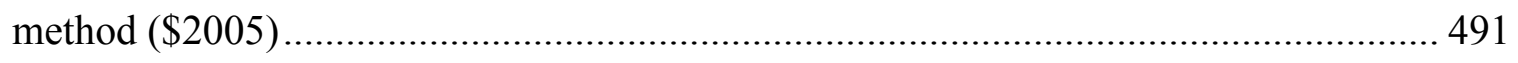

Table A.6: Summary of wealth data from four studies........................................... 493 


\section{List of Figures}

Figure 5.1: Recent trends in RRSP contributions, unadjusted dollars and percentage, 2000-2011

Figure 7.1: Federal budget 2008 table on equivalence RRSPs and TFSAs..................... 301

Figure 7.2 Laurin and Poschmann Table on TFSAs vs RRSPs..................................... 303

Figure 8.1: Unconditional and conditional median RRSP values, 1999........................ 348

Figure 8.2: Unconditional and conditional median RRSP values, 2005 ........................ 349

Figure 8.3: Conditional median RESP assets, 1999 ................................................... 354

Figure 8.4: Conditional median RESP assets, 2005 ..................................................... 355

Figure 8.5: Unconditional and conditional median housing equity, 1999 ...................... 360

Figure 8.6: Unconditional and conditional median housing equity, 2005 ...................... 361

Figure 8.7: Median portfolio (with pension assets) shares in tax-preferred assets by net

worth, 1999 365

Figure 8.8: Median portfolio (with pension assets) shares in tax-preferred assets by net worth, 2005 365

Figure 8.9: Median portfolio shares in tax-preferred assets by net worth, 1999 ............ 366

Figure 8.10: Median portfolio shares in tax-preferred assets by net worth, 2005 .......... 366 


\section{List of Appendices}

Appendix A: Wealth data in Canada ..................................................................... 456

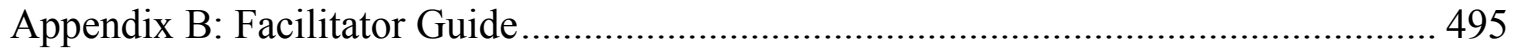




\section{Chapter 1: Introduction and aims of the thesis}

Researchers and policymakers may point to any number of determinants and indicators of individual or household well-being. These include, for example, adequate food and shelter, access to health services, labour force attachment, educational attainment and, perhaps mostly frequently, adequate income. To this list, many authors have added savings and assets with some calling for attention to 'asset-based policy' as a unique area of policymaking (for example, Oliver \& Shapiro, 1990; Sherraden, 1991; Sherraden 2005; Ackerman \& Alstott, 1999; Barr \& Sherraden, 2005; Midgley, 2005; Carter \& Barrett, 2006; Sussman \& Shafir, 2012). Starting from the principle that savings and assets are important aspects of wellbeing, 'asset-based policy' refers to a wide number of policy instruments available to government to distribute (or redistribute) savings and assets among citizens. This thesis examines one type of policy instrument—tax-preferred and account-based savings programs - and asks whether Canada's current tax-preferred savings programs should be considered as a coherent set. Furthermore, does the set of instruments constitute a hidden welfare system? If the instruments do in fact form a hidden welfare system, how does it distribute benefits for personal and household saving among citizens? I adopt the perspective that households for whom tax-preferred assets are relatively more important to their total wealth may be more dependent on a form of welfare system compared to households for whom these assets are a small or even nonexistent part of their total wealth. This is comparable, in some ways, to oft-mentioned analyses of household dependence on government transfers among lower and modest income families. While each of these savings instruments is visible, particularly as 
consumer financial products, there has been almost no attention to their common features and their effects on the distribution of savings and wealth.

This introductory chapter first reviews the literature on the welfare effects of savings and assets to establish that the distribution of financial assets is important to microeconomic policy. To promote these outcomes, governments have many different policy instruments at their disposal. I argue that tax-preferred and account-based instruments are worthy of further study because they blend both the tax-related incentives that have been examined in one tradition of research and some of the other factors the same literature has noted as important and unexplained. I then introduce the set of tax-preferred savings instruments that will be the focus of the new research presented in Chapter 4 through Chapter 8. Next, this chapter uses Esping-Andersen's theory regarding welfare typologies to set a basis for evaluating these instruments as a welfare system. The final section of this introduction provides an overview of the contents of the chapters to follow.

\subsection{The role of savings and assets in well-being}

There are at least two types of reasons that governments may want to encourage their citizens to save and build assets. The first type is macroeconomic. Pools of financial capital are required for investment by domestic firms. Governments can try to help firms attract investment capital from foreign sources, but domestic savings may be easier for firms to capture and use (Kosters, 1992; Organization for Economic Cooperation and Development, 2007). 
Governments may also want citizens to have private savings to smooth consumer spending and government revenues over the long-term (Kosters, 1992; Ballentine, 1992; Bostic, Gabriel \& Painter, 2009). Economics has long treated saving and capital as stored income for future use (Friedman, 1957; Modigliani, 1986) and governments may want to ensure that the contribution of consumer spending to the economy can continue even in times of employment and wage losses or when the labour force is shrinking, perhaps due to an aging population. It is also possible that encouragement to save and build assets will lead to some real increase (more than just smoothing between two periods) in consumer spending if households experience a so-called 'wealth effect' (Case, Quigley \& Shiller, 2013). ${ }^{1}$ As stored income for future use, governments that anticipate long-term changes to their population base for taxation (as in the case of an aging population) may want to encourage households to defer the taxation of some share of current household incomes to a later period when revenues from other taxable sources (particularly earned income) are expected to decline or demands for public spending (for example, on healthcare) are expected to increase (Mintz, 2009).

The second type of reason for promoting household savings and asset accumulation is microeconomic. ${ }^{2}$ Maintaining a constant level of income over the lifetime of individuals

\footnotetext{
${ }^{1}$ The 'wealth-effect' is the increase in spending that arises from an increase in the value of an asset. It is separate from any effect from additional income generated by the asset and arises instead from a perception of being richer and able to afford an increase in consumption.

${ }^{2}$ Assets may be accumulated through a number of methods such as gifts, inheritances and increases in market value as well as savings. Savings here refers to the act of setting
} 
and families is one such microeconomic goal, enabling them to avoid or mitigate risks to their wellbeing from reductions in consumption (Friedman, 1957; Modigliani, 1986). In this perspective, income is the key economic resource needed for wellbeing and assets are simply stocks of stored-up income flows to be used for future consumption needs. There is a wide-ranging literature that debates the adequate level of income needed for wellbeing, the importance of the sources of income and the importance of inequality in the distribution of income in a population (see for example Friedman, 1957; Titmus, 1962; Wilkinson \& Pickett, 2009). But a household's income does not necessarily predict its levels of saving or ownership of assets. Neither does a household's assets necessarily predict its future income. At least one international study of the relationship between measures of household income and household wealth finds a strong but far from perfect relationship between these important determinants of wellbeing (OECD, 2011). The distributions of household income and wealth have a similarly imperfect relationship in Canada. My own analysis of the correlation of income and wealth in Canada (discussed at section 9.2, Table 9.1) finds a strong and significant correlation (.557), but one that is imperfect and lower than the international average. For example, among households in the top $20 \%$ of the distribution by income, only $45.9 \%$ are also in the top quintile for net worth. Similarly, only $53.6 \%$ of households in the bottom income quintile are also in the bottom quintile for net worth.

aside money out of current income flows. The conceptual distinctions between saving, assets and wealth are discussed in Appendix B. 
Another rationale for asset-based policy is that there is an increase to wellbeing from holding and accumulating savings and assets that is separate and apart from their value as stored income. This has been termed the 'asset-effect' in the literature. Sherraden (1991) hypothesized that assets generate several positive impacts on wellbeing in addition to generating income, for example, in the form of investment returns) and smoothing consumption. He argues that assets enable individuals to take productive risks (such as returning to school or starting a new business) that can lead to long-term improvements in economic security and that ownership encourages individuals to attend to their assets, making new investments to maintain or improve their original value. Sherraden also argues that the act of saving and accumulating an asset can enhance an individual's sense of efficacy and their inclusion and participation in the wider economic, social and political community they live in. There is a disjunction in the literature on savings between those authors principally concerned with the macroeconomic effects (and policy levers for generating) private saving, and those principally concerned with the microeconomic effects of (and again policy levers for influencing) saving and assets on individuals and households. Within the body of literature on these microeconomic effects, there is a further subset that prioritizes the wellbeing of citizens with lower socioeconomic status. This thesis belongs to this subset.

My chief concern are those households who live in low-income and with low wealth. poverty or with very limited financial resources. At times in this thesis, my discussion includes attention to measures of household income as a flow out of which money might be saved up and as the primary basis on which income taxes are calculated. At other 
times, my discussion turns to the direct effects on the assets of households (in particular Chapter 8). References to "income" and "wealth" throughout are made deliberately and with care to the context for discussion, recognizing a close if imperfect relationship between these constructs. The distribution of income and wealth in Canada overlap but imperfectly so.

Studies of the effects of holding tangible assets, namely housing, do find some evidence for improvements to wellbeing on a range of measures. Homeownership has been found to be associated with increased civic engagement and social capital (Steinberger, 1981; Kingston \& Fries, 1994; DiPasquale \& Glaeser, 1999) and with increased family and residential stability (Rohe \& Stewart, 1996). Other studies find that homeownership is associated with increased economic security by increasing participation in paid employment (Goss \& Phillips, 1997; Miller \& Montalto, 1998). Research on vehicle ownership also finds that having a car increases employment, particularly for households on income assistance (Raphael \& Rice, 2002; Baum, 2009) although Gurley and Bruce (2005) suggest that it is access to the vehicle and not the ownership that is the important mechanism.

Another area of research asks whether ownership of one asset leads to increases in the ownership of other assets. The causal mechanism might be simply that some households are naturally 'savers' and accumulate more assets of all kinds compared to 'non-savers' (Gale \& Scholz, 1992). Alternatively, it might be that ownership of an asset reduces costs (for example, the costs of borrowing when debt is secured by an asset, and as a 
mortgage is paid off over time, the ongoing costs of housing) and therefore increases disposable income out of which more savings can be generated. Engeland, Lewis and Shillington (2006) find that homeowners are more likely to have financial savings than renters even holding age and income constant. Turner and Luea (2009) constructed a model based on data covering a fifteen-year period to look at net worth outcomes of American households and find that homeownership is associated with an increase in total net worth even when other factors such as age and income are controlled. Outside of homeownership, some research has found that financial capital for higher education (in the form of personal savings or early commitment programs) is associated with increased investments in human capital (Conley, 2001; Barr-Telford, Cartwright, Prasil \& Shimmons, 2003; Harnish, 2009).

A third question in the literature on the microeconomic benefits from private saving is whether financial assets have a positive impact on household well-being that is distinct from their value in smoothing consumption (as in the case of precautionary or retirement savings) or permitting the purchase of some other asset (such as saving to buy a house or pay for higher education). Reviews by Scanlon and Page-Adams (2001), Marks, Headey and Wooden (2005), and Lerman and McKernan (2008) find a wide range of effects associated with financial wealth including improvements to physical health, psychological well-being, family well-being, child development, household earned income, individual coping with transitions, and education outcomes of children. 
As Lerman and McKernan (2008) note, there is a substantial problem of endogeneitythe ownership of an asset (financial or tangible) may be the result or cause of the observed outcomes that seem to be related to that ownership. This problem is perhaps most obvious in the relationship between household assets and earned income where there are good arguments for the causal relationship to work in either direction.

However, the problem of endogeneity also applies to other associations with having financial assets. For example, do households who are, for whatever reason, innately more capable of managing transitions (such as job losses or marital dissolution) have some quality that makes them more likely to save? If so, then an association between financial assets and successful outcomes at transitions may not be a result of the financial assets. Further, as McKnight (2011) notes, it is possible that the asset-rich and the assetpoor are different in some unobserved way even when the dependent variable (for example, psychological wellbeing or education outcomes of children) is the same. Without addressing this problem of endogeneity, it impossible to say with any confidence how important financial assets are related to other indicators of wellbeing.

Advocates of government intervention to improve the financial assets of a wider base of households (see, for example, Ackerman \& Alstott, 1999; Sherraden, 1991; Boshara, 2001; Barr \& Sherraden, 2005) must be able to demonstrate that having financial assets is a goal worthy of public policy intervention in and of itself. They have based their arguments on the above 'asset-effect' arising from financial capital alone. As Rowlingson and McKay (2012) write, there has been "remarkably little strong evidence 
that such an effect exists" (p.16). Three comprehensive reviews (Page-Adams, 2001; Marks et al., 2005; Lerman \& McKernan, 2008) of a large number of correlational studies suggest strong associations but do not adequately deal with the issue of endogeneity to show a directional and causal relationship between financial assets and wellbeing, independent of intervening variables.

A first effort in 2001 to demonstrate an asset effect came from Bynner who used a large set of panel data from the U.K. National Child Development Study to examine the relationship between personal financial assets at age 23 and a range of wellbeing outcomes measured at age 33, while controlling for socioeconomic status at birth and through childhood, as well as homeownership and employment earnings at both ages 23 and 33. Using OLS regression, Bynner estimated the effects of financial assets on labour market attachment, health, family life and citizenship. He reported that increases in financial assets at age 23 were associated, at age 33 , with increases in full-time employment and improvements in self-rated health, and with reduced unemployment, smoking, marital dissolution and 'malaise'. ${ }^{3}$ Among women, increases in financial assets were also associated with reductions at age 33 in unemployment, marital breakdown smoking and political cynicism. However, as Rowlingson and McKay argue, Bynner did not adequately address the endogeneity problem since there may be some unobserved

${ }^{3}$ Bynner reports that the panel survey includes a variable of 'malaise' as a measure of low-grade psychological illness such as mild or moderate depression or dissatisfaction with one's life. 
quality responsible for both the difference in assets at age 23 and observed differences in wellbeing at age 33 .

In a more recent paper, McKnight (2011) improved upon Bynner's 2001 study. Using the same British panel data and examining observed financial assets at age 22 and outcomes at age 33, McKnight extended the analysis to include observed outcomes at age 42 but more importantly she appears to have completed the only study of asset effects on wellbeing to make an effort to control for endogeneity. She developed a treatment effects model, in addition to a simple OLS regression model comparable to Bynner. McKight's treatment effects model accounted for unobserved differences in "desire and ability to accumulate and/or acquire assets" to estimate a control where none otherwise exists. ${ }^{4}$ Her estimates of the asset effect using the OLS regression were larger but did not disappear under the treatment model. Active assets of $£ 100^{5}$ or more at age 23 led to an increase in wages at age 33 by $5 \%$ for men and by $7 \%$ for women. Under the treatment effects model, this declined slightly to an increase in wages at age 33 of $4 \%$ for men and $5 \%$ for women. Estimates for the effect of assets at age 33 on wages at age 42 were even larger at $10 \%$ under the OLS and $8 \%$ under the treatment effects model for both men and women. On her measure of physical health, she found that assets led to improved health at age 33 and 42 but most of the effect was among women. The measure of

\footnotetext{
${ }^{4}$ Briefly, she constructs a control variable based on the assumption that individuals in the sample who have more choice and ability to acquire or build an asset at the first observation (at age 23) will also be more likely to benefit from holding that asset by the second observation (at age 33 ) so that by a third observation (at age 42) some estimate of a treatment effect is possible.

${ }^{5}$ McKnight defined active assets as either $£ 100$ in liquid assets or $£ 200$ in illiquid assets.
} 
psychological health showed some improvement in reducing risk of depression at age 33 when assets are present at age 23 and a stronger effect by age 42 for assets at age 33 . It is important to note that McKnight's model did not distinguish between how the assets were used or levels of debt at a given point in time, but it did control for a range of other characteristics that might predict asset-holding at age 23 or 33 including social class and finances of the family of origin, educational performance, a proxy measure of health in childhood and attitudinal differences.

McKnight's study has not been replicated as of yet. However, taken together with the study by Bynner and the larger body of simple correlational research, it seems that there may be some validity to a claim that assets, including financial assets, have positive effects on individual and household wellbeing that are worthy of attention from policymakers.

\subsection{Choices in policy instruments: Tax-preferred, account-based instruments}

There are a number of policy instruments available to a government wishing, whether for macroeconomic or microeconomic reasons, to increase the savings and assets of its citizens. Governments can transfer capital in the form of public services. For example, they can provide education to its citizens out of general tax revenues, thus increasing the stock of human capital of its population. Governments can also transfer capital as grants of private goods. For example, past Canadians governments have provided grants of land, housing or lump sum financial assistance through the Dominion Land Grants and 
Veterans' Charter (Axworthy, 2006). ${ }^{6}$ Governments can also regulate the conditions under which citizens use markets (both deposit-taking financial institutions and investment markets) to save and seek returns on investments. Governments can offset household demand for private saving by creating social insurance programs to replace private saving, particularly for loss of wages and longer-term retirement income needs (Hubbard, Skinner \& Zeldes, 1995). Finally, governments can also create incentives for private saving and asset acquisition through tax and transfer (including voucher) ${ }^{7}$ systems (Kosters, 1992; OECD, 2007; Daniels \& Trebilcock, 2005). This is not an exhaustive list of policy instruments but illustrates some of the breadth of the relevant choices.

Within the subset of tax and transfer instruments, there is still more variation.

Governments can identify classes of investment that will receive preferential tax treatment. For example, governments might apply a lower rate of income tax to savings

${ }^{6}$ The Dominion Land Grants through the $19^{\text {th }}$ and very early $20^{\text {th }}$ centuries offered parcels of land to able-bodied men willing to settle and farm lands in several Canadian provinces, particularly the Prairies. The Veterans' Charter provided financial and housing benefits to returning servicemen following each of World War I and, with substantial enhancements, World War II. Benefits included lump sum cash payments, housing assistance, education and training assistance and capital for small business development. In the immediate post-war budgets, demobilization entitlements under the Veteran's Charter were the largest category of federal budgetary expense.

${ }^{7}$ As Daniels and Trebilcock (2005) note, voucher systems of delivery are similar in their basic design to tax and transfer mechanisms. Both allow a consumer to make a choice between competing market providers of a good or service and require direct contact between the consumer and the market provider to access that service. Vouchers differ from transfers only in so far as they are conditional on certain consumer choices and market providers whereas transfers of cash assistance place no restrictions on use even if there are restrictions on eligibility to receive the transfer. Many of the design issues related to vouchers including targeting, eligibility, optimal value of the benefit and supply-side failures apply equally well to policies that provide incentives through tax treatment or cash transfers. 
bonds over investments in equities (Hubbard, 1985; Poterba \& Samwick, 2002; Bergstresser \& Poterba, 2004; Dimmock \& Kouwenberg, 2010). They might offer deductions against current taxable income and defer taxation to future time periods when marginal tax rates may be lower (Venti \& Wise, 1986; Veall, 2001; Milligan, 2003; Nishiyma, 2009; Alan, Atalay, Crossley \& Jeon, 2010). Or they can offer credits for specific forms of asset-holding such as homeownership (Jappelli \& Pistaferri, 2007; Saarima, 2010). In this literature, some authors find that these tax incentives have effects on observed household savings and assets, but others find no such evidence.

Some authors note that the variation in the tax treatment of equity and bond investments and the existence of tax-deferred savings provide a natural experiment and that households, if sensitive to tax incentives, should respond by allocating their total household savings and assets in the most tax-efficient ways possible. Yet most studies find that portfolios are not optimally allocated, a problem referred to as the asset-location puzzle (Zhou, 2009) although as a household's marginal rate of taxation increases, its allocation gets closer to optimal (Amromin, 2003; Poterba \& Samwick, 2002; Bergstresser \& Poterba, 2004).

Other studies construct models, using either survey or synthetic data, to estimate how much households would save if a tax incentive were removed or altered. Some authors conclude that nearly all saving observed in tax-deferred instruments would have been saved in some other form and that the tax incentive is therefore ineffective (Ragan, 1994). However, most conclude that some meaningful portion of the saving is new and that 
savings rise as the value of the tax incentive increases (Gale \& Scholz, 1992; Venti \& Wise, 1986; Milligan, 2003).

Finally, some researchers look at household responses to policy changes in the taxtreatment of certain assets such as housing (Jappelli \& Pistaferri, 2007; Saarima, 2010; Munroe \& Kopczuk, 2013) and luxury goods (Joulfaian, 2013; Echevin, 2013). When the tax treatment is different from one period to the next, or between substitute assets, these researchers examine whether households adjust their portfolios to maximize their after-tax wealth. Jappelli and Pistaferri (2007) and Saarima (2010) found that changes to the tax-deductibility of mortgages for homeowners have almost no impact on rates of homeownership or household mortgage debts. By comparison, Munroe (2013) found that households are sensitive to differences in the taxation of housing transactions when tax rates increase sharply at a specific sale price. Echevin (2013) looked at changes in the allocations of French households in response to an increase in the surtax on household wealth and finds that there is no significant overall reallocation in household portfolios to avoid or pay for an increased wealth tax.

Taken as a whole, the literature on the effectiveness of tax-based instruments for influencing household savings is mixed. The tax incentives may change behaviour but only among households with sufficient tax liability. In some cases, household preferences for particular forms of saving and assets, particularly housing or luxury goods, are largely unresponsive to tax incentives. Bradford (2000) notes that the sheer variety and complexity in the tax treatment of savings examined in the literature is too 
great to support any meaningful generalizations about the effects of all taxation instruments on all forms of saving on all households. The observed outcomes in household savings and wealth may have more to do with factors not usually considered in traditional economic analysis (Gale \& Scholz, 1992). In addition to differences in marginal taxable income, households are likely to have different preferences for saving, different competing demands on available resources and other non-financial differences in their ability to make use of instruments for saving and accumulating assets. When taxpreferred instruments take the form of account-based instruments, there may be reason to suspect they will have more impact because they will act on these other variables in addition to delivering a tax-incentive.

A 2007 study by the Organization for Economic Cooperation and Development (OECD) defines tax-preferred accounts as "savings accounts that offer tax advantages" (p.7). The same study notes that Canada has, like many other comparable countries, a number of tax-preferred account-based instruments aimed at increasing household savings and assets (OECD, 2007). These instruments offer preferential tax-treatment but also create new vehicles for saving through new categories of accounts for specific forms and goals of saving. Generally the sale, structure, investments and deposit and withdrawal activity in these accounts are subject to government regulation to qualify for the preferential tax treatment. Currently in Canada, these include Registered Retirement Savings Plans (RRSPs), Registered Education Savings Plans (RESPs), Registered Disability Savings Accounts (RDSPs) and Tax-Free Savings Accounts (TFSAs). A complete list also includes two other now-defunct account-based and tax-preferred instruments: the 
Registered Homeownership Savings Plans and the much-older and short-lived system of individual compulsory savings collected through the personal income tax system during World War II.

Finally, for reasons discussed below, I add owner-occupied homes to this list. Canada does not charge a federal or provincial property tax. ${ }^{8}$ Nor does Canada tax homeowners on the amount they save by owning over renting the same housing (Perry, 1951; Horner, 1983). When the government introduced a new tax on capital gains in the 1970 's ${ }^{9}$ the capital gains realized upon the sale of owner-occupied homes were exempt from the tax and that exemption has been maintained consistently for the last 40 years. Several studies have suggested that households treat their equity in real property as another form of savings account (Cocco, 2004; Klyuev \& Mills, 2007), even as one account in their overall portfolio for long-term savings goals such as retirement income security (Schellenberg \& Ostrovsky, 2010). Furthermore, home equity has become more liquid and fungible over time as a result of new financial services products (such as home equity

\footnotetext{
${ }^{8}$ Under federal-provincial tax agreements of 1941 and 1947, provinces agreed to suspend provincial taxes on real property. In the post-war period, provinces shifted away from taxes on real property leaving it as a form of taxation for local governments (Perry, 1951). The notable exception is in the case of land transfer taxes payable to a provincial government in some but not all provinces. For example, in Ontario, homebuyers pay a one-time tax equivalent to between $0.5 \%$ and $2 \%$ of the purchase price, with reductions for first-time buyers.

${ }^{9}$ A capital gain (or loss) is the difference between the cost of an asset when it was bought and the price when it is sold. For example, an asset bought for $\$ 20$ and later sold for $\$ 30$ would create a capital gain of $\$ 10$ at the time of the sale. Capital gains are taxed at the same rate as taxable income but only one half of the total gain is subject to taxation. Capital gains exemptions on housing do not apply to secondary residences or investment properties. Taxpayers can also claim a deduction to reduce or eliminate their effective tax liability, up to a cumulative lifetime capital gains deduction limit of $\$ 750,000$.
} 
loans and reverse mortgages) that offer credit secured against equity in an owneroccupied home.

The value of equity in a primary residence grows without taxation, can be withdrawn (either through sale or through financial products that render some portion of the equity liquid) without taxation. Regular mortgage payments act, in many respects, as a kind of forced savings, requiring borrowers to repay some part of their debt and improve their equity stake in the asset. These characteristics make housing equity comparable, in all important respects, to other tax-preferred registered instruments.

Table 1.1 (below) summarizes the final list of these tax-preferred and account-based instruments to be discussed in this thesis. 
Table 1.1 Summary list of past and present tax-preferred and account-based instruments for individuals and households

\begin{tabular}{|c|c|c|c|}
\hline Instrument & $\begin{array}{l}\text { Introduced } \\
\text { (year) }\end{array}$ & $\begin{array}{l}\text { Terminated } \\
\text { (year) }\end{array}$ & Purpose \\
\hline Home equity & NA & Ongoing & $\begin{array}{l}\text { Owner-occupied housing is } \\
\text { exempted at all times from } \\
\text { taxation on income in Canada, } \\
\text { including capital gains realized at } \\
\text { time of sale }\end{array}$ \\
\hline Compulsory savings & 1942 & 1944 & $\begin{array}{l}\text { Raise wartime revenues, reduce } \\
\text { inflation and defer income for } \\
\text { post-war reconstruction }\end{array}$ \\
\hline $\begin{array}{l}\text { Registered Retirement } \\
\text { Savings Plans (RRSP) }\end{array}$ & 1957 & Ongoing & $\begin{array}{l}\text { Individual savings for retirement } \\
\text { outside of workplace pensions }\end{array}$ \\
\hline $\begin{array}{l}\text { Registered } \\
\text { Homeownership } \\
\text { Savings Plans } \\
\text { (RHOSP) }\end{array}$ & 1974 & 1985 & $\begin{array}{l}\text { Individual savings for } \\
\text { homeownership }\end{array}$ \\
\hline $\begin{array}{l}\text { Registered Education } \\
\text { Savings Plans (RESP) }\end{array}$ & 1974 & Ongoing & $\begin{array}{l}\text { Family savings for higher } \\
\text { education }\end{array}$ \\
\hline $\begin{array}{l}\text { Registered Disability } \\
\text { Savings Plans (RDSP) }\end{array}$ & 2006 & Ongoing & $\begin{array}{l}\text { Family savings for dependent } \\
\text { children with disabilities }\end{array}$ \\
\hline $\begin{array}{l}\text { Tax-Free Savings } \\
\text { Account (TFSA) }\end{array}$ & 2008 & Ongoing & $\begin{array}{l}\text { Individual savings for any } \\
\text { purpose }\end{array}$ \\
\hline
\end{tabular}

Not withstanding the mixed evidence for the effectiveness of tax incentives for saving, tax-preferred and account-based instruments may have certain advantages over other policy instruments in shaping household ownership and acquisition of assets. These are summarized below:

- Benefits are more transparent. The face value of the tax benefit or transfer is clear both to recipients and to the broader public. This offers political advantages 
because citizens can know how much each beneficiary is receiving. By comparison, promoters of social insurance systems funded through insurance premiums and public goods or services funded through taxes have a more difficult task in demonstrating costs and direct financial benefits to voters.

- Benefits can be highly targeted, particularly where the personal income tax system is involved. Compared to public delivery of goods or services, there is a lower risk of deadweight loss and free-rider problems. Benefits can be targeted to specific subpopulations, particularly where ability to pay is concerned, and can be regularly adjusted, at least annually when tax returns are filed.

- Separate vehicles are created for separate savings goals. Each separate registered vehicle is associated with some normative goal for saving. For example, RRSPs are for retirement saving and RESPs are for saving for a child's education. These separate labels signal which savings goals the government is prepared to support. ${ }^{10}$

- Benefits are tied to positive individual behaviour. Social insurance systems provide mechanisms for pooling risk and deliver benefits when eligible citizens face the risks for which the insurance is intended (for example, job losses in the case of Canada's Employment Insurance program). In the case of the taxpreferred savings instruments, the benefits are paid only after the account-holder

\footnotetext{
${ }^{10}$ As will be discussed in Chapters 4 through 6, there are exceptions to this feature. For example, the Tax-Free Savings Account does not restrict the purpose of the savings or their uses when withdrawn. However, it was introduced as a complementary vehicle for retirement savings alongside RRSPs.
} 
has taken some desired behaviour (opening an account or making deposits out of their own money).

- Distribution and administration is largely outsourced. Tax-preferred savings vehicles are all, without exception, available to savers only through consumption of private financial services. RRSPs, mortgages, RESPs and the like cannot be obtained from any government department or agency, only through a regulated financial service provider. These financial service providers have responsibility for marketing and distributing the accounts and for the ongoing administration of the accounts. This includes, for example, receiving deposits, calculating interest, preparing account statements, preparing forms for tax purposes and reporting on account balances and activity to government. Government's role in the implementation is substantially reduced, compared to administration of public services or social insurance programs, even when the instrument includes a cash transfer in addition to a tax-benefit.

In choosing between different policy instruments to achieve some desired goal—in this case improving the savings and assets of individuals and households - the advantages of tax-preferred account-based may be important to policy-makers (OECD, 2007). However, I believe that these instruments also have effects on citizens that have been largely overlooked. These are listed below:

- Requiring attachment to mainstream financial services. Saving in each instrument can only be achieved by buying a financial product from a regulated, mainstream 
financial services provider such as a bank, credit union, trust company or brokerage. For citizens with only a very weak (or even no) engagement with mainstream financial services, this may be an important obstacle to using the policy instruments. Marginalized citizens with more limited personal resources, the very ones who might see a proportionally larger improvement in their economic wellbeing by acquiring new assets, are also more likely to have more negative perceptions of financial institutions and to feel they are unwelcome in retail banks or credit unions (Buckland, 2010).

- Using tax exemptions, deferrals and deductions. Each instrument has some preferential tax treatment, whether exemption (deposits and earnings in the account are not taxed as income), deferral (deposits and earnings in the account are taxed later, likely at a lower rate), or deductions (some deposits trigger a deduction against taxable income). These benefits are only useful when an account-holder has a tax liability and the benefits rise with marginal income tax rates.

- Normalizing certain kinds of saving. For citizens with savings goals that conform to the label of each separate instrument, the distinct accounts may help them save simultaneously for different goals. Behavioral economists have noted that savers typically maintain "mental accounts" to organize and prioritize resources for different purposes, even if the dollars are held in one pool (Thaler, 1990; 1999). Making these "mental" accounts explicit may improve savings outcomes when they match the goals (or successfully shape the goals) of citizens (Thaler, 1999). The goals chosen also reflect certain social norms about which assets are and are 
not worthy of saving towards or worthy of government assistance. However, for savers with goals that are outside of these social norms, the labels attached to each account may create a further barrier. Citizens with smaller resources may be more likely to have goals and preferences for saving that fall outside of policysanctioned norms (Whyley \& Kempson, 2000)

- Permitting fungibility. Each instrument builds financial capital that, while perhaps intended for a specific type of goal (such as supporting retirement income needs or paying for a child's education) can be used by households for other purposes as well. In some cases, mechanisms for withdrawal are in place (for example, RRSPs allow for early and tax-benefitted withdrawals for adult learning or homeownership). In others, rules allow for transfers to other tax-benefitted accounts if the money is not used for the original purpose (for example, unused RESP balances may be transferred into an RRSP to reduce taxes that would otherwise be due). In some cases there are no restrictions on how the money can be used as long as basic withdrawal conditions are met (for example, TFSA money can be used for any purpose). Finally, in all cases, positive balances can improve access to credit or other financial products and services. ${ }^{11}$ Accumulated capital in these instruments is not perfectly fungible in the way that cash in a deposit account might be. However, these instruments create household resources

\footnotetext{
${ }^{11}$ For example, savings in any of these vehicles would be included by lenders in an assessment of lending risk and larger dollar values of assets will contribute to access to larger amounts of credit at lower interest rates. Furthermore, Canadian financial institutions all maintain a minimum threshold of the dollar value of investment portfolios before granting access to their private investment advice services.
} 
that are far more fungible, than for example, government pensions or social insurance. Over time, as new financial instruments have been created and public policies have changed to allow for more transfers and withdrawals, these instruments have become more fungible than in the past. But the quality of fungibility has a negative effect for households currently on or expecting to need means-tested benefits. With few exceptions, means-tested programs require that households liquidate and use their savings for current consumption needs. These means tests are justified in part by the fact that the savings are fungible and therefore can and should be used before public assistance is provided (Robson, 2008).

\subsection{Prior research on tax-preferred savings and household assets in Canada}

Having argued that savings and assets are important to microeconomic wellbeing, that tax-preferred and account-based instruments have unique features as mechanisms to distribute assets and savings, this section now reviews prior relevant research that has informed my research questions for this thesis. As described above (page 4), I am chiefly concerned with inequalities faced by poor Canadians in their opportunities to use and benefit from these tax-preferred accounts.

Previous studies of Canada's tax-preferred savings instruments have tended to look at each instrument in isolation. Some previous studies have looked separately at effects of RRSPs on household saving (Milligan, 2003; Steele, 2007; Alan et al., 2010), at implementation issues associated with RESPs (Knight, Waslander \& Wortsman, 2008; 
Wong, 2010; Girdhary, Simonova \& Lefebvre, 2010; Schwartz \& Ben-Ishai, 2012) and at early effects of the TFSAs on household portfolios (Scarlat \& Lefebvre, 2009). These studies have either questioned whether households would have saved at the same rate for the same goal (generally retirement or education) absent the incentive of the policy instrument, or have described features of a specific instrument that reduce their accessibility for poor households. They have not taken a horizontal look across the instruments to identify common design features and effects on households.

Two other studies have described the distribution of some of these instruments. Using bivariate analysis of the 1999 Survey of Financial Security, Kerstetter (2002) presents several cross tabulations of household wealth in Canada that include housing equity and registered savings such as RRSPs. ${ }^{12}$ He reports that, in 1999, the poorest $20 \%$ of households (measured as net worth quintile) owned less than $1 \%$ of all registered financial assets, ${ }^{13}$ and less than $1 \%$ of the total stock (measured as market value) of all owner-occupied homes in Canada. By contrast, the richest 20\% of Canadians in 1999 owned $72 \%$ of all registered financial assets and $48 \%$ of the total stock (again measured as market value) of all owner-occupied homes. He asserts that:

\footnotetext{
${ }^{12}$ Kerstetter notes that his cross tabulations were created by analysts within Statistics Canada and purchased as a custom data product on a fee for service basis.

${ }^{13}$ Kerstetter reports these as "RRSPs and other registered plans" but does not give a further explanation of which other registered savings are included in this category. In the 1999 survey, RRSPs, RESPs, RHOSPs and Registered Retirement Income Funds were included as well as the imputed value of registered workplace pensions. Kerstetter reported (p.7) that the data he used excluded workplace pensions.
} 
The tax policies of the federal government and some provincial governments have conferred huge financial benefits on the very wealthiest people, the one group capable of fending for themselves. Some of the tax breaks for the rich were so lavish that governments actually went out of their way to hide their full impact from the public. (p.60)

He goes on to suggest that this inequality in the treatment of household resources has likely increased overall wealth inequality in Canada: "Making the tax system more equitable should certainly be a priority for any government genuinely concerned about the skewed distribution of wealth in Canada" (p.62).

Kerstetter's study did not look at the details of tax-preferred savings instruments to describe the mechanisms through which they encourage asset-accumulation or why, in their design, they principally benefit wealthier households. Kerstetter's data also does not differentiate between the three different registered accounts that were included in the 1999 Survey of Financial Security yet each of these is aimed at different savings goals and delivers incentives in different ways through the tax system. Since 1999, there have been new tax-preferred registered savings instruments created that should be included in a discussion of the fairness of the use of tax incentives to boost household savings and assets.

In 2006, Morrisette and Zhang conducted a similar bivariate analysis of both the 1999 and 2005 Survey of Financial Security. Like Kerstetter, they report on the overall distribution of net worth in Canada and on the rates and mean values of ownership of 
certain categories of assets for households across net worth quintiles. Like Kerstetter, these authors do not report separately on each of the tax-preferred savings instruments or on net housing equity and only report on the mean amounts owned by households in three of the five quintiles. It is important to acknowledge that the chief objective for Morissette and Zhang was to provide more up-to-date information on wealth inequality in Canada and to present findings on a proposed measure of severe financial vulnerabilitydefined by those authors as households living with both low-income with no financial assets or financial assets that, if liquidated would not raise them above low-income. It was not to verify Kerstetter's claims regarding the role of tax incentives in the savings and assets of wealthy Canadians.

\subsection{Research questions for this thesis}

In short, neither of the studies described above have discussed the set of tax-preferred instruments as a type of policy lever for influencing household financial behaviour with policy advantages and weaknesses that are common across each of the sampled instruments. Therefore this thesis first asks: Do the instruments listed in Table 1.1 hold together as a coherent set of instruments that have sufficient shared policy history and design that they should be examined together, rather than only in isolation?

To address this question, I use the limited Canadian literature on the topic and present a new and detailed historical account from archival sources on each of the instruments of 
interest. ${ }^{14}$ The aim is to understand how and why each instrument was created, how they were viewed in the public policy discourse at the time and, which Canadians have, historically, used them. I conclude that across all instruments, the policy was created without adequate consideration of the effects on poorer Canadians. I find that there have been more recent efforts to make some of the instruments more progressive but the changes are either too early to show impact or have not adequately corrected the underlying inequalities in the instrument design.

Kerstetter's assertion is that these instruments deliver an important benefit, but only to wealthier Canadian households. While he does not use the term "hidden welfare system", one study of government incentives for household savings in the United States has. Woo, Schweke and Buccholz (2004) conducted an evaluation of federal policy instruments in the United States that "encourage the acquisition, control, and maintenance of assets" (p.7) among American individuals and households. They include, in their set of instruments, both tax credits and direct transfers but only for four selected asset goals: homeownership, retirement savings, general investment and small business development. They provide a very brief description of the instruments associated with each of these savings goals and estimate the value of the spending for households at different levels of net worth using a micro-simulation database. They conclude that the federal policies in the U.S. disproportionately benefit wealthier Americans in part

\footnotetext{
${ }^{14}$ The discussion on the tax-treatment of housing equity is unique since it has never been included in the taxation of income in Canada. It is addressed through the discussions of RHOSPs and the Homebuyer's Plan.
} 
because they have been created in an uncoordinated way, without attention to the growth of incentives for wealthy savers to maintain and enhance their assets, and in part because the majority of the policy instruments rely on tax credits that offer little value to households with little or no tax liability. As in Canada, each unique program may be visible and some of its effects may have been studied, but the combined effects from the collection of programs, had not previously been examined.

Howard (2007) has described the entire set of tax exemptions, deductions and other credits (collectively referred to as tax expenditures) in the U.S. as a hidden welfare state. He writes: "government is essentially collecting what taxpayers would owe under a 'pure' system and cutting some taxpayers a cheque for behaving in certain desired ways such as buying a home" (p.16). Noting that most tax expenditures serve the same objectives as direct spending, Howard argues that "a large and growing portion of the American welfare state does little to reduce poverty or narrow the gap between rich and poor" (p.205). "While these programs are theoretically available to all, in practice they are titled toward the middle and upper-middle class. They are a thin but politically attractive version of universalism" (p.206).

I do not look at all federal policy to promote savings or at all federal tax expenditures but instead at the smaller number of instruments where these two features intersect. Having constrained the analysis to this set of savings policy instruments, I pose a second research question for the thesis: Does the set of instruments examined form a welfare system? 
And, as a corollary: If so, is it progressive or regressive, and is it broadly consistent with Canada's liberal welfare regime?

Daniels and Trebilcock (2005) argue that a welfare state, of any typology, may have systems within it to:

- promote economic stability,

- regulate public morality, promoting certain socially-preferred activities and discouraging others;

- build social solidarity, maintaining a sense of shared identity and willingness to engage in collective action;

- insure individual risk, protecting citizens from risks they cannot manage alone and for which market solutions are inadequate;

- provide equitable distribution of resources, reducing the risks faced by the most destitute citizens.

When tax-preferred savings instruments are used to promote macroeconomic goals, I argue that they meet the criteria for inclusion in welfare analysis on the basis of promoting economic stability. When the same instruments are used to promote microeconomic goals, I argue that they meet the criteria for inclusion on the basis of regulating public morality (by prioritizing certain forms of saving and assets over others) and insuring individual risk (by supporting households in building and maintaining new resources that can prevent, mitigate or manage risks to wellbeing). Whether these instruments also promote an equitable distribution of resources is an open question. If 
the set of instruments does share a common history, key features in their design and a central policy aim (increasing household savings and assets), then they should be regarded as a system of delivering welfare to Canadian households. I suggest that, owing to financial and non-financial features, these instruments are largely regressive and confer far larger benefits on wealthier households, in effect allowing households in the top net worth quintile to shelter from income taxes fully half of all their household assets (excluding workplace pensions, and likely more if pensions are included), more than any other net worth quintile. At the other end of the distribution, the poorest $20 \%$ of households have, at the median, none of their household assets in these tax-preferred assets. Whether this system produces, on balance a net gain or loss to rich versus poor households, after taking into account progressive income tax rates, all possible adjustments to the tax system outside of income taxes, all possible adjustments to government spending and all possible behavioral adjustments on the part of Canadian households is beyond the scope of this thesis. However, these kinds of questions about the cumulative effects of an expanding list of programs are rarely if ever asked. Discourse on these instruments generally treats each one in isolation, with most public information aimed at explaining or critiquing their features as financial products for consumers. Yet, each seemingly minor adjustment to annual contribution limits or withdrawal rules has important and cumulative implications for the policy impacts of these instruments. In this sense, the constructs of "hidden" versus "visible" welfare systems are compatible with analyses that have pointed to "social policy-making by stealth" (Battle, 1998). 
To address the question of consistency with Canada's liberal welfare regime, I adopt Esping-Andersen's (1990 and 2006) framework for welfare analysis. He proposes that each welfare state (or "regime" in his work), is made up of systems of policies that:

- involve some expenditure of the state;

- can be characterized as either institutional (conferring benefits on the basis of citizenship) or residual (conferring benefits only in cases of demonstrated need);

- give expression to a conception of social citizenship, conferring (or denying), enhancing (or moderating) certain social roles, rights and particularly (in his framework) relationship with labour markets.

My evaluation of the selected set of policy instruments for consistency with a liberal welfare regime is also informed by my historical research that reveals something about the character and expression of social citizenship associated with each of the taxpreferred savings instruments I examine. It is also informed by a review of information I have compiled on the federal expenditures on each of the tax-preferred savings instruments, including foregone tax revenues and direct transfers into registered accounts. I find that the expenditures have generally increased over the last fifteen years. I also conclude that, while the interactions makes it impossible to arrive at the kind of total dollar value estimated by Woo et al. (2004), the dollar values involved are substantial.

Esping-Andersen's approach to welfare regimes also demands analysis that goes beyond studies of public expenditures. Therefore, I expand on the studies by Kerstetter, and by Morissette and Zhang, to examine how the selected savings instruments are distributed 
among households with different levels of net worth and how significant they are to household portfolios (as a share of total household assets). I also present the results of an exploratory qualitative study to understand differences in the non-financial considerations (such as information gaps, normative savings goals and social rights) that may play an important role, interacting with the income tax system, to shape the opportunities and capabilities of Canadian to use public policy instruments to save and acquire assets for their own wellbeing.

\subsection{Outline of the chapters to follow}

In sum, my two research questions are first, whether there is merit to grouping Canada's past and present tax-preferred savings instruments, and second, whether such a set forms a welfare system and how that system might be characterized. Before turning to the new research that addresses these questions, Chapter 2 provides a literature review on a wide range of microeconomic theories of how and why individuals and households save and build assets. I take a perspective that integrates multiple factors described by previous authors and highlights that the opportunity to save and acquire assets is more complex than simple measures of abilities to pay. Chapter 3 presents a new compilation of data on federal expenditures on the present-day tax-preferred instruments through both tax expenditures and direct transfers into registered accounts. The aim of the chapter is to establish that expenditures on these instruments are large and important ways of distributing public funds. Chapters 4 through 7 present a retrospective analysis of the original design, and then evolution over time, of each of the tax-preferred account-based instruments as well as the antecedent example, compulsory savings through taxation. 
The aim is to identify whether the instruments share common histories and policy features and also whether these features enhance or decrease the capabilities of poorer Canadians to directly benefit. Chapter 8 presents the methodology and results of a study to expand on the work of Kerstetter (2002) as well as Morissette and Zhang (2007). Chapter 9 presents the methodology and results of the exploratory qualitative study on public perceptions and responses to tax-preferred savings instruments. The concluding Chapter 10, responds to the two research questions and then, briefly, suggests some considerations for future research and policy. 


\section{Chapter 2: Theory on personal savings and asset-accumulation}

In Chapter 1, I began a review of the evidence that savings and assets may have welfare effects on individuals and households. I also reviewed the evidence that one type of policy instrument—-tax policy—can influence household savings and choices in assetholding. I have argued that tax-preferred and account-based instruments, as implemented in Canada, share certain common features. These, again, are: the requirement for engagement with private sector financial services; normalizing only certain reasons for saving; the use of the income tax system as a way to deliver a financial incentive; and, some fungibility of the financial asset within each account. In this chapter, I take a step backwards to review prominent ideas and theories about household savings. Ideas and assumptions in these theories have, I believe, influenced policy-makers as they craft policy instruments to promote household saving. The theoretical perspectives reviewed in this chapter offer a range of ideas about why household savings are important—-for microeconomic or, conversely, macroeconomic reasons. They also offer contrasting views on what levers might influence household savings outcomes — changes to interest rates, changes to household income, appeals to personal motives, and methods that use findings from the behavioral sciences. In practice, there is only rarely any evidence that theory has had a direct impact on policymakers. However, theory can become part of policy discourse and can indirectly shape the underlying ideas, options and priorities for policy-making.

As I noted in the previous chapter, governments might have macro-economic and microeconomic rationales for promoting saving and asset-accumulation among citizens. These 
governments also have several choices of policy instruments. In this chapter, I argue that macro-economic versus micro-economic rationales, while not necessarily mutually exclusive, can lead to very different choices of policy instrument. I also argue that underlying ideas about how and why individuals save and build assets—including theories of morality, theories that prioritize motivation and theories that emphasize institutions and choice architecture — will each point towards different policy choices. I conclude by arguing for attention to both individual and institutional factors, as well as the interactions between these. In my review of Canada's set of tax-preferred policy instruments that follow in Chapters 4 through 6, I adopt this perspective, arguing that individual and institutional factors will interact to shape observed outcomes. The concept of capability, introduced later in this chapter, is key and draws attention to the superficial universality of Canada's set of tax-preferred account-based savings instruments.

\subsection{Historical ideas: Saving as moral act versus saving as macro-economic goal}

Why do some people save and build assets? Why is it that some individuals do not save or build any assets? How do we account for observed differences (persistent or changeable) in the distribution of household wealth? Any response to these questions belies certain fundamental assumptions and, in the policy context, prescribes certain kinds of policy responses.

Nearly all of the celebrated early political and economic theorists took some position on the question of private property and its relation to the role of government. 
In "Of Property", Locke (reprinted in MacPherson, 1978) argued that the individual right to unlimited individual property is a natural law. Whatever a person makes through his own labour is, says Locke, self-evidently his own property and so too are whatever items of tangible or financial capital required for the work of creating a product - the freedom to make and retain capital is, according to Locke, the surest means of placing reasonable constraints on political power and forms the basis for democratic governance and development.

In "The Origin of Inequality", Rousseau (reprinted in MacPherson, 1978) countered that a natural law should lead to more equal outcomes in the distribution of ownership. This argument of course demands an a priori assumption that all persons are equal, at least at some point, in their ability to perform labour and to create wealth out of that labour. If inequalities in wealth exist, argued Rousseau, then the natural law argument implies that any order or institution that deprive some labourers of ownership is totally unjustifiable.

Later, in Chapter I, Book II of "Of Property" (reprinted in MacPherson, 1978), Mill argued instead that those inequalities are only due to accidents in the evolution of social and political institutions and, as such, can be remedied through policy change. Some tension between macroeconomic concerns (in this case, protecting property rights) and microeconomic concerns (in this case, promoting greater equality) is evident in these foundational writings in economic and policy theory. 
Starting in the $19^{\text {th }}$ and early $20^{\text {th }}$ Century, there were two distinct veins of thought about saving. The first focused on micro-economic concerns and made a moral argument about the virtue of saving and capital. These ideas developed before any suggestion or evidence for economic or welfare effects of saving and assets. Whereas the literature on the 'asset-effect' posits that savings and assets are good for individuals and households, the $19^{\text {th }}$ and early $20^{\text {th }}$ Century moralists argued that saving and building assets was morally good of individuals and households to do. Because these authors also recommended that the act of saving could improve an individual's character, the literature on the asset-effect is vulnerable to critique as a renewal of the moralistic ideas.

The second historical vein of thought comes from the development of macroeconomic and specifically monetary theory. For these authors the chief concerns were the need for investment capital and macroeconomic stability. ${ }^{15}$ Rather than focus on the household level, these authors looked at the national aggregate level of saving where distributional issues are less important. These authors were the first to argue that policy choices of governments, including incentivizing savings through taxation, can and do provide incentives (or disincentives) to accumulate capital.

The next sections briefly highlight some illustrative examples of each of these moral and macro-economic traditions before discussing what more contemporary theory and research may have inherited from each.

\footnotetext{
${ }^{15}$ This is in contrast with the earliest theorists who were principally concerned with property rights in the economy as a whole.
} 


\subsubsection{Saving as moral act}

In the morality tradition, there are books such as Thrift, a slim volume produced in 1876 as part of a series by Samuel Smiles, a popular writer of self-help and pop-philosophy at the time. In the book, Smiles wrote:

...comparatively few people can be rich: but most have it in their power to acquire, by industry and economy, sufficient [wealth] to meet their personal wants. They may even become the possessors of savings sufficient to secure them against penury and poverty in their old age. (p.27)

For Smiles, the key factor in observed differences in wellbeing was personal behaviour and morality.

Is it possible for a man working for small wages to save any thing, and lay it by in a savings-bank, when he requires every penny for the maintenance of his family? But the fact remains, that it is done by many industrious and sober men; [...] And if some can do this, all may do it under similar circumstances. (p.26)

Smiles went further, arguing that the poor who lack any savings or wealth, have only themselves, and their weak moral character, to blame for their misfortune: "People who spend all that they earn are ever hanging on the brink of destitution. They must necessarily be weak and impotent [...] They keep themselves poor" (p.28). The action of saving and, slowly over time, building even modest wealth, had for Smiles and his contemporaries, a moral quality, reflecting something of the character and quality 
of a person. "As a guarantee of independence, the modest and plebeian quality of economy is at once ennobled and raised to the rank of one of the most meritorious of virtues" (p.27 -28), wrote Smiles. Later in the same volume, Smiles presented a brief but intriguing list of positive effects from individual asset accumulation and ownership: Its very practice is improving. It indicates self-denial, and imparts strength to the character. It produces a well-regulated mind. It fosters temperance. It is based on forethought. It makes prudence the dominating characteristic. It gives virtue the master over self-indulgence. Above all, it secures comfort, drives away care, and dispels many vexations and anxieties which might otherwise prey upon us. (p.32-33)

This list of effects stands in contrast with the more recent theory and evidence regarding the effects of assets on individuals and households reviewed in Chapter 1. More recent authors have emphasized economic effects beyond smoothing income or effects on wellbeing that do not include improvements in "character".

These passages from Smiles are illustrative of a body of literature that argued that the act of saving out of earned income has a moral quality that demonstrates the virtue of thrift. This is a theme also evident in a genre of morality fiction based on Protestant (often Calvinist) values and codes of conduct that was also popular in the mid and late $19^{\text {th }}$ Century (Templin, 2004). These works of fiction extoled the virtue of thrift, exemplified by living modestly and building wealth through small, steady savings. This value of thrift, argued McCloskey (2006), is a blend of two cardinal virtues of temperance and 
prudence. As such, thrift is thought to demonstrate both the ability to restrain from spending in the face of temptation and the ability to exercise forethought, reason and "practical wisdom" (p.2). The wealthy, in this perspective, may not have the same moral fiber, or the opportunity to acquire this fortitude, if they acquire their wealth through means other than patient, deliberate thrift and saving.

It is a moral view likely heavily influenced by the same Calvinist code that was the subject of Weber's The Protestant Ethic and the Spirit of Capitalism (1930). This AngloSaxon Protestant asceticism was, according to Weber, "not a struggle against the rational acquisition, but against the irrational use of wealth" (p.115). "They set the clean and solid comfort of the middle-class as an ideal" (p.116). "When the limitation of consumption is combined with this release of acquisitive activity, the inevitable practical result is obvious: accumulation of capital through ascetic compulsion to save" (p.116).

What matters more than the having of wealth, to these authors, is the method through which it is acquired. Even the very wealthy industrialist and philanthropist Andrew Carnegie (1900, reprinted 1962), echoed many of the same arguments about the moral superiority of working-class savers. In his chapter on the "advantages of poverty", Carnegie argued that men raised without wealth are "better able to develop integrity [and] hard-work" (p.54). In describing his admiration for landowning farmers in America, Carnegie referred to "the magic power of ownership" (p.59) and posited an association between ownership and good character. However, even for those with wealth, Carnegie argued that they too have a duty to exercise thrift: 
The duty of the men of wealth: To set an example of modest, unostentatious living, shunning display or extravagance. To provide moderately for the legitimate wants of those dependent on him; and after [...] becoming the mere trustee and agent for his poorer brethren, $[\ldots]$ doing for them better than they would or could do for themselves. (p.25)

This duty to provide redistribution through philanthropy includes an obligation to alleviate the deepest poverty and destitution, wrote Carnegie, but "in doing this our thoughts should also turn to the benefits that are to accrue to those that are yet sound and industrious and seeking through labour the means of betterment" (p.69).

The legacy of this branch of thinking and writing from the $19^{\text {th }}$ century is a kind of "bootstrap capitalism" (Stoesz, 2007) that places a premium on independence, and hard work, that glorifies thrift and posits the act of saving as a virtuous, nearly sacred, behaviour. The working poor, particularly land-owning farmers, are given special status for their good character and morals, as revealed by their ethic of hard work and restrained consumption. However, there is some debate about the moral quality of the wealthy — who are to be judged harshly for their avarice or sloth but may be redeemed by philanthropy according to Carnegie. ${ }^{16}$ The poor who are lazy or wasteful are deemed undeserving, in a similar thread to the British—and later Canadian—Poor Laws (Robson, 2008).

${ }^{16}$ Like Carnegie, Smiles also cautioned the wealthy to demonstrate the same thrift and restraint as their working class counterparts, suggesting that it is economic behaviour rather than economic resources that are most important to him. 
What is implied but never stated explicitly in this perspective is that the financial outcomes of an individual or household - particularly whether or not they have any savings or assets - are presumed to be entirely within the control of individual economic actors and outside of the influence of either markets or states. Within these moralist texts there is no discussion of the role of public and private institutions in shaping opportunities, risks and returns to saving or investment.

\subsection{2 "Savings" in early macroeconomic theory}

The most dramatic departure from $19^{\text {th }}$ century writings about the virtues of thrift likely came from Keynes and his contemporaries in macroeconomic theoryHayek and Mises. In fact, in his General Theory, Keynes (1936) bemoaned "the opprobrium of two centuries of moralists and economists" who had been writing according to an "austere doctrine, extoling the virtue of the utmost of thrift and economy" (Chapter 23).

A full exploration of the distinctions and disputes between Keynes and the Austrian school (namely Hayek and Mises) is outside of the scope of this thesis, ${ }^{17}$ but it is worth noting two important differences. The first, and better-known, is the difference in the proposed economic effects of savings. Keynes (1930)

${ }^{17}$ For a good summary see Garrison, R. (2004) "Overconsumption and forced saving in the Mises-Hayek Theory of the Business Cycle", History of Political Economy, vol. $36(2)$. 
suggested a "paradox of thrift" in which a widespread campaign of consumer thrift reduces consumer demand and creates excess saving that is not absorbed by the market. ${ }^{18}$ Although, in the short-run, saving proves beneficial for individual consumers and households, in the longer-run firms respond to falling revenues by reducing production costs and wages, which in turn further reduces demand and leads to a recessionary spiral. For Keynsians, savings and thrift may be good in small doses but are potentially disastrous if widespread.

By comparison, Hayek and Mises were concerned with "forced saving", a construct Hayek (1933) traced back to Bentham's text The Defence of Usury written in or near 1804. According to both Mises and Hayek, saving or frugality in the market is "forced" whenever interest rates are artificially low. ${ }^{19}$ While Hayek acknowledged that saving in the short-term reduces revenues for firms, he did not predict this would lead to a recessionary cycle as Keynes did. Instead, for Hayek and Mises, markets will always eventually clear this excess saving by mobilizing it as investment capital and returning to some equilibrium (including a balance between individual savings and investment capital used by firms). In

\footnotetext{
${ }^{18}$ It is not clear from Keynes' writings whether he supposes a case in which the demand for investment capital is lower than the rate of saving because no further expansion is possible or because there is no economic incentive to do so. His parable of the banana republic in the Treatise on Money posited a closed economy and did not imagine diversification in the production of goods and services.

${ }^{19}$ Here artificially low is taken to mean at a price reflecting the real rates of risk and return where all costs are known to capital investors.
} 
fact, for Mises (1966), the greater source of macroeconomic risk is

"malinvestment" or "overconsumption" fueled by facile access to credit.

A second important distinction between Keynes and the Austrian school is the factor which each supposes will have the greatest incentive (or disincentive) effect for individual savers. For Keynes (1936), personal incomes were key. When wage incomes rise, savings also increase (although at a rate lower than capital investment):

The fundamental psychological law, upon which we are entitled to depend with great confidence both a priori from our knowledge of human nature and from the detailed facts of experience, is that men are disposed, as a rule and on the average, to increase their consumption as their income increases, but not by as much as the increase in their income. (Chapter 8)

By contrast, Mises (1966) wrote:

It is necessary to remember that the greater propensity of the wealthier classes to save and to accumulate capital is merely a psychological and not a praxeological fact. ${ }^{20}$ It could happen that these people to whom the inflationary movement

${ }^{20}$ Praxeology is a term dating back to the $17^{\text {th }}$ Century, referring to logic (logos) of action (praxis). While it has been associated with $19^{\text {th }}$ Century French philosophers, the Austrian economists used it to describe the foundations of their scientific method. The Austrian school rejected logical positivism and instead argued that the fundamental assumption, from which the other necessary theory could be deduced and evaluated, is that human beings engage in deliberate action. In the passage above, Mises is asserting that a preference for or "propensity" towards saving is a matter of psychological differences, not differences in deliberate action. 
conveys additional proceeds do not save and invest their boon but employ it for an increase in their consumption. (p.549)

In other words, personal savings may sometimes rise with personal income but different people will have different preferences for saving (or marginal propensities to save) that are independent from income. For Mises and Hayek, the key incentives for saving lay in interest rates whereas for Keynes wages were the most important variable. These two perspectives lead to very different ideas about which kinds of policy responses might influence savings and investment.

For the purpose of the present study, it is maybe more important to note that, despite the well-known areas of debate and disagreement between Keynes and members of the Austrian school (namely Hayek and Mises), they appear to agree on at least two fundamental ideas:

1) The important effects of saving are those on the behaviour of firms and markets and there is some optimal supply of savings to meet demand for capital investment to sustain or increase total national wealth.

2) Rates of saving can be influenced by both personal preferences (a propensity to save) and by institutional factors (such as wage controls or rates of interest).

The first of these points stands in sharp contrast to the moralist writers discussed at the outset of this chapter. If the central preaching of the $19^{\text {th }}$ century moralists was that each 
individual in an economy should have to make and build their own wealth, then the principal inquiry for the early $20^{\text {th }}$ century economists was how best to mobilize savings to build the aggregate wealth of the economy. In this macroeconomic perspective, the role and effect of savings and assets becomes less about the well-being of households and more about the proper functioning of markets-which are in turn expected to generate economic growth and foster the well-being of consumers. But something important is lost in a macroeconomic perspective that overlooks the potential for positive effects of savings and assets on individuals and households.

If the policy rationale for personal saving is only to provide investment capital, then this leads to policy instruments that favor forms of assets and savings most in demand by or most useful to capital markets rather than considering the preferences and capabilities of individual savers. Giving priority to macroeconomic goals also implies that it is wiser to target savers who are those most likely to produce (by saving and investing) the desired investment capital. These target markets for saving and investment products might be drawn from a very few über-wealthy with large sums to invest (a narrow base), or from the broader mid-section of the wealth distribution with more modest individual sums to invest but who, collectively, can generate substantial capital (a broad base). ${ }^{21}$ By contrast, if the primary aim of saving is related to microeconomic objectives, then this might suggest a set of policy instruments more aligned with the needs and preferences of individuals and households and, possibly, a more progressive orientation in setting

${ }^{21}$ See Chapter 3 for a discussion of the wartime national savings policy in Canada that was based on theory from Keynes and targeted the middle class. 
benefit rates. The macroeconomic goal is aimed at pulling the greatest amount of investment capital out of households while the microeconomic goal is aimed at increasing the capital in households.

A second conclusion from the $19^{\text {th }}$ and early $20^{\text {th }}$ century theorists concerns the interplay between personal and institutional factors. In contrast to the $19^{\text {th }}$ century moralists, the macroeconomic theorists allow that institutional factors do matter, even if they disagree about which institutions matter and why. This is an important change because it provides the rationale for attention to the influence of public policy on household savings. If, as the moralists suggest, so-called 'good people' save, then there is very little role for policy-making short of finding some way to turn 'bad' people into 'good' people. However, if large institutional forces such as rates of interest, wages and the supply of money can interact with personal preferences, then there is some opportunity for policymakers to increase (or decrease) savings and asset-holding through these and other levers - including the tax-preferred account-based savings instruments that are the focus of this thesis.

\subsection{More current theoretical work on saving and assets}

For the $19^{\text {th }}$ Century moralists, the explanation for household differences in saving and assets was almost completely about the individual—either people had the moral fortitude to exercise thrift or they did not. For classical schools of economic thought, people saved and acquired assets as rational actors in response to external market conditions. 
Individual differences in preferences were acknowledged but downplayed in comparison to exogenous market signals and incentives. ${ }^{22}$

In the more recent literature on saving there has been a greater microeconomic emphasis. Much of the literature from the post-war period offered ideas about the individual or household-level determinants of saving and wealth accumulation-namely motivations that come from within savers themselves. More recent literature from behavioral economics has emphasized the importance of institutions-public policy, financial systems, consumer financial products—on household savings behaviour. Both perspectives have valuable ideas to contribute but neither seems to have won the full approval of members of the research or policy communities. Barr and Sherraden (2005) seem to have accurately assessed the state of the literature when they concluded that "no theoretical perspective has been found to have strong and consistent empirical support" (p. 5). In other words, the field is still very much evolving and new contributions towards theoretical or empirical work on household financial behaviour are no doubt needed.

${ }^{22}$ Although a careful reading of each Keynes and Hayek reveal that both authors acknowledged psychological factors as important determinants of economic behaviour. This interpretation may not have received a great deal of attention in the theoretical or empirical literature and certainly is less prominent in the neo-classical school of economic writers by the mid $20^{\text {th }}$ Century. 


\subsubsection{Motivational models}

The contemporary literature on individual and household savings generally supposes that there are some personal motivations for saving (Modigliani, 1986; Poterba, Venti \& Wise, 1996; Browning \& Lusardi, 1996; Thaler, 2001; Lerman \& McKernan, 2008, Turner \& Luea, 2009; Fisher \& Montalto, 2010; Toussaint, 2011). Motivation shapes observed individual behaviour by setting and sustaining choices over other alternatives (Bandura, 1986; Ryan \& Deci, 2000). In this case, motivation—in the form of a savings goal or planned use for the saving - can encourage individuals to direct more of their resources towards a designated savings vehicle, over other alternative behaviours, such as spending.

Some of the proposed motivations are largely uncontroversial in the mainstream economic literature (Carroll \& Samwick, 1997), namely:

- Precautionary motives. Related to the value of thrift discussed earlier in this chapter, these involve setting aside some resources to manage potential future risks such as interruptions in income or costs that would otherwise disrupt current living standards, within a given budget constraint.

- Bequest motives. The desire to accumulate wealth to be passed onto one or more heirs but possibly also a desire to create a pool of funds for philanthropic giving.

- Lifecycle motives. Similar to the precautionary motive above, but in this instance applied as preparation or insurance against an expected future decline 
in household income when, as part of a normal lifecycle, a worker retires and ceases to earn employment income.

It is possible to imagine other life-events (such as anticipating future education or health costs) that might be linked to a life-cycle motive for saving but in general the model supposes that individuals are motivated to maintain a stable (or permanent) level of income during working and older age (Friedman, 1957; Modigliani, 1986). The reason for saving income in the current period is to smooth out income (and in turn consumption) in a future period when current sources of income are reduced or unavailable. The model predicts that, during working life, savings and wealth will grow up to retirement and then be spent down when employment ceases. The same Life-Cycle Hypothesis allows that some additional saving, or at least a slower spending down of peak assets, will take place to fulfill bequest motives but secondarily to a desire to smooth income (Modigliani \& Brumberg, 1954; Modigliani, 1986; Friedman, 1957). However, as Thaler (2001) noted, there are serious problems with this model in that it presumes that individuals will have perfect information about timing (of both work cessation and eventual death), perfect ability to make the necessary calculations, and perfect self-control to save the optimal amount in the current period to meet future needs. ${ }^{23}$ A further problem with the Life-Cycle Model is that does not adequately deal

\footnotetext{
${ }^{23}$ Another criticism made by Thaler is that the Life-Cycle Hypothesis assumes perfect fungibility of resources. In fact, many forms of saving cannot be moved or switched, such as locked-in pension assets and contractual pension contributions.
} 
with diversity or generational change in the order, timing and impacts of life events. ${ }^{24}$ Theory that emphasizes the precautionary motive may be as prone to critiques about information and self-control but may be more applicable to differences in life events or stages.

To the above list, at least three more types of motivations can be added:

- Instrumental motives. 'Saving-up' for a large purchase that could not be afforded out of regular income flows alone (McKay \& Kempson, 2003;

Robson, 2006; Kempson \& Finney, 2009) such as a down-payment for a house, a vacation or an expensive durable good like a car or computer.

- Normative motives. Saving because thrift is expected or valued perhaps as part of a self-image (Canova, Rattazzi \& Webley, 2005) or because of, as Keynes described "unreasonable but insistent inhibitions against acts of expenditure as such" (Keynes, 1936). And,

- Speculative or profit-seeking motives. Saving to insure for some positive risk that is expected to generate new income such as investment income or income from a new business venture (Keynes, 1930; McKay \& Kempson, 2003; Tousaint, 2011).

\footnotetext{
${ }^{24}$ The order and timing of events that used to mark key life stages no longer conform to reliable patterns for a growing share of the population. This makes it increasingly hard to talk meaningfully about "life stages" (Beaujot, 2008). For example, younger Canadians now stay in education longer and join the workforce, leave home and start long-term relationships and families later than their parents and grandparents did.
} 
There is evidence from several different studies that savings motives, in practice, do not divide neatly into separate categories. Canova, Rattazzi and Webley (2005) found that adults report multiple and inter-related goals or rationales for saving. Their analysis of the patterns suggested that goals may resemble Maslow's 'Hierarchy of Needs', with more concrete goals at the bottom and more abstract, self-actualization-like goals towards the top. Even simple consumer surveys find self-reports of multiple and wide-ranging motives for saving.

For example, a February 2011 survey of adult Canadians commissioned by the Certified General Accountants of Canada found that $84 \%$ of adults reported saving something out of their current incomes. ${ }^{25}$ When asked about the reason for saving, instrumental motives (such saving for vacations or consumer goods) were most commonly cited (78\%), followed by life-cycle or long-term retirement motives (59\%), precautionary motives (43\%) and speculative motives (17\%). ${ }^{26}$ Interestingly there were substantial differences by housing tenure and age of the respondent, suggesting that motivations may change with life circumstance or life stage.

\footnotetext{
${ }^{25}$ The wording of the question permitted multiple answers but provided only 8 response categories (CGA, 2011, Appendix B, p.121).

${ }^{26}$ Outside of private sector opinion surveys, there is almost no national data on consumer motives for savings in Canada. For example, the Canadian Survey of Financial Capability asked respondents if they were motivated to save for certain pre-determined goals - a child's education, a new home, retirement and a large purchase of any kind over $\$ 10,000$. If a respondent had motivations that did not conform to these categories, that information would not be captured by the survey.
} 
Similarly, Toussaint (2011) described findings from in-depth interviews with 240 households in three European countries regarding their declared and revealed motivations for building a particular kind of asset—home equity. She found that households show a range of motivations including precautionary, speculative, bequest and even normative motivations, but found considerable differences between households in different countries. Toussaint concluded that "the history, welfare system and housing market, and the norms and customs of a country are important" (p.337) in shaping motivation and attitudes about household financial resources.

Kempson and Finney (2009) reviewed data on lower-income households in the United Kingdom and found a mix of psychological and instrumental motives interacted with both short-term and longer-term goals, and with passive and more active strategies for setting aside money. They found that overall $43 \%$ of adults in the UK in 2000 reported saving something out of their current income, either regularly or sporadically. When asked about their main reason for saving, savers were more likely list instrumental motives (37\%) and life-cycle or long-term retirement motives (9\%) than investment or speculative motives such as investing in education or the value of a home (4\%). Perhaps most interestingly, the survey found that among savers the most common reason for saving was "no particular reason" (41\%). This suggests that individuals may only be partially aware of their own motives and may be saving as much out of habit as out of conscious planning and goal-setting. 
Understanding motivation is crucial for theory about household savings behaviours because, as Kempson and Finney (2009) wrote "the ways in which people save are linked with their reasons for doing so" (p.3). But while there is evidence that individual motivations have a role in individual and household savings, the above results suggest that motivational theories are at best incomplete because motivations may multidimensional, changeable and only semi-conscious. Saving is a dynamic process and an individual or household's reasons and preferences for saving are almost certain to shift over time. Some of the dynamism also no doubt comes from changes in personal circumstance and from changes in institutional settings — such as changes to savings account rules or public policy. As McKay and Kempson (2003) and Kempson and Finney (2009) noted, there is an important distinction between an individual's propensity to save - that is their motivation to choose saving over spending — and an individual's ability to save - that is their opportunities to set aside income. This ability, or capability, to save, as distinct from a propensity or motivation to save, informs other perspectives to understand poverty and household financial behaviour. This construct of capability is discussed in the next section.

\subsubsection{The construct of capability}

Observed savings behaviour and even self-reported motivations may not be reflective of household motivations or preferences, independent of all other variables. In Choice, Welfare and Measurement, Sen (1982) wrote "a person's choices may not be made after much thinking or after systematic comparisons of alternatives" (p.60). The choices consumers make and the goals they set for saving might be shaped by contextual 
factors-including social norms, persuasion and economic incentives. Sen also noted that there are "difficulties arising from open or hidden persuasion involved in advertisements and propaganda, which frequently mess up not only one's attitude towards the alternatives available but also towards the act of choice itself" (p.61).

The ability to freely make choices is, according to Sen (2009), as important as any other aspect of wellbeing. This freedom to choose, given Sen's point above about the role of outside influences on personal choice and even on willingness to make choices, is likely on a continuum where no one is perfectly free in his or her choices or perfectly constrained. According to Sen, any real analysis of fairness, justice or equality, has to consider not just the distribution of goods but also the distribution of individual capability to use these goods in one's own interest. ${ }^{27}$ The important question for analysis, wrote Sen, is "can the person actually do these things or not?" (p.307).

Sen's concept of capability does not presume, as the $19^{\text {th }}$ century moralists might have, that the ability and willingness to make financial choices must be a result of individual effort. While his theory does not recognize endowments through luck as a real increase in capability, Sen does allow that individuals and households can exercise choice through direct control and with assistance.

${ }^{27}$ This perspective builds on Rawl's concept of justice as equality in the distribution of goods unless any further redistribution would make the least advantaged member of a society worse off, a contrast to the classical concept of Pareto optimality. Sen's position is that the Rawlsian concept of equality as justice should be expanded to include equality of capabilities not just resources or wealth. 
Applying this construct to household savings, the distinction between saving by luck and saving with help seems to be somewhat false. If, as Sen says, what really matters is "can a person actually do these things or not?" then whether the capability is acquired through effort, with help or by chance is largely irrelevant. If I save $\$ 10$ intentionally by setting it aside from my income, or if I save $\$ 5$ and have someone else give me a matching $\$ 5$, or if I find \$10 I had left by chance in a coat pocket last year, the net result is the same- -I have $\$ 10$ in savings. There are many ways to build financial assets and it is unhelpful, in understanding the real-world decision-making of households, to include some financial events but exclude others. Furthermore, the outside factors acknowledged by Sen as influences that shape personal choices (for example, factors that might change an individual's motivation or propensity to save) or access to outside help (for example, incentives or rewards for saving and acquiring assets) may well be determined by chance.

Another body of literature that must be discussed here is the theoretical and empirical work on financial capability. The term "financial capability" was developed by Elaine Kempson and a team of researchers who surveyed hundreds of British households to find the common threads in how ordinary people understand good financial practice and described personal financial competence (Kempson, Collard \& Moore, 2005). Based on this research, Kempson and her colleagues developed a model of financial capability that emphasized behaviour, while recognizing knowledge and attitudinal components, across five domains of personal finance:

1. Making ends meet

2. Keeping track 
3. Choosing products

4. Planning ahead, and

5. Staying informed and getting help.

Each of these domains includes financial knowledge, attitudes towards personal financial and financial behaviours that together make up financial capability. ${ }^{28}$ However, similar to Sen's emphasis on whether or not an individual can in fact do something, Kempson, Collard and Moore (2005) suggested that it is the behavioral element that may be most important for research and policy-making.

Applied to the accumulation or maintenance of assets, this model of financial capability is more specific than Sen's overall idea of attention to equality of capabilities. Financial capability asks whether an individual or household is able to

- economize out of their income flows (what McCloskey might call the practice of temperance);

- know what resources they have and where they are stored;

- make decisions in their own interest about the financial products for formal saving (such as choosing between investment options or deposit accounts);

- forecast and prepare for their own future resource needs (the practice of prudence according to McCloskey);

\footnotetext{
${ }^{28}$ For example, the domain of "Making ends meet" would include knowledge of how to match expenditures to income, a positive attitude or orientation towards making ends meet and also observable efforts to balance spending and income.
} 
- engage in learning and seek help as needed, an idea consistent with Sen's concept of indirect power or control within the construct of "individual capability".

Research on financial capability ${ }^{29}$ paints a very mixed picture with regards to savings and wealth outcomes. In some studies, financial literacy is measured only as knowledge of selected financial terms and concepts. These studies generally find that people with greater levels of financial knowledge are more likely to have savings and assets (Garman, 1997, Lusardi, 2003; Capuano \& Ramsay, 2011; Van Rooij, Lusardi \& Alessie, 2011, 2012). However, it may be these studies are confounding financial knowledge with prior wealth and other unobserved variables.

In studies of low-income and low-wealth participants, exposure to financial learning and counseling appears, within limits, to increase the frequency of regular, formal savings out of income flows (Sherraden, 2008; Leckie, Hui, Tattrie, Robson and Voyer, 2010; Grinstein-Weiss, Sherraden, Rohe, Gale, Schreiner \& Key, 2012). However, these studies find no measureable increase in the net worth of participants above and beyond what might have occurred anyway.

It is important to recall that there are many ways to acquire and maintain assets. Some mechanisms are passive - such as growth in the value of an asset due to market forces

${ }^{29}$ I include here the body of literature on financial capability and financial literacy. The two terms are frequently used interchangeably. 
(for example, passive growth of housing value) and others even depend on luck (for example, gaining an inheritance or winning a lottery). These do not depend on saving out of household income. Individuals have little control over the passive mechanisms for acquiring assets. By definition, these allow for very little personal agency but result in an increased financial capacity. Other approaches are more active, such as regular deposits into a savings vehicle or acquiring and investing in an asset to realize a capital gain (ie: renovating a house to increase its value). In fact Whyley and Kempson (2000), McKay and Kempson (2003), Kempson and Finney (2009) suggested that there are multiple patterns of saving based on analysis of quantitative and qualitative data on British households. Leckie et al. (2010) drew a similar conclusion based on analysis of an experimental savings program in Canada. All three studies suggest that while some individuals practice (and perhaps prefer) regular, steady deposits, others are more irregular or "lumpy". Still other households or individuals are not savers at all (in the sense that they do not make deposits out of income flows) but may still experience a passive increase in their total net worth or the value of their assets. Similarly, Stapleton (2009) suggested that even very low-income households dependent on social assistance may periodically gain new and unexpected financial assets (such as lottery winnings, court settlements or inheritances).

In contrast to the moralists of the $19^{\text {th }}$ century, there seems to be little evidence or logic to support the idea that consistent saving out of income flows is a necessary or even advantageous method to acquire financial or realizable assets. Certain approaches for saving may be easier for households with greater incomes, as measured by absolute 
dollars saved. However, lower income households may experience reduced capability to save and build assets because of institutional factors in policy and product design. The role of institutions on observed financial behaviour and outcomes is discussed in the next section.

\subsubsection{Behavioural models}

Sen and Kempson and her colleagues each call attention to the question of whether or not a personal can, in practice, engage in a financial act-such as saving or owning an asset. Behavioural economists are now offering theory and evidence for a wide range of institutional factors that shape individual financial practices.

Behavioural models in the social sciences first originated in psychology through the study of learning. The example of Pavlov's experiments to train dogs to respond to a bell through classical conditioning is well known. Subsequent work by Watson and later Skinner suggested that the ways in which individual behaviour might be learned or shaped according to external stimuli were more complex and included not only rewards and punishments but also timing, context and perception (Watson, 1924; Skinner, 1953, 1978).

In the field of microeconomics, behavioural economists have proposed and found evidence for several external determinants of individual economic behaviour. Together these form what Thaler and Sunstein (2008) refer to as 'choice architecture'. Sen and behavioral economists might in fact agree that individuals are rarely rational decision 
makers and the choices they make are heavily influenced by external factors. ${ }^{30}$ In this section, I briefly review four examples of institutional determinants of individual economic behaviour. These are: endowment effects, loss aversion, defaults, and mental accounts (Barr \& Sherraden, 2005; Thaler, 1999; Thaler \& Sunstein, 2008; DellaVigna, 2009; Mullainathan \& Shafir, 2009).

Having ownership of a good or asset seems to change subsequent economic decisions, independent of prices. Behavioral economists refer to this as an endowment effect. Having been given a resource, even a token good such as a coffee mug or a pen, individuals come to value the resource and seek greater compensation before they are willing to part with it (Kahneman, Knetsch \& Thaler, 1990; Tversky \& Kahneman, 1991, Bernatzi \& Thaler, 1995) than they would have been willing to pay prior to owning the good. These studies generally examine cases in which an asset is acquired as a gift, rather than saved up out of current income over time so that personal effort should not play a role in the decision. If anything, it may be that when assets are acquired through payments over longer periods of time, that the over-valuation is even greater, as in the case of homeowners who are unwilling to lower the asking price of their house for sale, even as it sits on the market for extended periods of time (Thaler and Sunstein, 2008).

\footnotetext{
${ }^{30}$ There is some divergent opinion in the field of behavioral economics about the degree to which human behaviour is irrational. Some experts such as Dan Ariely and Daniel Kahneman argue that human behaviour is generally error-prone and irrational, even in systematic, predictable patterns. Others, such as Richard Thaler argue that choices have a rationale in the context in which they are made and can be rendered more rational, in the sense of leading to greater utility, by addressing gaps in information.
} 
In other studies, researchers have found that subjects over-value projected losses to projected gains at ratio of approximately two to one (DellaVigna, 2009; Thaler \& Sunstein, 2008). In other words, to willingly experience a financial loss, a subject requires an incentive worth at least twice as much as the potential loss. Behavioral economists posit that savings out of current income are experienced as a loss (Knetsch, 2010; Thaler, 2010; Morrison \& Oxoby, 2011). If this is true, then incentives to save out of current income today would generally have to be large enough to offset the subjects' loss aversion to be effective on observed savings behaviour. Thaler and Sunstein (2008) and Bernatzi and Thaler (2004) propose that one way to overcome loss aversion and boost individual savings, is to invite subjects to pre-commit to save out of income they have not earned yet. These 'save more tomorrow' proposals aim to take advantage of the propensity of many people to discount future economic resources substantially compared to current resources. If income earned net year is less valuable to me than income earned today, then, the 'save more tomorrow' model predicts that I will be more willing to part with it and require a much lower incentive than a $\$ 2$ to $\$ 1$ return on my saving.

In addition to an endowment effect and loss aversion, behaviour economists suggest that the defaults built into policies and programs have important influences over individual savings and asset accumulation. If given an opportunity to contribute to an employer's pension plan at a standard rate or to contribute at a higher rate, employees will generally take a passive approach and contribute at the rate set as the default even if a higher contribution rate is in their own best interests (Choi, Laibson \& Madrian, 2004; Thaler \& Sunstein, 2008; DellaVigna, 2009). Behavioral economists suggest that individuals 
generally have a status quo bias, preferring the present situation where benefits and costs are familiar to strategies requiring change and exposure to new costs, even if new gains can be realized. This status quo bias is just one of several heuristics, or simplifying rules, used by people to make decisions (Rabin, 1998; List, 2004, DellaVigna, 2009). Thaler and Sunstein (2008) and Barr, Mullainathan and Shafir (2012) are among several authors who have suggested that defaults in savings policies and programs can substantially improve savings outcomes by increasing default savings rates and using voluntary optout over proactive opt-in enrolment mechanisms. More recent work by Oxoby and Morrison (2011) has suggested that it is possible to improve savings outcomes, increasing the number of participants who actively chose to save more than a default level by simply by exposing them to financial information that may serve as a cue or trigger to attend more carefully to the savings decision at hand. Studies of workplace pension plans also find some evidence for increases in participation following workplace financial education initiatives (Garman, 1997; Lusardi, 2003; Capuano \& Ramsay, 2011).

The question of attention leads to a final construct from behavioral economics: mental accounts. The term 'mental accounts' refers to the idea that individuals maintain a mental model of their finances and use different notional accounts in that model to make decisions (Thaler, 1999; Thaler, 2000; NEF, 2005). Furthermore, households generally use a model based on current income flows - rather than their overall net worth (Thaler, 1999, 2000; Thaler \& Shefrin, 1981). The concept of mental accounts also suggests that individuals label certain pools of money according to their intended purpose (for example "grocery money" or "money to cover recurring bills") even though the money is fungible 
and may even be held in a single deposit account (Thaler, 1999; Thaler \& Sunstein, 2008;

Finnie \& Davies, 2011). These mental models serve as one strategy to overcome difficulties in self-control or a propensity to spend rather than to exercise thrift. When these mental accounts are reinforced by external cues, such as dedicated single-purpose deposit accounts and barriers to withdrawal, these external commitment devices seem to have an important effect on behaviour and formalize saving (Thaler \& Shefrin, 1981; Thaler, 1999; Finnie \& Davies, 2011).

\subsection{Summarizing the individualist vs. institutionalist schools of thought}

In searching for microeconomic explanations of how and why individuals and households save and acquire assets, the current literature offers two dominant schools of thought: individualist models that focus on internal motivations and institutionalist models that focus on external cues, program design and 'nudges' on individual choice. In the middle of these two schools of thought sits the construct of capability, and more specific to household savings, financial capability.

Most people save something at some point in their lives (Whyley \& Kempson, 2000) independent of whether or not they, at any given point in time report being a "saver" (Whyley \& Kempson, 2000; McKay \& Kempson, 2003; Kempson \& Finney, 2009). If some share of the explanation for household savings and asset accumulation is individual differences in motivation or other psychological variables, then there should be some consumers who are identifiable as "savers". Looking at Canadian data sources, there are striking patterns of stability in the self-reported ownership and savings behaviour of 
Canadian households. These studies look at different forms of assets and savings and find that between half and three-quarters of Canadians are identifiable savers:

- Hou (2010) compared three different birth cohorts of adult Canadians and finds that, across all cohorts studied, between $73 \%$ and $78 \%$ of households buy a home at some point in their lifetime, a surprisingly small range of intergenerational differences considering the substantial legal, social and economic changes that would have affected each cohort differently.

- Moussaly (2010) examined trends in formal retirement savings through both employer-sponsored and private registered plans and found that there was remarkable stability in the percentage of workers who saved in private pension plans, whether they also had an employer-sponsored pension or not. Of those with an employer-sponsored plan, roughly half also saved in a private plan, a proportion that change only slightly from over a decade earlier despite substantial increases in tax incentives for saving over the same time period.

- Guilmette (2012) found that $70 \%$ of parents with dependent children aged 18 or younger reported that they were or previously had saved some money for their child's future education. A survey a decade earlier had similarly found that $72 \%$ of parents reported that they planned to or were currently saving for their child's education, a remarkable level of stability considering the major policy changes to formal, registered education savings instruments and to the costs of posteducation (Shipley, Ouellette \& Cartwright, 2003). 
It may be that some individuals and households have particular preferences, motivations, financial knowledge and psychological traits that make them more likely to manage their resources in ways that promote savings and asset accumulation. However, like the $19^{\text {th }}$ century moralists, a perspective that considers only individual factors risks being, according to Barr and Sherraden (2005) "consumed by "culture of poverty" theories of social deviance, laziness, and imprudence as describing the poor" (p. 3). Mullainathan and Shafir (2009), also warn that "the 'culture of poverty' perspective is motivated by the impulse to change how the poor function" (p.121). I am uncomfortable with a "culture of poverty" perspective on both philosphical and empirical grounds. I do not believe that individual differences are without merit as part of the explanation for how and why individuals households save and build assets, but I believe that individualist perspectives are incomplete on their own.

Institutionalist perspectives do not face the same potential objections as a "culture of poverty" analysis since the important variables of interest are thought to affect everyone, regardless of poverty or wealth. Behavioral economists have generally focussed on empirically showing the effectiveness of one or more institutional factors rather than promoting a comprehensive theory of personal savings and asset accumulation. However, Barr and Sherraden (2005) have proposed a theory of seven different determinants of savings that they say is heavily informed by behavioral research. These are:

- Access: Eligibility for savings and asset-enhancing programs.

- Information: Knowledge of both financial products and relevant public policies. 
- Incentives: Financial as well as non-financial returns, recognizing that higher returns can actually decrease savings rates by accelerating the pace at which an individual may reach a particular goal.

- Facilitation: A wide range of external factors of program design that can promote saving. Examples include the default parameters in savings programs and automated withdrawals from income flows.

- Expectations: Dominant norms regarding savings and thrift, peer pressure and goal-setting.

- Restrictions: Factors that create barriers to spending an asset.

- Security: Both enhanced protection from risk through savings (a sort of selfinsurance process) and also the protection of savings from risk (assurances that deposits will not be lost).

There are at least two difficulties with the proposed Barr and Sherraden model in trying to apply it to analyze a program or policy. The first problem is that the list above may not be adequate or even sufficiently clear description of the wide range of institutional variables that might, based on both traditional and behavioral economics, be expected to exert some influence over household savings and assets. For example, their distinction between 'facilitation' and "restrictions" may be exaggerated. If an account is locked-in, that is subject to some restriction, that prevents the user from accessing his or her money for particular time periods or all but particular uses, this could be both a 'restriction' and a 'facilitation' - similar to other program design features such as account labels or automatic contributions. Similarly, it is the role of personal financial advice in this model 
becomes very unclear. By best estimates, roughly half of adult Canadians seek formal or informal advice on one or more topics in their personal finances (CFCS, 2009). This advice may be seen as primarily enhancing 'information' of the individual decisionmaker or it could be understood as another form of 'facilitation' where the advisor helps to prompt or maintain some choice or behavior.

The second, and perhaps more fundamental difficulty with the institutional model proposed by Barr and Sherraden, is that it lists several factors that do not, by definition, exist independent of individuals. For example, 'expectations' do not exist separate from the individuals who form and maintain them. Furthermore, psychologists have documented important individual differences, as a psychological trait, in sensitivity to perceived norms and peer expectations (Johnson-Cartee \& Copeland, 2004; Hogg \& Smith, 2007). Similarly, 'information' to support financial decisions only has an impact if it can be accessed, absorbed and used by individuals - where individual differences in literacy and numeracy can make an important difference.

In a separate article, Barr may have articulated a more useful, fruitful and sustainable principle for a framework to understand household saving and assets: "human behaviour turns out to be heavily context dependent, a function of both the person and the situation" (Barr, Mullainathan \& Shafir, 2012, p.2).

I suggest that a useful framework for understanding individual and household savings and asset behaviours should not overlook individual differences. In analyzing the savings 
policies and programs that are the central focus of this thesis, I will necessarily be concentrating on institutional variables - features of program design and delivery through tax and private sector financial systems. However, my analysis also takes the perspective that individual differences are also important. The normative goals that are reflected in the names and policy goals of separate savings account may not align with the savings motivations of many Canadians. Programs that demand engagement with mainstream financial services will also have different effects for Canadians who perceive themselves as excluded from retail banks and credit unions. Programs that have complicated rules are likely to have different effects for Canadians with different levels of literacy and numeracy. Complicated rules, often phrased in policy or financial jargon, will have also different effects for individuals with higher or lower levels of self-confidence (or locus of control) in their ability to make sense of complicated information and navigate complex systems. Rather than adopt a strictly individualist or strictly institutionalist perspective on household savings, I take a perspective that focuses on capability. I suggest that it is the complex and multiple interactions between individual and institutional factors that give rise to differences in capability to save and accumulate assets using the policy instruments under analysis in this thesis. 


\section{Chapter 3: Estimating public expenditures on tax-preferred savings}

\section{instruments}

This chapter first provides a very brief description of each of the tax-preferred savings instruments that are the centerpiece of this thesis. ${ }^{31}$ More detailed discussion and analysis on each instrument follows in Chapters 4 through 6 . The current instruments each rely on some form of tax-preferred treatment as an incentive for saving. These include:

- exemptions that remove some type of income that would otherwise have been included in the calculation of taxable income for income tax purposes;

- deferrals that allow a taxpayer to postpone some part of their tax liability to a later period, when their marginal effective tax rate is likely to be lower;

- deductions that allow a taxpayer to reduce their taxable income by subtracting some amount, up to a specified dollar value; and,

- tax-prepaid status that recognizes deposits into an account as having been made using after-tax income and therefore does not subject withdrawals to taxation.

In turn, each of these measures results in some reduction of revenue to government through foregone taxes on personal income. Losses of tax revenue are generally regarded

\footnotetext{
${ }^{31}$ Registered Pension Plans receive tax-preferred status on the grounds that contributions and earnings are deferred compensation rather than saving out of total current income. In this chapter I report on annual federal tax expenditures on these workplace pensions because of their potential interactions with individual savings through Registered Retirement Savings Plans. Workplace pensions are not fungible, not account-based and require attachment to a sponsoring employer rather than mainstream financial services. Therefore I refer to them when it is relevant to do so but do not treat them as part of the defined set of policy instruments.
} 
as tax expenditures (Maslove, 1978; Howard, 2007; Burman, Toder \& Geisser, 2008). Following the description of the tax-preferred savings instruments, this chapter briefly discusses the literature regarding the calculation of tax expenditures and clarifies several important points in the methods used by the federal Department of Finance Canada, some of which have not previously been published by the Department. Next, I present a compilation of the Department's own estimates of annual tax expenditures from the earliest available (for the 1992 tax year) to the most recent available (for the 2012 tax year). Two of the relevant savings policy instruments also have direct transfers associated with them (in the form of matching savings grants and income-tested savings bonds). Therefore, I also include the costs of these direct spending programs in my estimate of the total federal expenditure.

Because of potential interactions between different forms of savings, the total cost of the current tax-preferred savings instruments cannot, strictly speaking be, calculated as the sum of each individual cost (Finance Canada 2010; Lester, 2012). Estimates for expenditures associated with individual tax measures are derived by eliminating that expenditure, holding all other factors constant, and evaluating how much government revenues would likely change. In reality, eliminating one tax measure may prompt consumers to increase (or decrease) their use of one or more other tax measures, changing the true cost of the measure being eliminated. I argue that the most likely interaction is between Registered Retirement Savings Plans (RRSPs) and Registered Pension Plans (RPPs) where taxpayers may adjust their savings in one instrument in 
response to their savings in the other. I argue that the magnitude of the interaction is, in the short-run, unlikely to substantially change the estimates as presented.

I conclude, at the end of this chapter, that the federal expenditures on tax-preferred, account-based instruments are very large and have increased over time over the reference period (1992 to 2012).

\subsection{A brief description of the tax-preferred savings instruments}

What follows in this section is a very brief description of each the seven instruments, as listed in Table 1.1 (Chapter 1), that are central to this thesis.

\subsubsection{Equity in a principal residence}

Canadians have never been required to pay income tax on money they make through real estate investments when the property is their primary residence. In this thesis, I define home equity as the net of the market value of the home less all debts secured against the home-including mortgage debts and home equity loans. This is broadly consistent with other studies of household wealth that examine homeownership (Chawla, 1990; Klyuev \& Mills, 2007; Toussaint, 2010).

The Income Tax Act defines taxable income in Canada as the total of "the taxpayer's income for the year from each office, employment, business and property" (Section 3), less applicable deductions and losses, where income from business and property includes “the taxpayer's profit from that business or property for the year" (Section 9). 
One interpretation of such a definition of taxable income is that any change in the value of an owner-occupied home should be included in the calculation of annual profit from property. As Perry (1951) noted, historically the British tradition was to include an annual amount of imputed rental income. ${ }^{32}$ The imputed rental income is an estimate of the costs savings to the homeowner from occupying a home they own rather than renting a comparable property. Horner (1983) advised that annual imputed rental income can be estimated by multiplying the equity of the homeowner in the property against the mortgage rate on the property. ${ }^{33}$ As equity in the property rises with each year of ownership, the imputed rental income should rise as well, all else being equal. If the market value of the property declines or the mortgage rate falls, then the value of ownership over renting declines. However, Canada's approach to defining taxable income, including income from property, does not and never has included imputed rent from homeownership.

In addition to annual profit from property, Canadian taxpayers may also have taxable capital gains when they sell or are deemed to have sold an asset. The capital gain is the increase in the value of the asset at the time of sale, compared to the value of the asset when the taxpayer acquired it. The taxable portion of the capital gain is one half of that increase in value. However, here again, Canadian homeowners do not pay any tax on any capital gain they receive when they sell their principal residence. Principal residence is

\footnotetext{
${ }^{32}$ The British tax system no longer includes imputed rental income and a principal residence is similarly sheltered from taxable capital gains.

${ }^{33}$ In this method, the housing market is assumed to be at some equilibrium where mortgage rates reflect the costs to the lender, including opportunity costs.
} 
defined in Section 54 of the Income Tax Act and the definition recognizes virtually any type of housing structure as a principal residence and allows several different forms of ownership including sole ownership, leaseholds and shares in cooperative housing. When a taxpayer has two residences, only one can be claimed as the principal residence. A second or third real property is subject to capital gains when it is sold but tax rules also allow a generous personal exemption on taxable capital gains in such cases, up to a lifetime limit of \$750,000 (Canada Revenue Agency, 2013a).

\subsubsection{Registered Retirement Savings Plans (RRSPs)}

To help Canadians save for their own retirement, the federal government created a class of tax-preferred accounts called Registered Retirement Savings Plans. RRSPs are longterm savings accounts that are recognized, under Section 144 of the Income Tax Act, as qualifying for five different preferential tax treatments. These are:

- Deposits into qualifying accounts can be deducted from taxable income, up to an annual limit. The annual limit for this deduction is the lesser of $18 \%$ of earned income in the previous tax year, or $\$ 22,970$ for the 2012 tax year (CRA, 2013b). From year to year, the limit on the deduction is cumulative - the unused portion of this annual deduction limit is carried forward and added to the new maximum annual deduction. Contributions to an RRSP made over the annual limit are not eligible for the deduction and are included in the calculation of taxable income. Taxpayers cannot contribute to their RRSP after age 71. Deposits to the RRSP of a spouse can also be deducted from taxable income, up to the taxpayer's annual limit. 
- During the lifetime of the account, investment earnings on the principal are exempt from income tax. There is no limitation on the value of this exemption. RRSPs can only be issued by qualifying private sector financial institutions (including insurance companies, banks and trust companies) and deposits are subject to certain investment rules (such as limits on the amount of non-Canadian investment vehicles). Companies wishing to offer an RRSP must apply to the Minister of Finance for permission, called 'registration' in the Income Tax Act.

- Tax on RRSP withdrawals can be deferred until retirement, when marginal tax rates may be lower compared to working years, resulting in a net reduction on lifetime income taxes paid. Money in an RRSP does not have to be withdrawn until age 71 when the balance can be transferred, without tax penalty, into an annuity to pay out regular income or a Registered Retirement Income Fund (RRIF). Taxpayers with a RRIF must take out, and claim in their taxable income, some minimum portion of the RRIF balance. Outside of these rollovers and the exceptions discussed below, withdrawals from an RRSP are treated as taxable income.

- Tax-sheltered withdrawals from RRSPs are allowed for first-time homebuyers under the Home Buyer's Plan (HBP). The HBP allows RRSP owners to withdraw, tax-free, up to $\$ 25,000$ from their RRSP balances in the year they buy their first home. HBP withdrawals must be repaid to an RRSP within 15 years. If an annual minimum repayment is not made, it is treated as a taxable withdrawal from the RRSP for the year that the repayment was missed. 
- Another program, the Life-Long Learning Plan, also allows for tax-sheltered withdrawals from RRSPs for adults returning to education. The LLP allows RRSP owners to withdraw, tax-free, up to $\$ 20,000$ from their RRSP balances when they start a full-time education or training program. The withdrawals are repayable and treated much like the HBP withdrawals described above.

RRSPs were initially introduced as a retirement savings vehicle for those workers who did not have a workplace pension. Since the start of the federal income tax system, workplace pensions have received tax-preferred treatment. Like RRSPs, Registered Pension Plans (RPPs) must be registered and must comply with both federal and provincial pension regulations to maintain their tax-preferred status. Contributions made by an employee into a pension plan are treated as deferred compensation. Employees receive an annual deduction for their contributions that is subject to the same global limit as RRSPs $-18 \%$ of earned income or $\$ 22,970$. When a pension member retires and begins to receive regular pension benefits, these are included in taxable income, usually at a lower marginal rate than during their working years. Employer contributions and investment earnings to the pension pool are excluded from the employee's income. This includes both pension plans with guaranteed retirement benefits (defined benefit plans) and plans with guaranteed annual employer contributions (defined contribution plans).

Registered Pension Plans (RPPs) are unlike the other tax-preferred, account-based savings instruments. They are not structured as individual accounts where individual owners have control over deposits and withdrawals. Contributing to the pension plan is, 
generally speaking, a condition of employment and individual workers have little say in whether, when and how much to save in the pension plan. Payments from RPPs are also heavily restricted to plan members who have retired (either partially or fully) from the paid workforce. The other savings vehicles give owners far more control over both the amount and the timing of contributions and withdrawals.

In the compilation of data on the annual expenditures on tax-preferred savings vehicles in Section 3.5 below, I include RPPs only because of the potential interactions with RRSPs. Pension plan members may have substantially smaller RRSP savings, reducing the annual cost of the tax benefits on RRSPs. This potential interaction is discussed later in this chapter in Section 3.6).

\subsubsection{Registered Education Savings Plans}

To help Canadians save for future education costs, the federal government created another class of tax-preferred savings accounts, Registered Education Savings Plans (RESPs). Like RRSPs, RESPs are subject to rules (in Section 144 of the Income Tax Act) for 'registration', or permission from the Minister of Finance. RESPs benefit from four different benefits:

- Like RRSPs, investment earnings on the principal (including government cash assistance) are exempt from income tax during the lifetime of the RESP account. In contrast to RRSPs, there is no annual contribution limit on RESPs and contributions do not receive any deduction against taxable income. 
- RESPs offer a form of tax deferral because payments out of the account are normally made to a student who is expected to have little or no income tax liability. RESP rules (CRA, 2013c) recognize a contract between the person who opens the account (the subscriber), the firm selling the RESP (the provider) and the person (the beneficiary) who will eventually receive payments (called Education Assistance Payments) for their education costs. A subscriber can also be the beneficiary. In most cases, however, a beneficiary is a child related to the subscriber (for example, a child or grandchild). While there is no annual limit on contributions, there is a $\$ 50,000$ lifetime contribution limit for the total of all RESPs for any one beneficiary.

- There is a matching savings grant on contributions to RESPs for a beneficiary child under 18 years old. Through the Canada Education Savings Grant, the federal government contributes $20 \%$ of the annual contributions to an RESP, up to a limit of $\$ 600$ in matching grants in any one year and up to a lifetime limit of $\$ 7,200$. For children in low and middle-income families, the matching rate is higher (between $30 \%$ and $40 \%$ ) for the first portion of annual contributions.

- There is an income-tested savings bond available to RESPs for children born in 2004 and later. In contrast to the Canada Education Savings Grant, once the account is opened, no contribution to the RESP is required to receive the Canada Learning Bond. Only families receiving the low-income supplement of the 
Canada Child Tax Benefit are eligible for the Bond. ${ }^{34}$ The first bond payment is $\$ 500$ and subsequent payments are $\$ 100$ annually, up to a lifetime maximum of $\$ 2,000$ for each eligible child.

\subsubsection{Registered Homeownership Savings Plans}

Between 1974 and 1985, taxpayers who did not already own their own home ${ }^{35}$ were eligible to open another class of tax-preferred savings account to save for a future purchase of a home. Federal Registered Homeownership Savings Plans (RHOSPs), offered three different tax-benefits:

1. Like RRSPs, a deduction against taxable income was allowed on up to $\$ 1,000$ per year in RHOSP savings, to a lifetime limit of $\$ 10,000$ per accountholder (Finance Canada, 1974).

2. Like both RRSPs and RESPs, investment income earned on the principal was exempt from income tax.

3. In contrast to both RRSPs and RESPs, withdrawals were not taxable as long as they were used to buy a first home or furniture for that home. When the RHOSP was cancelled, this was amended to allow withdrawals on remaining balances for any reason (Finance Canada, 1985). The policy on RHOSPs required that balances be used within 20 years of opening the account.

\footnotetext{
${ }^{34}$ The Canada Child Tax Benefit is a refundable tax credit tied to family size and annual income. Families with low incomes may be eligible for a supplement to the basic benefit called the National Child Benefit.

${ }^{35}$ Initially the policy only required that a home not be owned in the account-holder's name and permitted adults to open RHOSPs while living in a home owned by a spouse or parent.
} 


\subsubsection{Registered Disability Savings Plans}

To help Canadians caring for a family member with a severe disability, the government created yet another type of tax-preferred savings account - the Registered Disability Savings Plan (RDSP). The program is particularly (though not exclusively) geared towards parents concerned about the future security of a child with a disability. Like RRSPs and RESPs, providers and investment vehicles are regulated as conditions for registration. The RDSP also has several benefits in common with RRSPs and RESPs:

1. Like RRSPs and RESPs, investment income earned in RDSPs is exempt from income tax (CRA, 2013d). Withdrawals from RDSPs are also excluded from taxable income, in contrast to RRSPs and RESPs that provide mechanisms to reduce the tax burden on withdrawals. Like RESPs, contributions to RDSPs are regarded as originating from after-tax income and do not receive a deduction. Contributions to an RDSP are not subject to annual limits but are subject to a lifetime limit of $\$ 200,000$. Contributions cannot be made after a beneficiary of an account turns 59 years of age. Withdrawals are subject to complicated annual and age-related limits. ${ }^{36}$

2. Like RESPs, eligible contributions to RDSPs may receive a matching savings grant. The Disability Savings Grant matches annual contributions at a rate of at

\footnotetext{
${ }^{36}$ Prior to age 60 , a beneficiary of an RDSP cannot withdraw the grant and bonds within ten years of their deposit into the account and any withdrawals are subject to a hold-back to cover grant and bonds deposited over the last ten years. After age 60, RDSP beneficiaries must withdraw a minimum amount from the account. The amount is determined through a formula that considers the market value of the account and the lifeexpectancy of the beneficiary.
} 
least $100 \%$, with accelerated rates on the first contributions from lower and middle-income families. The grant is subject to an annual limit of $\$ 3,500$ and a lifetime limit of $\$ 70,000$ over 20 years or up to a beneficiary's $50^{\text {th }}$ birthday.

3. Like RESPs, eligible RDSPs may also receive an income-tested savings bond. No family contribution into the RDSP is required to qualify for the Disability Savings Bond. The bond may be worth up to $\$ 1,000$ per year, depending on family income, to a lifetime maximum of $\$ 20,000$.

\subsubsection{Tax-Free Savings Account}

The most recent of the tax-preferred account-based instruments is the Tax-Free Savings Account (TFSA). While it is sometimes described as an alternative to the RRSP as a vehicle for long-term saving (Finance Canada, 2007; Laurin \& Poschmann, 2010, Milligan, 2012; Kesselman, 2012), any Canadian adult may open a TFSA and the taxpreferred treatment is not limited by the use of the withdrawals. Like the other registered instruments listed above, providers and investments are regulated as conditions of registration. The TFSA has just two tax benefits:

1. Like all of the other registered instruments, investment income earned on the principal is exempt from income tax. There is no limit on this exemption (CRA, 2013e).

2. Like RESPs and RDSPs, contributions to TFSAs are viewed as having been made out of after-tax income. This tax pre-paid treatment means that no deductions are offered on contributions, but no tax is paid on withdrawals either. There is an annual contributions limit of $\$ 5,500$ with no lifetime limit. This annual limit is 
expected to increase to $\$ 10,000$ by 2015 . Like RRSPs, contribution room can be carried forward to future years. Contributions over the total available room for a taxpayer are subject to a penalty.

\subsection{Defining a "tax expenditure"}

The term "tax expenditure" was first coined in a 1967 speech by Stanley Surrey who used it to describe the set of exemptions, deductions and credits that reduced taxation (and therefore increased income) for eligible claimants while reducing the overall revenues to government (cited in Toder, 2005). Maslove (1978) defines tax expenditures as a set of "special provisions in the tax laws providing for preferential treatment" (p.149) either to grant relief to individuals under certain circumstances or to provide taxpayers with incentives to behave in certain ways through tax exemptions, deductions or credits. In nearly all cases, these kinds of changes to the overall federal flow of collecting and spending tax revenues are neither reported in the annual or supplementary estimates of government departments nor are they voted on by Parliamentarians as such.

In Canada, transfers to other orders of government, costs to service the debt, program operations and administrative costs, and direct transfers to individuals are all included in the federal estimates that are submitted to Parliament for authorization through the business of supply. ${ }^{37}$ However, when the government opts to offer an exemption from

${ }^{37}$ The business of supply refers to the process through which the government seeks the approval of Parliament to raise taxes and spend public funds. It includes the process of 
tax, a tax deduction or a credit against taxes payable, this results in some net cost to the fiscal framework. Note that this is an accounting cost, as the numbers represent lost revenue, but not an economic cost since the numbers do not include opportunity costs or the net benefit to government or other parties involved. Government revenues from income taxes may fall over the short-run in response to a new tax credit or deduction, but the ultimate economic cost of that same credit or deduction depends on the behavioral responses of consumers, firms and government itself. It is conceivable that a credit in one area may actually increase consumer spending and government revenues in another area. It is also conceivable that a government might reduce tax revenues and then reduce program expenditures to fit the reduced fiscal framework. ${ }^{38}$

The use of taxation as a way for government to 'spend' may be particularly appealing to governments in Canada, perhaps owing something to our combination of both a Westminister system and strong federal system of government. In fact an estimate from the Parliamentary Budget Office (2011) suggests that as much as $28 \%$ of total federal spending in Canada is in the form of tax expenditures and that, as a percentage of GDP, Canada is more reliant on tax expenditures than many countries including Spain, Japan and the United States.

regular estimates, the annual budget, supplementary estimates and votes to approve each of these.

${ }^{38}$ Because of cost-shared programs, federal transfers of cash and tax points, and the potential for particular regional effects, a full calculation of the economic cost of change to the federal fiscal framework would also have to include the impacts on provincial and territorial revenues and spending. 
Given some benchmark tax system, any deviation that reduces tax revenues is deemed an expenditure (Altshuler \& Dietz, 2008; Finance Canada, 2010; Poterba, 2011; PBO, 2011). Economists, however, do not always agree on how to define that benchmark system or how to define and measure a deviation from it.

Defining the benchmark system requires a decision about the rightful basis for taxation generally either income or consumption. The Department of Finance (2010) argues that the right benchmark system is one based on income, and the Haig-Simons definition of income in particular: "the net accretion to economic power between two points of time" (Haig, cited in Perry, 1951). That economic power can be measured as all consumption in a given period plus the change in wealth from the start to the end of that period, on the basis that all resources will either be spent or saved. Dodge (2012) notes that while this has been the "gold standard" for tax theory and policy, it creates a great deal of ambiguity in the treatment of both consumption and wealth in any implementation. Some economists argue that consumption is a preferable basis for taxation on the grounds that it may improve equity in taxation according to ability to pay (horizontal equity) and promote environmental sustainability (Brundtland, 1994; Mintz; Kesselman \& Poschmann, 2001; Spaargaren, 2003; Mont \& Plepys, 2008; Kesselman, 2009). If consumption is the baseline system of taxation, then exemptions, deductions and other credits for saving would not be defined as a deviation but rather as part of the baseline.

There have been many changes over time to Canada's tax system that some have argued have the effect of making it, incrementally, more like a consumption tax system 
(Kesselman, 2009). For households that shelter some important share or even all of their savings and assets in sheltered instruments, a personal income tax can be viewed as a consumption tax system, notwithstanding the title. In this hypothetical state, if all saving is sheltered from taxation, then the income outside of the shelter that is taxed is all of the income that has been spent on consumption. The taxation on that income would be equivalent to a tax system based on consumption. But the Canadian federal personal tax system lacks the estate tax that is a requirement of a tax system based truly on consumption (Shaviro, 2004). Canada has never truly embraced a switch from incomebased taxation to consumption-based taxation. If anything, we are moving the opposite direction at the federal level. Federal income taxes (on individuals and corporations) now (based on 2009, most recent data available) make up $65 \%$ of the direct revenues of the government (up from 63\% in 2005) while consumption taxes make up just $18 \%$ (down from $22 \%$ in 2005). ${ }^{39}$

\subsection{Measuring tax expenditures on tax-preferred savings}

Policy-makers in the Department of Finance Canada continue to regard the personal income tax as a system of taxation based on income, not consumption. In its own calculations of annual tax expenditures, the Department of Finance (2010) uses a benchmark system that includes all sources of income with the exception of:

\footnotetext{
${ }^{39}$ Source: Statistics Canada, CANSIM Table 385-002.
} 
- non-market transfers between individuals such as gifts, inheritances or child support; ${ }^{40}$

- imputed rental income from owner-occupied housing.

In an income-based system, the exemptions, deductions and credits for personal saving, are not only expenditures, they are among some of the largest of the tax expenditures (Maslove, 1978; Howard, 2007; OECD, 2007; Carroll, Joulfaian \& Mackie, 2008; Poterba, 2011).

Studies of the notional total cost of all federal tax expenditures in Canada arrive at very large dollar estimates. In his 1978 study of the cost of all federal tax expenditures, Maslove included the cost of the measures related to RRSPs, Registered Pension Plans (RPPs) and the RHOSP and arrived at an estimate of $\$ 8$ billion in total tax expenditures on personal and corporate income taxes. The Parliamentary Budget Office (PBO) in their 2011 study of federal tax expenditures, concluded that the notional total of all federal exemptions, deductions and credits itemized in federal tax expenditure reports is over $\$ 160$ billion annually. The PBO cautioned that this is an order of magnitude estimate since the true cost of all of the individual measures depends on various

\footnotetext{
${ }^{40}$ Though not discussed in Finance Canada's 2010 “Tax Expenditures and Evaluations Report", it should also be noted that previously child support was included as income in the hands of the recipient parent and was deductible from income in the hands of the paying parent. Other non-market flows such as lottery winnings and social assistance income, while non-taxable in Canada, are included in the baseline definition and the exclusions are reported as tax expenditures. In other words, the definition of inclusions and exclusions from the baseline income is always subject to policy change.
} 
interactions that can either reduce or inflate their combined net value. They suggested that the true cost of foregone revenues is closer to $\$ 100$ billion annually.

At least one previous study of annual tax expenditures has found that that those related to household savings are very costly policy instruments. Horner (1983) estimated the combined cost of tax expenditures for RRSPs and RPPs at \$1.6 billion in 1978 and the cost of RHOSPs at $\$ 92$ million in that same year. ${ }^{41}$ By comparison, Lester (2012) argued that other expenditures on business research and development credits and charitable donations are more significant than amounts aimed at household savings and assets. However, Lester included both corporate and personal income taxes in his analysis and eliminated nearly half of all personal income tax expenditure items that he regarded as structural or part of his definition of a baseline system. Among the items he eliminated from his analysis are RRSPs, RPPs and TFSAs, but not the more targeted RESPs and RDSPs. Lester did include the RESP, RDSP as well as the Homebuyer's Plan and Lifelong Learning Plan that are fundamentally linked to the RRSP. Including some but not all RRSP items as well as some but not all tax-prepaid accounts seems to be a very selective and problematic approach to defining a baseline system and overlooks much of the common design and implementation among these instruments. A more consistent

\footnotetext{
${ }^{41}$ Horner also developed a model to estimate the indirect cost to provincial revenues through foregone provincial income tax revenues. With those tax expenditures included, his estimate for the combined federal and provincial costs for RRSPs and RPPs rises to $\$ 2.3$ billion and costs for RHOSPs rise to $\$ 130$ million. At the time, most provincial taxes were set as a ratio of federal taxes making such a model feasible as a constant for provincial taxation could be programmed. Since provincial income taxes have been delinked since the mid-1990s, no estimates on combined federal and provincial impacts of tax measures appear to have been developed.
} 
approach is to take as given a Haig-Simons income-based taxation and to then look at the global cost, through taxation. That is the approach taken by the Department of Finance and in Section 3.4 below.

Outside of Canada, some studies have estimated the costs of national tax-preferred savings programs. Examining the U.S. income tax system, Howard (2007) estimated that federal tax expenditures just to support homeownership amounted to (USD)\$115 billion in 2005, and that at least one half of this amount was directed towards households with more than (USD)\$100,000 in annual income. Carroll, Joulfaian and Mackie (2008) found that U.S. federal tax expenditures on mortgage interest deductibility and private retirement savings accounts were the second and third largest expenditures through the American personal income system. ${ }^{42}$ Their results are confirmed by Poterba, (2011) who also finds that expenditures on the deductions for mortgage interest and private retirement accounts are the second and third largest expenditure items. Neither of the recent studies of tax expenditures in Canada (PBO, 2011; Lester, 2012) provides comparable results for Canada.

Reporting on data prepared internally by government departments or agencies is common in the literature on tax expenditures. Five of the studies mentioned above (Howard, 2007; Carroll, Joulfaian \& Mackie, 2008; Poterba, 2011; PBO, 2011; Lester, 2012) use

\footnotetext{
${ }^{42}$ These authors, as well as Poterba (2011), report that the exclusion of employer-paid health benefits is the largest single expenditure under the American personal income tax system. The comparable tax expenditure in Canada is proportionally much smaller because of country-to-country differences in health care financing.
} 
previously published national government data. This may be as a result of very limited access to the microdata on individual tax-filers that would be required to accurately model expenditure items.

Estimating the $\operatorname{cost}^{43}$ of Canada's tax-preferred and account-based instruments to promote household savings and assets requires a compilation of the estimates the annual loss of foregone tax revenues for each instrument of interest. The OECD (2007) conducted an international analysis of tax-preferred account-based instruments that excluded retirement savings and concluded that the most costly savings programs are those that have a positive savings credit or grant paid in addition to the tax benefit. In Canada, both the RESP and the RDSP include these positive savings grants. Therefore, a better estimate of the cost of these instruments includes the federal expenditure on the savings grants as well as the foregone tax revenues.

\subsection{Notes on calculations of Department of Finance}

Analysts in the Tax Policy branch in the federal Department of Finance now prepare annual reports on Tax Expenditures and Evaluations based on a combination of data from the "T1 tax-filer Database" - a collection of annual data that covers all tax returns in Canada - and administrative data. Those reports form the basis for this current review, alongside published data on the annual direct spending through various savings grants and bond associated with the RESP and RDSP.

\footnotetext{
${ }^{43} \mathrm{As}$ discussed earlier in this chapter, this is in accounting not economic terms.
} 
The first tax expenditure report published in 1995 covers the tax years 1992 and 1993. The next, published in 1997, covered the years 1994 through 1997 and made forward projections to 1999 . The reports for 1998 onwards have been published annually and usually cover some range of years retrospectively and prospectively. More recent reports have not provided any forward-looking projections. In the years 1992 through 1996, data are based on retrospective reviews where tax-filing information is more likely to be complete for the years in question. ${ }^{44}$ In all subsequent years, I use the figures for the same tax year as the date of the report. This is still a projection since final tax and administrative data are unlikely to be complete in time for analysis. The most recent year included is 2012.

In the following paragraphs I will briefly clarify the information sources used by the Department of Finance to estimate tax expenditures that cannot be derived solely from annual income tax returns.

The Department of Finance estimates the foregone tax revenue from the capital gains exemption on principal residences based on internal analysis of national housing market data. The Department relies on data regarding volume and price of resale housing from the Canada Mortgage and Housing Corporation as well as the Canadian Real Estate

\footnotetext{
${ }^{44}$ Not all taxpayers in Canada file returns on time. With additional time, it is more likely that late returns can be included in T-1 tax-filer database that is used for the tax expenditure analysis.
} 
Association (Finance Canada, 2013). It also estimates the value of capital investments in owner-occupied housing using survey data on major renovations. The value of the capital gains exemption appears to be based on a model that estimates the increase in value of a home between some point (perhaps purchase) and the point of sale, adjusted for some estimate of owner's capital costs. Presumably the model also adjusts for differences in the marginal effective tax rates of homeowners, but this cannot be verified based on the information published by the Department.

The expenditure data reported by the Department of Finance on RRSPs include the total cost of the tax deduction for all RRSP contributions made in the tax year, plus the estimated cost of the foregone taxes on investment income earned in RRSPs in the same year. The total of this gross expenditure is then reduced by the amount of income tax revenue collected on taxable RRSP withdrawals. This latter would include both retirement and pre-retirement taxable withdrawals. The net expenditure, as calculated by the Department of Finance, suffers from a problem of attributing the cost to a specific time period. Some portion of the investment income earned in a given year is actually earned on principal accumulated in previous years. The estimates of the tax expenditure do not adjust for any such difference.

The data reported by the Department of Finance on the tax revenue lost to preferential treatment of RESPs are based on administrative data submitted by providers to the 
Canada Education Savings Program. ${ }^{45}$ The calculation of the tax expenditure uses an estimate of the investment income at the tax rate of the subscriber, less any tax paid on RESP withdrawals (as Education Assistance Payments) in the hands of beneficiary students. The investment income estimates include interest on education savings bonds and grants but not the dollar value of the bonds and grants themselves. I add the reported federal expenditure on each the Canada Education Savings Grant and Canada Learning Bonds in Table 3.1 below. These are available for 1998 onwards (after the grant was created) and are based on administrative data reported in annual Departmental Planning and Priorities Reports, annual Departmental Performance Reports and occasional statistical reports for programs at Human Resources and Skills Development Canada between 1998 and 2013.

None of the estimates includes the costs of program administration. While these are properly part of the estimates of total costs, the administrative costs to government are likely to be quite low given that most of the task of monitoring accounts and keeping records is outsourced to private sector financial service providers. Similarly, some programs (such as the RESP) spend money to raise public awareness of the savings instrument and government grants. While these are, again, properly part of the total public expenditure on the savings instrument, they are unlikely to have a meaningful effect.

${ }^{45}$ Personal communication with Director General Tax Policy Evaluation and Analysis, Finance, 2013 
In the case of the TFSA, data from Finance Canada are based on indirect observation of mandatory reporting by financial institutions registered to sell the accounts. ${ }^{46}$ The product providers submit returns on the total value of all TFSA accounts as well as personal balances and contributions identified by Social Insurance Number. These estimates do not indicate the market rate of return or the class of asset (for example cash, stocks or term deposits). Based on surveys conducted by a private, subscription-based firm (Investor Economics Institute), Finance analysts estimate the portfolio holdings and investment incomes for the year of TFSA account holders. Any taxes or penalties paid on over-contributions beyond the annual limit are not deducted from this line item.

Dollars values reported in Table 3.1 below are all based on the rate structure and policies (including contribution limits and transfer rules) in place at the time. All dollar figures are nominal since the income and tax incidence all take place in the same calendar year. Amounts are all based on a cash-flow analysis rather than lifetime or net present value analysis. The Department of Finance (2013) argues that this is generally consistent with the structure of the Canadian income tax system, yet the benefit of the tax expenditures will accrue over time. ${ }^{47}$ As such, items that permit a deferral of income (as in the case of the RRSP and RPP deduction-deferral measures, are reported as expenditures.

\footnotetext{
46 Ibid.

${ }^{47}$ For example, all instruments include an exemption on taxation of investment income. Over time, the amount of principal will increase the dollar value of the return on the investment in any year, all else being equal. The annual tax expenditures will include some estimate of the sheltered investment income in a year but will not be adjusted for earnings on principal invested in a previous year.
} 
Finally, the cost of each item is estimated on a model that holds all other variables constant. This has several implications. The first is that no behavioral change is included in the model. For example, if the non-refundable Employment Tax $\mathrm{Credit}^{48}$ were cancelled, the model assumes that Canadians would not decrease their paid labour, resulting in a systematic reduction in taxable incomes and therefore federal revenues. In this case, the cost of the single credit is likely to be more accurate. But the same assumption of no behavioral change is also maintained for items such as Registered Pension Plans where cancellation of the favorable tax treatment might reasonably be expected to lead to increases in precautionary savings in RRSPs, TFSAs and life insurance policies that would all continue to receive preferential tax treatment. In these cases, reasonable assumptions of behavioral response may lead to higher or lower estimates of the true cost, and, furthermore, point to interactions between various line items. The exact effects, in terms of foregone tax revenues, from interactions between expenditure items depends in part on the marginal tax rate of the individual in question. For individuals in the midpoint of a tax bracket, one or more small changes in their taxable income or tax payable are unlikely to result in any net change to taxes paid. But, when the cumulative effect of a series of credits serves to reduce a tax-filer's taxable income to a lower bracket, or even to reduce their tax liability to $\$ 0$, then the true cost is greater than the sum of the individual items (Finance Canada, 2010; Lester, 2012). However, if items are substitutes for one another then the true cost of the combined items is potentially smaller than the sum of the individual items. It is impossible to make an

${ }^{48}$ A credit of $\$ 1000$ at $15 \%$ (or $\$ 150$ ) against federal taxes owed. 
exact calculation unless the model involved can account for each individual tax-filer's effective and marginal tax rates under multiple scenarios, as well as accurately predict their likely behavioral response. In section 3.6, I briefly discuss the most probable of the interactions between the instruments in Table 3.1 -interactions between RRSPs and RPPs.

Estimating the total economic cost of any of the tax expenditures would also require a model that predicts behavioral responses of employers and the policy responses of governments. From my own review of the Canadian and U.S. literature, it does not appear as though this type of full economic cost analysis has ever been conducted. For the purpose of this thesis, it is beyond the scope of analysis.

\subsection{Estimates of tax and direct expenditures on tax-preferred account-based savings}

Table 3.1 (below) presents the annual expenditure estimates for each of: capital gains exemptions on an owner-occupied home, RRSPs, RPPs (principally for comparison to RRSPs), RESPs, RDSPs and TFSAs. 
Table 3.1a: Annual federal and tax and direct expenditures on tax-preferred account-based savings instruments and RPPs, $1992-2001$

\begin{tabular}{|c|c|c|c|c|c|c|c|c|c|c|}
\hline (\$ millions) & 1992 & 1993 & 1994 & 1995 & 1996 & 1997 & 1998 & 1999 & 2000 & 2001 \\
\hline Exclusion of capital gains on primary residence & 3215 & 2385 & 2390 & 1445 & 1660 & 1745 & 1250 & 1170 & 1475 & 1575 \\
\hline RRSP deduction for contributions & 3685 & 4490 & 4785 & 5405 & 5945 & 6540 & 7040 & 7675 & 7315 & 6765 \\
\hline $\begin{array}{l}\text { Non-taxation of investment income and } \\
\text { withdrawals for HBP and LLP }\end{array}$ & 2760 & 3325 & 3565 & 4080 & 4605 & 5180 & 4415 & 3890 & 4465 & 4290 \\
\hline Tax on RRSP withdrawals & -1000 & -930 & -1620 & -1765 & -1930 & -2105 & -2230 & -3020 & -3015 & -3185 \\
\hline Net RRSP expenditure & 5445 & 6885 & 6730 & 7720 & 8620 & 9615 & 9225 & 8545 & 8765 & 7870 \\
\hline RPP deduction for contributions & 4990 & 5205 & 4890 & 5180 & 5490 & 5820 & 5380 & 5080 & 5220 & 4005 \\
\hline Non-taxation of investment income & 7865 & 8610 & 9540 & 10260 & 10915 & 11580 & 9315 & 7985 & 9985 & 9325 \\
\hline Tax on RPP withdrawals & -4580 & -4930 & -4010 & -4490 & -5030 & -5630 & -6465 & -6890 & -7900 & -7140 \\
\hline Net RPP expenditure & 8275 & 8885 & 10420 & 10950 & 11375 & 11770 & 8230 & 6175 & 7305 & 6190 \\
\hline RESP non-taxation of investment income & n.a. & n.a. & n.a. & n.a. & n.a. & n.a & n.a. & 78 & 135 & 98 \\
\hline Canada Education Savings Grant & & & & & & & 151 & 291 & 318 & 348 \\
\hline \multicolumn{11}{|l|}{ Accelerated Canada Education Savings Grant } \\
\hline \multicolumn{11}{|l|}{ Canada Learning Bond } \\
\hline Total RESP expenditure & & & & & & & & 369 & 453 & 446 \\
\hline
\end{tabular}


Table 3.1b: Annual federal and tax and direct expenditures on tax-preferred account-based savings instruments and RPPs, 2002-2012

\begin{tabular}{|c|c|c|c|c|c|c|c|c|c|c|c|}
\hline (\$ millions) & 2002 & 2003 & 2004 & 2005 & 2006 & 2007 & 2008 & 2009 & 2010 & 2011 & 2012 \\
\hline Exclusion of capital gains on a primary residence & 2810 & 3665 & 5210 & 7160 & 8650 & 5285 & 3015 & 3785 & 4140 & 4790 & 4495 \\
\hline RRSP deduction for contributions & 7395 & 7585 & 7100 & 6720 & 7520 & 7705 & 8595 & 7850 & 7280 & 7390 & 7555 \\
\hline $\begin{array}{l}\text { Non-taxation of investment income and withdrawals } \\
\text { for HBP and LLP }\end{array}$ & 6055 & 6020 & 5105 & 5485 & 5645 & 8072 & 8695 & 5270 & 5020 & 7645 & 7295 \\
\hline Tax on RRSP withdrawals & -2915 & -4010 & -4695 & -4490 & -4720 & -4545 & -4850 & -4600 & -4985 & -5125 & -5480 \\
\hline Net RRSP expenditure & 10535 & 9595 & 7515 & 7720 & 8445 & 11235 & 12440 & 8520 & 7315 & 9910 & 9370 \\
\hline RPP deduction for contributions & 4470 & 4550 & 5265 & 9405 & 8700 & 9750 & 9295 & 9485 & 10740 & 11860 & 12750 \\
\hline Non-taxation of investment income & 8975 & 10325 & 8155 & 10005 & 10670 & 13975 & 15675 & 8665 & 8055 & 11155 & 10590 \\
\hline Tax on RPP withdrawals & -7485 & -7415 & -7500 & -7870 & -7560 & -6770 & -7195 & -6820 & -7175 & -7390 & -8350 \\
\hline Net RPP expenditure & 5960 & 7460 & 5920 & 11540 & 11810 & 16950 & 17775 & 11330 & 11620 & 15625 & 14990 \\
\hline RESP non-taxation of investment income & 105 & 83 & 125 & 135 & 175 & 180 & 170 & 140 & 180 & 185 & 155 \\
\hline Canada Education Savings Grant & 370 & 389 & 426 & 462 & 500 & 557 & 575 & 593 & 639 & 658 & 715 \\
\hline Accelerated Canada Education Savings Grant & & & & 7 & 14 & 22 & 28 & 43 & 39 & 45 & \\
\hline Canada Learning Bond & & & & 0.45 & 16.74 & 33.7 & 47.42 & 56.46 & 65.18 & 79.02 & 106 \\
\hline Total RESP expenditure & 475 & 472 & 551 & 604.45 & 705.74 & 792.7 & 820.42 & 832.46 & 923.18 & 967.02 & 976 \\
\hline $\begin{array}{l}\text { RDSP non-taxation of investment income less } \\
\text { taxable withdrawals and repayments of grants and } \\
\text { bonds }\end{array}$ & & & & & & & 0.94 & 1.33 & 2.25 & 4 & 4 \\
\hline Disability Savings Grant & & & & & & & 30.6 & 42.9 & 83.9 & 142.8 & 178.3 \\
\hline Disability Savings Bond & & & & & & & 11.2 & 16 & 15.7 & 70 & 73.4 \\
\hline Total RDSP expenditure & & & & & & & 42.74 & 60.23 & 101.85 & 216.8 & 255.7 \\
\hline $\begin{array}{l}\text { TFSA non-taxation of investment income and } \\
\text { withdrawals }\end{array}$ & & & & & & & & 45 & 155 & 220 & 305 \\
\hline
\end{tabular}


The dollar values of each separate item in Table 3.1 above are in the order of hundred of millions and even billions of dollars. In the most recent year, the exemption of capital gains on a principal residence was worth nearly $\$ 4.5$ billion, deductions and exemptions for RRSPs (net of tax on withdrawals) were worth nearly $\$ 9.4$ billion, exemptions and direct contributions to RESPs were $\$ 976$ million, exemptions and direct contributions to RDSPs were \$256 million and exemptions for TFSAs were worth \$305 million.

As a system for assisting Canadian households to save and build assets, these instruments are very large, larger even than some of the federal programs more traditionally recognized as part of the Canadian welfare state. As an illustrative comparison, the annual federal expenditures on parental and caregiver income support benefits (through Employment Insurance) income support benefits were $\$ 4.2$ billion in fiscal year 2011-12 (HRSDC, 2013), which is substantially less than the tax expenditures on owner-occupied housing equity and private RRSP savings during the same time period.

The overall time trend in Table 3.1 is, generally, one of increase in the nominal cost of each of these tax-preferred savings instruments. The capital gains exemption for owneroccupied housing has shown a more cyclical pattern, rising and falling with the overall national housing market. The cost of RRSPs also shows some cyclical change over the reference period. For example the global financial crisis and recession in Canada is likely the cause of the decline of RRSP costs from 2008 ( $\$ 12.4$ billion) to 2009 ( $\$ 8.5$ billion) and 2010 (\$7.3 billion). Despite the cyclical variation, the notional total of these expenditures was larger in 2012 than it was in 1992. 
From the available data, the tax pre-paid instruments (RESPs, RDSPs and the TFSA) appear to be much less costly (in accounting terms) to the fiscal framework than the deduction-deferral instruments (RRSPs and RDSPs). Some of this is likely due to the very small target market for the RDSP, the niche use of the RESP and the more modest annual limit on the TFSA (compared to the combined limits on RRSPs and RPPs). However, if the contribution room on the TFSA increases, as projected, to $\$ 10,000$ per year with annual rollovers of unused room, the future fiscal costs could be substantial.

The data also suggest that demographic changes matter in determining the overall cost of tax-preferred savings instruments. For example, Table 3.1 shows a decline in the expenditures on RESPs in 2003, due in large measure to a steep decline in the foregone taxes on investment income. Recall that this was the year that the so-called double cohort in Ontario entered post-secondary education ${ }^{49}$ and it is likely that more RESPs would have matured and started to generate payouts to beneficiary students. Withdrawals would have been taxed as income for the beneficiary students and investment returns would have been smaller on these matured plans. Similarly the long-term trend towards increasing taxes paid on RPP withdrawals is almost certainly related to the aging Canadian population. Whether this continues will depend on the pension coverage of current and future cohorts of retirees.

${ }^{49}$ Source: CBC News (2003) "Ontario's double cohort strains resources”, August 31, available online at: http://www.cbc.ca/news/canada/story/2003/08/31/doublecohort030831.html 
Another notable finding is that the income-tested portions of the expenditures, the savings bonds associated with the RESP and RDSP are miniscule compared to other costs in Table 3.1. The same data illustrate that the matching savings grants associated with each of these instruments are substantially more costly than the foregone revenues from the investment income in the accounts. In Chapters 5 and 6, I argue that the majority of the dollars of the matching grants are flowing to households with larger incomes and larger assets who would be more likely to save anyway. However, I also argue that an important share of the expenditures are likely going to poorer households who might benefit more from the transfer of wealth.

Previous studies have concluded that, as a share of GDP, tax expenditures constitute an impressively large outlay by government (Burman, Toder \& Geisser, 2008; PBO, 2011). Several other studies of tax expenditures have summed up the total cost of the individual items and arrived at an impressively large figure in dollar terms (Maslove, 1978; Howard, 2007; PBO, 2011; Toder, Harris \& Lim, 2011). If the cost of the current registered, taxpreferred savings instruments were equivalent to the sum of the net tax expenditures plus the cost of direct savings incentives, the total would be nearly $\$ 30.4$ billion in 2012, twice the cost in 1992. By way of comparison, total federal spending ${ }^{50}$ in 1992 was (in nominal terms) \$166 billion growing to \$275 billion in 2012 (CTF, 2013). This means that the

\footnotetext{
${ }^{50}$ Includes transfers to other levels of government as well as debt-servicing charges.
} 
rate of increase in these selected tax expenditures has been far greater than the rate of increase in total federal spending.

However, Poterba (2011) cautions, "because of the way tax expenditures are calculated, they cannot be aggregated. Changing one tax provision could affect tax payers' marginal tax rates and $[\ldots]$ consequently, the magnitude of other tax expenditure estimates" (p.452). Since we do not know the true amount of interaction between the instruments, it is impossible to arrive at an accurate total figure for all of the savings instruments combined. Home equity, RRSPs, RESPS, RDSPs and TFSAs may interact with tax measures that are outside of the scope of the thesis and they may also interact with one another.

For the present study, the most important interaction is between RRSPs and RPPs both of which offer a deduction-deferral model under a global contribution limit. The Department of Finance (2010) argues that these two items are substitutes for one another and therefore the real cost of having both items in the tax code is less than the sum of the individual estimates. However, the opportunity for Canadians to substitute evenly between these options, notwithstanding the coordination of contribution room and transfer provisions, is limited. ${ }^{51}$ For self-employed workers (approximately $15 \%$ of the

\footnotetext{
${ }^{51}$ Each individual tax expenditure will also have some substitution and income effects on current versus future consumption. If the net effect of the expenditure is to make future consumption more attractive, then it will increase savings in the present. A deduction against taxes can also have an income effect, causing people to spend some or all of the
} 
labour force) and employees without a workplace pension ${ }^{52}$, there is no interaction effect because there is no registered pension amount possible. If the RRSP were cancelled tomorrow, there is no guarantee that these workers would want or even be able to change employment and become eligible for a workplace pension, at least in the short-term. ${ }^{53}$

According to Mousally (2010), 16\% of all employed tax-filers in Canada have only a Registered Pension Plan and do not contribute to RRSPs. For them cancelling the RRSP provisions is likely to have little to no effect. However, Mousally also estimates that another $16 \%$ of workers have both a workplace pension and contribute to an RRSP within their global contribution limits. For this latter group, some substitution into the workplace pension may be possible if they lost the tax benefit of saving in an RRSP, but much depends on the terms and conditions of their existing pension plan. In defined benefit plans (which make up approximately $80 \%$ of pensions held by Canadian workers),${ }^{54}$ workers are generally subject to set contribution levels determined by actuarial analysis of current and ongoing liabilities of the plan.

added room in their budget constraint. If this income effect is greater than the expenditure effect then the expenditure will not meaningfully increase new saving. ${ }^{52}$ Mousally (2010) states that $18 \%$ of all employed workers in Canada have only an RRSP and no workplace pension. Employer-sponsored pension coverage is approximately $32 \%$ for all employees in Canada but is higher for workers in public sectors compared to the private sector.

${ }^{53}$ Over the long-run, it is possible that pressure from labour would encourage employers to adjust their non-wage benefits and expand access to workplace pensions. Another possibility is that pressure from labours would force governments to make a policy change of some kind to improve retirement income security.

${ }^{54}$ Author's calculation based on 2006 data in CANSIM Tables 282-0002 and 280-0008) 
I suggest that it is unlikely that RRSP amounts are currently suppressing the total value of RPP amounts. Therefore, substitution effects in this direction are likely to be small or inconsequential. Estimating the interaction effect between the net cost of the RRSP and RPP comes down to asking: "How much more would people save in an RRSP if there were no tax-preferred treatment for RPPs?" Between the two options, workers with a workplace pension are more likely to contribute first to their pension and only secondarily to an RRSP, generally because they are required to do so as a condition of their employment. For those workers with only an RPP and those with both an RRSP and an RPP ${ }^{55}$ there is a greater possibility of interactions and substitutions. However, estimating the substitution away from RRSPs because of RPPs would require detailed data on individual tax-filer pension provisions, contribution room, personal preferences and marginal tax rates. Reliable data of this kind does not appear to be available to researchers in Canada therefore the discussion is limited to speculation. I suggest that it reasonable to presume that the one-third of workers with an RPP are saving less, or even nothing, in an RRSP because their workplace pension either completely uses their global contribution limit or, likely for some large share of workers, meets their preferences for retirement savings levels. ${ }^{56}$

\footnotetext{
${ }^{55}$ Estimated by Mousally (2010) at 16\% of the labour force for each group respectively. ${ }^{56}$ This analysis does not presume that the current savings are objectively "adequate" for retirement income needs. I assume only that pension members feel less anxiety or motivation to use RRSPs since retirement planning is already taken care of through their employment.
} 
The methodology behind the figures published by the Department of Finance for RRSPs and RPPs is based on a model in which one instrument is removed from the existing tax framework and all other conditions remain unchanged. The estimate for the cost of RPPs, independent of RRSPs, is likely to be a relatively accurate estimate of the real cost. The estimate of the cost of RRSPs on the other hand is potentially lower than the real cost, depending on the rates of substitution and federal taxation for the one-third of workers with some choice in the decision between pensions and private retirement savings.

\subsection{Concluding thoughts regarding federal expenditures on tax-preferred savings}

In general terms, it is difficult to set criteria against which to determine whether it is measurably better for governments to spend money through direct programs and transfers or through tax expenditures (Kesselman, 1988) and different policy goals demand different types of policy instruments. Quite apart from objective (or normative) criteria for policy analysis, spending money through the tax system offers several important political advantages for governments over spending money through programs.

First, and as noted earlier in this chapter, tax expenditures are not subject to the same scrutiny as program expenditures, neither at the time they are introduced in a federal budget, nor on an ongoing basis. By contrast, program expenditures require regular review either by statue (as in the case of the Canada Pension Plan) or, if not required by statute, by Treasury Board policy. 
Second, tax expenditures engender very little or no opposition. This is perhaps in part to a widespread reluctance by any political party in Canada, of any stripe, to be viewed as a so-called "tax and spend" party. But it is also likely due to the technical difficulties of conducting any analysis of the potential impacts and offering a feasible alternative. Critiquing tax expenditures in Canada depends on access to very limited data about individual tax measures and a high degree of technical knowledge regarding the instruments in question.

A third advantage is that, in an era of declining trust in government and declining belief in the efficacy of government, tax expenditures are a way for governments to take action without facing the implementation challenges of launching and coordinating a new program. This may be particularly advantageous in decentralized federations like Canada.

Finally, to the extent that governments are concerned with the durability of their policies, tax expenditures are very attractive for their resilience. Program expenditures that are "booked" and periodically reviewed and audited are easier to see and easier to cut. Tax expenditures on the other hand, once introduced, become part of the fiscal framework, the framework that governments then use to determine what can and cannot be afforded in future policy and programming choices.

"Eliminating all tax expenditures is neither politically feasible nor desirable. Some advance important public policy goals," wrote Burman, Todder and Geisser (2008, p.13). 
No doubt they do. The question though is whether they are advancing public policy goals in ways that are efficient, effective and equitable.

Tax expenditures on savings have been defended as a desirable move towards a more consumption-based system of taxation. Sørensen (2007) argues that, between pure income-based and expenditure-based taxation systems, the Nordic countries have developed a middle ground dual system that combines a highly progressive tax rate on labour income with a flat tax on capital income. The definition of capital income however, includes "interest, dividends, capital gains, rental income, imputed returns on owner-occupied housing, and an imputed return on capital invested in unincorporated firms" (p.562). This uniquely Nordic approach is not inconsistent with analysis of welfare state typologies (see for example Esping-Anderson, 1990; Ebbinghaus, 2012) and may, according to Sørensen, have some promising features for Canada. But Canada does not have either a consumption-based tax system or the Nordic dual model. As such, the current set of tax expenditures on saving operate in the tax system we have, not the one we aspire to create.

Canada has its own hybrid form of taxation that is clearly largely income-focused and yet has large, and expanding, tax incentives for certain forms of saving. Whatever degree of progressiveness we have in our income tax and transfer system, we have little in our treatment of savings and assets. Worse still, through tax expenditures, we may in Canada, as Howard (2007) asserts is true for the US, "negate a lot of the redistribution accomplished by traditional anti-poverty programs" (p.206). 
This does not imply that we ought to immediately eliminate the programs altogether. We have evolved our current system through a series of incremental policy changes, based on precedent and political pressure. There are discussed in Chapters 4 through 6 that follow.

A rethinking of the current policy mix requires attention to how we developed the system we have, how much the present system costs (the focus of the present chapter), as well as the observed effects and policy preferences of Canadians. It would not come as a surprise to most if the majority of the tax expenditures on the registered, tax-preferred instruments were to flow to higher income and higher wealth Canadians. They, after all, have more money to save and larger tax liabilities that a tax-preferred instrument might reduce. In terms of registered accounts opened, the distribution may be reasonably equitable while in terms of dollars saved, the distribution may be much less so. However, as long as wealthier households have larger unsheltered resources as well, the tax system should capture more of those resources, helping to even out the playing field on the treatment of both income and assets. In other words, some degree of vertical equity is still possible in Canada's hybrid (but not deliberately dual) system if, as a share of total household wealth, savers at different levels of resources are able to shelter a comparable level of their resources from taxation. ${ }^{57}$ That distributional analysis is addressed quantitatively in Chapter 7 and qualitatively in Chapter 8.

${ }^{57}$ This should be regarded as a minimum condition for vertical equity in the treatment of savings with a progressive income tax. In a progressive system of taxation on savings, households with fewer resources should actually receive proportionally greater benefit. 


\section{Chapter 4: The start of tax-preferred savings: 1939-1971}

\subsection{Aims and approach}

This chapter, with Chapters 5 through 7, report on a retrospective analysis (Dunn, 2012) of each of the following tax-preferred account-based instruments: compulsory savings in this chapter, Registered Retirement Savings Plans (RRSPs) in this chapter and Chapter 5, Registered Homeownership Savings Plans (RHOSPs) in Chapter 5, Registered Education Savings Plans (RESPs) in Chapter 6, Registered Disability Savings Plans (RDSPs) and Tax-Free Savings Accounts (TFSAs) in Chapter 7. I do not include a history of the tax treatment of equity or imputed rent in owner-occupied housing because there has been almost no change to these since the federal system of income tax was first created. Where relevant, I do refer to policy to promote savings for and asset accumulation in homeownership. This includes the discussions of the RHOSPs (Chapter 5) and sheltered withdrawals for housing from RRSPs (Chapter 6).

The aims of these chapters are: 1) to empirically describe the sequence of events in the creation and lifecycle of each instrument, up to present day status or termination, and 2) to critique the policy design choices that were made in the development of each instrument with attention to the effects on the capability of Canadians, particularly those from lower and modest income or wealth households to directly benefit from the policy. ${ }^{58}$

\footnotetext{
58 The construct of capability implies an interaction between individual and institutional factors in any observed outcome. It is discussed in Chapter 2.
} 
The approach to the research and analysis in this chapter, as well as Chapters 5 through 7, is guided by the literature on policy studies (Brewer \& DeLeon, 1983; Dye, 1995; Dunn, 2003, 2012; Prince, 2007). Dunn (2012) used the term 'retrospective policy' analysis to describe the application of the craft of policy analysis to past policy problems and solutions. Dye (1995) and Dunn (2003, 2012) suggested that retrospective policy analysis aims to understand past government action by understanding the public problem that was to be resolved, questioning the available policy responses, examining how the chosen policies were put in place, and examining the policy outcomes.

In this retrospective analysis I do not describe in detail the policy problems that were articulated by the federal government or stakeholders as requiring a response from the Government of Canada. As Brewer and DeLeon (1983) emphasized, governments often pursue policies in the absence of public 'problems' and recognition or prioritization of problems is often contentious. However, I do note where government or stakeholders positioned the new or amended tax-preferred savings instrument as a response to a stated problem because I believe this provides relevant information about the observed policy choices. Informed by theory on household savings, discussed in Chapter 2, I highlight evidence of macroeconomic versus microeconomic policy rationales, and evidence of the prioritization of certain goals or motivations for private saving. 
My retrospective account of the policy choices and implementation is based on original research and describes the federal policy choices as they were made. ${ }^{59}$

My research drew on a wide range of primary sources including: federal budget documents ${ }^{60}$ Parliamentary debates, archival documents (including government media releases, government information pamphlets, ministerial correspondence, public speeches) retrieved from each Library and Archives Canada, Library of Parliament and the Library of the Department of Finance, archival media coverage, ${ }^{61}$ archival departmental reports including annual statistical reports on taxation from the Canada Revenue Agency and its predecessors, archival records from The Canada Gazette, ${ }^{62}$ and archival information from the database of records of Cabinet decisions maintained by Library and Archives Canada. ${ }^{63}$ I supplemented this primary research with the few secondary sources that have been published on each instrument, cited in the relevant

${ }^{59}$ I do not conduct a comprehensive review to consider alternative policy goals or choices of instrument to achieve the same stated policy goal. That analysis is beyond the scope of this thesis.

${ }^{60}$ Federal budget papers are available electronically for the period 1968 to the present on the website of the Department of Finance, www.fin.gc.ca. Budgets prior to 1968 are available in print form through The Debates of the House of Commons (Hansard). ${ }^{61}$ Based on searches of The Globe and Mail historical database for 1944 onwards (available via ProQuest Historical Newspapers), The Toronto Star (available online at http://pagesofthepast.ca) and English and French language media retrieved from Canadian Newsstand Complete and Canadian Business and Current Affairs Complete. ${ }^{62}$ The database covers archival copies of The Canada Gazette from 1841 to 1997, available online at: http://www.collectionscanada.gc.ca/databases/canada-gazette/indexe.html. Copies of the publication are available online for 1998 forwards on the website of The Canada Gazette: www.gazette.gc.ca.

${ }^{63}$ The database covers the written conclusions from federal Cabinet meetings from 1944 through 1976, available online at http://www.collectionscanada.gc.ca/databases/conclusions/index-e.html. 
sections. I present the facts regarding the policy decision and implementation of each of the tax-preferred savings instruments in a narrative and chronological format, consistent with accepted practice in political historical research (Wawro \& Katznelson, 2010).

As noted by Prince (2007), "nothing is more political, organizational and relational than doing policy work in and for the state" (p.163). In the present study, I pay particular attention to the role and statements of political figures - namely federal ministers of finance and other Parliamentarians - as well as stakeholders outside of the formal policymaking apparatus of government - including private sector organizations, lobbyists or advocates and prominent academics who were actively engaged in the policy discourse on the tax-preferred instruments of interest. I highlight relevant information about the organizational and interpersonal relationships of those involved because I believe this provides important information about the political and social context in which the policy choices were made (Porter, 1965). Attention to stakeholders outside of the government policy-making system is also consistent with Savoie (1999) and Prince (2007) who have noted that Canadian public servants no longer enjoy a monopoly over advice on government policy priorities and options. These authors have generally argued that this change began within the last two or three decades. However, the present research suggests that non-governmental influence was strong on tax-preferred savings instruments many decades earlier.

Finally, consistent with Savoie (1999) and Schick (2007), I give federal budget documents (including ministerial speeches and budget papers tabled in Parliament) 
particular prominence as research sources. Savoie has argued that federal budgets in Canada have fundamentally shifted from a simple projection of government revenues and planned expenditures to more political tools to communicate a government's policy agenda. Schick has noted a similar trend in the United States. Savoie has argued that until the mid-1990's, federal budgets contained "no new major expenditure programs and no major policy statements" (p.188). He further argued that more recent federal budgets provide a centralized mechanism, with little or no scrutiny from Cabinet or Parliament to craft public policy and then to communicate that policy using tactics of political marketing. Without disputing Savoie's characterization of the increased politicization of budgets,${ }^{64}$ I disagree with his suggestion that older budgets contained no announcements of major policy or spending. In fact, all of the tax-preferred savings instruments included in this retrospective review were first announced through a federal budget. Federal budgets have also been the vehicle through which major policy changes to existing tax-

${ }^{64}$ Until the early 1970's, the budget of the Government of Canada was communicated only as a speech to the House of Commons, a "Ways and Means Motion" to ask the House to vote in favor of the budget expenditures and legislative changes, plus one or two supporting documents placed on the Order Paper and published directly in the House of Commons Debates by Hansard. These documents (often referred to as "Budget Papers") included a review of the government's own accounts and, beginning in the wartime period, a publication of national economic statistics. The former is the predecessor to the annual Public Accounts of the Government of Canada and the latter is the predecessor to the annual publication of National Accounts (now prepared and published by Statistics Canada). Beginning with the 1971 budget, a separate copy of the budget speech and papers were printed and circulated by the Department of Finance. In 1972, the department also added a "Budget Highlights" document summarizing the major policy announcements. While these documents continue to be prepared and published by the department for each federal budget, it was not until the 1983 budget presented by Marc Lalonde, P.C., M.P. that the look and feel of modern day budget documents is really in evidence with more deliberate use of visual data and photos to give the budget greater value for public political communications. 
preferred savings instrument are announced. As made clear in Chapter 3 from the compilation of tax and direct spending estimates, these policy instruments are indeed "major".

\subsection{Contributions from the historical study and overview of key findings}

While there have been some previous reviews of several of the instruments of interest, ${ }^{65}$ this is the first retrospective analysis of tax-preferred account-based savings instruments to cover the full period from the earliest days of Canada's personal income tax to the present day, to detail the changes made over time to each instrument, and to include attention to the policy discourse and political debate surrounding decisions on taxbenefitted savings. This is also the first retrospective analysis to trace the historical linkages from one instrument to the next. In some cases, the linkage is in explicit reference to an earlier tax-preferred account as an example of precedent or policy to be replicated. In other cases, the linkages include the federal officials involved or the roles played by external stakeholders.

While histories of pre- versus post-war government social policy-making describe a clear trend of expansion of the spheres and instruments of policy intervention in the lives of ordinary citizens (Moscovitch \& Albert, 1987; Guest, 1991), the pattern of federal policy intervention in household savings and assets shows remarkable convergence in the instruments and approach. It is difficult to imagine now that the Government of Canada

${ }^{65}$ Citations for previously published historical research are not listed here for the sake of brevity, but they are provided in the text of Chapters 4 through 6 . 
might compel, by law, Canadians to save in individual accounts, or provide basic financial services and sell financial products. ${ }^{66}$ And yet past Canadian governments experimented with all of these as ways to promote savings and assets for Canadian citizens. ${ }^{67}$ From the launch of the Registered Retirement Savings Plan (RRSP) in 1957 through to the introduction of the Tax-Free Savings Account (TFSA) in 2008, taxbenefitted account-based instruments have been increasingly used to promote individual and household savings. More importantly, each new policy instrument has been based on past precedent with only incremental changes.

As stated in Chapter 1 (pp.19-21), I find that the tax-preferred account-based instruments as implemented all: 1) require attachment to a mainstream financial services provider; 2) use the personal income tax system to deliver incentives in ways that confer larger benefits on those with larger taxable incomes; 3) normalize only certain kinds or goals for personal savings; 4) promote financial capital that is fungible and may be beneficial to

\footnotetext{
${ }^{66}$ Each year the Government of Canada issues Canada Savings Bonds for sale to consumers. The first debt securities were issued by the Government of Canada during the Second World War as "victory bonds" to finance the costs of the war. Between 1997 and 2010, the Bank of Canada also made available a retirement savings product as a Registered Retirement Savings Plan contract. Currently Canada Savings Bonds are available primarily for sale through automated payroll deductions. In 2012, the Bank of Canada amended the terms and conditions on the sale of bonds by reducing the maturity date from 10 years to 3 and allowing Premium Bond holders to cash in their bonds at any time in the year, effectively making the CSB a more short-term and liquid vehicle for savings.

${ }^{67}$ Between 1942 and 1944, the Government of Canada required Canadians to save through compulsory but refundable taxation on top of their personal income tax. Between 1868 and 1968, the Government of Canada offered basic financial services, including deposit accounts, through the network of Post Office Savings Banks. Between 1908 and 1975 the Government of Canada issued annuities as long-term savings products to individual Canadians and employers.
} 
the saver outside of the strict savings goal of the tax-preferred account. But, as is discussed in this and the next two chapters, each of the instruments also responded to outside policy advice or policy advocacy from influential stakeholders of elevated socioeconomic status, and sometimes stakeholders who might personally or professionally gain from the creation of a new account.

The result has been a convergence of policy-making and a set of instruments that are, to use Howard's (2007) terminology only thinly universal. That is they are notionally available to all but, in practice, confer more benefit to wealthier households. More recent, incremental changes over the past decade show some greater attention to poorer Canadians but may not be sufficient to alter the dominant direction of federal policymaking.

The remainder of this chapter provides the retrospective analysis of compulsory savings during wartime and the creation of the Registered Retirement Savings Plan. The analysis continues, in chronological order, through Chapters 5, 6 and 7.

\subsection{Compulsory savings: 1940-1944}

Canada's experiment with compulsory savings as part of its wartime finance may be a rare example where a proposal from an academic theorist fundamentally shaped 
government policy. ${ }^{68}$ In 1940, John Maynard Keynes published a small pamphlet entitled "How to Pay for the War", a condensed re-statement of many of the same arguments he had made in articles throughout 1939 (reprinted in Keynes, 1962). Keynes recommended that the Government of the United Kingdom increase personal income taxes but convert a substantial portion of the taxes on individuals to a compulsory and repayable loan to government. By forcing people to save during wartime, Keynes' argued, government could both raise the substantial capital needed to finance the costs of continuing to fight in World War II and, at the same time, reduce demand for personal consumption, freeing up more of the productive output from the British economy for use by government and the military in the war effort.

Despite rationing and thrift campaigns, the British government found itself in competition with its own citizens for access to consumables including food and manufactured goods. Any substantial increase in personal income taxes would reduce the purchasing power of individual Britons. But, by making a substantial portion of it a loan that the government would refund after the war, Keynes suggested that a compulsory savings program would support a post-war improvement in economic equality in the United Kingdom, particularly compared with the option of borrowing from and then repaying a smaller pool of wealthy capital holders. He wrote, "the accumulation of working class wealth under working class control $[\ldots]$ embodies an advance towards economic equality greater than any we have made in recent times" (p.368).

${ }^{68}$ As will be discussed in Chapter 6, the Tax-Free Savings Account is another such case study. 
Keynes recommended a temporary increase in personal income taxes on the broadest base of taxpayers possible with a compulsory savings portion to be withheld by employers and deposited into locked-in accounts. The accumulated capital in the accounts would then be returned (with interest) to individual workers after the war had ended. To maintain government revenues after the war, Keynes suggested that government introduce a levy on capital and stimulate demand during reconstruction by expanding access to credit. The net result, according to Keynes, would be a drop in wartime prices, steady government revenue and a post-war capital fund for reconstruction in a more egalitarian manner than the pre-war period.

Keynes' writing on the subject was widely read in the United Kingdom and were even sent by Canada's High Commissioner in the United Kingdom, Sir Vincent Massey, directly to the Deputy Ministers of External Affairs and Finance (Barnett, 2001). Like the U.K., the Canadian government faced a substantial shortfall in its budget, projected at $\$ 180$ million by the summer of 1942 (National War Finance Committee, 1942), equivalent to roughly $\$ 2.5$ billion in 2013 terms,${ }^{69}$ and mounting competition and rising prices for consumer goods. Throughout 1940 and 1941, it appears as though Keynes' proposals were read and debated in Canada.

${ }^{69}$ Using the Bank of Canada on-line calculator, based on Statistics Canada, Consumer Price Indexes for Canada, Monthly (V41690973 series) 
An editorial in The Globe and Mail from November 1940 referenced the proposal for compulsory savings with skepticism, suggesting the government should be looking for ways to reduce its spending first. "The Government ought to make a much better showing than this before talking about compulsory saving”. According to Barnett (2001), the Department of Finance commissioned a review of Keynes' proposals by a panel of economists at Queen's University. Eventually published as part of a volume of essays entitled War Finance in Canada (Brown, Gibson \& Plumptre, 1940), the review compared the option of increased direct taxation on the rich to a system of progressive income taxation with a compulsory savings component only for working class Canadians.

According to Gibson (1940), the compulsory savings option had two advantages over the increase in taxation at the top end: 1) it would meet with less public opposition than an increase in income taxes alone; and 2) it would increase the purchasing power of the working and middle-classes in the post-war period, avoiding a much-feared economic slump and even depression when government spending slowed and production levels fell from war-time highs.

This more positive assessment seems to have also been matched by a warming tone towards compulsory savings in the national media. In contrast to its 1940 editorial, The Globe and Mail, released an editorial in 1941 that listed compulsory savings alongside price and wage controls as policy options available to a government that must compel people to act in certain ways, even against their will, if the war was to be won, and also 
printed opinion columns strongly in favour of a compulsory savings (Lipmann, 1942a, 1942b).

\subsubsection{Canadian amendments to Keynes' proposal}

Canadian officials also monitored the response of the British government to Keynes'

proposals. It was only after British policy-makers signaled that they would be moving ahead with a new compulsory savings scheme that the Canadian government acted to introduce it here (Barnett, 2001).

Over the course of the war, only the United Kingdom and Canada would eventually introduce compulsory personal savings programs through their income tax systems and both introduced them only after trying a program of strictly voluntary savings through government secured debt, so-called war-bonds or "victory bonds". Barnett (2001) noted that internal memoranda within the Department of Finance at the time argued that the government could not rely on voluntary savings alone to meet wartime fiscal demands. Finance officials suggested that the refundable nature of the Keynesian compulsory savings proposal might help to smooth over an otherwise unpopular hike in personal income tax rates on a wider base of the population. ${ }^{70}$ By early 1942, Finance officials began to develop the policy proposals for a Canadian adaptation of Keynes' compulsory

\footnotetext{
${ }^{70}$ Internal memos of the Department of Finance cited by Barnett suggest that there was concern within the department that the structure of personal income taxes were allowing too many loopholes for self-employed workers, farmers, small business owners and those whose income came in some part from investment income. Interestingly enough, the same memos also suggest that working class workers were among those Canadians that the Department felt were not paying adequate tax on their personal incomes.
} 
savings within a policy to increase personal income taxes. The officials proposed that the government make part of "this year's [1942] increase a repayable one, so that those who pay it would get it back in some form or other after the war" (cited in Barnett, 2001, p.33). Unlike Keynes' proposal that saw a role for employers, the Government of Canada would itself collect the refundable portion and keep it in accounts, earning government-paid interest at 3\% per year until it was repaid. By the time the policy was announced, the annual interest rate was reduced to $2 \%$. The planned deadline for repayment would be three fiscal years after the end of the war. The refundable compulsory savings portion of income tax would be capped at one-third of the total personal income tax payable annually. In contrast again to Keynes' proposal, the policy design from the Department of Finance was for a compulsory savings that would apply to all Canadian taxpayers and be refundable to all Canadian taxpayers.

The Finance officials also proposed "allowing a credit against the tax, or a deduction from income, for expenditures or commitments of some types" (cited in Barnett, 2001, p.33). The idea was to reduce the new compulsory saving for taxpayers who were already saving in other ways such as contributing to a pension or paying a mortgage. This latter design feature would prove critical to the way in which compulsory savings would be implemented in Canada and, more importantly, set a precedent for future taxpreferred forms of saving. Given that the macroeconomic aim was to reduce demand for goods, giving credit for other forms of saving was thought to ensure that consumer demand would still be lower without imposing hardship on people who were already saving privately. When the policy was announced in the 1942 budget, the Minister noted 
that these credits would be limited to mortgage payments (but only for mortgages held in a man's name) and life insurance premiums (Hansard, June 23, 1942). ${ }^{71}$ After the budget, an August 1942 pamphlet produced by the National War Finance Committee noted that contributions to a workplace pension were also deductible as a savings credit against the new tax (NWFC, 1942). This credit was on top of the deduction for contributions to eligible pension plans, up to an annual maximum of $\$ 300 .^{72} 73$ Taken together, these credits against the new compulsory savings represented a new baseline for the treatment of personal savings in a still new system of personal income tax in Canada. ${ }^{74}$ Although internal memoranda at Finance pondered similar credits for rental payments, medical expenses and perhaps even debt repayment, none of these were included in the final set of credits available to Canadian taxpayers (Barnett, 2001).

By contrast, Keynes had recommended that new life insurance policies and also some unspecified level of liquid savings (as personal insurance against emergencies such as

\footnotetext{
${ }^{71}$ Initially the 1942 Budget had proposed that only existing life insurance policies be eligible for the offset credit but following debate in the House of Commons on the budget, the government relented and accepted an amendment to extend a credit to premiums on new life insurance up to $\$ 100$ (in 1942) per year.

$72 \$ 300$ in 1942 is equivalent to approximately $\$ 4,180$ in constant 2013 dollars (calculation using Bank of Canada inflation calculator based on Statistics Canada, Consumer Price Indexes for Canada, Monthly (V41690973 series). By comparison, the current maximum allowable deduction for contributions to a workplace pension is approximately $\$ 24,000$ for the 2013 tax year or $18 \%$ of earned income, which ever is less (CRA, rates tables, http://www.cra-arc.gc.ca/tx/rgstrd/papspapar-fefespfer/lmtseng.html).

${ }^{73}$ Based on a review of the Minister of Financial budget speech for 1942, the abovementioned 1942 pamphlet of the National War Finance Committee and an archival copy of the 1943 Individual Income Tax Return, Form T-1 (posted online at www.wartimecanada.org, last retrieved February 7, 2013).

${ }^{74}$ In 1942, Canada had only had a national system of income tax for 25 years.
} 
illness and unemployment) be given credit against the new compulsory savings. The type of credits available to offset the compulsory savings was no small matter. The original proposal by Keynes would have included rental payments and premiums on life insurance. As such it would not have privileged homeowners over renters with otherwise similar incomes but may have created a demand for new life insurance policies, at least among those households able to afford the regular premiums. However, the credit for liquid savings set aside as personal insurance would not necessarily have privileged wealthier households over poorer ones particularly in considering that Keynes' proposal for refundability was limited to taxpayers with low and modest incomes. In Canada, the final set of credits meant that fewer working class households, compared to wealthier households, would have qualified for credits against the new compulsory savings. As a result they were less able to take advantage of any reductions and paid a larger share of the new compulsory savings. In fact, Finance officials (cited in Barnett, 2001) had projected that their amended version of Keynes' compulsory savings would be largely if not fully offset by credits for voluntary savings for taxpayers making $\$ 2,400$ or more in 1942. While Keynes' proposal was for a broad-based tax with income-tested refundability, the Canadian implementation became an income-tested compulsory savings scheme.

Another element of the design that is worth noting is in the collection and administration of the savings funds. In Keynes' original proposal, he had called for employers to be responsible for withholding and then depositing the compulsory savings portion of the 
income taxes into locked-in accounts. ${ }^{75}$ In Canada, the funds were collected as part of regular income tax payments collected by employers and transferred or 'remitted' to the Government. The 1942 tax year was the first time that the government relied on withholding from earnings and remittances by employers alongside annual individual tax returns to reconcile individual tax accounts. ${ }^{76}$ However, in the lead up to the 1942 budget, internal Finance memos showed that officials originally recommended that the funds be collected and held by chartered banks with government oversight to "get around [the] administrative difficulties for income tax" (cited in Barnett, 2001, p.37).

Departmental officials also explored the idea of using a system of vouchers which could only be purchased from banks and then deposited into locked-in accounts until after the war. In addition to out-sourcing the current administrative burden, the Department was thinking of ways to "work the chartered banks more and more into [the] administrative machinery of the government" as a long-term change for the post-war period (cited in Barnett, p.37). In the end, the government decided to blend the basic income tax with a

\footnotetext{
${ }^{75}$ This is similar to the way the United Kingdom currently administers other publiclyfunded benefits such as parental leave. Employers in the UK are required to pay their employees on parental leave and then claim a reimbursement from the government. The normative assumption of standard employment is also noteworthy. In Canada, selfemployment levels have hovered at roughly $15 \%$ of all adults in the paid workforce for the last several decades (Robson, 2012) but rates of self-employment in the UK have only very recently reached $14 \%$ of their labour force (The Guardian, March 2, 2012, "Selfemployment: The rise of the 'odd-jobbers"'.

${ }^{76}$ Employers in Canada are required to withhold income taxes and other payroll deductions before issuing payment to their employees. The amount withheld must be remitted to the Canada Revenue Agency within 60 days (CRA, 2012). The federal budget of 1942 introduced this system for the first time in contrast to an earlier system of individual annual returns and lump sum payments.
} 
war-time surtax and make the compulsory savings payable directly to the government as well.

The government may have abandoned ideas to shape a role for private financial institutions in its policy out of a desire to keep the new tax regime as simple as possible. Making payments to two separate collectors, the government and a financial institution, may be confusing. Or it may have been that government felt public trust in the refundability of the savings portion would be compromised if the funds were held by forprofit private banks. In implementation however, simplicity and trust in the refundability became major obstacles alongside growing concerns about disincentive effects on work.

But when the Liberal government announced the new compulsory savings in June 1942, none of the above concerns, simplicity, transparency, fairness and work disincentives, were raised by either of the Conservative or Co-operative Commonwealth Federation (CCF) opposition parties. In fact both Conservative and CCF caucus members voiced general support for the compulsory savings. ${ }^{77}$ The debate, based on the Hansard transcripts, was almost entirely about the list of the offsetting savings credits. Initially the list of credits only recognized premiums on existing but not new life insurance policies. The government eventually relented and added premiums on new policies to the list of credits. The initial list of credits also excluded premiums paid on paid on government-issued annuities but the government refused to address this until well after

${ }^{77}$ Based on a review of the Debates of the House of Commons, (Hansard) for June 23, 1942. 
the initial introduction of the compulsory savings policy. These annuities were, at the time, an important savings mechanism for many working class Canadians. ${ }^{78}$ In addition to perceptions of unfairness in the credits, the implementation also faced challenges to public understanding the compulsory savings scheme and trusting in the refundability of amounts "saved".

\subsubsection{Stakeholder criticisms of the policy of compulsory savings}

In 1942, representatives of the Canadian Labour Congress, the CCF and even the federal Minister of Labour all expressed concerns to the Minister of Finance about the inequity in the compulsory savings policy (cited in Barnett, 2001). They were concerned that while wealthier taxpayers could reduce their compulsory savings through credits for mortgage payments, insurance premiums and private pension plans, working class taxpayers could not deduct many of the mandatory payments they had from their more limited budgetsrent and premiums on government annuities they had already purchased (Barnett, 2001). Furthermore, lower-income and working class Canadians were unlikely to be able to afford the other kinds of savings recognized for credit against the compulsory savingsmortgages and private insurance. Although the policy was eventually amended in 1943

\footnotetext{
${ }^{78}$ Between 1908 and 1975, Canadians were able to purchase Dominion Annuities from the Government of Canada as an individual or workplace-based retirement savings vehicle. Premiums were payable to the Government as part of the annuity contract and these products were predominantly used by working class Canadians or their employers as an alternative to a pension fund. According to the Department of Human Resources and Skills Development Canada (HRSDC, 2009), approximately 2,000 of these annuity contracts are still in force and are expected to mature within the next 30 years. According to departmental reports, the annuities that have now matured are paying benefits of an average of $\$ 600$ per year to annuitants that are now on average in their 80 's with a total of approximately $\$ 35$ million in total benefits paid annually (HRSDC, 2009).
} 
in response to public pressure and extended credit for saving through government annuities (Ilsley, 1943), it appears that the damage to the perception of the compulsory savings program was already done. A 1944 memorandum between finance officials in preparation for the next federal budget, noted a strong and negative public response to the compulsory savings policy (cited in Barnett, 2001). The public mood towards the compulsory savings plan changed dramatically between 1942 and 1944. In May 1942, immediately prior to the federal budget, a public opinion poll reported that $51 \%$ of adult Canadians said they would agree to give as much as $10 \%$ of their income as refundable savings to the Government of Canada and without interest (Canadian Institute of Public Opinion, 1942 cited in Barnett, 2001). But by June 1944, on the eve of the 1944 federal budget, nearly half (49\%) of Canadians wanted to see the compulsory savings scheme cancelled (CIPO, 1944 cited in Barnett, 2001). A table included in the 1944 federal budget documents may help to explain why.

The table gave the Department of Finance's own estimates of the net effect of the changes to the basic personal income tax and the new compulsory savings tax. For Canadians with incomes below $\$ 3,000$, the refundable savings portion was projected to be as much as half of their total tax payable. ${ }^{79}$ According to the Department of Finance memos cited in Barnett, these workers made up $90 \%$ of all income earners in the country and earned $75 \%$ of all the income. A wide tax base that included more of the lower income workers would increase government revenues and reduce the deficit more

\footnotetext{
${ }^{79}$ Published in Debates of the House of Commons (Hansard) for June 23, 1942.
} 
effectively than a targeted increase in taxes on the smaller pool of wealthier earners (National War Finance Committee, 1942; Barnett, 2001). However, the policy, as implemented also meant that a married man with three dependent children earning $\$ 2,000$ per year would see his federal income taxes more than triple from $\$ 60$ in 1941 to $\$ 215$ in 1942 but a man with a similar family but earning $\$ 20,000$ would see his federal income taxes increase by less than $50 \%$ from $\$ 7,800$ to $\$ 11,000$, with only $\$ 1,200$ payable in compulsory savings. ${ }^{80}$

In addition to objecting to the unfairness of the offsetting credits, many taxpayers may not have believed that the government would in fact refund the compulsory savings as promised. In his 1943 budget the Minister of Finance addressed this point directly, saying that too little public attention was being given to the refundable nature of the required savings (Ilsley, 1943). In the same speech, the Minister sought to deflect further demands for changes to the offsetting credits by, prophetically, pointing out the trade-offs between a demand for simplicity and more granular levels of equity: "We cannot make our tax so complicated that the ordinary man cannot understand it. [...] Furthermore, every additional allowance that we make, increase the difficulty in administration and the risk of arbitrariness in administration." (Ilsley, 1943).

Another criticism of the compulsory savings policy was that it was created a disincentive to work (Department of Finance memo cited in Barnett, 2001). Critics would have

${ }^{80}$ Author's calculations based on Government of Canada data in Hansard, June 23, 1942 
argued that working class Canadians reduced their hours of paid work (for example refusing overtime) as a way to manage their tax liability and avoid paying a marginally higher rate of personal income tax. The validity of this criticism is more difficult to evaluate. A search of the available records found no empirical evidence for hours of labour lost. Personal income tax rates were high in Canada, as they were in most western Allied countries, ${ }^{81}$ but it is difficult to assess the degree to which the blame for absenteeism was legitimately placed on the compulsory savings or whether the compulsory savings measure was instead a convenient target for workers and taxpayers who had been exhausted through years war time production and taxation.

\subsubsection{Assessing the household effects of the compulsory savings policy}

Based on the available records, it is impossible to estimate the fiscal or distributional effects of the policy. It is also impossible to quantitatively evaluate the effects of the choices in policy design to select certain kinds of saving to count as a credit against the new compulsory savings. It is notable that the number of private insurance policies sold increased dramatically in this period (Higgins, 1944), suggesting that those with sufficient incomes were able to buy private insurance and reduce their total personal income taxes. It may have been that these taxpayers doubted they would see a return of their compulsory savings and preferred the risks of a private insurance contract instead. While the policy intent of the department was to broaden the tax-base, the decision to include higher rate-payers in the refundable compulsory savings likely also took away

${ }^{81}$ See comparison tables prepared by the Department of Finance and published in the 1943 Budget, in Debates of the House of Commons (Hansard) for March 2, 1943. 
any real redistributive effects on personal savings and wealth that had been theorized by Keynes.

Based on Department of Finance projections, higher income earners would pay roughly $\$ 1,200$ per year in refundable compulsory savings to the government (based on a married worker with 3 children earning $\$ 10,000$ per year or more). ${ }^{82}$ At the promised $2 \%$ annual interest, this taxpayer would have been eligible for a return of $\$ 2,568$ (in nominal dollars) when repayments began in 1946. By comparison, a married person with three children earning $\$ 2,500$ would have been eligible for a refund of just $\$ 347$. By refunding the savings of both higher and modest income taxpayers, the Canadian amendment to Keynes' original proposal removed any post-war redistributive effect on household wealth.

It is impossible to know whether the policy, as implemented in Canada, led to any real increase in household savings above what might have occurred without a compulsory savings policy. The internal analysis of the Department of Finance in the development of the compulsory savings policy suggested that voluntary thrift and savings through the purchase of war bonds were both below the hoped-for rate. But that analysis was almost entirely based on macroeconomic targets of inflation control and the federal fiscal framework. It may have been that households, particularly the $90 \%$ earning less than $\$ 3,000$ per year, were already saving the maximum they could without hardship.

${ }^{82}$ Budget documents published in Debates of the House of Commons (Hansard), June 23, 1942. 
Because the policy design did not include credits for, as Keynes had originally proposed, emergencies, and until midway through the lifecycle of the policy it excluded credit for the retirement savings vehicle most used by the working class, it gave little recognition or reward to the ways that lower and modest income earners might ordinarily have been saving and building assets. Greater attention to these more microeconomic factors might have lead the Finance officials in a very different direction, a point made too late by opposition Parliamentarians.

In the debate on the 1944 budget, members of the Conservative caucus reversed their 1942 position in support of the compulsory savings and instead admonished the Minister of Finance: "The Minister of Finance will learn that human nature exists and that he is not likely to find out very much about it from a select group of officials" (Jackman, 1944). These 'select officials' would have been senior public servants in the Department of Finance. It is likely that these officials would have had above average annual incomes and would have participated in an employer-sponsored pension plan. When these officials imagined the effects of their compulsory savings policy on ordinary Canadian taxpayers, it is likely their understanding of effects was higher for taxpayers most like themselves. Perhaps this helps to explain the choices of credits for other saving to reduce taxes owed through the new compulsory savings policy.

In 1944, the CCF caucus also urged the government to cancel the compulsory savings but suggested that the accumulated savings be redistributed to lower income Canadians either through increases to the Old Age Pension benefits or by converting future personal 
income taxes for the lower income brackets fully into refundable savings (cited in Barnett, 2001). Both proposals were flatly rejected by the government.

\subsubsection{Cancellation of the policy and repayment of the compulsory savings}

The June 1944 federal budget announced an immediate end to the compulsory savings program with the final deductions from income for this portion of taxes taking place June 30, 1944 (Ilsley, 1944). Otherwise personal income taxes in Canada were left largely unchanged. An internal memo from the Department of Finance written before the budget had advised the Minister to cancel the policy on the grounds that the public did not support it and the government, for political reasons, would want to be seen to be responsive to public opinion (cited in Barnett, 2001). The same memo also noted but did not verify criticisms that the policy was too complex, treated working class Canadians unfairly and created disincentives for paid work.

There is very limited information on the repayment of the compulsory savings following the end of World War Two. Barnett (2001) claims that a total of \$296 million (in nominal terms) was collected between June 1942 and June 1944 and that it was fully repaid by March 1949. The budget documents for 1945 through 1946 make no reference to the compulsory savings collected and held by the Government of Canada. There is a very brief mention in the documents tabled in the House of Commons to support the 1947 federal budget. According to the "Review of Government Accounts 1946-47"83 a total of

\footnotetext{
${ }^{83}$ Published in Debates of the House of Commons (Hansard), April 29, 1947.
} 
\$38 million was collected in 1942, \$135 million in 1943 and \$72 million in 1944 for a total of $\$ 245$ million $^{84}$ over the lifecycle of the policy. The same report noted that $\$ 3$ million of this total had already been repaid. While Barnett claims that most of the total had been collected from modest income earners and would have been returned to them, she offers no evidence to support this claim. The illustrative example above (pp. 124 to 125 ) of two households with three children and annual incomes of either $\$ 2,500$ or $\$ 25,0000$ suggests that the refunds would have been much larger for households with larger annual incomes. If households did regard the compulsory savings as a regular tax and therefore a sunk cost, then these refunds might have been experienced as unexpected or windfall gains. While it may have been true, in the aggregate, that most dollars were saved by and returned to modest income Canadians, for individual households, it appears that the policy made little progress towards Keynes' goal of a redistribution of wealth in the post-war period.

What Keynes intended as a great equalizing policy in the UK was instead, implemented in Canada as a windfall for the private insurance industry and wealthier Canadians. Far more redistribution in wealth is likely to have come out of the post-war demobilization spending. This spending included lump sum financial transfers to returning veterans alongside generous support for housing and education and made up the largest share of

${ }^{84}$ Equivalent to approximately $\$ 3.3$ billion in constant 2013 dollars using the Bank of Canada on-line calculator, based on Statistics Canada, Consumer Price Indexes for Canada, Monthly (V41690973 series). 
the demobilization sub-set of the total federal budgets for 1945 through 1948. According to the Public Accounts of Canada for the fiscal year 1948-49:

- $\$ 641$ million was spent by the government on cash benefits for returning veterans between 1945 and 1948,

- $\$ 27$ million was spent on training and education benefits for veterans over the same time frame

- tens of millions more were spent to support homeownership (through cash grants and subsidized development of new housing) for eligible veterans.

Some authors have argued this demobilization spending was critical to greater wealth equality and expansion of the middle class in the post-war period (Sherraden, 1991; Axworthy, 2004; Paxton \& White, 2006).

Shortly after the end of the war, the government began a series of tax cuts in each of its federal budgets but even managed to build a budgetary surplus by 1948 . To the extent that there was any attention to household savings in government policy, it was included only in the back pages of budget documents in the aggregate estimates of rates of personal saving as one among many other macroeconomic indicators of the health of the Canadian economy. 


\subsubsection{Lessons from the compulsory savings experiment for tax-preferred account-}

\section{based instruments}

It was another decade before the Government of Canada would again look to the tax system as a way to bolster household savings in personal accounts. Nonetheless, there were certain elements of the experiment with compulsory savings that would reemerge when, in 1957, the government introduced a tax-preferred personal account to support private retirement savings, the Registered Retirement Savings Plan (RRSP).

By 1957, the new Deputy Minister of Finance was an official who had joined the department during the war and experiment with compulsory savings. ${ }^{85}$ The government was no longer concerned with increasing household saving - indeed any exhortations to Canadians to save had become the domain of an expanding private financial services sector. ${ }^{86}$ But like the compulsory savings policy, the new RRSP would use the personal income tax system and individual accounts in a new policy-preferred form of private savings. Like the compulsory savings policy, there was a tension in the policy design between recognizing saving that was already taking place and offering an incentive for new saving. Like the compulsory savings, discourse on the RRSP was couched in terms

${ }^{85}$ In late 1952, W. C. Clark unexpectedly passed away and was replaced by an internal candidate, Kenneth Taylor who had joined Finance in or around 1945 (Source: Slater, D. 1997, Economists and the Department of Finance 1945-1980, Canadian Business Economics, Winter/Spring, pp.79-88).

${ }^{86}$ A search of the national newspaper, The Globe and Mail for the period 1953 through 1957 finds only scant references to personal savings in Canada in the news, editorial or business sections. However there are multiple and prominent advertisements from a wide range of financial institutions selling savings products. 
of equity and universalism but, by design, offered greater benefit to professional classes of workers with higher incomes.

The role of private sector financial services had been minimal in compulsory savings, except for insurance providers who provided a substitute to the new tax for taxpayers able to afford the premiums. It is plausible that, having learned from the experience of the compulsory savings experiment, the Department of Finance was keen to outsource the administration and communication of the new tax-related savings policy to Canadian financial institutions. Certainly there are early musings on an enhanced role for financial institutions in government policy to be found in the wartime memos of the department (discussed above). When the federal budget was introduced in 1957, it set in place the framework for a new registered tax-benefitted personal savings mechanism, likely informed by the compulsory savings experiment. The RRSP instrument created a model that, notwithstanding changes over time, remains largely intact and serves as the benchmark for all other registered tax-benefited savings accounts.

\subsection{Registered Retirement Savings Plans: 1956-1971}

When RRSPs were created in the 1957 federal budget, Canada was no longer faced with the macroeconomic challenge of raising funds to finance a war or reconstruction. There was, it seems, no looming crisis in need of a policy response. In the decade after World War II, federal budgets in Canada announced several substantial reductions in income tax rates. This included, new tax credits, collapsing personal income tax brackets and reducing statutory rates paid. While there was no macroeconomic crisis to resolve in the 
mid-1950's, there were organized stakeholder groups who could be effective advocates for new public policy instruments.

The website of the Canadian Medical Association (CMA), the professional association for medical doctors in Canada, has a brief newsletter posted on March 2007 that noted the $50^{\text {th }}$ anniversary of the launch of RRSPs in Canada ${ }^{87}$ According to then-president Colin McMillan, "most Canadians, physicians included, aren't aware that the CMA was the driving force behind the decision to introduce the RRSP in 1957. Fifty years later, it has fundamentally changed the way Canadians approach retirement planning." According to the CMA, representatives of the association met with the Minister of Finance (Walter Harris), on January 6, 1956 to plead "for tax deferral ${ }^{88}$ for self-employed taxpayers who wanted to save for retirement" (CMA, 2007). The history of the creation of RRSPs in Canada is not included in most major studies of post-war economic and tax policy in Canada. Neither is the role of the CMA in the creation of RRSPs usually acknowledged. Most histories of Canadian taxation and fiscal policy in the immediate post-war period tend to focus on federal-provincial agreements and subsidies for industrial development (for example, Wardhaugh, 2010; Perry, 1984, 1989; Boadway \& Kitchen, 1984).

${ }^{87}$ Source: Canadian Medical Association (2007). "As RRSP turns 50, CMA marks one of its greatest lobbying victories", retrieved from http://www.cma.ca/index.php?ci_id=10038169\&la_id=1, February 13, 2013.

${ }^{88}$ As discussed in Chapter 3, a tax deferral allows a taxpayer to postpone some portion of their tax payable to a future point in time. Often the deferral results in a reduction of the marginal tax rate. 
The advocacy position of the CMA received support through the spring and summer of 1955 from several opposition Conservative Parliamentarians. In June 1956, Ellen Fairclough, a Conservative Member of Parliament rose to take part in a debate on national revenue. In her remarks, Fairclough drew attention to "the position in which the self-employed person finds himself with regard to the building up of retirement funds" (Fairclough, 1956). Perhaps informed by her own background as an accountant, ${ }^{89}$ she urged the House to respond to representations from the CMA and the Canadian Dental Association (the professional association for dentists in Canada) that had each called for a new tax deferral against personal income tax for contributions to annuities or other personal retirement funds. In contrast to the deductions and deferrals available for employer-sponsored pension plans, said Fairclough, "this situation, apart from being unfair, does little to encourage individual initiative". Because the debate was on the operations of the department of National Revenue, the government declined to respond. However, the policy question resurfaced again in late July 1956 when Daniel Michener, another Conservative M.P., echoed Fairclough's call for attention to the long-term savings needs of the self-employed (Michener, 1956). Interestingly, Michener, himself a barrister, made sure to draw a much larger circle around the ranks of the self-employed, including, in addition to doctors and dentists, lawyers, accountants, architects and engineers as well as farmers and salesmen.

${ }^{89}$ Source: "Parliament of Canada", ParlInfo database, retrieved February 2013. 
The following day the Minister of Finance, Walter Harris, spoke in the House, acknowledging that encouraging retirement savings among self-employed persons was an important issue for the government. ${ }^{90}$ The Minister did express concern about the potential costs to taxpayers of any tax-benefited savings instrument based on the proposals of the CMA and CDA. This is an important signal that the government of the time recognized that any new tax deduction or credit would result in a loss of government tax revenue that would, all else being equal, need to be made up in some way through increases to another area of taxation or reductions in government spending. In his remarks, and most likely based on projections from his department, Harris estimated that the cost of the foregone tax revenues would be "perhaps $\$ 60$ million" to the federal treasury. In inflation-adjusted dollars, this would be approximately $\$ 498$ million today. ${ }^{91}$ As noted in Table 3.1, Chapter 3, the current cost of RRSPs is estimated by the Department of Finance at $\$ 9.3$ billion for 2012 .

The argument in favour of a new instrument for retirement savings was founded on a comparison with employer-sponsored pension plans that already received tax-preferred

\footnotetext{
${ }^{90}$ Harris' statement on July 31, 1956 references a commitment in 1955 by the government to study proposals and options for supporting the retirement savings of selfemployed Canadians. No reference to this commitment could be found in the Hansard record for 1955. Similarly, when the RRSP was announced in 1957, Progressive Conservative caucus members claimed to have called for such a measure as early as 1953 but no records on this could be found in the Hansard Debates for that year. Similarly, a search of the only national newspaper of the time (The Globe and Mail) found no mention of the Opposition or Government statements for 1953 or 1955. ${ }^{91}$ Using the Bank of Canada on-line calculator, based on Statistics Canada, Consumer Price Indexes for Canada, Monthly (V41690973 series).
} 
status by 1956. To understand the original RRSP policy, it is important to first discuss the treatment of workplace pension plans at the time.

\subsubsection{Tax-preferred retirement savings before RRSPs}

In his book on Canadian tax policy, written immediately before the study and introduction of RRSPs, Perry (1951) provided a very good discussion of the taxation of employer-sponsored pensions and government annuities as of the early 1950s. According to Perry, the tax-treatment of long-term savings in Canada in the post-war period was "uniquely Canadian" (p.53) and without precedent in either the British or American systems. It was based on the 1945 recommendations of the Royal Commission on the Taxation of Annuities and Family Corporations, also called the Ives Commission (Privy Council Office, 1945).

Outside of pensions, the practice in Canada had been to tax, in full, the proceeds of an annuity as income when it matured, in keeping with British precedent (Perry, 1951). But the taxation of pensions had evolved in a very different direction. ${ }^{92}$ Beginning in 1919 , the federal government allowed a deduction from income for payments made into a workplace superannuation or pension fund as long as the benefits paid during retirement were later taxed as income-a deduction and deferral model of treating savings (PCO,

\footnotetext{
${ }^{92}$ For a detailed discussion of the earliest evolution of the taxation of pensions in Canada, the report of the Ives Commission is an excellent source. Many of the changes were administrative or highly technical, such as the definition of pension funds eligible for preferred tax treatment, the treatment of lump sump amounts and contributions to catchup for past service. These are outside of the scope for my thesis therefore the discussion here is limited to the basic question on the nature of the tax benefit.
} 
1945). By 1936, the government moved to cap the value of the deduction at $\$ 300$ per year for employees as pension coverage broadened among some Canadian workers, increasing the total cost of the deduction to government revenues. Recall that, during the compulsory savings experiment, pension contributions were also credited against the mandatory refundable savings, giving in effect, a double tax benefit to Canadians with a workplace pension.

The problem faced by the government, and to which the Ives Commission was asked to respond, was the inequality of treatment between personal savings in annuities and pensions. By taxing annuities in full, the Commission noted, the government was taxing annuity-holders twice on the capital portion of the annuity since contributions to the annuity were made out of after-tax income. The Commissioners wrote:

As the law now stands one class of individual in Canada is required to pay tax on his savings in their entirety during the period when his services are being rendered. The other class, through the medium of a pension fund or plan, is permitted to postpone the taxation of some part of the reward for his services until after he has retired from active employment. (p.38).

Achieving some measure of equity between these groups, argued the Commissioners, required that either the workers with a pension lose the deduction and pay tax on some 
valuation of the deferred income locked in their pension, ${ }^{93}$ or that annuitants not be taxed on withdrawals of capital when their contracts matured. ${ }^{94}$ These two options-deduction and deferral or tax pre-paid status - have been used in every subsequent tax-preferred account-based savings instrument.

According to the Department of Finance (2003) and Davies (2009), the presence of both of these tax-treatments in the income tax system is useful because it allows households facing different marginal tax rates to smooth out their lifetime incomes in the most efficient way possible for their own circumstances. For people expecting to see their post-retirement taxable incomes fall from their working-life levels, the deduction and deferral model offers the greatest tax benefit because it allows them to defer taxation on a portion of their current income to a time when their marginal effective tax rate will be significantly lower. For those expecting to maintain, or even modestly increase, their income in retirement, the tax pre-paid model is likely to be a better option because taxation is levied in a more stable way over the life-course without taxing income twice. But perhaps more importantly for policy purposes, the assumption of the Department of Finance (2003) and others (Mintz, 2001; Poschman \& Robson, 2004) is that tax prepaid

93 The Commission and subsequently the Government adopted the view that contributions to a workplace pension are a form of delayed or deferred compensation. ${ }^{94}$ A further problem identified by the Commissioners was inequality in the tax treatment of various workplace pensions. In their 1945 report, the Commissioners allude to instances in which no deduction had been allowed to the employee but no taxes were taken from the pensions paid out as the entire pension was taxed in the hands of a third party trustee. The Commissioners' report contemplates treating workplace pensions in the same way as private annuities, where tax would only be collected on the interest earned on the original contributions of the employee (not the employer), however they ultimately rejected this option as too administratively burdensome. 
and tax-deferred treatments of saving are essentially equivalent in terms of their longterm impacts on federal revenues. This, at least theoretically, removes much of the macroeconomic arguments for policy choices between the two models.

While Perry (1951) states that the 1946 federal budget essentially adopted the recommendations of the Ives Commission in full, there was a very notable recommendation that was not adopted. The Commission report notes that the $\$ 300$ annual limit on the deductions for contributions to pensions in place in 1945 was too low to ensure adequate post-retirement income. In fact, the Commission report claims that experts advised a cap closer to $18 \%$ of annual earned income ${ }^{95}$ be allowed within the pension limits (p.41). By contrast, the Commissioners argued that, if all pensions were to be treated equally, with deferred taxation status, then "it would seem unnecessary to provide for any upper limit on the employee's contribution" (p.41). Their argument was that, any upper limit implied, by definition, that the tax measure was not in fact neutral. Recall that the assumption built into the model is that the deduction for pension contributions is allowed on the grounds that it is deferred compensation and will be fully taxed at a later date. If this is true, then the amount contributed should not matter for equity purposes, unless of course, a worker today will face a dramatically lower marginal

\footnotetext{
95 This $18 \%$ of annual earned income is the same threshold currently used for calculating new RRSP contribution room.
} 
tax rate as a pensioner - this latter being most true for higher income earners who drop by a full income tax bracket. $^{96}$

The changes adopted in the 1946 federal budget did simplify and make more uniform the tax treatment of employer-sponsored pensions and annuities. Taxation of annuities was limited to the investment income earned on the capital. However, the 1946 budget did not substantially change the limit on annual contributions to a workplace pension. In fact, by 1957, the annual limit on workplace pension contributions was still just $\$ 900$, approximately double the 1946 limit after taking into account the effects of inflation between 1945 and 1957.

When the federal government introduced its budget in March 1957, it might have opted to treat the retirement savings of self-employed professionals as tax pre-paid, consistent with the taxation of private annuity contracts. The tax-prepaid policy model would have placed the self-employed professionals on a par with other workers (self-employed or in standard employment) who relied on annuities, including the Dominion Annuities that had been debated in the credits against war-time compulsory savings. Or it might have opted, as it was petitioned by the professional associations of doctors and dentists, and urged by Opposition Conservatives, to treat these individual savings on par with employer-sponsored pensions, offering a deduction for current contributions and taxing

\footnotetext{
${ }^{96}$ In 1945 and still in 1957 there were exponentially more federal income tax brackets than there are today. Decreases in marginal tax rates due to a reduction in total taxable income would have been more gradual.
} 
withdrawals only in retirement. The deduction and deferral policy option would have been more attractive to higher income professionals because it would reduce their taxable income during their working life (through the deduction) and allow them to be taxed on retirement withdrawals at a lower marginal tax rate.

\subsubsection{The creation of RRSPs: 1957}

In its 1957 budget the federal government introduced the new RRSP. All taxpayers would be able to set aside money in a private annuity and claim an annual deduction against their taxable income. The limit on the deduction for the new RRSP was set at $10 \%$ of earned annual income or $\$ 2,500$ per year, $\$ 1,500$ for those RRSP holders who also were members of a registered pension plan (for a combined amount of $\$ 2,400$ annually). Investment income in the RRSP would grow without tax penalty. Withdrawals would be taxed as income but withdrawals were only permitted in retirement. The annuities would require approval from the federal government to qualify for the tax deduction and exemption - "registration" in the language of the Income Tax Act.

The RRSP was announced as part of "a general policy of allowing tax postponement on limited amounts of earned income set aside for retirement by any taxpayer" (Harris, 1957). However in its design, the new program was not really for "any taxpayer".

First, as discussed above, because the RRSP offered a deduction against current tax payable along with a deferral of taxation to retirement when marginal rates would be lower, it offered far more benefit to higher income earners who had both a greater 
immediate tax liability and an expectation of decreased tax liability in their retirement years.

Second, the RRSP policy required that a taxpayer buy "a particular kind of annuity" from a qualified private sector provider. Initially this included only licensed trusts already issuing annuity contracts in Canada. The government later (by April of 1957) allowed an amendment to broaden the qualified RRSP issuers to include life insurance companies, syndicates that might be formed by private investors (the predecessor of mutual funds) and finally Dominion Annuities that were still an important source of long-term saving for many working class Canadians. ${ }^{97}$ Although access to Dominion Annuities as RRSP vehicles may have been important for some working-class savers, until the demise of the government annuities business in 1975, it does not appear as though the government actively promoted awareness or take-up of Dominion Annuities as an RRSP option. ${ }^{98}$ Rather than take a lead role in implementing the new policy, both the media reports and

${ }^{97}$ That definition remained largely unchanged until amendments to the Income Tax Act in 1980 that allowed deposits as qualified RRSP investments and finally with reforms to the Bank Act in 1987 and 1992 that allowed retail banks to acquire securities dealers as subsidiaries (some of whom may have been able to sell products eligible for RRSP registration) and eventually to acquire or engage in insurance and trust business directly (Armstrong, 1997).

${ }^{98}$ An exchange between NDP MP Stanley Knowles and the Minister of Finance in the debate on the 1957 budget suggests that the Liberal government at the time may have been willing to invest in promoting the Dominion Annuities as an RRSP vehicle but they lost the election later that spring to the Conservatives. A contemporary parallel can also be drawn with the Canada RSP program. Between 1997 and 2010, Canadians could purchase a RRSP savings product through the Canada Savings Bonds Program. Bonds could be purchased in either $\$ 500$ lump sums or through payroll deductions of as little as $\$ 10$ a week. Unlike many other RRSP products, the Canada RSP was not subject to fees and did not need to be rolled into a self-managed plan. Furthermore, an automatic rollover into a compatible product at age 71 was also available. 
the Finance Minister's own statements make clear that that the details of the RRSP were worked out with "insurance company experts". 99

Third, the preferential tax status was available only to new and locked-in annuity contracts, starting retroactive to January 1,1957 . This meant that anyone with an existing contract for an annuity (private or government-issued) prior to that date would have needed other savings or sufficient income to purchase a new RRSP-eligible annuity. The government also expressly rejected any option for early withdrawals from the RRSP annuities, even in cases of disability. The Minister of Finance at the time stated the "purpose of course is to provide annuities and not to provide some kind of insurance" (Harris, 1957). For lower and modest income workers more prone to economic shocks, flexibility in the withdrawal of savings instruments may be an important feature. Wealthier individuals and households are more likely to have a wider range of financial resources they can liquidate to cope with similar shocks.

A fourth design feature of RRSPs that worked in favor of higher income earners was the elevated annual contribution ceiling, particularly relative to employees contributing to workplace pensions. Recall that the key argument for RRSP advocates had been parity in retirement income security with pension plan members. In 1957, a member of a workplace pension could deduct from their taxable income no more than $\$ 900$ in contributions to a pension. By contrast, and as noted earlier, the contribution limit for the

\footnotetext{
${ }^{99}$ Reported in The Globe and Mail, March 15, 1957.
} 
new RRSP was set at $10 \%$ of earned annual income or $\$ 2,500$ per year, or $\$ 1,500$ for those RRSP holders who also were members of a registered pension plan to a combined limit of $\$ 2,400$ annually. This meant that the greatest tax assistance for any retirement savings would have gone to the highest income self-employed professionals. It was not until the 1984 budget that the contribution room on RRSPs and registered pensions was harmonized. Furthermore, there were no penalties for those RRSP-holders who contributed more than the annual maximum deduction limit, a loophole that wasn't closed until 1976. This meant that, until 1976, wealthy RRSP-holders could contribute well above the annual limit without paying tax on the over-contribution or the interest it earned inside the plan.

Considering its prominence today, it is ironic that the RRSP received little political or public scrutiny. None of the above critiques were raised by either Conservative or NDP Opposition Parliamentarians in the debate that took place on the 1957 budget. Like the policy of compulsory savings, the response from the Opposition benches was largely positive, criticizing the government only for having been too slow to act. Similarly, the reports from the national news media at the time made far more of a new $\$ 100$ deduction (without receipts) for charitable donations, union dues and medical expenses (Davey, 1957). Even the official minutes from the Cabinet meeting on the 1957 budget downplayed the importance of the new policy instrument. The Minister of Finance is said to have described the forthcoming 1957 budget as offering "no general changes in taxes of great significance" (PCO, 1957). The Cabinet is recorded as having "noted with approval" all of the Minister's proposals without discussion. 
A June 1957 election saw the Liberal government replaced by Conservatives who were supportive of the RRSP policy and left it unchanged. A review of the Parliamentary and Cabinet records for the period immediately after the launch of the RRSP (summer 1957 through 1958 and 1959) found no further references to the policy or questions on how it was being implemented or affecting Canadians. Similarly, a search of national print media over the same time period found no mentions of RRSPs. It is almost as though the new tax-preferred savings instrument was forgotten by both policy-makers and stakeholders alike.

\subsubsection{Evidence on early RRSP take-up}

The annual taxation statistics published by the predecessor to the Canada Revenue Agency offer some clues about the early implementation and take-up of the RRSP. ${ }^{100}$ In Table 4.1, below, I present data based on calculations from those annual reports for the 1957 and 1958 tax years as well as the 1971 tax year for comparison. The next change to RRSP policy was not made until 1971.

\footnotetext{
100 The statistical reports of the time and through to at least the mid 1980's reported on the amounts claimed in a tax year for each line item on the personal income tax return but both the income and the employment of the tax-filer.
} 
Table 4.1 Value of RRSP deductions (\$ millions), unadjusted

\begin{tabular}{l|lll} 
Tax year & $\mathbf{1 9 5 7}$ & $\mathbf{1 9 5 8}$ & $\mathbf{1 9 7 1}$ \\
\hline $\begin{array}{l}\text { Total deductions } \\
\begin{array}{l}\text { Deductions claimed by self- } \\
\text { employed professionals }\end{array}\end{array}$ & $\$ 270 *$ & $\$ 19$ & $\$ 319$ \\
$\begin{array}{l}\text { \% of total deductions } \\
\text { claimed by self-employed } \\
\text { professionals }\end{array}$ & $2.6 \%$ & $\$ 1.1 \%$ & \\
$\begin{array}{l}\text { Deductions claimed by } \\
\text { highest category of income } \\
\text { earners for that tax year }\end{array}$ & $\$ 8.1$ & & $18.5 \%$ \\
$\begin{array}{l}\text { \% of total deductions } \\
\text { claimed by highest income } \\
\text { filers }\end{array}$ & $3 \%$ & $\$ 5.1$ & $\$ 21$ \\
\end{tabular}

\footnotetext{
*Includes amounts for both RRSP and pension deductions, not reported separately in the report for the 1957 tax year. If Using the highest income category reported for that year's Taxation Statistics Report. In 1957 and 1958, the highest income category reported was $\$ 25,000$ or more, in 1971 it was $\$ 50,000$ or more. In all years, this category corresponds to between the richest $1 \%$ and $4 \%$ of all tax-filers for that year.

Source: Author's calculations using data in the Annual Taxation Statistics reports from 1959, 1960 and 197, Supply and Services Canada, Ottawa.
}

In the tax year before RRSPs were introduced (1956), the "Tax Statistics" report indicated a total of $\$ 202$ million $^{101}$ claimed in deductions for pension contributions. Of this, self-employed professionals (including doctors, dentists, lawyers, farmers, architects, salesmen, accountants and small business owners) claimed just $\$ 441,000$ in deductions and higher income earners (those making $\$ 25,000$ or more per year) claimed a total of \$3 million. In the 1959 report for the 1957 tax year, deductions claimed for

${ }^{101}$ All amounts in this section are reported in unadjusted dollars unless otherwise noted. 
RRSPs were not reported separately from amounts claimed for pension contributions. As indicated in Table 4.1, above, a total of $\$ 270$ million in deductions for both pensions and RRSPs was claimed by all Canadian tax-filers that year. Within that total, $\$ 7.1$ million was claimed by self-employed professionals, a year over year increase of $\$ 6.7$ million and perhaps some indication of the initial response to the RRSP incentive among selfemployed professionals. Given the driving role of the Canadian Medical Association in the RRSP policy, it is maybe not surprising that of the \$7.1 million claimed as deductions in 1957, \$4 million was claimed by doctors and surgeons alone. The rate of increase among the highest income earners (those making $\$ 25,000$ or more a year) was slightly more modest but still substantial, rising from \$3 million 1956 to \$8.1 million 1957 .

In the next year, the 1960 report did separate RRSP and pension deductions for the tax year 1958. Although the 1957 budget had made the RRSP policy applicable to eligible annuities starting January 1 of that year, it is unlikely that annuity providers would have been able to market and sell substantial numbers of RRSP-eligible products until after the budget announcement, making 1958 the first full tax year in which RRSP providers would have been marketing their products to Canadian consumers. In that year, RRSP deductions came to $\$ 19$ million in total, of which $\$ 7.8$ million was claimed by selfemployed professionals, only a slight increase, including $\$ 4.4$ million claimed by doctors and surgeons. The CMA may have been entirely justified in celebrating a victory for its members on the anniversary of the launch of RRSPs given the early take-up of the program among Canadian doctors. There was also considerable take up among high income earners (those making $\$ 25,000$ or more) who claimed $27 \%$ of all RRSP 
deductions (see Table 4.1 above) but made up just $4 \%$ (the richest $4 \%$ mind you) of all tax-filers in 1958.

From 1957, the RRSP as a policy instrument was unchanged until the federal budget of 1971. By that time, the proportion of total deductions claimed by the very wealthiest income tax filers had declined substantially, from $26.8 \%$ in 1958 to $6.5 \%$ in 1971 . The proportion of total deductions claimed by self-employed professionals had also declined substantially from $41.1 \%$ to $18.4 \%$. By 1971 , although the policy instrument had not been changed since it was introduced as a savings vehicle for self-employed professionals, the population of RRSP users had changed remarkably.

\subsubsection{The first changes to RRSPs: 1971}

There were no policy changes to RRSPs for 14 years until the 1971 federal budget. The central focus of that budget was to respond to the recommendations of the Royal Commission on Taxation (also called the Carter Commission) and the government's own White Paper. The Carter Commission had been launched in 1962 by the Progressive Conservative Diefenbaker government to "inquire into the incidence and effects of taxation imposed by Parliament" (PCO, 1966, volume 1, p.iii). Chapter 16 of the final report, issued in 1966, addressed RRSPs as part of a broader discussion on deferred income plans, including pensions and life insurance contracts.

The Commissioners recommended that "tax deferment related to the deduction in computing income of payments into such plans should, in general, be eliminated" (PCO, 
1966, volume 3, p.409). But at the same time, the report acknowledged that registered savings instruments had become an "embedded" (p.411) part of the tax system and served important social goals in promoting individual saving and self-sufficiency in retirement. In general, the Commissioners favored a move towards a taxation system based on annual consumption rather than income (see Chapter 3 for a discussion of the differences between these tax bases). They saw an avenue in RRSPs and registered pensions for incremental changes towards their preferred model not by increasing deduction limits, but instead by further constraining these limits.

The Commissioners argued that increasing annual limits on RRSP deductions would disproportionately benefit high-income taxpayers:

First, the higher the limits on the retirement saving contributions that can be deducted from income, the more certain it will be that upper income individuals will substitute registered retirement saving for other kinds of saving. Second, the higher the limits, the more the system will depart from ability-to-pay taxation. (p.416)

While they argued that low and middle-income Canadians had likely experienced "indirect positive effects on saving" from what they termed "liberal retirement savings policies," 102 the Commissioners also acknowledged that there was "no conclusive

${ }^{102}$ The Commission report is not more specific than this in describing the relevant policies and it is unclear how they arrived at the characterization of retirement provisions as "liberal". 
evidence one way or the other" that increases in the tax benefits for retirement saving "would have any effect on their rates of personal saving" (p.414). The report also, briefly, argued in favor of allowing much greater flexibility in the design of RRSP and other income deferral instruments so that low and middle-income users might have access to their own money as precautionary savings, not just long-term savings:

Unless people put a premium rather than a discount on future income, we doubt that more generous tax provisions would induce low and middle income people in such a position to increase their retirement saving, unless the withdrawal privileges were relaxed to the point where retirement saving and precautionary saving merged. (p.416)

The recommendations for more flexibility in pre-retirement withdrawals and more restricted use of tax deductions as savings incentives would have led to a very different and possibly more progressive RRSP policy. However, the government's first response to the Commission, the 1969 White Paper on Tax Reform, rejected these recommendations as it did many or even most of the Royal Commission's ideas (Robinson \& Cutt, 1973; Hale, 2002).

When the Government of Canada, now a Liberal government under Pierre Trudeau, introduced its 1971 budget, the Minister of Finance, Edgar Benson, announced modest changes to RRSP limits. The annual limit on deductible RRSP contributions was raised to $\$ 4,000$ or $20 \%$ of earned income, whichever was less. The contribution ceiling had not been changed since RRSPs were first introduced in 1957. Although this doubled the 
annual amount a taxpayer could save and deduct from their current income, much of the increase was actually just catching up with inflation. ${ }^{103}$ By contrast, the annual deductible contributions for pensions were increased to $\$ 5,000$, up from $\$ 1,500$.

In his budget speech, Benson claimed "these changes will enable taxpayers to put aside considerably more money for their retirement and will also significantly increase the level of personal savings available to finance growing capital investment in Canada" (Benson, 1971). The last part of this sentence is the most important part. The real thrust of the government policy was not the microeconomic concern of promoting savings and asset-accumulation among Canadian households, but rather the macroeconomic concern of mobilizing Canadian capital to fund Canadian investment in Canadian enterprise. The policy change to the cap on RRSP contributions was very small—amounting to just $\$ 600$ over and above inflation-related increases in a period of 14 years. More important was the move to restrict foreign assets in an RRSP (to a maximum of $10 \%$ of the total of the RRSP) ${ }^{104}$ and to set more stringent rules for investment vehicles that might qualify for registration. ${ }^{105}$ The Minister noted that he was "confident that these changes will have a

103 To keep up with inflation, the annual RRSP limit would have had to rise to $\$ 3,500$ by 1971, calculation using Bank of Canada inflation calculator based on Statistics Canada, Consumer Price Indexes for Canada, Monthly (V41690973 series).

${ }^{104}$ The $10 \%$ rule on foreign assets was only modified in the 1992 budget by offering RRSP owners additional space in their portfolio for foreign assets when they invested in Canadian small enterprises.

${ }^{105}$ Rules regarding the registration of eligible investments for RRSPs are set out in The Income Tax Act at sections 146 and 204. In 1971 the investments would have been limited to annuities and mutual funds. The new rules principally concerned regular reporting and compliance measures. 
significant effect in channeling the investments of retirement funds into Canadian development, which otherwise might well have been placed abroad" (Benson, 1971).

During the June debate on the 1971 budget, Opposition and backbench MPs generally voiced a common concern regarding foreign ownership and did not challenge the budget proposals on RRSPs. ${ }^{106}$ The silent consent may not have been surprising in light of a 1970 report of the Commons Standing Committee on Finance, Trade and Economic Affairs that had called for government "action to increase long-term savings because of their importance to the economy" (cited in Popkin, 1971). There was also political pressure from provincial governments lobbying for measures to promote domestic investment as a tool of economic development (cited in Popkin, 1971; Hale, 2002). A 1971 paper from the Private Planning Association of Canada, the predecessor of the C.D. Howe Institute, similarly called for a policy of promoting domestic savings and investment through a package of tax incentives (Popkin, 1971). Faced with what seems

\footnotetext{
${ }^{106}$ In fact, the central issue in the debate on the 1971 budget was the introduction of a new tax on capital gains, one of a few recommendations adopted from the Carter Commission's report. The new tax treated the increase in the value of a capital asset when the gain was realized on the sale of the asset and justified as a more equitable and coherent approach to defining income using a Haig-Simons definition (for a very good discussion see the final report of the Carter Commission). The tax applied to personal property, excluding a principal residence or valuables worth less than $\$ 1000$, and was set at half of whatever rate the taxpayer paid on other income (similarly a deduction was available for capital losses at half the taxpayer's normal rate on other income). The budget also included measures to allow transfers between spouses (without taxation) and options to allow payment to be delayed to a year when a taxpayer had a lower tax liability. NDP MPs argued for no exemptions on capital gains taxes to discourage Canadian capital holders from selling to foreign buyers. Progressive Conservative MPs primarily argued against the inclusion of capital gains for the special cases of small business owners and farmers who may use their homes for their business as well as living space.
} 
to have been near unanimous belief at the time that Canadian dollars should stay within Canada to finance Canadian economic development, the decision to impose the foreign asset restrictions on RRSPs seems to have been primarily a decision to use a microeconomic lever to fulfill macroeconomic priorities. It is remarkably similar to the decision to use personal income taxation (a microeconomic lever) to force individual savings to make up the fiscal shortfall (a macroeconomic goal) during the compulsory savings experiment.

\subsubsection{Critiques of the 1971 policy change}

Like the compulsory savings experiment, much of the thinking in this period seems to have been about how to re-direct the finances of lower and middle-class Canadians towards a national objective. According to the Private Planning Association of Canada, a very large share (45\%) of the financial assets held by individual Canadians in 1971 were actually held by those making between $\$ 2,500$ and $\$ 10,000$ in annual income (Popkin, 1971). ${ }^{107}$ The data in Table 4.1 similarly suggest that less than $10 \%$ of all RRSP deductions in 1971 were claimed by the wealthiest taxpayers. In contrast to the original policy intent to recognize the retirement savings of self-employed professionals, by 1971 \$212 million of the \$319 million in total RRSP deductions claimed were claimed by employees, and primarily private sector employees.

107 The report by Popkin (1971) states that this figure was derived from data on individual taxpayers by income, which would not have reflected total household wealth. Incomes between $\$ 2,500$ and $\$ 10,000$ in 1971 would be equivalent to approximately $\$ 14,800$ and $\$ 59,600$ in 2013 terms (calculation using Bank of Canada inflation calculator based on Statistics Canada, Consumer Price Indexes for Canada, Monthly, V41690973 series). 
In the context of the Carter Commission and government response, the Private Planning Association of Canada also saw policy change to RRSPs as an opportunity to broaden the number of Canadians with savings and to increase the dollar value of the assets of low and modest income earners: "For those with little or no capital, the important feature of tax policy must be to encourage the saving and investing that can lead to capital" (Popkin, 1971, p.43). In addition to calling for limits on foreign investment, the Planning Association proposed that the RRSP tax incentive be limited for saving by those Canadians with $\$ 9,000$ or less in annual income.

In 1966, the Carter Commission had also called for better targeting of tax assistance for long-term savings towards those with low and modest incomes who would be less likely to save otherwise compared to wealthy Canadians:

If the justification for tax concessions is primarily social, the value of such benefits should be designed primarily for the low and middle-income groups where encouragement of saving is more socially desirable. To the extent that the tax incentive does have an impact on the level of saving, it is largely manifested in the low and middle-income groups. (PCO, 1966, volume 3, p.420)

However, the same report conceded that there was no economic evidence to support a major initiative to promote domestic savings or restricting foreign ownership of Canadian enterprise. These were, wrote the Commissioners, primarily matters of policy preference. 
In 1971, the federal government made the first changes to the RRSP policy since it had been introduced. It could have redirected the policy to be more progressive either by reducing the annual limit on contributions ${ }^{108}$ or, as suggested by the Private Planning Association of Canada, restricting the tax benefits to those below some income level. The government did neither of these things. Instead, as part of a package of measures on domestic investment, it aimed to use RRSPs more as a tool for investment in the Canadian economy.

The 1971 budget had introduced some modest changes to restrict recognition (or "registration") of a financial product for the preferential tax treatment as an RRSP, on top of the new limits on foreign assets. Despite these restrictions, total of annual deductions for RRSP contributions grew from \$319 million in 1971 to $\$ 1.5$ billion in 1975 (Revenue Canada, 1973, 1975), roughly a fivefold increase. Contributions by self-employed professionals increased in the same period roughly threefold but contributions by the highest income taxpayers soared from \$21 million in 1971 to \$146 million in 1975, a sevenfold increase. Instead of changing the policy to target low and middle-income Canadians, it was wealthier Canadians who used the increased contribution room.

\footnotetext{
${ }^{108}$ To be more precise, the Carter Commission had recommended that the annual limits on RRSPs not be set in relation to current income but instead in relation to the future projected benefits that might be paid out of an RRSP. This model would lead to declining annual contribution room over time. Such a model is likely to reduce the value of an RRSP to very high income earners who would more quickly reach the cut off level sooner while leaving in place some incentive savers who needed more time to reach the target benefit level. However, calculating the projected future value of an RRSP in each year for tax purposes would be administratively cumbersome and fraught with assumptions open for debate (such as projected rates of return and future inflation trends).
} 
Remarks of Duncan Blair, a Liberal M.P. and a member of a Commons committee tasked with reviewing and responding to the Carter Commission and the government's White Paper, might help to explain the government's policy choice. In the June debate on the 1971 budget, Blair briefly references his experience in touring the country to consult with Canadians on tax reform. "It is quite obvious now that this nation does not find acceptable the grand, schematic proposals for the overall alterations of established institutions”, Blair remarked (Blair, 1971). On matters of taxation, he continued, Canadians "like better the devil they know than the devil unknown." Once the RRSP had been introduced and established as a tax-preferred account-based savings vehicle, it became politically resistant to change. It seems the government found it politically unappealing to make dramatic changes to the RRSP, even to target the benefits towards lower and modest-income savers. The decision to restrict foreign investments was, it seems, largely uncontroversial at the time. Similarly, the increase to the annual contribution limit also appears modest and incremental when inflation is taken into account. The same modest, incremental approach to changes on RRSPs has continued to the present as outlined in the next chapter. The underlying framework of RRSPs remains largely intact from its original 1957 design—a tax-preferred savings instrument that, for several reasons, is more accessible and useful to wealthier Canadians. 


\section{Chapter 5: Relentless incrementalism: RRSPs and RHOSPs}

Chapter 4 ended with a discussion of the 1971 changes to Registered Retirement Savings Plans (RRSPs), the first policy changes since the instrument was created in 1957. In the three decades that followed, there would be a series of incremental shifts in RRSP policy but none of them, at any time, fundamentally altered the original program design of deduction and deferral. More importantly, these policy shifts exacerbated the regressive nature of the policy and turned it into a heavily subsidized savings instrument for wealthier Canadians who might well save anyway. Furthermore, the RRSP served as a precedent and model for other new tax-preferred account-based savings instruments.

This chapter examines the major policy changes to RRSPs after 1971. I limit my discussion to those policy changes that are relevant to individual Canadians in determining how much they could save, what benefit they would receive from an RRSP and how they could use their RRSP assets.

This chapter also discusses the Registered Homeownership Savings Plan (RHOSP), a taxpreferred account-based savings instrument created in 1974. I begin with the 1974 budget that made further changes to RRSPs, as well as announcing the RHOSP. Section 5.1 discusses the trajectory of the RRSP from 1974 onwards. Section 5.2 discusses the RHOSP. The retrospective analysis continues in Chapters 6 and 7. 


\subsection{RRSPs from 1974 onward}

\subsubsection{Spousal contributions}

In the 1974 budgets, ${ }^{109}$ Finance Minister John Turner introduced changes to RRSPs, created the new RHOSP and the new RESP. The public debate and discussion on these tax-preferred instruments focused exclusively on the RHOSP—discussed in Section 5.2 in this chapter. There was no attention paid to the new spousal contributions feature added to RRSPs.

Introduced in 1974 and still in place today, the rules on spousal contributions allow Canadians to contribute and, claim as a deduction against their own income, not only savings in their own RRSP but also savings in their spouse's RRSP. ${ }^{110}$ The total amount of the deduction to be claimed for both personal and spousal RRSPs cannot exceed the annual deduction limit for the contributor (Finance Canada, 1974; CRA, 2013f). In 1974, this would have meant that a taxpayer could not deduct more than $\$ 4,000$ (or $20 \%$ of his or her earned income, whichever was less) from his or her income for contributions to RRSPs, regardless of whether the plan was personal or owned by a spouse.

A superficial analysis suggests this incremental change would not have increased the tax benefit of RRSPs and would not have delivered any additional benefit to higher income

\footnotetext{
${ }^{109}$ There were two federal budgets in 1974 . The first was in May of that year. The government lost a confidence motion in the House of Commons. Following a general election, a second and nearly identical budget was introduced in November of the same year.

${ }^{110}$ Since the late 1990 's, the definition of spouse has, for tax purposes, included common law partners who have lived together for at least 12 months.
} 
taxpayers. However, the benefit of spousal RRSP contributions is not the immediate deduction against current income. Rather, it is the reduction in household taxation later in retirement. ${ }^{111}$ In couples where one spouse earns substantially more income than the other, they can, as a couple, substantially lower their combined by tax liability by shifting some of the income of the higher-earning spouse to the lower-income spouse.

In 1976, ${ }^{112}$ women in heterosexual married couples in Canada earned, on average $\$ 0.60$ for each dollar earned by their husbands. ${ }^{113}$ The discrepancy in male to female earnings within couples suggests there was substantial room for, and potential gains from, incomesplitting. Particularly in the case of the highest income households with a spouse making (in 1974 dollars) $\$ 25,000$ per year and a spouse making $60 \%$ of this (or $\$ 15,000$ ), there could be substantial tax savings in retirement by equalizing the household's two incomes. For example, presuming an $80 \%$ replacement rate for working-age income on the above illustrative case, a couple using income-splitting through RRSPs could pay taxes on the household income based on two separate streams of $\$ 16,000$ each rather paying taxes on one smaller retirement income of $\$ 12,000$ and a larger retirement income of $\$ 20,000$.

This income splitting only makes sense, objectively, when there is both a substantial discrepancy between the incomes of two spouses and when one spouse faces a high

\footnotetext{
${ }^{111}$ Consumer websites for most RRSP-providers make note of spousal RRSPs as a means of income-splitting.

${ }^{112}$ Ideally I would present data for 1974 when spousal contributions were added to RRSPs. The earliest year for which this kind of data on personal and household earnings is available from Statistics Canada is 1976.

${ }^{113}$ Author's calculation using data from Statistics Canada, CANSIM, Tables 202-0104.
} 
marginal tax rate. Spousal RRSP contributions seem to be particularly attractive for high-income couples where one spouse is the main or only breadwinner. The incomesplitting feature also challenges a key assumption made in the original design of RRSPs that the current costs of the tax deduction will, generally, be offset through taxation on withdrawals at a later date.

\subsubsection{Further changes to RRSP contribution rules}

The next incremental change to RRSPs came in the 1976 federal budget. Then Finance Minister Don MacDonald announced another increase to the annual contribution limit from $\$ 4,000$ to $\$ 5,500$, the first increase since 1971 . Like the 1971 increase, it was quite modest when the effects of inflation are considered. In fact, to keep pace with inflation, the increase should have been $\$ 700$ larger. ${ }^{114}$ It does not seem as though the new contribution limit was based on sophisticated economic analysis. In the debate on the budget, the Finance Minister noted that there was "no magic in the figure. It is one that seemed reasonable" (MacDonald, 1976a). However, in the same speech, the Minister also noted that "few people earning $\$ 10,000$ or $\$ 12,000$ or even $\$ 15,000$ a year could use the full limit" and expressed concern that a larger increase in the annual limit could encourage those with very high incomes to avoid their share of taxation.

In the same debate in the Commons, the Opposition Progressive Conservatives spent most of their allotted debate time arguing that RRSPs served an important social or

\footnotetext{
${ }^{114}$ Calculation using Bank of Canada inflation calculator based on Statistics Canada, Consumer Price Indexes for Canada, Monthly, V41690973 series.
} 
symbolic function. One conservative M.P., Marcel Lambert, spoke of RRSPs as a powerful mechanism to prevent individual Canadians from adhering to "a socialist philosophy of earning all he can, spending all he can, and at the age of 65 holding out the pockets of his trousers and saying 'I have spent everything, now the state will look after me", something he bemoaned was "too prevalent" (Lambert, 1976). Promoting selfsufficiency and thrift, more akin to a $19^{\text {th }}$ Century view of saving, was according to Lambert, "the greatest of the social objectives that we can have in so far as the state is concerned" (Ibid). This statement is notable for how different it is from the original rationale of parity in the tax treatment of retirement savings. However, it illustrates the degree to which, by the mid 1970 's, policy-makers had started to view RRSPs more as a quasi-universal instrument for personal savings than as a niche instrument for selfemployed professionals without a pension plan.

Another, and perhaps the more important, change from the 1976 budget was to close the loophole that had allowed RRSP owners to contribute more than the annual limit without any real penalty. Until the policy was changed, contributions over the annual limit could not be claimed as a deduction against taxable income. But investment income earned on savings above the annual limit continued to enjoy tax-exempt status. Since RRSPs had been created in 1957, this would have allowed RRSP owners an avenue to generate more tax-sheltered investment income.

The 1976 budget amended the Income Tax Act to: a) require that RRSP providers create a way to refund contributions before retirement, and b) impose a tax penalty on 
contributions over the annual limit. ${ }^{115}$ RRSP owners were granted a grace period of a full year to take out over-contributions. After the grace period, over-contributions were taxed at a rate of $1 \%$ per month. This penalty rate of $1 \%$ per month remains in place to this day but taxpayers can apply for the penalty to be waived (CRA, 2013). The Finance Minister observed that the lack of penalties on over-contributions "has resulted in some taxpayers deliberately making large over-contributions to RRSPs" (MacDonald, 1976). The problem was almost certainly concentrated in a very small group of very high income Canadians with sufficient income to save more than $\$ 5,500$ a year in 1976 - equivalent to just over $\$ 22,000$ in 2013 terms. ${ }^{116}$ In the years that followed the 1976 budget, the most frequent policy changes to RRSPs have been ever more relaxed and rising contribution limits.

In the February 1984 budget, the federal government made two more changes to RRSP contribution limits. First, the government changed contribution rules to allow taxpayers to rollover unused contribution room from one year to the next. Currently, annual contribution limits for RRSPs include unused room retroactive to 1991. Allowing retroactive contribution room can substantially increase total the contribution limit wellabove the annual statutory limit on "new" room in any given year. This feature of RRSPs particularly benefits working-age adults who experience an increase in income over time.

115 Source: "Notice of Ways and Means Motion", Budget 1976, Finance Canada.

${ }^{116}$ Calculation using Bank of Canada inflation calculator based on Statistics Canada, Consumer Price Indexes for Canada, Monthly, V41690973 series. 
Second, the 1984 federal budget announced that it would harmonize the annual limits for RRSPs and workplace pensions, creating a global ceiling for both kinds of retirement savings of $18 \%$ of earnings or $\$ 15,500,{ }^{117}$ whichever was less. The change was introduced gradually between 1984 and 1988 (Finance Canada, 1984). This was the first increase in the deduction limits for RRSPs and workplace pensions since $1976 .{ }^{118}$ But more importantly, the 1984 budget tied future annual deduction limits to inflation, starting in 1989. Contribution limits on RRSPs, in tandem with workplace pensions, have increased in every year since.

For 2013, the annual deduction limit for RRSPs is $\$ 23,820$, plus unused contribution room from previous years and less amounts contributed to registered workplace pension plans (CRA, 2013). But increased contribution room does not, on its own, appear to lead to increased RRSP contributions for most taxpayers. Figure 5.1 below shows the total dollar value of accumulated RRSP room and the median amount contributed by Canadians to RRSPs. ${ }^{119}$

\footnotetext{
${ }^{117}$ Equivalent to $\$ 31,550$ in 2013 terms. Calculation using Bank of Canada inflation calculator based on Statistics Canada, Consumer Price Indexes for Canada, Monthly, V41690973 series.

${ }^{118}$ In 1976, the deduction limit for RRSPs was $20 \%$ of earned income or $\$ 5,500$ (whichever was less). For workplace pension it was $\$ 7,000$ of which not more than $\$ 3,500$ could be claimed by each the employee and employer.

${ }^{119}$ This includes the "new" room granted for each new tax year, plus the accumulated unused room for past years, less contributions to workplace pensions.
} 
Figure 5.1: Recent trends in RRSP contributions, unadjusted dollars and percentage, 2000-2011

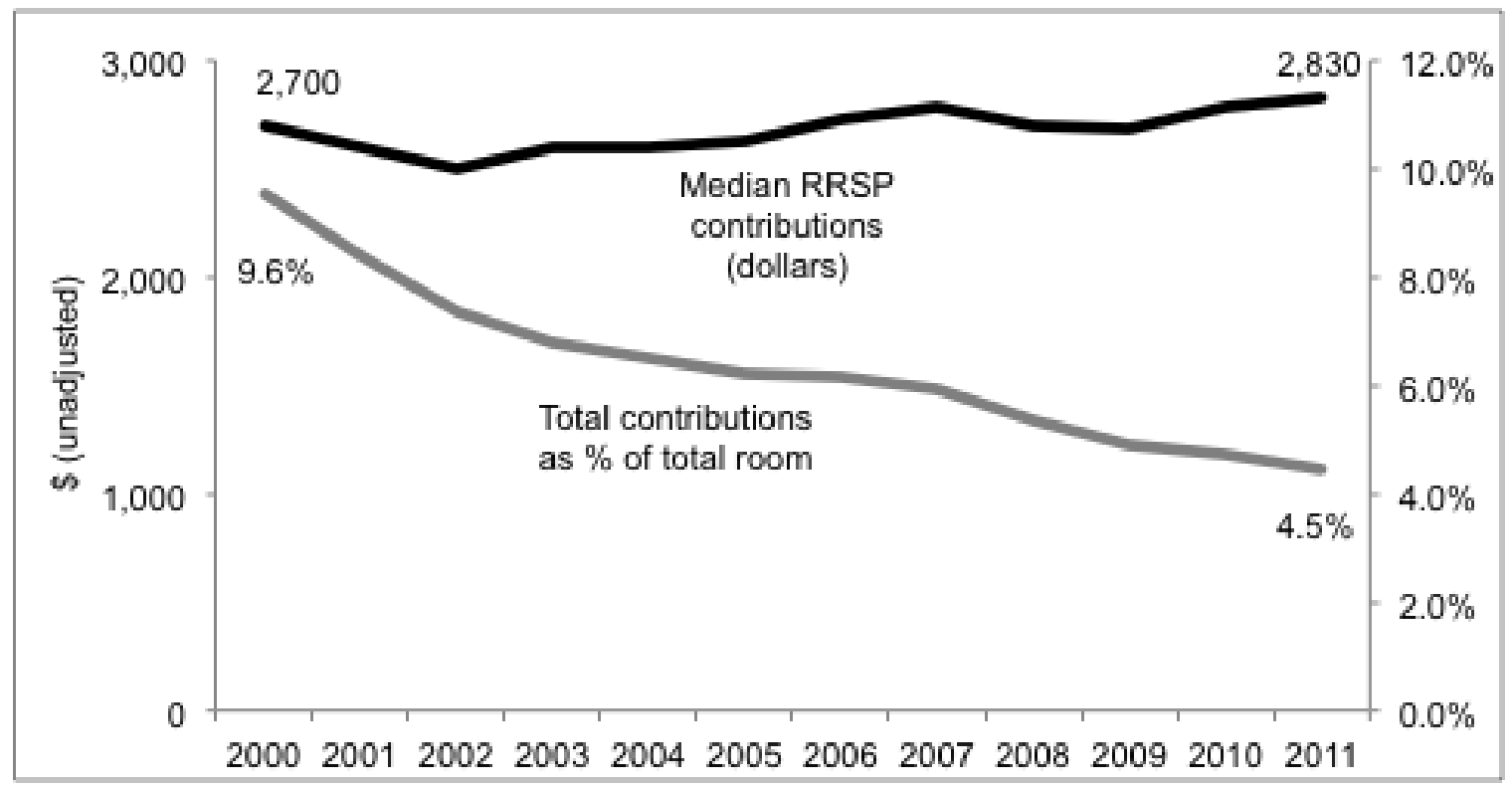

Source: Statistics Canada, CANSIM Tables 111-0039 and 111-0040, Total RRSP room includes new and accumulated contribution room.

Between 2000 and 2011, total contribution room more than doubled (not shown). However, median contributions increased just $17 \%$ over the same period. Although contribution room grows each year, Canadians are actually contributing smaller proportions of what they, notionally, could save under allowable limits. In 2000, Canadians used up $9.6 \%$ of their accumulated RRSP room. Today they use less than half of that.

One possible explanation for the non-response of Canadian households to increases in RRSP limits is that they have other sources of retirement savings, namely workplace pensions. However, the data in the figure above already take into account adjustments to the RRSP limit made for saving through workplace pensions. Furthermore, rates of pension coverage among all working-age Canadians have declined from $37 \%$ of all 
Canadians in the labour force in 1976 to $32 \%$ of all Canadians in the labour force by $2006 .^{120}$

Perhaps a more likely explanation is that the statutory RRSP limits are simply much higher than what most households are able to make use of. Schellenberg and Ostrovsky (2009) reported that the principal reason working-age adults gave for not saving more for their retirement is that they feel they cannot afford to save more, given their income level and other financial commitments. It is likely that only Canadians with large disposable incomes are able to reach their global limit for RRSP savings—-limits that include past contribution room and new annual room of more than $\$ 20,000$ each year.

Yet, the recent policy discourse on RRSPs has generally called for further increases to RRSP contribution limits. For example, a federally appointed panel to study retirement income adequacy concluded that "replacement rates for those earning $\$ 120,000$ and $\$ 150,000$ are affected by the RPP/RRSP dollar limits” (Mintz, 2009). ${ }^{121}$ Mintz argued that the RRSP dollar limits were too low to enable Canadians making between $\$ 120,000$ and $\$ 150,000$ to save enough for an adequate replacement rate in retirement - which he defined as at least $60 \%$ of working-age income. Mintz wrote: "High-income households are less able to achieve their targeted consumption levels with [Registered Pension Plans] and RRSPs since limits are imposed on contributions made to these plans.” By contrast,

${ }^{120}$ Source: Statistics Canada, CANSIM series 282-0002

${ }^{121}$ The replacement rate is the proportion of working age income that an individual or household can expect, from all sources, in their retirement. 
he found that "those with low incomes generally have sufficient retirement income to achieve desired consumption levels after retirement due to government transfers and CPP/QPP benefits.”

The argument in favour of further increases to RRSP limits on the grounds of low replacement rates for higher income Canadians ignore differences in the dollar values of projected retirement incomes. Mintz (2009) reported a projected replacement rate of $87 \%$ for an individual making $\$ 20,000$ per year during their working years, when income from public pensions and senior's benefits are included in retirement income. His projection for the replacement rate of a typical individual making $\$ 150,000$ is much lower at $52 \%$, below his $60 \%$ threshold for 'adequacy' suggesting a problem in need of a policy response. However, Mintz does not report that the same projections lead to estimates of $\$ 17,000$ in retirement income for the first case and $\$ 78,000$ in retirement income for the second case (Robson, 2010). A retirement income of just $\$ 17,000$ would leave an individual below the after-tax Low-income Cut off (LICO) and it is difficult to see how this income would truly meet "desired consumption levels". Moreover, given the already high cost of RRSPs as a tax-preferred savings instrument, support for a further increase to contribution limits to raise the retirement incomes of wealthy Canadians seems difficult to justify.

Incremental increases to contribution limits have been important policy changes to RRSPs. However, there have been two other substantive policy changes - the treatment 
of RRSP capital at retirement and programs to mobilize RRSP capital for household needs other than retirement. These are each discussed in the next sections of this chapter.

\subsubsection{Creating Registered Retirement Income Funds}

Until 1978, RRSP owners had just two options as they approached retirement:

- either an RRSP owner could liquidate his or her entire savings and pay taxes on the lump sum in a single year,

- or alternatively, he or she could move RRSP savings into an annuity to provide a fixed monthly income. The transfer of funds to an annuity incurred no tax as long as the annuity was purchased anytime before the RRSP owner turned 70 years of age.

Annuities are well-known to be expensive and their costs only increase with each additional security feature (Yermo, 2001). For example, an annuity that will guarantee a monthly income indexed to inflation is more expensive than an annuity that guarantees a basic nominal payment. Similarly, an annuity that will continue to make payments to an estate is more expensive than an annuity that forfeits unused capital to the investment pool if the annuitant dies before the annuity expires. ${ }^{122}$ If lower-income households have some combination of a lower tolerance for risk, a lower capacity to absorb personal financial risk, or discount future income more heavily than do higher income households,

\footnotetext{
${ }^{122}$ Based on a review of consumer information from two major annuity providers in Canada, Sun Life Assurance Corporation and Great West Life Assurance Corporation as well as the Investor Education Fund.
} 
then they may be simultaneously better served by and less able to afford private sector annuities. Throughout the 1960's and 1970's, without another vehicle for their RRSP savings, many Canadians approached retirement and simply took out their savings in cash, paying taxes on the lump sum in that year. ${ }^{123}$

As early as December 1976, stakeholders had petitioned the federal government to change the rules on maturing RRSPs. Much of the debate was about whether the status quo, requiring RRSP owners to either cash out their savings or use them to buy an annuity by age 70 , most benefitted consumers or the annuity industry. Briefs by both the Consumers' Association of Canada and the Canada Life Assurance Company were cited in Parliamentary debate on the Income Tax Act. In response, the Minister of Finance committed to an internal review of retirement income options (MacDonald, 1976b; PCO, 1976).

It appears as though the federal government's internal review of RRSPs continued well into 1978 and included the departments of Finance, Health and Welfare, and the Treasury Board Secretariat, with periodic reports to Cabinet. ${ }^{124}$ In the 1978 federal budget, the government announced that the Income Tax Act would be amended to: 1) eliminate the option to withdraw RRSP savings as cash at age $71 ; 2$ ) delay the option to buy an annuity

${ }^{123}$ Author's review of statements by Members of Parliament in debate on amendments to the Income Tax Act, The Debates of the House of Commons (Hansard) June 19, 1978.

${ }^{124}$ Based on published statements in The Debates of the House of Commons (Hansard) April 26, 1978. 
using RRSP funds to age $60 ;{ }^{125}$ and 3) create a new registered instrument, the Registered Retirement Income Fund (RRIF) as a vehicle for accumulated RRSP savings in retirement and an alternative to annuities. Similar to the original announcement of RRSPs in 1957, the government announced the new RRIF with many unresolved details of the policy and signaled its expectation that RRSP providers would play a role in the design (Chrétien, 1978).

Currently RRIFs are very much like an RRSP in terms of the kinds of investments that can be held under the registered portfolio. Instead of placing limits on the amount of income that can be deposited into the registered vehicle, RRIFs require that a minimum (and declining) amount of taxable income must be withdrawn annually from the pool of accumulated savings. If the actual withdrawals are lower than the minimum required (based on calculations by the Canada Revenue Agency), then taxes and other penalties may be levied on the difference, with avenues to appeal or request flexibility (CRA, 2013).

Rational, self-interested choices between RRIFs and annuities depend on a wide range of factors including, but not limited to interest rates, ${ }^{126}$ household risk factors, ${ }^{127}$ and life

\footnotetext{
${ }^{125}$ Previously, RRSP owners could purchase annuities with their RRSP savings at any time. Generally speaking, fixed income annuities are more expensive when a buyer is younger and has a longer life expectancy.

${ }^{126}$ In the period between 1957 when RRSPs had been introduced and the early 1970s, interest rates had been rising or largely holding steady, making annuities a more attractive investment option. Throughout the 1970s, there was substantial variability in interest rates, falling precipitously and then rising sharply by the end of the decade (Bank of
} 
expectancy. At the time of the debate over RRIFs, a substantial number of RRSP owners died before they had exhausted their savings, leaving behind a pool of capital to pass on to their spouse or children. For RRSP owners who had cashed out and paid the tax on their savings, it was easier to find ways to pass on the capital, tax-free, to their heirs. But for RRSP owners who died before cashing in their savings, prior to 1978, the account was closed and the balance taxed in the hands of the person receiving the income. Following the 1978 changes, in cases where an RRSP or RRIF owner passed away, the account would be closed and the balance taxed as part of the estate of the deceased.

This issue of estate taxes appears to have been the key issue in the public debate took place on the 1978 budget changes to RRSPs. One Parliamentarian representing a low to modest-income constituency, noted that constituents were upset about the taxation change and wanted a mechanism that would meet bequest motives (Knowles, 1978). Another read into the record a speech from the government's Minister of Health and Welfare, Monique Bégin (Orlikow, 1978). Bégin was quoted expressing concerns that the greatest tax benefits in the RRSP and new RRIF system were flowing to those Canadians with high incomes and wealth. Bégin is said to have remarked that the taxpreferred account-based policy instrument of RRSPs "may well be good fiscal policy and

Canada, Selected Historical Interest Rates, based on Statistics Canada series V122530 and V122496). It is likely that this sudden fluctuation contributed to some of the uneasiness with annuities as a retirement savings vehicle.

${ }^{127}$ For example the presence of dependents, other sources of capital or income and special and extraordinary costs such as out of pocket medical costs. 
in some respects it is good social policy too - but still, it does seem odd that those who need the benefits most are least likely to get them" (cited in Orlikow, 1978).

Overall the 1978 budget package of changes did three things that might have raised real and understandable concern for more modest income savers. It:

- eliminated lump sum cash withdrawals for RRSPs at retirement,

- introduced a forced choice between two somewhat more restrictive retirement income vehicles, annuities and RRIFs, and

- made unused savings taxable as part of a deceased's estate.

It may have been preferable for some low or modest income earners to cash out an RRSP and pay the taxes at the front end, to give them greater certainty about their retirement income going forward. As McKay and Kempson (2003) have noted, the value from sense of agency or personal control over finances may, to a low or modest income earner, outweigh the cost of a transaction. Taking out their money in cash may have also been an attractive option for RRSP owners who felt uncomfortable or unwelcome in financial institutions catering more to the needs of upper-middle and upper-wealth clients. It is important to note that by 1975 , the federal government had ceased to sell the Government of Canada annuities (see discussion in Chapter 4) that had historically been popular alternatives to private sector annuities for lower and modest income Canadians. The requirement to choose between annuities or RRIFs would force all RRSP owners to make further choices in the private sector financial system when they retired. 
Finally, taxing the estate rather than the recipient may have had unintended consequences for low and modest income families. It is reasonable to assume that beneficiaries of estates would often have had substantially lower income and would have paid a lower rate of tax on the accumulated RRSP savings than if the estate were liquidated and taxes paid before assets were distributed. In this circumstance, the largest tax savings would certainly have gone to wealthier households. But as long as those same wealthy households had other resources and assets, the new estate taxes paid on the liquidated RRSPs may not have had severe consequences on the wellbeing of the beneficiaries. It is not possible, given the limited information available on household wealth, RRSPs and taxation for the time period, to retroactively determine with any certainty whether the changes were, objectively speaking, better for wealthy or poorer RRSP savers. However, from the record of the debate in the House of Commons and the Cabinet record of decision, it is clear the government the wellbeing of poorer and modest wealth households did not feature prominently in the deliberations of the government.

\subsubsection{The Homebuyer's Plan}

RRSPs had been introduced in 1957 as a relatively small program aimed at facilitating the retirement savings of self-employed professionals. By the 1970's the number of RRSP owners and the value of private RRSP savings had grown so large that the federal government saw RRSPs as an important lever for an unrelated macroeconomic goalincreasing domestic investment in Canadian enterprise (discussed earlier in this chapter). By the 1990's, it seems that the federal government once again regarded RRSPs as good vehicles to achieve other policy goals. Rather than create a policy for affordable 
homeownership or a policy to reduce the costs of leaving the workforce to return to school, federal governments created mechanisms to allow Canadians to borrow from their own RRSPs. The result may have been that RRSPs have become a sort of lifelong savings account in which money cycles in and out, rather than the long-term retirement savings instruments they were intended to be. Below, I discuss each the Homebuyer's Plan (HBP) and the Lifelong Learning Plan (LLP).

The HBP was created in the 1992 federal budget as a temporary measure in an economic recession by a government in a political slump. It is, however, still in place today. The program allows Canadians with RRSP savings a one-time repayable RRSP withdrawal, without penalty, of up to $\$ 20,000$ for use towards the downpayment on a home. ${ }^{128}$ The rules in the budget required that the RRSP had to be in place before February 28, 1992, the RRSP owner had to be a first-time homebuyer and the home purchase had to take place before March 31, 1993. As per the original 1992 announcement, HBP withdrawals must be repaid, but the repayments may be spread out over a number of years. Minimum repayments are calculated, without interest, as the total of the RRSP withdrawal divided over 15 years. ${ }^{129}$ Repayments do not receive any deduction against taxable income. If an RRSP owner misses a minim repayment in any year, that minimum amount is treated as a taxable withdrawal from his or her RRSP for that one year.

\footnotetext{
${ }^{128}$ For couples this cap applies to each member of the couple effectively doubling the total amount of the HBP loan to $\$ 40,000$.

${ }^{129}$ However, repayments can be accelerated and paid off as quickly as the RRSP owner wishes. Repayments under the HBP are not eligible for the deduction against taxable income.
} 
Nine months after announcing the HBP, the Finance Minister declared the program "an unqualified success", stating that 130,000 HBP withdrawals had been made by RRSP owners since the program's launch (Mazankowski, 1992). He announced that the program would be extended for another year but in fact it never expired.

The HBP remains in place, largely unchanged, to this day with two exceptions. The first is that the definition of qualified homebuyer has been expanded to included persons who have not owned their own home ${ }^{130}$ for at least the last 5 years (CRA, 2013b). The second is that, as part of the 2009 "Economic Action Plan", the federal government increased the maximum withdrawal limit under the HBP to $\$ 25,000$ for each eligible RRSP holder.

There are likely at least two explanations for why the government decided to take this unprecedented step to open the use of RRSPs for purposes other than retirement. The first is that the Opposition Liberals had dared them to. ${ }^{131}$ In 1992, the Progressive Conservative government was sitting a distant third in public opinion polls and knew that

${ }^{130}$ This also include those whose married or common-law spouse has not owned a home in the last 5 years.

${ }^{131}$ By at least as early as February 14, 1992 (11 days before the budget), Liberal M.P. David Kilgour spoke in the House of Commons to ask the government to adopt the Liberal proposal to allow Canadians to borrow up to $\$ 7,500$ from their RRSPs to buy homes as first-time buyers (Hansard, February 14, 1992). The dare was repeated regularly by Liberal caucus members in the lead-up to the budget (Hansard, February 17, 1992). 
it would have to face election the following year. ${ }^{132}$ Adopting an idea from an Opposition party would remove at least one potential election platform idea from their electoral competitors.

But likely a more important driver was a desire to find inexpensive stimulus for a slumping economy. In 1992 Canada was in a recession and saddled with substantial federal deficits. The 1992 budget was largely crafted as a cost-cutting and economyboosting package of policy measures. Between 1987 and 1992, new housing starts had steadily declined (CHMC, 2006). Other indicators also suggest that the housing market was in decline, including falling average housing prices and volume of housing sales. Stimulating demand for housing, particularly among first-time buyers, was seen by the government and Opposition, as one way to stimulate the economy. ${ }^{133}$ By using existing RRSP capital, it also meant that the stimulus would come with no new direct cost to the government. In the government's "Budget Papers" for 1992, it noted that the "estimated revenue costs of this measure were small" (Department of Finance, 1992). In short, it was housing policy and macroeconomic stimulus based on encouraging private citizens to use their own money. This echoed the past examples from wartime compulsory savings and the redirection of RRSP for domestic investment goals.

There are two primary questions for a retroactive analysis of the HBP program. The first is whether it had the desired effect in stimulating the housing sector of the economy.

${ }^{132}$ Canadian Gallup Poll, May 1992

${ }^{133}$ Hansard Debates, House of Commons, February 17 and February 26, 1992. 
Looking at the housing market data for the early to mid 1990's, it is difficult to see any noticeable effect from the introduction of the HBP. New housing starts did rise a little in 1992 but then fell in 1993, stayed the same in 1994 and plummeted in 1995 (CMHC, 2006). Similarly the volume of housing sales rose in 1992 over 1991 levels, but the growth had been larger between 1990 and 1991 and the volume followed the same pattern as new starts, falling in 1993 over 1992 levels, stagnating in 1994 and plummeting in 1995.

The second question regarding the net benefit of the HBP is whether the costs were as small as projected by the government. Using the strictest costing criteria, the HBP does result in a loss of tax revenue in each year that a borrowed amount remains unpaid by a taxpayer since this would normally be a taxable withdrawal. But because the withdrawal under the HBP is repayable and repayments are not eligible for any new deduction against taxes, it is likely that the government projected the cost of the program at or near $\$ 0$.

According to Steele (2007), the HBP costs in foregone tax revenue were actually between $\$ 144$ million and \$283 million annually in 2006. Steele's analysis included the case where RRSP contributions, the HBP withdrawal and the HBP repayment all took place over a period in which the RRSP owner's marginal tax rate remained unchanged. If the repayments took place after the HBP borrower's income and marginal tax rate had increased, then the estimated foregone tax revenue increased to $\$ 283$ million. As Steele noted, this was more than the federal government spent in 2006 to reduce homelessness. 
Steele's analysis acknowledged but did not include returns to the RRSP owner from gains in the value of the purchased home. As noted throughout this thesis, a principal residence has always been excluded from the calculation of income tax in Canada. When the capital gains tax was introduced in 1971, owner-occupied residences were explicitly and deliberately excluded from the new tax, in contrast to the practice in the US of taxing (allowing for substantial exclusions) gains realized on a principal residence when the house is sold. ${ }^{134}$ It is also in contrast to practice in many European countries of taxing some imputed market rate of rent the homeowner would other have paid to live in a comparable property (Echevin, 2013). In the case of the HBP, there is a cost arising out of the RRSP contribution towards the homebuyer's equity in a new home that is never recovered by the federal government. The HBP increases the equity of the household in the primary residence by reducing the amount of mortgage debt, the cost of mortgage insurance (if applicable), ${ }^{135}$ and indirectly by improving the mortgage rate available to the homeowner. ${ }^{136}$ Although there is a notional debt the household owes to his or her

\footnotetext{
${ }^{134}$ The current exclusion rates on the gains realized on the sale of a home are USD $\$ 250,000$ for each owner or USD $\$ 500,000$ for a couple. At such a high exclusion rate, it is unlikely that many homeowners would be subject to the tax. However, capital losses on the sale of a home cannot be deducted against taxes and, while a homeowner maintains a mortgage, mortgage interest paid is deductible, making the tax treatment of housing the US quite regressive.

${ }^{135}$ Mortgage insurance is required for all purchases of residential real estate with a downpayment of less than $25 \%$ of the total purchase price. Mortgage providers will generally roll the one-time insurance premium into the total mortgage issued. ${ }^{136}$ Mortgage rates offered by lenders have to ensure a return relative to the risk associated with borrowing. All other factors being equal (including purchase price, credit ratings, household income and the assessed property value), when downpayments are
} 
own RRSP, the debt is spread over 15 years, while the capital is immediately available as equity in the new home. The gains are larger for households with higher marginal tax rates who buy more expensive houses. An illustrative example is included at Box 1 (below). All else being equal, I find that a couple with $\$ 150,000$ in taxable income save $\$ 2,000$ more in federal taxes on the same HBP withdrawal as couple with $\$ 75,000$ in taxable income.

\section{Box 1: Illustrative example of the household benefits from the Homebuyer's Plan (HBP) under two conditions of household income}

A couple uses the Homebuyer's Plan to withdraw \$50,000 from their Registered Retirement Savings Plans - based on the current maximum limit for couples. They use the money towards a house costing $\$ 300,000$ with a mortgage of $4.24 \%{ }^{1}$ Assuming a $\$ 75,000$ household taxable income and 2013 federal income tax rates, ${ }^{1}$ in the year they withdraw from their RRSP, their total federal taxes payable will be $\$ 13,450$ before any other credits or deductions. Had they paid taxes on the RRSP withdrawal, they would have owed $\$ 25,966$ in federal taxes, an increase of \$12,516 in federal taxes alone. This also does not include any tax savings from splitting the withdrawal unevenly if one spouse in the couple has a substantially higher income than the other.

Even if the couple has no other capital to use as a downpayment, the equity of $\$ 50,000$ at the mortgage rate of $4.24 \%$ generates an imputed rental income of $\$ 2,120$ that would otherwise lead to an increase of $\$ 466$ in federal taxes payable. Combining the value of the savings on the imputed rental income and shelter on the RRSP withdrawal, the couple will have saved $\$ 12,982$ in federal taxes in the first year of homeownership. As the couple's equity in the home increases, due to any combination of paying down their mortgage or increases in the market value of the property, that tax savings on the imputed rental income increases and, if their household income increases, that tax benefit is accelerated. The couple continues to avoid paying taxes on the RRSP withdrawal as long as they deposit at least $\$ 3,333$ a year back into their RRSPs in each of the next 15 years.

For comparison, if a couple with a combined income of $\$ 150,000$ were to make the same RRSP withdrawal, they would save $\$ 14,5000$ in federal taxes in the first year of homeownership would have the same repayment of $\$ 3,333$ per year for 15 years to repay their HBP loan. 
The cost of foregone taxes due to the HBP would be reduced somewhat by any taxes paid on missed repayments. According to the Canada Revenue Agency, approximately 35\% of the repayments due annually under the HBP are missed each year. ${ }^{137}$ According to the most recent published data (published 2010 for the 2008 tax year), among taxpayers under age $45,{ }^{138}$ HBP repayments were just $5.4 \%$ of the total of HBP balances, $1.27 \%$ below the rate needed to keep up with the 15 -year repayment schedule. Looking at an earlier time period, 2001 to 2003, Steele finds a similar gap in the expected versus actual repayment rate and notes that repayment rates are highest among upper income earners at $11 \%$ among taxpayers (under age 45 ) with incomes of $\$ 100,000$ or more and just $4.1 \%$ for taxpayers earning between $\$ 20,000$ and $\$ 30,000$.

A review of the most recent data suggests that, while overall annual repayment rates are lower than in 2003, they are still substantially higher (and certainly above the minimum $6.7 \%$ required to avoid incurring a tax liability) for the highest income earners. ${ }^{139}$ As a

${ }^{137}$ CRA data for 2012 cited by Robert McLister (2013) "Disapointing new stats on the RRSP Home Buyer's Plan", Canadian Mortgage Trends, website. Posted February 5, 2013. Available on-line at: http://www.canadianmortgagetrends.com

${ }^{138}$ Although peak RRSP contribution years take place after age 45, most first time buyers are likely to be under age 45 and taxpayers under age 45 make up two-thirds of all taxfilers with an HBP balance.

${ }^{139}$ Author's calculation based on CRA data for 2010 tax year, "Income Statistics, T-1 Final Statistics". 
program to mobilize tax-preferred savings, the HBP appears to be a better program for higher income Canadians.

As of December 2012, over $\$ 27.9$ billion has been withdrawn from RRSPs under the HBP, used by a little over 2.5 million Canadian homebuyers since the program was launched in 1992 (McLister, 2013). But to date, the government has published no evaluations to determine whether or not the HBP does increase rates of homeownership or, as per the original 1992 policy intent, has a stimulating effect on the country's housing industry.

The review above supports Steele's (2007) conclusion that the policy gives substantially more benefit to higher income users. What began as a temporary and politicallymotivated policy measure in 1992 has become an entrenched part of the RRSP framework. This is all despite evidence that the program gives greater benefit to higher income earners and seemingly no evidence for a positive effect from the program on rates of homeownership or the Canadian housing market.

Like the HBP, the Lifelong Learning Plan (LLP) has also become part of the RRSP framework, despite a lack of evidence for a positive impact from the program. I discuss the LLP in the following section.

\subsubsection{The Lifelong Learning Plan}


The Lifelong Learning Plan (LLP) was announced in the 1998 federal budget by then Finance Minister Paul Martin. The LLP is similar in many respects to the HBP-not surprising since it was modeled on the HBP (HRDC, 1994). Like the HBP, it offers RRSP owners a tax-free withdrawal from their RRSP savings that is repayable over a 15year period. Like the HBP, the maximum LLP withdrawal is capped. However, while the HBP has a lifetime limit of $\$ 25,000$, the LLP has a lower total cap of $\$ 20,000$. LLP users can withdraw up to $\$ 10,000$ in a single year and can spread their tax-free withdrawals over four consecutive years. LLP amounts can be withdrawn from the RRSP owner's personal RRSP and from his or her spouse's RRSP as well — to a total of $\$ 20,000$ per couple (CRA, 2013).

To be eligible an RRSP owner must, with some limited exceptions, ${ }^{140}$ be enrolled in a full-time post-secondary education program - including university, college and other designated post-secondary education (PSE) providers such as private vocational training institutes. Amounts withdrawn under the LLP only become repayable once the student leaves the full-time program or five years after the fist LLP withdrawal. Minimum repayments are spread evenly over a ten-year period and, like the HBP, missed annual minimum repayments are taxed as an RRSP withdrawal for that single year only.

${ }^{140}$ Students with disabilities may use the LLP for part-time studies. Their disability status has to be directly or indirectly (by claiming the disability tax credit which itself requires medical certification) certified by a medical doctor. 
There have been no published studies or reviews of the program and the CRA does not include it, in contrast to the HBP, in its annual tax statistics reports, suggesting the numbers must be so low as to be negligible. The 2008 Canadian Survey of Financial Capability did ask respondents who reported a pre-retirement RRSP withdrawal if the withdrawal had been under either the HBP or LLP. ${ }^{141}$ Overall, $22.8 \%$ of households reported having ever taken money out of their RRSP for reasons other than their retirement income. Among those, just 3.2\% (or $0.73 \%$ of RRSP owners) reported that they had withdrawn money under the LLP. With the exception of households in the second income quintile, ${ }^{142}$ rates of LLP use rise with household income. However, the magnitude of the difference is very small. Table 5.1, below, presents data from the Canadian Survey of Financial Capability on the percentage of households (by household income quintile) who reported using the LLP.

Table 5.1 Rates of self-reported RRSP withdrawals under the Lifelong Learning Plan as a percentage of all households with non-retirement RRSP withdrawal by household income quintile, 2008.

\begin{tabular}{|c|c|c|c|c|}
\hline Bottom 20\% & $\mathbf{2 1 - 4 0 \%}$ & $\mathbf{4 1 - 6 0 \%}$ & $\mathbf{6 1 - 8 0 \%}$ & Top 20\% \\
\hline 1.8 & 3.3 & 2.5 & 3.2 & 3.2 \\
\hline
\end{tabular}

\footnotetext{
${ }^{141}$ The Canadian Survey of Financial Capability was a survey of 15,000 Canadian households conducted by telephone in 2008 by Statistics Canada. The survey covered questions about household income, net worth, financial practices, knowledge and attitudes. Results reported here were calculated using the Public Use Microdata File accessed through ODESI.

${ }^{142}$ For the CSFC, the second quintile for household income corresponds to those reporting between $\$ 32,001$ and $\$ 54,999$ in total annual household income.
} 
The data in the table above suggest that the LLP is a program that almost no one in Canada uses. This is not surprising. First, consider that rates of participation in formal education among working-age adults is very low, estimated at just $7 \%$ of Canadians aged 25 years and older and in the labour force (Drewes, 2008). Second, those working age Canadians who do take part in formal education or training are more likely to take part in short-term, or part-time and job-related programs (Knighton, Hujaleh, Iacampo \& Werneh, 2009), programs that would not qualify for the tax-sheltered LLP withdrawal. The fact that there was likely to be little demand for the LLP does not appear to have been an impediment to its creation.

The concept of a tax-sheltered withdrawal from RRSPs to support mid-career education and re-training was first proposed in Canada in a federal government policy green paper. "Improving Social Security in Canada: A discussion paper" was released in October of 1994 by the then Minister of Human Resources and Skills Development, Lloyd Axworthy. ${ }^{143}$ The paper was intended to propose a number of reforms to federal social policy and invite public reaction and comment. On post-secondary education, the paper contemplated a package of potential reforms including a reduction in the cash transfers to provinces, new direct grants and income-contingent loans for students and "at the same time, increasing flexibility in RRSPs [...] to use personal savings for lifelong learning” (p.63). Such a new education program attached to RRSPs, could, the report suggested, be

\footnotetext{
143 The author worked as a junior member of Axworthy's staff periodically between 1993 and 1995. She also worked in the Office of the Prime Minister between 1995 and 1997 and as an advisor to the Minister of Intergovernmental Affairs. Some of the information in this chapter is based on the author's own recollections.
} 
based on the HBP and would be aimed at "mid-career boot-strappers keen to up-grade their skills" (p.63). The paper also noted that, within the overall package of reforms to education funding, the RRSP withdrawal option would "also reinforce the idea of encouraging mutual responsibility among Canadians for managing a greater share of their own social security" (p.63).

The government did not act on many or indeed most of the policy options in the green paper. In the immediate aftermath of the green paper, the government launched a wave of significant cuts to spending and transfers, beginning with the 1995 federal budget and continuing through 1996 and 1997.

After several years of cost-cutting budgets, the 1998 budget was the first federal budget to project a federal surplus. The Finance Minister, Paul Martin, had decided it would be a thematic and so-called 'good news' budget, with increases in federal spending on some area of policy that was top of mind for Canadians. With the economy emerging from recession and jobs declining as the key concern for most voters, healthcare and education appeared to be politically fruitful areas for new federal spending. Compared with health care, the federal government has a greater opportunity to use direct transfers to individuals to make policy change in higher education. For a first 'good news' budget, a package of education-oriented measures would have been easier to implement.

Officials in the department, political aides and paid consultants were tasked with developing a policy framework and narrative around education, skills and the knowledge 
economy (Martin, 2008). The narrative component of the budget was key for Martin. He wanted a budget with a compelling and coherent story to communicate. There was already widespread agreement in the policy discourse that Canada was in transition to a knowledge-based economy in which higher skills, education and innovation were key to global competiveness and productivity. Political and bureaucratic policy advisors in Finance and the Prime Minister's Office were keen to find policy options that would demonstrate federal leadership without treading on provincial jurisdiction.

On education, the "Canadian Opportunities Strategy" of the 1998 federal budget included a range of changes to federal student loans, new targeted grants for students, incentives to help families save for a child's education (discussed in Chapter 6) and the LLP withdrawals from RRSPs. These were described in the budget as a set of policy measures that would deliver some federal support for learning from childhood through to working age adulthood (Finance Canada, 1998).

The 1994 green paper would have been familiar to many of officials working on proposals for the budget and indeed some advisors had themselves been part of the 1994 social security review exercise. The LLP option was not included in the 1998 budget because it was the best policy option among many for working-age learners. It was included, it seems, because it was available and filled a place for a policy for adult learners. 
The cost of the tax-free withdrawals from RRSPs under the LLP was estimated, in the 1998 budget, at $\$ 15$ million for the $1998-99$ fiscal year, rising to $\$ 45$ million by $2000-01$. Given the data, described above, on LLP use, the projected take-up was well above what has transpired in practice. It is doubtful whether it has had a meaningful impact on rates of participation in adult formal education and training. If very few Canadians ever use the LLP, then the costs of the program on top of the costs of RRSPs would be small or negligible.

One impact of the LLP may be on consumer withdrawals from their RRSP. I believe that the LLP, but particularly the HBP, have made RRSP withdrawals more acceptable to Canadian consumers, even when these withdrawals are taxable.

Looking at data for 1991, prior to the introduction of either the HBP or the LLP, Frenken and Standish (1994) found that over 600,000 RRSP owners under age 65 had withdrawn a total of $\$ 3.2$ billion from their RRSPs. They estimated that one quarter of the cases and one third of the dollars withdrawn could be explained by early retirement before the age of 65 . But, $55 \%$ of the withdrawals and $42 \%$ of the $\$ 3.2$ billion total was taken out by Canadians under the age of 45 .

According to data published by the Canada Revenue Agency, taxpayers under age 45 withdrew \$2.1 billion from their RRSPs in 2008 (excluding sheltered HBP and LLP amounts), making them responsible for $23 \%$ of all RRSP withdrawals among all Canadians, including those near or above retirement age (CRA, 2010). 
Mawani and Paquette (undated) looked at RRSP withdrawal data from 1998 to 2003 for pre-retirement taxfilers ${ }^{144}$ and concluded that missing HBP repayments was responsible for the RRSP withdrawal in $40 \%$ of the cases, a finding consistent with the abovementioned data on missed HBP annual repayments. However, it appears, from selfreported data, that a substantial share of the pre-retirement withdrawal activity is taking place outside of the HBP and LLP altogether. The Canadian Survey of Financial Capability found that, among the $22.8 \%$ of households who reported ever making a preretirement RRSP withdrawal, a strong majority (66.8\%) said it was outside of the HBP or LLP. What the HBP and LLP withdrawal mechanisms may have done, inadvertently, is to help normalize withdrawals from RRSPs that are not for retirement income. If this is true, it changes the nature of the instrument from a long-term deduction and deferral model to a more fluid, medium-term savings vehicle.

Yet, while very few Canadians ever use the LLP program, it has not been cancelled. Like all of the incremental changes to the original RRSP design that have been reviewed in this chapter - spousal contributions, ongoing increases to annual contribution limits, rules on annuities and RRIFs and the HBP — once in place, the LLP has become part of the fabric of RRSPs as a tax-preferred savings instrument. As RRSPs have evolved ever

\footnotetext{
144 Their study defined the pre-retirement age group as those aged 25 to 59 . This definition may include too many Canadians between ages 55 and 59 who are in fact retired or semi-retired. As a result, their analysis of the effects of the HBP may be an underestimation.
} 
further from their original design, these new features have become embedded parts of the instrument itself, resistant to cancelation or change.

\subsubsection{Concluding thoughts on the RRSP}

What began as a small, boutique program to support the retirement plans of a subset of self-employed professionals seems to have become, through relentless incrementalism, a multi-purpose tax-benefitted savings vehicle. Yet the RRSP retains enough of its original design, magnified by several decisions along the way, to be a program that disproportionately benefits the already well-off. In Table 5.2 below, I repeat some of the data from Table 4.1 on the earliest take-up of RRSPs in 1957-58 and compare these to the most recent data available.

Table 5.2 Value of RRSP deductions, selected years and selected tax-filer characteristics (\$ millions, unadjusted)

\begin{tabular}{l|ccc} 
Tax year & 1957 & $\mathbf{1 9 5 8}$ & $\mathbf{2 0 0 9}$ \\
\hline $\begin{array}{l}\text { Total deductions } \\
\begin{array}{l}\text { Deductions claimed by } \\
\text { self-employed } \\
\text { professionals }\end{array}\end{array}$ & $\$ 270^{*}$ & $\$ 19$ & $\$ 33,000$ \\
$\begin{array}{l}\text { \% of total deductions } \\
\text { claimed by self-employed } \\
\text { professionals }\end{array}$ & $2.6 \%$ & $41.1 \%$ & $4.2 \%$ \\
$\begin{array}{l}\text { Deductions claimed by } \\
\text { highest category of } \\
\text { income earners for that } \\
\text { tax year }\end{array}$ & $\$ 8.1$ & $\$ 1,400$ \\
$\begin{array}{l}\text { \% of total deductions } \\
\text { claimed by highest } \\
\text { income filers }\end{array}$ & $3 \%$ & $26.8 \%$ & $21.5 \%$
\end{tabular}


*Includes amounts for both RRSP and pension deductions, not reported separately in the report for the 1957 tax year. 'Using the highest income category reported for that year's Taxation Statistics Report. In 1957 and 1958, the highest income category reported was $\$ 25,000$ or more. In 2009 , it was for those reporting $\$ 150,000$ or more a year in income. In all years, this category corresponds to between the richest $1 \%$ and $4 \%$ of all tax-filers for that year.

Source: Author's calculations using data in Annual Taxation Statistics reports from 1959, 1960, Supply and Services Canada, Ottawa and Annual Taxation Statistics reports from 2011, Canada Revenue Agency, Ottawa.

When the tax-preferred RRSP instrument was first created in 1957, it seems to have met its goal of reaching self-employed professionals without pensions. Today self-employed professionals make up a very small share of tax filers claiming an RRSP deduction. The relative share of very high-income tax-filers (those in the top $1 \%$ to $4 \%$ of all annual tax filers) among those claiming the deduction has changed very little. The dollar values in Table 5.2 above are nominal. When these are adjusted for inflation (not shown), the value of all RRSP deductions claimed in 2009 is 222 times larger than in 1957. The value of the instrument is vastly larger today than was likely ever contemplated by its original designers.

The incremental changes over time have:

- Reinforced the key role of private sector financial providers in the marketing of RRSPs, the administration of accounts and the transfer into other financial products, annuities or RRIFs, in retirement. The complexity of RRSP rules now also means that the technical expertise of the financial sector is more valuable than ever before.

- Enhanced the tax benefit of the RRSPs, particularly for wealthier Canadians, by escalating, in perpetuity, contribution limits even when the majority of Canadians are not responsive to these changes. 
- Made RRSP capital more fungible by creating tax-sheltered mechanisms for certain kinds of withdrawals, through the HBP and LLP.

- Sanctioned only selected savings goals — retirement, purchasing a home and returning to education - that would likely already be of interest to wealthier Canadians but may not reflect the savings goals or motives of lower-income and lower-wealth Canadians.

The RRSP was the first tax-preferred account-based savings instrument in Canada after the failed compulsory savings experiment in wartime. It cast the mold on which all of the other tax-preferred savings instruments have been based-either exactly replicating features of the RRSP or making incremental changes in contrast to it. It is an instrument that many Canadians now own whose complexities likely few fully understand.

Politically speaking, RRSPs offer a model on which other new instruments can be based, allowing these new replicas to be more easily communicated by policymakers and accepted by the general public as familiar. But it also means, politically, that fundamental change to the instrument or even cancelation is difficult to contemplate because so many Canadians would be affected and in ways that would be difficult to communicate.

Finally, it is noteworthy how frequently federal governments used policy change on RRSPs as an avenue to mobilize private household savings for some macroeconomic policy goal—stimulating domestic investment, reducing projected fiscal strain to government and stimulating an economy in recession. The microeconomic effects of 
RRSPs were sometimes mentioned, but almost never with attention to the difference in impacts on poorer households.

In the next section I discuss the next tax-preferred account-based instrument to have been created, the Registered Homeownership Savings Plan.

\subsection{The Registered Homeownership Savings Plan 1974-1985}

Before the Home Buyer's Plan to allow tax-free withdrawals from RRSPs, the Government of Canada experimented with a variety of ways to promote homeownership among Canadians. It was a contentious area of public policy. In 1968, Paul Hellyer, then Minister of Transportation, was asked to lead a national task force on housing. His recommendations for a more active and direct federal role in local housing (Hellyer, 1969) ultimately led to his resignation from the Trudeau government a few months later. $^{145}$

Throughout the 1970s, the federal government launched a number of experiments in housing, in directions largely contrary to Hellyer's report. For example, the Trudeau government amended the National Housing Act to allow the Canada Mortgage and Housing Corporation (CMHC) to offer low-cost loans for the construction of new housing (Moscovitch \& Germain, 2006). Soon after, CMHC also introduced mortgage

\footnotetext{
${ }^{145}$ For example, Hellyer recommended that the federal government engage directly with municipalities on the construction of subsidized rental housing, skirting the authority of provincial governments. Trudeau disagreed on this as well as other recommendations, pursuing a very different policy direction on housing.
} 
subsidies targeted to modest income households who earned too much to qualify for lowcost public housing but too little to be able to qualify for a conventional mortgage with a private lender. As Moscovitch and Germain noted, the program (referred to as the Assisted Homeownership Program or AHOP) was gradually and incrementally changed to expand eligibility and eventually became a housing subsidy for middle-income Canadians instead of those in greater need. ${ }^{146}$ In a context of spiraling inflation, the program was eventually declared a failure and many homeowners found themselves unable to keep up with their mortgage payments but also unable to sell their homes. Many owners abandoned houses they had had so hopefully bought as their homes.

CMHC's program never deviated from a requirement that eligible households have a minimum down-payment of at least $5 \%$ of the purchase price of the qualifying home. But none of the agency's programs provided any assistance to the low and modestincome target clients to save and accumulate that downpayment. In 1973 through 1975, the average purchase price of houses under the CMHC program was just under $\$ 25,000$. A 5\% or larger down payment would have required a household to save or otherwise

\footnotetext{
${ }^{146}$ Moscovitch and Germain describe a series of policy changes throughout the AHOP lifespan that gradually moved eligibility from households only at or near average incomes to households well above average income levels. Similarly, the original mechanism to reduce the costs of mortgages for qualifying households was a grant. In 1975 the grant was replaced with a five-year decreasing loan so that the amount of mortgage relief would be reduced in a step-wise fashion in each of the first five years of homeownership and would then be repayable in full to CMHC or could be refinanced in a second loan or mortgage on the same house.
} 
accumulate a downpayment of at least $\$ 1,250 .{ }^{147}$ While there is no mention of a link to the Assisted Homeownership Plan in the 1974 budget or the Parliamentary debates on a new housing savings plan, it seems reasonable that the government may have been keen to find ways to fill a gap in their housing policy framework. A program to promote saving for homeownership would have both accelerated the ability of AHOP-eligible households to build up the needed downpayment and have offered something to households who would not qualify for AHOP assistance.

In the May 1974 budget the government announced that it would create a new Registered Homeownership Savings Plan (Finance Canada, 1974). The new RHOSP would be available to all taxpayers over the age of 18 who were not already homeowners. Each RHOSP holder would be able to contribute up to $\$ 1,000$ per year to a lifetime maximum of $\$ 10,000$ and to deduct annual contributions from their taxable income, similar to an RRSP. ${ }^{148}$ The accounts would be available from financial institutions already authorized to sell RRSPs. Interest earned in the plan would, like RRSPs, be exempt from taxation. Unlike an RRSP, RHOSP funds would not be taxed as long as they were used to buy a home or essential furnishings for the home- such as appliances and furniture. The budget provided no information on how compliance on withdrawals would be monitored except to insist that RHOSP owners had to be resident in Canada, could only open one

\footnotetext{
${ }^{147}$ Outside of saving, downpayments might also come from gifts, inheritances or the sale of some other asset to give a few examples.

${ }^{148}$ Adjusting for inflation, \$1,000 would be equivalent to \$4,927 dollars in 2013 and $\$ 10,000$ would be equivalent to $\$ 49,277$ (calculations using Bank of Canada "Inflation Calculator", based on Statistics Canada series V41690973).
} 
plan in their lifetime, and must withdraw all funds, or transfer unused balances to an RRSP, on termination.

In the budget debate that followed, two Opposition M.P.s raised the RHOSP to criticize it. Marcel Lambert, Progressive Conservative M.P. for Edmonton West and critic for tax policy and economic affairs asserted that the RHOSP was just "thrown out as something novel as though it were going to do something big" (Lambert, 1974). He criticized the annual and lifetime maximums as "practically meaningless". In contrast, David Lewis, the leader of the New Democratic Party asked "how many young Canadian couples make the kind of income that would enable them to save $\$ 1,000$ a year? The Minister ought to have looked into that" (Lewis, 1974). For the Conservatives, the RHOSP was too small, for the NDP it was too large, but both parties regarded it as a "gimmick" (Lewis, 1974). The Government lost the confidence of the House over the same budget but was returned, and with a majority, following the summer election. The November 1974 budget was for all intents the same as the May version and repeated the proposal for the RHOSP. There was no further mention of the RHOSP in Parliament or the national media until the March 1977 federal budget.

In that budget, the new Minister of Finance, Donald MacDonald, announced that since the policy had been introduced, over 400,000 RHOSPs had been opened (MacDonald, 1977). While celebrating the robust take-up of its new policy, the government expressed concern that some families may have used the RHOSP to shelter money in the name of a spouse or adult child. For example, if a husband and wife lived in a marital home, the 
title to the house may not be registered in the wife's name. In this case, the wife was not prevented from opening an RHOSP, claiming annual deductions and then rolling-over the account into an RRSP, or perhaps, purchasing a second or vacation home. The RHOSP had created an unintended loophole that allowed certain couples to maximize their tax benefit for certain forms of saving. The government aimed to close the loophole by introducing a series of new rules.

As of the 1977 federal budget, spouses of a homeowner were no longer eligible to use the RHOSP and unused RHOSP funds could no longer be rolled-over into an RRSP. The budget also announced that furnishings were no longer eligible uses of RHOSP withdrawals. Presumably this would have been among the most administratively difficult aspects of the original program to police and it is likely that fraudulent or at least noncompliant uses were common. The budget also created a new 20 -year maximum time limit to use all RHOSP balances but promised unspecified relief for RHOSP account owners who might cross that time limit and be forced to close their account without purchasing a home. The program remained in place, unchanged, until it was cancelled in the federal budget of 1985 .

\subsubsection{Analysis of the household effects of the RHOSP}

A retrospective analysis of the effects of the program requires some examination of the population of RHOSP beneficiaries. Englehardt (1997) used data from the 1978, 1982 
and 1984 Survey of Family Expenditure ${ }^{149}$ to construct a probit model estimating RHOSP use. He found that employment, education and residence in Ontario were all positively associated with RHOSP use. However, these variables are also each associated with higher marginal tax rates, either through increased income or provincial differences in taxation. Englehardt concluded that the marginal tax rate was the important explanatory variable. Using a model that presumed income is related to marginal tax rates in a linear way, Englehardt found that each $10 \%$ increase in marginal tax rates was associated with a 3.7\% increase in RHOSP use. After adjusting the model to reflect a non-linear relationship between income and marginal tax rates, Englehardt's estimate of RHOSP take-up increased: for every $10 \%$ increase in marginal tax rate, RHOSP use rose by $4.2 \%$.

Englehardt also estimated the effects of the RHOSP on the transition of households from renting to homeownership by comparing the differences in the transitions of both low marginal tax rate and high marginal tax rate households before the program was cancelled (for the years 1978, 1982 and 1984) and after the program was cancelled (using data from the same survey for 1986). High marginal tax rate households had higher rates of transition from renting to owning, compared to low marginal tax rate households, during and after the program. This is unsurprising given that the higher marginal tax rate is likely, in most cases, to imply greater financial resources (both income and capital) needed to facilitate a home purchase. Englehardt estimated that the difference in the rates

\footnotetext{
${ }^{149}$ The survey was conducted periodically by Statistics Canada to examine the income and consumption patterns of Canadian households. It was terminated in 1997 in favor of a new Survey of Household Spending. The years included in Englehardt's study are the only ones available during the lifetime of the RHOSP program.
} 
of tenure transitions between low and high marginal tax rate households was $3.3 \%$ larger than after the program was terminated. Dividing this by the mean increase in tenure transitions for RHOSP holders (1.65\%), Englehardt estimated that the RHOSP raised overall rates of transition to homeownership by $20 \%$. Englehardt arrived at similar estimates using the marginal effects (the differences between during and after-program transition rates) for RHOSP contributors at the mean marginal tax rate. His data, however, made clear that much of this result is driven by RHOSP-holders with higher marginal tax rates - hence, his estimates of the marginal effects rose with income bracket.

Another way to look at the use of the program is to again look at the annual tax statistics published by the Canada Revenue Agency and its predecessors. Table 5.3 (below) summarizes the data on annual RHOSP deductions claimed in the first and last two tax years of the RHOSP program to provide some indication of the size of the program and the distribution of the short-term benefits during its lifetime.

Table 5.3 Data on RHOSP deductions selected years (\$ millions, unadjusted)

\begin{tabular}{l|ccc}
\hline \multicolumn{1}{c|}{ Tax year } & $\mathbf{1 9 7 5}$ & $\mathbf{1 9 8 4}$ & $\mathbf{1 9 8 5}^{\mathscr{H}}$ \\
\hline $\begin{array}{l}\text { Total RHOSP deductions claimed } \\
\text { (unadjusted) }\end{array}$ & $\$ 364$ & $\$ 483$ & $\$ 128$ \\
$\begin{array}{l}\text { Total claimed by highest income filers* } \\
\% \text { of total claimed by highest income }\end{array}$ & $\$ 5.4$ & $\$ 14.5$ & $\$ 7.6$ \\
$\begin{array}{l}\text { filers } \\
\text { Total claimed by low to average income }\end{array}$ & $\$ 102$ & $3 \%$ & $\$ .9 \%$ \\
filers* & & $\$ 108$ & $\$ 77$ \\
$\begin{array}{l}\% \text { of total claimed by low to average } \\
\text { income filers }\end{array}$ & $28 \%$ & $22.3 \%$ & $60 \%$ \\
\hline
\end{tabular}

*Taxfilers with $\$ 50,000$ or more in income in 1975 and 1984 or the top $2 \%$ of taxfilers. 
**Taxfilers with up to $\$ 10,000$ in income in 1975 , up to $\$ 16,000$ in 1984 and up to $\$ 20,000$ in 1985 or those at or below the to $55^{\text {th }}$ percentiles of taxfilers.

Hata for 1985 would include only the partial tax year leading up to the federal budget in May.

Source: Author's calculations using data in the Annual Tax Statistics, 1977, 1986 and 1987, Supply and Services

Canada.

The data above suggest that, compared to the RRSP, the RHOSP take-up was far less skewed towards the very wealthiest tax-filers. It is probable that many high-income tax filers already owned a home and so were ineligible to open and contribute to an RHOSP.

The data above are reported without adjustments for inflation making it difficult to see the overall trends for each group in dollar terms. ${ }^{150}$ However, as a proportion of the total dollars deducted in contributions to the new tax-preferred savings instrument, the RHOSP shows a slight decline for low and moderate income taxfilers between 1975 and 1985, from $28 \%$ to $22.3 \%$ of all deductions. The sudden increase in the share of RHOSP deductions claimed by low and moderate income taxfilers in 1985 may have more to do with the timing in the calendar year. The program was cancelled, effective at the end of the month of the 1985 federal budget, May 1985. If low and moderate-income Canadians were using it actively as a savings instrument, they may have been making regular contributions throughout the year. By contrast, if for high income taxfilers the RHOSP was simply a way to shelter left-over income, then it is possible that more of their contributions would have come closer to the end of the tax year.

\footnotetext{
${ }^{150}$ Between 1975 and 1984, the first and last full years of the program's lifespan, contributions by low and moderate income Canadians increased $\$ 6$ million in nominal terms but actually fell dramatically in real terms. To keep up with inflation alone, contributions by the same group in 1984 should have been $\$ 218$ million. By contrast, the contributions by the richest income earners rose $\$ 2.9$ million in real terms. Adjusting for inflation, \$5.4 million in 1975 would be equivalent to \$11.6 million in 1984 terms (Bank of Canada Inflation Calculator based on Statistics Canada series V41690973)
} 
It is clear from the data in the table above, alongside the analysis conducted by Englehardt (1997) that modest income Canadians did make use of the RHOSP, and that very high income Canadians used the RHOSP proportionally much less than the RRSP.

\subsubsection{Analysis of the political impact of the RHOSP}

It is perhaps ironic that the policy problem — housing affordability — to which the RHOSP had been directed, soon dissipated after the policy instrument was created. In fact, after the sharp increases in much of the 1970s, housing prices peaked in 1980 and then fell dramatically, particularly in the Prairies (UBC, 2013). When the Progressive Conservative government came to power after the 1984 election, their new Minister of Finance, Michael Wilson, announced the RHOSP would be terminated in his first budget, delivered in May 1985.

Wilson's speech listed the RHOSP last in a series of small but cumulative measures that were framed, on top of reviews to program spending and larger changes to personal and corporate income taxes, as deficit-reduction measures. In fact, the RHOSP cancellation was the last spending or revenue change announced in the 1985 budget, suggesting that the government felt it would be non-controversial, allowing it to position more politically problematic measures, such as a new federal minimum income tax, in the middle of the public announcement. The Minister projected that eliminating the RHOSP would save the government $\$ 80$ million in the next fiscal year, possibly an underestimate given the total value of the deductions claimed in 1984 (see Table 5.3, above). 
Wilson assured RHOSP holders that, despite the cancellation of the program, they would be able to withdraw their accumulated savings and use them for any purpose (including but no longer limited to housing) with no tax penalty. In his budget speech, he noted:

There is currently more than $\$ 2$ billion in such plans. I am confident that, with the measures I have announced to provide incentives to growth and job creation, a substantial portion of these funds will find their way into entrepreneurial and jobcreating investments, as well as providing a boost to housing and consumption. (Wilson, 1985a)

In Parliament, the Opposition seized on the cancellation as one of their major critiques of the budget. Opposition members noted that the budget had introduced a new and substantial lifetime capital gains exemption and had extended assistance to private sector financial institutions (Copps, 1986). They accused the government of favoring wealthy Canadians and banks over average, hard-working savers and even introduced a motion in the House of Commons to preserve the RHOSP.

For their part, the Progressive Conservatives argued that cancelling the RHOSP was:

- Closing "a small tax shelter, merely a loophole" (Blenkarn, 1986).

- Ending a program that had never been intended to go on in perpetuity and, in any case, would have been cut by the outgoing Liberals if they had had the chance (Gormley, 1986). 
- Terminating a program that had been intended to cool-off housing markets in the 1970s by encouraging buyers to save and delay and a program that had no impact on housing outcomes even after 10 years (Duguay, 1986).

- Wrapping up a program whose take-up had been lower and slower than expected and, given the new capital gains exemptions, Canadians now had better alternatives (Wilson, 1985b).

Some of the arguments for cutting the program, including the slower take-up and its feature as a tax loophole for many seem to have some support in the available evidence. But the argument that the RHOSP had been intended to reduce demand for homeownership bears some discussion. To reduce current demand for homeownership, the perceived value of the RHOSP would have had to be greater than the perceived benefit of buying a house.

Consider the illustrative example of a taxpayer with $\$ 16,000$ in income in $1982,{ }^{151}$ an amount close to the median, and a home with a purchase price of $\$ 71,800$, the mean price of an existing home at that time (Chawla, 2011). Middle income earners in 1982 would have been subject to a combined federal and provincial marginal income tax rate of $38 \%$, all else being equal. A $\$ 1,000$ deposit into an RHOSP earning annual interest of

${ }^{151}$ Although 1982 represents a year outside of the heated and volatile housing markets of the 1970s, it is nevertheless a year within the lifetime of the RHOSP program and a year for which historical estimate on housing prices and marginal tax rates were available. The analysis is illustrative of the direction of the likely effects on housing decisions of individual taxpayers, even if the magnitude of the impact may vary from year to year. 
$11.5 \%{ }^{152}$ would result in an annual tax savings of $\$ 423.70$, taking into account the reduction in federal and provincial taxes that would otherwise have been payable on a $\$ 1,115$ in income. A conventional mortgage, with at least a 25\% down-payment, or $\$ 17,950$ on a home with a purchase price of $\$ 71,800$ in 1982 with an interest rate of $17.25 \%{ }^{153}$ on the illustrative case of the average home, would generate a tax-free imputed rental income of $\$ 3,096$ in the first year alone, ${ }^{154}$ on top tax-exempt capital gains in the real property.

Without changing the structure of the tax rates, the RHOSP annual deduction would have needed to rise to nearly $\$ 7,000$ per year to match the tax savings of purchasing a house as soon as was feasible for a household. This is, of course, assuming rational economic behavior, an assumption that, as discussed in Chapter 2, should not be taken lightly. But even on face value, given a desire to purchase a home, which the RHOSP design presumes, it is unlikely that any household able to do so would reasonably postpone the purchase for very long or at all in order to claim a $\$ 1,000$ deduction against their income tax.

${ }^{152}$ Based on Bank of Canada "Selected Historical Interest Rates" for savings deposits in 1982 , series V122493.

${ }^{153}$ Ibid, series V122521.

${ }^{154}$ The imputed rental income is an estimate of the costs savings to the homeowner occupying a home they own versus renting a comparable property. Horner (1983) advises that annual imputed rental income can be estimated by multiplying the equity of the homeowner in the property (in this case $\$ 17,900$ in the first year) against the mortgage rate on the property (in this case $\$ 17,900 \times 17.25 \%$ ). As equity in the property rises with each year of ownership, the imputed rental income should rise as well, all else being equal. If the market value of the property declines or the mortgage rate falls, then the value of ownership over renting declines. 
In at least two provinces, the cancellation of the federal RHOSP was followed by new provincial tax-benefitted savings programs for homeownership. ${ }^{155}$ The Ontario Homeownership Savings Plan (OHOSP) was introduced in 1988 and offered a tax credit of up to $\$ 500$ per year for 5 years that was tied to both savings levels and taxable income (Finance Ontario, 2001). The OHOSP allowed adult Ontario residents who did not already own a home to save in a provincially registered account and receive a tax credit. $^{156}$ Eligibility was further restricted to taxpayers with no more than $\$ 40,000$ in net ${ }^{157}$ personal income or $\$ 80,000$ in net household income. In this respect, the OHOSP seems to have been designed to be somewhat more progressive than the quasi-universal RHOSP that was unrestricted by income. For contributions up to $\$ 2,000$ per year, ${ }^{158}$ eligible OHOSP account holder could claim a non-refundable tax credit against their provincial income taxes worth between $\$ 125$ and $\$ 500$, depending on income. The tax credit was reduced by $\$ 125$ for each $\$ 5,000$ in net income above $\$ 20,000$ until it was

${ }^{155}$ A 2008 briefing document prepared for the Canadian Homebuilders' Association makes reference to past tax-benefitted homeownership savings plans in Ontario, Nova Scotia and Quebec (Altus, 2008). A preliminary search found no further references to a Quebec plan, very limited information on the Nova Scotia plan and some information on the Ontario plan. Provincial policy is an important aspect of understanding overall incentives for savings and ownership and, while largely outside of the scope of the current study, should be prioritized for future research.

${ }^{156}$ Available public information could not confirm whether the interest income in OHOSP accounts was exempt from provincial and federal income taxes. Financial institutions holding the OHOSP were required to issue annual receipts for deposits to verify the amount of contributions eligible for the provincial tax credit.

${ }^{157}$ Because the credit relied on net income, after deductions have been applied, it is very likely that the gross incomes of eligible participants were higher than the $\$ 40,000$ to $\$ 80,000$.

${ }^{158}$ There was no absolute ceiling on contribution to an OHOSP but only the first $\$ 2,000$ was eligible for the provincial credit. 
phased out completely at $\$ 40,000$. However, the tax credit was also reduced in proportion to the amount of savings deposited into the OHOSP. As a result, someone with a higher disposable income but lower net taxable income would be most likely to be able to claim the maximum tax credit of $\$ 500$. Accountholders could only claim the tax credit for five years within a seven-year window after opening the account and, like the RHOSP, could not carry-forward unused contribution room.

The OHOSP was terminated in the 2004 Ontario provincial budget as part of a deficit reduction-themed budget, one of many measures to reduce or eliminate provincial tax expenditures (Finance Ontario, 2004). Unused account balances could be withdrawn without penalty, very much like the treatment of RHOSP savings on cancellation in 1985 .

Based on the limited public information, the Nova Scotia Homeownership Savings Plan, introduced in 1989 and cancelled sometime before the 2007 repeal of its regulations, appears to have worked in a very similar manner to the Ontario plan. While the end of the federal program created a political space for provincial action, it was limited and short-lived.

\subsubsection{Concluding thoughts on the RHOSP and provincial plans}

In the case of the RHOSP and the short-lived provincial duplicate programs, governments dabbled in incentives to promote homeownership through individual or household savings. In all cases, it appears that the programs were eliminated once deficit reduction became a primary objective because they were viewed politically as niche tax 
expenditures. In contrast to the large and widespread RRSP, these smaller, somewhat more targeted programs are less costly to the public purse but also less resilient in the face of mounting fiscal challenges.

These instruments relied on after-tax household contributions and tax incentives that (with some limits in the provincial programs) rose with disposable income. As a result, they likely ended up rewarding bigger savers more heavily than smaller ones. To echo, Monique Bégin's remarks on the RRSP (see section 5.1.3 in this Chapter), there may be good policy arguments for this design but it does seem odd.

There may be good political value in being seen to support households in saving for what continues to be the single largest asset (and liability) for most Canadians - a home. There are also good microeconomic and macroeconomic reasons to want to promote homeownership including financial security, community development and citizen engagement goals (see the literature review in Chapter 1).

It is difficult to assess the effects of the income-tested provincial homeownership savings programs. The federal RHOSP seems to have accelerated transitions from rental housing to homeownership, which was counter to the self-declared though retrospective intent of federal policy-makers who claimed the intent had been to postpone home purchases. However, the accelerating effect into ownership was much stronger for higher income earners. 
The RHOSP and the provincial replicate programs were short-lived experiments that had proportionally larger take-up among lower and moderate income Canadians, compared to RRSPs. These programs still required attachment to mainstream private sector financial services. These programs still used an incentive in the tax system, a deduction against taxable income, that was more valuable to higher than lower income taxpayers. These programs also subsidized savings that were highly fungible - either as home equity if used as intended or as tax-free savings if not used before the program was cancelled. And, like the Homebuyer's Plan, they gave policy sanction to a particular motive for saving - buying a future home. This may have been an attractive goal to many lower and modest income savers, but it is not inclusive of all savings goals related to affordable housing. ${ }^{159}$

It is unlikely that these experimental tax-preferred savings instruments dedicated to homeownership will be introduced again in the near future. Given that the Homebuyer's Plan has been institutionalized as part of RRSPs, federal and provincial policy-makers are more likely to feel housing as a savings goal that has already been addressed.

${ }^{159}$ For example, renters may wish to save for the costs of a rental deposit or the move from one location to the next. 


\section{Chapter 6: Registered Education Savings Plans}

Chapter 3 described the war-time history of compulsory savings and the post-war history of RRSPs. I have argued that the war-time compulsory savings experiment in many ways set the precedent for the introduction of Registered Retirement Savings Plans (RRSPs) in 1957. Chapter 4 described the evolution over time of RRSPs from the 1970's through to the present and argued that what began as a niche instrument for selfemployed professionals eventually became a large, widespread and costly program. The RRSP also became an attractive mechanism for government to leverage private household savings for public policy goals outside of the wellbeing of individuals and families. As RRSPs became more familiar and used by more Canadians, they also became a model for the creation of new tax-preferred account-based savings instruments. The first such replication was the creation of the Registered Homeownership Savings Plan (RHOSP). This chapter examines another instrument that followed the RRSP precedent—Registered Education Savings Plans (RESPs).

Like RRSPs, the other tax-preferred savings instruments each: a) demand attachment to mainstream financial services, b) deliver their primary incentive through the income tax system, c) create fungible capital that can increase overall household wealth, and d) sanction only certain reasons or goals for saving but not others. The result is a thin universality - while they are notionally invited to participate, lower and modest-income Canadians are not truly included. 
This chapter provides what seems to be the first historical account RESPs from their creation in the early 1960s. The federal government, it seems, only reluctantly created the instruments in 1974 (retroactive to 1972) with most of the policy design adopted from private sector group savings plans (discussed in this chapter). These plans in turn had been designed by and for middle and upper-middle income Canadians seeking ways to make higher education more affordable for their children. ${ }^{160}$ More recent policy changes have aimed to expand take-up of RESPs and make them more accessible to low and modest income families with young children.

Over time, there has been some, but limited, responsiveness to the needs and preferences of so-called 'small savers'. ${ }^{161}$ It is too early to yet conclude whether these changes will have the desired effects for low and modest income Canadians. Based on my analysis in this chapter, I conclude that the recent changes suggest better new avenues for inclusive account-based savings instruments but do not resolve problems in the underlying RESP instrument for low and modest-income Canadians.

${ }^{160}$ In this chapter I provide greater detail on the socioeconomic status of the key figures involved in the early design of education savings accounts. I believe this is relevant because the individual involved for the first decade were acting as private citizens, outside of elected or public service policy-making positions. Neither were they part of a professional stakeholder organization comparable to the Canadian Medical Association. However, just as the senior public servants, elected officials and self-employed professionals who were involved in the design of RRSPs and RHOSPs, the earliest architects of the RESP benefitted from above average socio-economic status.

161 'Small-savers' is a term used in American legislation and international media to describe the population of people with low or modest assets who do not have a negative net worth. It can, in some contexts, have a normative as well as descriptive value, signaling the importance of saving money, even in small sums. See Chapter 2 for a discussion of ideas about the value of saving and thrift. 


\subsection{Launching a new private education savings plan}

In October 1962, Peter Wright, the president of the Canadian Scholarship Trust

Foundation wrote his first letter as part of the annual report to subscribers. ${ }^{162}$ Wright, a lawyer and later Ontario provincial court judge, was then the head of a foundation that oversaw a new education savings plan. Aimed at families who expected their young children to attend university and wanted to begin saving while the child was young, the savings plan promised subscribers "scholarship" payments to their children (once in university) in exchange for ongoing deposits to a group savings plan. Individual deposits were pooled together in the group savings plan, invested and managed as a private trust fund. If and when a child entered university or college, a subscriber's principal would be withdrawn to help him or her cover the costs of the first year of university and, for subsequent years, the pooled fund would pay out a "scholarship" to the benefitting child. If the beneficiary child did not pursue a post-secondary program recognized by the plan, for any reason, then the subscriber's savings were forfeited to the pool. No refund of contributions or scholarships would be paid for savings made in that child's name. To be willing to enter the plan, these earliest participating parents must have had strong and reasonable expectations that their child or children would attend post-secondary education.

${ }^{162}$ The author gratefully acknowledges the assistance of the C.S.T. Foundation who provided copies of annual reports to subscribers for 1962 through to 1975. 
The first subscriptions to the savings plan had been sold starting March 31, 1961 as private contracts with individual Canadian families. These families purchased shares in a pooled savings plan, not individual savings accounts. The foundation, as Wright noted in his annual letter, did not hold the money deposited by subscribers to the plan. Instead deposits were held and invested by The Eastern Trust Company, a long-standing financial institution with strong ties in corporate Canada (Marchildon, 1996). Neither was the foundation responsible for the direct sale of the subscriptions to the group savings plan. Instead, the plan formed an arm's length corporation, Scholareps of Canada Limited, a network of individual commissioned salespeople, who Wright would note in his next annual report sought "a reasonable assurance of a living for their work" (Wright, 1963). While the first annual report of the foundation assured savings plan members that "we do not operate Scholareps nor accept the risks of its operations" (Wright, 1962), by the following year, the foundation had taken over full ownership of the sales firm. In 1965, the Foundation entered into an agreement with an un-named company to take over responsibility for the sales and enrolments of the group savings plan. This complexity and changeability in the structure and organization of the first education savings plan in Canada is worth noting because it would become part of an ongoing public relations and governance challenge for both the private-sector providers but also policy-makers, as will be noted later on in this chapter.

The founding directors of this first scholarship plan were a noteworthy group with high social capital:

- Justice Arthur Wright, who served as a voluntary and part-time president. 
- Arthur Piggott, an accountant and husband of Jean Pigott, the CEO of the Standard Bread Company and later a Progressive Conservative M.P. and head of the National Capital Commission.

- Gladys Neale, head of the educational publishing division of Macmillan Books.

- Kenneth Carter, a prominent accountant, chair of the Canadian Tax Foundation and head of the Royal Commission on Tax Reform from 1962-1966.

The aim, as reflected in the first letter to the subscribers, was to help more Canadian children start university with some savings to cover the costs of tuition, books and living expenses. The broader context of participation in higher education, education costs and financing is worth noting here to understand the landscape in which the new education savings plan was created.

In 1961, the year that the first education savings plan contract was sold in Canada, 12\% of youth (aged 18-21 years) enrolled in undergraduate university programs, a number that was only somewhat higher than the participation rate in 1951 (7\%) when returning veterans would have had access to millions of dollars in federal funding for education and training (Wisenthal, 1983). It is unclear whether the original designers of the savings plan were motivated by rising education costs. Tuition fees between the mid 1960's and late 1970's remained almost flat but may have been a heavier burden for most families relative to other demands on their household budget (Pelletier \& Thomas, 1998). In 1962, the first cohort of "Baby Boomers" born to returning servicemen were turning 17, making decisions about pursuing post-secondary education and would not, as many of 
their fathers had, have access to a free university or college education. This intergenerational shift may also have contributed to a perception of rising costs and household financial pressures.

The launch of the new education savings plan also came immediately before the 1964 launch of the Canada Student Loans Program, the successor to the very small DominionProvincial Student Loan Program (Raaflaub, 2006). Debate on education financing in the in the House of Commons at the time reflect a more general concern about the appropriate balance between government and private investment in higher education policy. In his speech to the House of Commons introducing the legislation on the CSLP, the Minister of Finance made a passing but positive reference to the C.S.T. Foundation as an example of an "imaginative and worthwhile arrangement" (cited in Wright, 1964).

Finally, it is also worth noting that, according to Wright's 1962 report, two other pooled education savings plans launched in Canada that copied the Canadian Scholarship Trust's (CST) model - the University Scholarship Foundation of Canada and the N.C.S Foundation, both launched in 1962. The former soon merged with the C.S.T. Foundation, but the launch of three separate pooled savings plans suggests that entrants felt there was a market demand for their education savings products.

The early reports to subscribers of the C.S.T. Foundation savings plan suggest that the administrators were very keen to expand the base of contributors to the group savings plan. What is less clear is what they presumed about their target market's motivation and 
capability to save for a child's education. The 1963 annual report from Wright urged current plan members to spread word of the plan to other families: "It is in the interest of all that as many citizens as possible enter the Plan. [...] I enclose a copy of the current brochure. If you want to help yourself and the Plan, will you please bring this to the favourable attention of someone interested in the university education of a child now under eight" (Wright, 1963). Similarly in the 1965 report, the president thanks the subscribers for responding to the appeal for referrals of names and contact information for families who might be interested in joining the plan (Wright, 1965). One interpretation of this desire to expand might be that the Foundation was behaving like a firm in a competitive market, seeking as large a market segment as possible. However, another interpretation is that the structure of the plan required on-going renewal of is subscriber base, much like a defined benefit pension plan.

Like a defined benefit pension plan, the pooled savings promised a rate of return to investors (within some margin of error) based on how many units or shares in the pool they purchased. To be able to manage the risk associated with this guarantee, the pooled plan would require a certain level of return and the larger the investment pool, the larger the nominal investment returns. With this in mind, it may be possible to make some inference about the families the Foundation saw as their early target market. A defined benefit savings plan designed to be accessible only to very wealthy families would likely quickly exhaust any expansion in its investment base and would need to rely only on (less certain) market returns. Likewise, it is unlikely that a pooled savings plan would offer much real benefit to very wealthy families over and above the savings or other 
mechanisms they would have for transferring wealth to their children for education and other goals.

Instead, it seems likely that the pooled savings plan was designed to be most attractive to families with young children, giving them and the plan the maximum amount of time to build a pool of capital and compound investment earnings. Because families would have to meet monthly savings commitments in the pooled savings plan, it is likely they would need at least a moderate and steady flow of income. In sum, the ideal candidate family for the pooled education savings plan of the C.S.T (and almost certainly the other contemporary replicate plans) would have had one or more young children and likely a middle or upper middle-class income. Using financial data from the earliest annual reports of the C.S.T. Foundation, Table 6.1, below, I present data on the average deposits into the plan for each beneficiary. For comparison, I also include data on more recent average annual contributions to Registered Education Savings Plans (RESPs). It is important to note that the current RESPs may or may not be provided by a group savings plan provider similar to the C.S.T. Foundation. This comparison may provide information on whether the users of the precursors to RESPs were larger savers compared to current RESP users. 
Table 6.1 Average annual education savings 1961-62, 1963, 2000 (unadjusted and adjusted, constant 2013 dollars)

\begin{tabular}{l|lll}
\hline Year & $1961-62 * *$ & $1963 * *$ & $2000 * * *$ \\
\hline $\begin{array}{l}\text { Average annual deposits to education } \\
\text { savings plan }\end{array}$ & $\$ 123.47$ & $\$ 129.08$ & $\$ 1,346$ \\
& & & \\
$\begin{array}{l}\text { Average adjusted amounts } \\
(\$ 2013) *\end{array}$ & $\$ 964.95$ & $\$ 989.88$ & $\$ 1,755.09$ \\
\hline
\end{tabular}

* Author's calculations using Bank of Canada Inflation Calculator, Statistics Canada Table V41690973.

**Author's calculations based on 4,321 subscriptions with total value of \$533,503 at August 31, 1962 and 10,916 subscriptions with a net increase in total value of $\$ 1,409,058$ at August 31, 1963.

Mean household employment income in 1962 would have been approximately $\$ 4,200$ (Meltz, 1983) ${ }^{163}$ suggesting that deposits to the earliest pooled education savings plans would have been $3 \%$ of average employment income. In 2000, average household employment income was $\$ 62,600$ meaning that average RESP deposits that year were also $2 \%$ of average employment income - a remarkable level of stability over time and despite the creation of new financial incentives through public policy, discussed later in this chapter. The proportions of average household income saved may not be an indication of revealed preference but rather an indication of the financial capacity to save. For example, Guilmette (2011) finds that a majority of families with a household income over $\$ 55,000$ report that they are saving for both retirement and their children's higher

${ }^{163}$ This measure is used for comparison purposes to historical data available for 1962 but is not a complete measure of household income which would normally include non-wage earnings from investments, self-employment and business income as well as non-market income from government transfers and benefits. 
education but that under that level, it appears that households make trade-offs in what they save for, if they save at all. ${ }^{164}$

At the same time that the early annual reports from the C.S.T. Foundation expressed an on-going desire to see the contribution base expanded, the Foundation seems to have faced little and often failed competition from new entrants. Annual reports from the Foundation for 1964 through 1972 continued to press current plan members to provide referrals for prospective new clients. At the same time, the 1969 report stated "there have been over twelve plans basically similar to the C.S.T. Plan [...]. Nearly all of these have fallen by the wayside leaving behind, I am sure, disgruntled subscribers" (Wright, 1969).

This limited competition and rather short lifespan for many new entrants is echoed in one of the only mentions of education savings plans in the House of Commons before 1998 . In April 1970, Lorne Nystrom, an NDP M.P. from Saskatchewan had placed a written question on the Order Paper to ask about the number of scholarship trusts in Canada, their reporting requirements, the existence of any oversight mechanisms on the use of funds, bankruptcy and whether the Government of Canada had any plans to absorb them into a

\footnotetext{
${ }^{164}$ Guilmette (2011) used data from the Canadian Financial Capability Survey that asked respondents about household preparation for retirement (inside and outside of registered pension or retirement savings plans) and children's education (inside and outside of RESPs). For households in the lowest quintile (with less than $\$ 32,000$ ), just over $60 \%$ were saving for one or both of retirement and education with about twice as many households opting to save for a child's education as for retirement. At the next quintile ( $\$ 32,000$ to $\$ 54,000$ in household income), retirement savings were more likely than a child's education. The data suggest that for households with income near or above average income, retirement and education are not substitutes but for households below the average trade-offs on savings are made within a more constrained budget line.
} 
national plan. The Parliamentary Secretary to the President of Privy Council, Yves Forest, provided the response on behalf of the Government, noting that there were, in 1970, five plans in existence, two of which had been dissolved. Forest also emphasized that the federal government regarded these as private contracts and had no plans or interest in regulating or otherwise "nationaliz[ing]" them in any way manner (Forest, 1970).

Yet, from the early annual reports to subscribers, it seems that the C.S.T Foundation recognized they would need some form of government regulation for their new savings instrument. Notwithstanding the government's assertion that it regarded the plans as private contracts and saw no role for federal intervention, it is clear that the C.S.T. Foundation both desired and sought out a policy engagement on education savings.

In the 1966 report, the Foundation announced it had developed a plan for families to finance their plan contributions out of their federal monthly family allowance cheques. This would have been a way to make the plan more attractive to families would might otherwise view the family allowance money as windfall income and created a link between an existing federal policy instrument and the savings plan. ${ }^{165}$ If enough families began to use their family allowance as a savings stream, then it is likely that federal policy-makers overseeing the family allowances program would have developed an

${ }^{165}$ In 1966, average annual family allowances amounts paid by the federal government would have been approximately $\$ 80.62$, author's calculation based on data in Robinson, T. (1983) "Health and Welfare" in Historical Statistics of Canada, Statistics Canada, Ottawa. 
interest in how the program dollars were being used. This link to a federal income support benefit would reappear many decades later when the federal government introduced a system of matching and income-tested contributions to RESPs.

"I regard the Plan as a stabilizing factor both for individual costs and generally. I have always advocated its adoption by some public body because it appears to me to relate the various financial responsibilities involved in university education to each other in a very remarkable way", wrote Wright in his 1969 report to subscribers. He also reported that he was "happy" to report that provincial securities regulators were proceeding to regulate the sale of education savings trusts and was "hopeful that the effect of the work of the administrators under the Securities Act will be to ensure that only worthy plans can continue to be offered to the public". Given the volatility of many of the competitor group savings plans, it is likely that the C.S.T. Foundation viewed securities regulation as an important way to increase consumer confidence in their products, manage reputation risk and also to reduce the number of potential new entrants into the market.

\subsection{From private plans to public policy}

In the 1970 annual report, the new C.S.T. Foundation president, A. C. Ryley ${ }^{166}$ raised the question of the taxation of savings and eventual withdrawals from the savings plans. According to his report, the interest earned in the plans was being included in the annual taxable incomes of the parents who had bought into the group savings plan for their

\footnotetext{
166 The 1975 annual report to subscribers lists Ryley as a Partner with the accounting and business services firm Coopers and Lybrand.
} 
dependent children. He wrote, "I believe that a more 'equitable' incidence of tax would result if the Income Tax Act were amended so that the interest earned on subscribers' accounts would be taxed as income of the students at the time scholarships are received" (Ryley, 1970).

The plan projected that the first cohort of children from the 1961-62 sales would be entering university in 1972. In that year, the plan would change roles - both collecting and managing deposits and then paying out scholarship dollars and refunded subscribers' principal. The question lingered of how those payments and refunds from the plan would be treated for tax purposes. Not withstanding Ken Carter's role in both the C.S.T. Foundation and the Royal Commission on Taxation, education savings plans were not specifically addressed in Carter's report to the government in 1966.

Carter had recommended a new series of tax credits for students and their supporting parents (PCO, 1966, Vol. 3). His final report had also argued that:

The tax burden on saving can be reduced most effectively through allowing a deduction of specific forms of saving from gross income in determining taxable income, and through reducing the tax borne by the income generated by the assets acquired by such saving. By restricting the volume of saving that can be deducted, the benefit to the upper income groups can be limited. [...] The system we recommend could be modified to encourage more contractual saving. (Vol. 2, page 128) 
The Commission's discussion of RRSPs and their recommendation to constrain rather than expand the value of the deduction and deferral in RRSPs has already been discussed in Chapter 4. The passage cited above suggests that Carter and his fellow commissioners had a general orientation towards deducting savings from income and exempting (or at least reducing) the interest on savings, up to some maximum and reasonable amount. In a March 18, 1966 speech shortly after his final report to the Government of Canada had been published, Carter spoke to the Empire Club of Canada to defend his policy recommendations. In that speech, he did not address the taxation of savings plans like the C.S.T. pooled education savings plan either but did note "I think a tax system should not exempt all savings from tax" (Carter, 1966). It is unclear whether Carter regarded the plans as a form of saving that should be taxed or whether he, and his fellow C.S.T founders, had simply not anticipated that taxation of scholarship payments and subscriber refunds would become an issue for plan subscribers.

Whatever the prior opinion of Carter on the matter, ${ }^{167}$ Ryley indicated that he and other C.S.T. representatives had requested a meeting with the federal Minister of Finance, Edgar Benson, to present their position and recommendations on the taxation of the pooled savings plans. ${ }^{168}$

\footnotetext{
${ }^{167}$ Ken Carter passed away in 1968 and so could not have any role in the eventual discussions with the federal government.

168 The list of the members of the 1970 C.S.T. Foundation advisory group shows continued involvement of Canadians with significant social, economic and political capital. In addition to the ongoing participation of Jean Tory, Justice Arthur Pigott and Justice Peter Wright, by 1970 members included: Irvine Barrow, chair of Lester Pearson's 1962 and 1963 election campaigns and future Liberal Senator, prominent
} 
The following year, the 1971 annual report to subscribers noted that the Foundation had engaged in "much time and effort $[. .$.$] making representations to the Department of$ Finance concerning the special circumstances [of the pooled education subscribers]" (Ryley, 1971). The president reported that representatives of the C.S.T. plan had met with the Minister of Finance and seniors members of his staff. The position of the Foundation was that "scholarships paid under our plan would not constitute income for tax purposes because they are a return of tax-paid income" (Ryley, 1971).

The Foundation further argued for an amendment to the Income Tax Act to add provisions for education savings plans that "would be roughly equivalent to those for Registered Retirement Savings Plans”. This included: a) language to define recognized education savings plans, b) conditions to register plans, c) exemptions from taxable income for the principal and interest earned in the plans, and d) taxation of eventual payments from the plans as part of the incomes of beneficiary students not the subscribing, and higher income, parents.

Quebec laywer Maurice Delorme, Neville Scarfe the Dean of Education at the University of British Columbia and the Honorable David Cameron the son of a long-time Alberta MLA and an Independent Liberal Senator. A copy of a November 1, 1971 letter from Ryley to the Minister of Finance lists the names of some of the most prominent Canadians involved in the pooled savings plan and suggests that the Foundation was not shy about using the social and political capital of its members to achieve a desired policy aim. This is neither a unique nor a necessarily discreditable tactic in public policy advocacy. 
The same annual report also cited a November 1, 1971 letter from the Minister of Finance to the Foundation that had thanked the Foundation for their proposals, noted they had been carefully considered but concluded "it was decided not to introduce a special provision in the law to deal with the taxation of interest on savings earmarked for the education of a taxpayer's child. Your request will be reviewed again when amendments to the Income Tax Act are next under consideration" (Benson cited in Ryley, 1971). However in March of 1971, Benson had introduced the government's budget with changes to RRSPs and a new capital gains tax, as the government's cautious effort at tax reform (discussed in Chapter 4). If there was any internal federal plan for further substantial changes to the Income Tax Act, there was no such indication in the government's own budget or public remarks.

As an interim measure, Ryley encouraged plan subscribers to write to their Members of Parliament to express their concerns. It is unknown whether any did so and whether this resulted in any government attention but the Hansard records for the period do not suggest M.P.s were rising in the House to speak on the matter in response to persuasive numbers of concerned constituents.

\subsubsection{Taking the matter to the courts}

In June 1971, a C.S.T. Scholarship Plan subscriber, Jack Harvey Quinn, received a notice from the Department of National Revenue (Tax Review Board, 1972). His 1970 tax return had been reassessed by the Department to include $\$ 110.44$ in investment income based on the T-5 slip issued by the C.S.T. Foundation. Quinn had not included in the 
amount in his self-reported income and the tax office had concluded he owed outstanding taxes on this amount. Quinn decided to appeal the reassessment to the federal Tax Review Board. ${ }^{169}$ The key question in the matter was whether the investment income in question was truly Quinn's.

The Board ruled in Quinn's favour. It noted that Quinn did not have access to the interest income since the terms of the contract with the C.S.T. Foundation were that the interest was credited to Quinn's beneficiary's notional account but retained in a pooled investment fund. The Board further noted that Quinn's contributions and notional investment income earned in the pool would be forfeited by Quinn and his beneficiary child if that child did not meet the post-secondary participation requirements of the Foundation. The Board concluded that the investment income would never be received by Quinn and, in its decision, it noted that:

The Board failed to see how amounts credited to an interest account kept in the name of a subscriber for identification purposes, over which he had little or no control and which he could not draw out or utilize for his own purposes, could be construed as income in his hands under section 6(1)(b)[of the Income Tax Act], as that money was not paid or payable to him at any time in the future (TRB, 1972).

${ }^{169}$ Quinn was self-represented before the Tax Review Board suggesting he may have had some professional knowledge of tax law or at least access to very good legal advice. The Federal Court records state that Quinn had joined the C.S.T. pooled savings plan in 1965 for his son (then aged 9). No explanation is offered as to why in 1970 Quinn refused to report and pay taxes on the interest income if he, presumably, had not done so for 1965 through 1969. In the 1973 report to plan members, Quinn is listed as a member of the C.S.T. Foundation's Board of Directors and his occupational title is listed as Director of Pharmacy for K-Mart Pharmacy Limited. 
The Crown appealed the decision.

In a January 1973 letter to C.S.T. subscribers, the Foundation President A.C. Ryley, publicized the results of Quinn's successful appeal and, in a bold font to highlight the words, wrote "a subscriber may wish to consider not including the interest earned in his account in his income for tax purposes when completing his 1972 return” (Ryley, 1973). Ryley also cautioned subscribers to include a written explanation and to recall that they may be reassessed, pending the Crown's appeal of the Quinn case. The same annual report also noted that the Foundation continued to press the government for a policy and legislative change. Further, following a December 1972 meeting with the new Minister of Finance (John Turner), Ryley wrote that the Minister had committed "to take a fresh look at the problem" (Ryley, 1972).

Although the Minister of Finance had committed to re-examining the tax treatment of the pooled education savings plans, federal lawyers for the Minister of National Revenue instead prepared for their appeal of the Quinn Case in the Federal Court. The case was heard in early 1973 and a decision issued by Justice J. Heald in April 1973 (Quinn, 1973).

Justice Heald's decision is interesting because, while it upheld the Board's finding on the grounds that the interest income was not "receivable" by Quinn (or other subscribers) under the terms of the Income Tax Act, the decision also noted that neither could the 
Trustee ${ }^{170}$ of the pooled savings be taxed for the investment income. Since the subscriber to the plan only transferred the ownership of the interest earned when the savings plan matured and the interest, pending eligibility of the beneficiary child, was turned into a scholarship payment. For the Department of National Revenue, this would have presented a problem — in whose hands should the investment income be taxed? There was investment income being earned. If it could not tax the subscriber and it could not tax the Trustee of the pooled savings plan, the Department faced a problem of coherence in the application of the Income Tax Act.

At the time of the decision, there were 81 eligible beneficiaries who would have received "scholarship" payments out of the pooled savings in the amount of \$750 each in 1973 (Ryley, 1973). The tax treatment of these payments made in 1973 for 1972 personal income tax is unclear. It is likely that students receiving the money would have declared it as income and then used the exemption of $\$ 500$ in annual scholarship funds. Combined with other credits for education amounts, it is unlikely that any of them would have paid any net income tax on the $\$ 250$ of taxable scholarship payments from the C.S.T. Foundation. Nevertheless, the entire system was operating in a grey-zone that had been

\footnotetext{
${ }^{170}$ By the time of this court case, the pooled savings plan had a more complex structure and involved many more financial institutions than at its inception in 1961-62. In 1972, the Canadian Imperial Bank of Commerce (CIBC) had taken over depository services for plan contributors, four trust companies (Canada Permanent Trust, National Trust, Guarantee Trust and Quebec Trust) acted as trustees for the pooled savings while Canada Permanent Trust acted as the trustee for the payment of scholarships starting that same year.
} 
largely ignored by policy-makers and tolerated by subscribers for the first decade of the education savings plans. As Justice Heald noted in his decision on the Quinn case:

This case is in the nature of a test case. While the amount of interest in this particular case is small, it is in the same position as the interest credited on some 39,000 other agreements in force in the Canadian Scholarship Trust Plan in1970. At October 31, 1970, there was on deposit with the trustee under this plan as deposits, a figure in excess of 26 million dollars. The accumulated interest on deposit was in excess of 6 million dollars (Quinn, 1973).

This would have been a substantial amount of income and capital on which to forego income tax revenue.

\subsubsection{Policy response}

A search of the federal budget documents and Parliamentary debates for 1972, 1973 and 1974 found no reference to the taxation of the education savings plans. Similarly, a search of Cabinet records of decision found no references to this file either. Finally, a search of the departmental archive for the Department of Finance and Treasury Board also found no record of departmental documents on education savings prior to 1998 . However, from the C.S.T. Foundation, I obtained a copy of an October 15, 1972 press release issued by the federal Minister of Finance, John Turner.

In the press release, the Minister announced the government's intention to introduce amendments to the Income Tax Act. The amendments would create a new registered 
education savings plan and clarify the tax treatment of deposits, interest earned and payments made to beneficiaries (Department of Finance, 1972).${ }^{171}$ The press release positioned the legislative change as a necessary response to resolve uncertainty arising from the Quinn decision and made clear that:

1) Education savings plans would be registered and, presumably like RRSPs, would need to meet certain conditions for registered status.

2) Deposits into these new RESPs would, not be taxable. ${ }^{172}$

3) Interest earned on RESP contributions would also be exempt from taxation in the hands of the contributor and the trustee.

4) Money in RESPs would only be taxable in the hands of beneficiaries when "scholarship" amounts were paid out.

5) For RESP beneficiaries whose subscriber parents had already paid taxes on interest earned between 1961 and 1972, credit against the taxes payable on their RESP income would be granted to avoid double-taxation.

The above was entirely consistent with the position of the C.S.T. Foundation. The Foundation's 1973 report to subscribers noted that it was "pleased" by the Minister's announcement and "delighted to be able to bring [members] this long-awaited news" which made the plans a "unique" savings and investment vehicles. The group education savings plans would, following the amendment, be recognized as RESPs.

${ }^{171}$ At the time of the amendment, the only education savings plans in place were the group savings plans like the C.S.T. Foundation.

${ }^{172}$ Contributions were subject to a $\$ 1,500$ annual limit until 1996. 
The legislative amendment passed in February 1975, a year following two federal budgets and a federal election, none of which saw any reference to RESPs. The amendment was made retroactive to 1972. Even now, the relevant section of the Income Tax Act makes reference to plan agreements formed before and after 1971 (section 146.1).

However, the Foundation's 1973 report also highlighted a new set of administrative issues. To refund taxes paid in error in 1972, pending the 1973 decision on the Quinn case, and to be able to reconcile future payments to beneficiaries with pre-1971 taxes paid on interest earned, Social Insurance Numbers and plan details would be required from each subscriber and beneficiary by the Department of National Revenue.

Furthermore, the Trustee for the pooled plan would now have to assume responsibility for calculating and informing students how much taxable income to report from their total payments out of the savings plan. Like RRSPs, the private providers had taken a central role in the details and implementation of the federal policy. Administration of the taxpreferred savings instrument was largely outsourced to the private providers.

For a small private sector organization this represents a substantial task. For the years 1974 and 1975, the C.S.T. Foundation paid out scholarships from matured savings to approximately 2,000 students (Ryley, 1975). Currently the organization makes payments to approximately 5,000 students per year (C.S.T. Foundation, 2012). 


\subsubsection{RESPs as niche but entrenched instrument 1975-1996}

In the years after the 1975 change to the Income Tax Act, there was little if any public attention to RESPs. Not unlike the first decades of the RRSP program, a small number of RESP providers worked in a niche market and continuing to attract new subscribers largely through word of mouth or direct marketing to parents. ${ }^{173}$

A search of major national news media for the period found just one article on RESPs between 1975 and 1997. In May 1981, the Toronto Star highlighted RESPs as a way for parents to plan ahead for rising university costs (Crawford, 1981). The article referred to just two RESP providers, the C.S.T. Scholarship and University Scholarships of Canada. Both had been among the original education savings plan providers and offered pooled savings plans described above. The same article quoted an official from the Department of National Revenue calling the plans "good for people who want to force themselves to save". The article was generally positive, noting that youth with the savings plans appeared to have higher rates of post-secondary education participation (between $45 \%$ and $54 \%$ on the two plans named) compared to the reported national average of $13 \%$.

The proposed behavioral effects of the plans were later cited by policy-makers in preparation for the 1998 budget. In that budget, the government would also wrestle with whether and how to address the roughly half of all pooled savings that were not being

${ }^{173}$ For example, consultants selling the C.S.T. Foundation RESP product might monitor local birth announcements in newspapers or set up information booths in shopping malls or community fairs. 
used by registered beneficiaries. ${ }^{174}$ But until the 1998 budget, RESPs were very much a niche instrument, serving a small sub-market of families with children.

\subsection{RESPs since 1996: Playing politics on private savings}

The federal government made no changes to RESPs until the 1996 budget. The then Finance Minister and his chief of staff, Terry O'Leary had a personal interest higher education and were familiar with RESPs (Ibbitson \& Taber, 2003; Martin, 2008). It is also likely that RESPs would have received renewed attention from federal policy analysts looking for options to implement the government's 1995 Green Paper proposal for personal learning accounts (discussed in Chapter 5).

The 1996 federal budget made a modest increase to the limit on annual contributions to RESPs $\$ 1,500$ to $\$ 2,000$ (Finance Canada, 1996). In addition to annual limits, RESPs are

${ }^{174}$ In fact part of the original design of the pooled plans was an expectation that not all beneficiary children for whom subscribers joined the plan would in fact go on to be eligible for scholarship payments. In the 1972 report to subscribers, the president of the Foundation noted that the first cohort of beneficiaries to receive payments from the pooled fund "were enrolled in the Plan when they were six and seven years of age and much was known about their student ability. [...] In the later years of eligibility, students will have been enrolled variously from birth to 8 years of age. Presumably, therefore the retention and acceleration rates will decline." Similarly, in the 1973 report cautioned that it was difficult to project the exact value of payments to beneficiaries or to guarantee an increase in payments from year to the next since a "factor in determining the level of scholarships is "dropouts". Because relatively large numbers of nominees have accelerated their progress through secondary school and first-year university, dropouts have not made any significant contribution to date." In other words, the structure of the pooled plans at this time was a wager that your child was more likely to go on to university compared to the children of other subscribers. This aspect has been addressed to some degree through changes to the operations of the group savings plans and certainly through the introduction of individual and family savings plans. 
also subject to a lifetime limit on contributions. The 1996 budget increased the lifetime RESP contribution limit as well, from $\$ 31,500$ to $\$ 42,000$.

There were also some important changes to RESPs in the 1997 budget. The government again increased the annual limit on RESP contributions, this time from $\$ 2,000$ to $\$ 4,000$ (Finance Canada, 1997b). The budget also announced a change to the Income Tax Act to allow parents to move unused RESP savings into an RRSP without tax penalty. ${ }^{175}$ For parents in the group RESP savings plans, this would provide them (subject to their contracts with the RESP provider) with an assurance that they would not lose their savings if their child did not pursue higher education. These policy changes were also included in the long list of policy measures that made up the governing Liberal Party's 1997 election platform. While these changes to RESPs were not featured prominently in the development or final version of the platform, they were included as examples of policy to promote access to higher education. ${ }^{176}$

In 1997, then Finance Minister Paul Martin began preparing for his 1998 budget. Martin is known to have liked budgets crafted around certain policy themes and to have insisted that his senior departmental officials and selected political advisors begin work on next year budget very soon after he had delivered the latest federal fiscal plan (Ibbitson \& Taber, 2003; Delacourt, 2004; Wells, 2006). The process for these thematic budgets

\footnotetext{
${ }^{175}$ RESP owners can transfer up to $\$ 50,000$ to an RRSP if all beneficiaries have not used up the RESP capital. The RRSP owner must have sufficient contribution room for the transfer.

${ }^{176}$ The author worked as a researcher on the 1997 Liberal Party Election platform.
} 
consisted of developing a menu of concrete, announceable policy measures that might show federal action on one or more central socio-economic challenges that had been selected as the theme for the budget. The menu might include measures geared to different sub-populations. The task of budget-making was then to cobble together a more-or-less coherent narrative based on a refined list of components from that menu. Given the climate of fiscal restraint in the early and mid 1990's, an ideal policy announcement in a federal budget would be both appropriate to the central theme and offer a large expected return for a modest level of federal spending.

The Minister and his team had determined that the 1998 budget would focus on skills and higher education. The 1997 budget had, after projecting a balanced federal budget for 1998-99, announced increases in income support for low-income families and seniors as well as spending on health care. There was also general agreement among senior political advisors and many senior civil servants, that federal investments in higher education should be enhanced (Martin, 2008). Skills and education were viewed as crucial to future economic competitiveness, prosperity and social mobility. Political advisors also saw higher education as an area where new federal spending might be perceived as responsive to the financial strains faced by middle-class voters who wanted to send their children to college or university but were deeply concerned by rising education costs. 


\subsubsection{Adding education savings grants}

By 1997, there were 22 different organizations offering RESPs in Canada. Senior officials at the Department of Finance were directed to review the state of the RESP industry and to identify ways to enhance the attractiveness and accessibility of the savings products for more Canadian families (Martin, 2008). Although the number of RESP providers had increased substantially since the 1975 amendment to the Income Tax Act, many of the providers were either group scholarship trust plans, including the C.S.T. Foundation discussed earlier in this chapter, or commission-based investment dealers. ${ }^{177}$ Generally speaking, banks, credit unions and other personal banking service providers were not engaged in the RESP market at all. To even find out about the RESP, Canadians had to either be the client of an investment advisor or dealer or had to hear about them through the marketing efforts of the group plan providers.

Because the group plan providers generally work through commissioned sales people and have no storefront, they may use a range of outreach strategies to find new clients. The early annual reports of the C.S.T. Foundation made clear that word of mouth referrals were an important way to identify prospective new plan members. Word of mouth and other non-traditional marketing approaches among some group RESP providers continue to this day according to Knight, Waslander and Wortsman (2008). In their review of

${ }^{177}$ Even according to the most recent statistical review published by the government, fully one third of all RESP assets are held by group RESP providers, another third by investment banking and securities dealers, $15 \%$ by portfolio and investment managers and slightly less than $15 \%$ by personal banking institutions (HRSDC, 2008). 
provider practices, they note that some group RESP providers use the following methods to reach prospective clients:

Advertising through the major media and newspapers is generally considered too expensive, group scholarship providers do market in a myriad of other way including: participation in trade shows; exhibits and kiosks in malls and shopping centres; contests for a free RESP; placing flyers in doctors' offices; or through advertisements in community newspapers—all targeting families with young children (p.16).

It is likely that these types of method of direct marketing, alongside periodic complaints to and disciplinary action by securities regulators over the sales and market conduct of certain group plan providers, ${ }^{178}$ would have been of concern to officials in Finance. On the one hand, the federal government was taking steps to make RESPs more attractive as tax-preferred account-based savings vehicles. On the other hand, there was little in existing policy to address the overall transparency and stability of the RESP market.

\footnotetext{
${ }^{178}$ Knight, Waslander and Wortsman (2008) outline several concerns about the complexity of the prospectus used in the sale of group RESPs as well as the fine print governing the terms of the contract, fees and contribution schedules. A search of provincial securities commissions did find several references to cease trade orders, fines and other disciplinary measures issued against representatives of or some group RESP providers themselves. In 2000, five of the larger group RESP providers formed a selfregulating umbrella organization, the RESP Dealers' Association of Canada (RESPDAC, 2013). The organization maintains a code of conduct and provides certification courses for employees and representatives of members. In 2012, the Ontario Securities Commission issued a series of temporary orders against some RESP providers following a large-scale review of industry compliance with securities regulations (OSC, 2013).
} 
In 1997, Canadians could go to a retail financial services provider—such as a bank or credit union - to borrow for a mortgage and open an RRSP, but they could not open an RESP. Well into the late 1990 's, RESPs were only available through a specialized network of providers and limited numbers of investment fund dealers or advisors who had relationships with the providers. One way to improve the market for Canadian consumers was to increase the supply of RESP providers. ${ }^{179}$ This did not fully eliminate real or perceived consumer risk but would help to rationalize the "government's approach of 'buyer-beware' - the consumer decides and trades off the possibility of a larger return against the risk of no or a partial return" (Knight, Waslander \& Wortsman, 2008). ${ }^{180}$ The central policy question then was how to make RESPs more attractive to mainstream financial services providers (Martin, 2008). The departmental officials developed a proposal to offer a $10 \%$ government top-up to be paid-into RESPs up to some annual maximum saved by a subscriber. The annual top-up would both motivate RESP

\footnotetext{
${ }^{179}$ The regulation of RESPs in Canada is quite complex. The regulation of retail sales and marketing of RESPs is managed by provincial securities regulators and, in the case of federally regulated banking institutions, by the Financial Consumer Agency of Canada with the Office of the Superintendent of Financial Institutions. Compliance with the requirements for registration of the savings plans is the domain of the Canada Revenue Agency. The conduct of the investment funds or trusts in which RESP deposits are held is overseen by provincial securities regulators. In cases of consumer complaints, RESP providers generally offer some internal dispute resolution mechanism that, if unsuccessful, may be referred to the Office of the Ombudsman for Banking Services and Investments if the RESP provider or dealer has agreed to be covered by the voluntary Ombudsman.

${ }^{180}$ The review by Knight and his colleagues also noted that each year a small portion of RESP plans are terminated before they mature, either because the subscriber cancels their agreement or, in approximately $1.9 \%$ of plans, because the group provider closes the plan.
} 
subscribers to save more (generating better returns for RESP providers) but also to provide a better marketing device to promote the product to consumers.

The appeal of the group plans is the wager that the return will be several times larger than the original contribution. Individual plans can only offer returns based on the performance of investment markets. The tax-treatment of RESPs that exempts investment interest for the subscriber but taxes withdrawals for the beneficiary is complicated. On its own it is unlikely to be attractive to all but wealthier families who understand their tax liability or have hired a personal advisor to plan their affairs. This is in contrast with RRSPs where individual tax-payers experience an immediate and visible deduction against their current taxable income. However, a government incentive that promises 'free' money is easier to communicate than comparatively complex tax shelters. As an incentive, direct grants may be effective for some savers, even at small dollar values or matching rates. ${ }^{181}$

During the development of the budget options, the value of the government grant was changed to a $20 \%$ top-up on annual eligible contributions. At this level, mainstream retail financial institutions might have an incentive to begin marketing and distributing

${ }^{181}$ Results from matched savings experiments including learn\$ave (see Leckie et al, 2008) and the Savings Gateway (see Kempson, 2003 and Emmerson, Tetlow \& Wakefield, 2007) suggest that incentives to match personal contributions can accelerate deposits into a savings account and are viewed by accountholders as attractive account features. In qualitative research, even comparatively low matching rates are reported as appealing. Debate remains however about whether these matching incentives generate "new" savings or simply encourage households who would already save to switch deposits into the matched account over other vehicles. 
RESPs. From the provider perspective, RESPs, if not central to the business (as in the case of the group RESP providers) are not products that offer large profits on their own (Knight, Waslander \& Wortsman, 2008). Financial institutions offer RESPs to clients not because they believe they are profitable products, but rather because it is a way to demonstrate a full-service capacity for their clients and, also, to stave off an opportunity for clients to build a relationship with a competitor. ${ }^{182}$ Consumers in Canada generally maintain their financial products and services with one provider (Statistics Canada, 2009). Purchasing one financial product from a competitor might lead to future purchases. In order to prevent client loss, financial institutions that did not offer RESPs before the 1998 budget now had a greater incentive and capacity to do so.

At the same time, private sector education savings providers note that the disclosure process and administrative burden increase the costs to supply the product. ${ }^{183}$ The Chief Executive Officer of a British firm, The Children's Mutual, that offers a savings product very similar to RESPs, has argued that government expectations of providers regarding disclosure, client education and administration are often well above what a profitable firm can afford without passing on costs to consumers (White, 2003). Similarly Knight, Waslander and Wortsman (2008) found that Canadian RESP providers reported that they find the administrative burden of RESPs quite high and the level of support from government to be quite low. Providers of RESPs would have an incentive to improve their profit margin by reducing the administrative burden. A new government top-up on

182 Author's conversations with senior retail banking officials at RBC Royal Bank, 2002. ${ }^{183}$ RESP providers are responsible for submitting regular reports on account deposits and withdrawals in order to collect or return government savings incentives. 
household education savings would also provide a way to recover some of the administrative costs through investment income on the additional $20 \%$ of capital, in a variant of rent-seeking. The new federal grant would provide some assurance of revenues without the need to encourage RESP owners to contribute more to their education savings plans. For federal policy-makers, the new top-up grant for RESPs would be attractive to families and encourage new firms to enter the RESP market.

The 1998 budget announced a new incentive offered RESP-holders a 20\% top-up on deposits in an RESP for a child (Finance Canada, 1998b). To qualify for the 20\% grant, called the Canada Education Savings Grant (CESG), the RESP beneficiary had to be a child under $18^{184}$ and deposits could be made into the account by anyone —including parents, extended family and even community members - up to an annual maximum of $\$ 2,000$ in deposits (the same ceiling set in the 1997 budget) or a maximum federal grant of $\$ 400$. Unused contribution room could be carried forward, like RRSPs, up to a total of $\$ 4,000$ in any one year. Like RRSPs, over-contributions are subject to penalties if not corrected within a set timeframe. The matching grant was not income-tested, unlike the provincial homeownership savings credits in Ontario and Nova Scotia. In other words, this meant that the more an RESP owner saved, the larger the value of the government grant, up to the annual maximum.

${ }^{184}$ For beneficiaries aged 16 and 17, the CESG was limited to those who had some minimum RESP deposits in the previous years. This measure was aimed at reducing windfall gains. 
The government promoted the new measure as part of an overall "Canadian Opportunities Strategy", alongside the new Life-long Learning Plan withdrawals from RRSPs discussed in Chapter 5 and other education-related programs (Finance Canada, 1998). RESPs, with the new grant were described as "now be among the most attractive savings vehicles available for your child's education [...] one of the best things that parents can do for their children, that uncles and aunts can do for their nephews and nieces, and that grandparents can do for their grandchildren" (Finance Canada, 1998). This reference to extended family is notable because it suggests that much of the aim of the government was to extend the target subscribers to RESPs from parents to include extended family members as well. If the political aim was to be seen to be helping middle income families experiencing financial strain, then it could not have been assumed that these families already had $\$ 2,000$ per year to set aside in an RESP.

The department responsible for most federal post-secondary and skills training programming, the then-named Human Resources and Social Development Canada, was not heavily involved in the design of the CESG. Rather the program was presented as a largely fait accompli shortly before the budget was released publicly. The department opted then to take on the administrative roles of providing information to RESP providers and the public and, with regular reports from financial institutions holding the RESP 
accounts, to calculate and monitor the amount of grant to be transferred into the accounts. $^{185}$

\subsubsection{Critiques of the new grant}

In the House of Commons debate on the budget, the Progressive Conservatives were alone in their criticisms of the changes to the RESP. "This type of stop-gap, one-off, cobbled approach to education will not be effective", warned Scott Brison, M.P. for Kings-Hants (Brison, 1998a). ${ }^{186}$ Brison argued that, while the grant was a step in the right direction, RESPs were still too complex and too inflexible. He also warned that the new program was likely vulnerable to misuse and would encourage families to switch savings out of their RRSPs by making the RESP comparatively more attractive, presuming a set level of funds available to save. ${ }^{187}$ "By creating a policy like this, we will create a policy that will ultimately create financial insecurity for Canadians in terms of their retirement accounts", said Brison (1998b).

The data on overlap between retirement and education savings from Guilmette (2011) suggest that substitution is unlikely for households at and above median income levels

185 The grant is transferred quarterly to RESP accounts and earns interest like other deposits. In cases where the RESP is terminated before maturation or where it is not used by the beneficiary and is either cashed out or rolled into an RRSP, the total grant paid over the life of the RESP and the interest earned on that amount are returned to the Government of Canada by the RESP provider.

${ }^{186}$ Mr. Brison joined the Liberal Party when the Progressive Conservatives merged with the Canadian Alliance to form the Conservative Party.

${ }^{187}$ Brison appeared to have overlooked the paragraph in the proposed legislation (paragraph 34 of Bill C-36, 1998) that dealt with provisions for recovery of grants and interest earned on those grants. 
but may be an issue for the poorest $40 \%$ of households. It is important to note, however, that Guilmette's analysis looked at self-reported savings by purpose, not instrument. In other words, families in the lower two income quintiles who seemed to be most prone to trade-offs between saving for education and retirement were not necessarily reporting on savings in RESPs and RRSPs. In fact, results from the same 2009 survey, the 2002 Survey of Approaches to Education Planning ${ }^{188}$ and reports from HRSDC ${ }^{189}$ suggest that, among families reporting that they are saving for a child's education, lower income households are less likely to report saving inside RESPs. Table 6.2 below, shows the ratios of median savings earmarked for a child's education outside of RESPs to those inside of RESPs by household income.

Table 6.2 Ratio of median savings for a child's education outside vs inside of RESPs, 2001

\begin{tabular}{l|lllll}
\hline $\begin{array}{l}\text { Household } \\
\text { income }\end{array}$ & $\begin{array}{l}\text { Under } \\
\$ 25,000\end{array}$ & $\begin{array}{l}\$ 25,000 \text { to } \\
\text { under } \\
\$ 45,000\end{array}$ & $\begin{array}{l}\$ 45,000 \text { to } \\
\text { under } \\
\$ 65,000\end{array}$ & $\begin{array}{l}\$ 65,000 \text { to } \\
\text { under } \\
\$ 85,000\end{array}$ & $\begin{array}{l}\$ 85,000 \text { and } \\
\text { more }\end{array}$ \\
\hline $\begin{array}{l}\text { Median } \\
\text { savings outside } \\
\text { of RESPs } /\end{array}$ \\
$\begin{array}{l}\text { median savings } \\
\text { inside of }\end{array}$
\end{tabular}

Source: Author's calculations using data in Shipley, Ouellette and Cartwright (2003), Table A-16. Data are for deposits made in 2001 only.

${ }^{188}$ Shipley, Ouellette and Cartwright (2003) "Planning and Preparations: First results from the Survey of Approaches to Educational Planning", Statistics Canada, Ottawa. ${ }^{189}$ HRSDC (2008) "Canada Education Savings Program: Annual statistics review", Government of Canada, Ottawa; HRSDC (2009) "Formative Evaluation of the Additional Canada Education Savings Grant and Canada Learning Bond", Government of Canada, Ottawa. 
Brison's accusation that RESPs with the new matching grant would create a retirement savings crisis may not have had much basis in fact but his concerns about the complexity and barriers to usability may have been accurate. For all households, there is a substantial share of their savings earmarked for a child's education that is being done outside of RESPs. The share is largest for the wealthiest families and the lowest income families, but likely for very different reasons.

In the case of the wealthiest families, it may be that there are savings options such as private trust funds and real estate investments that provide better tax sheltered returns than an RESP, even after taking into account the $20 \%$ matching CESG. In the case of the lowest income families, the reasons are more likely related to the administrative burden, complexity and real barriers to opening an RESP.

Lower-income families are deterred by the length of the forms, jargon and multiple steps involved in applying to open an RESP (Wong, 2010; Girdharry, Simonova \& Lefebvre, 2010; Schwartz \& Ben-Ishai, 2012; Stapleton, 2013). To open an RESP, a subscriber must have already obtained a social insurance number for the beneficiary child (HRSDC, 2013). A social insurance number can only be obtained by applying to HRSDC with copies of a child's birth certificate or other acceptable proof of identity and citizenship. Both of these steps alone can take several hours and multiple trips to government offices, at a cost to a working parent both in out-of-pocket costs for transportation and childcare 
but also foregone employment income (Stapleton, 2013). ${ }^{190}$ Even when applications are available on-line, lower income families still face barriers in computer and Internet access (Schwartz \& Ben-Ishai, 2012). Once ready to open an RESP, even after changes to increase the supply of RESPs by mainstream, retail financial service providers, a parent now has to chose and contract with a provider. Particularly for parents with low and modest incomes or assets, the choice of providers can create yet more barriers to using RESPs.

In the case of the group RESP plans, media reports of certain disciplinary measures by securities regulators may have led to a perception that they are not trustworthy investments. Apart from this concern about trust, there may be other aspects related to the design of group plans that makes them less attractive to lower-income parents. For example, plans that require a contract for regular contributions, with penalties for missing contributions, may dissuade lower-income families who feel uncertain about their ability to meet contractual payments (Knight, Waslander \& Wortsman 2008). Similarly plans with limited refundability in case a beneficiary child does not pursue higher education or restrictions on the kinds of education that will be recognized by the RESP provider are also likely to meet with understandable resistance among lower-income families who

\footnotetext{
${ }^{190}$ Following a pilot project, some provinces including Ontario have integrated their provincial birth registration applications with federal applications for a social insurance number and even income-tested child benefits. A single on-line portal allows for simultaneous applications to all programs at the same time. This option is only available however to parents of children born in Canada, in participating provinces with access to a secure Internet connection and computer.
} 
may be hopeful but less confident that their child will in fact go on to higher education (Knight, Waslander \& Wortsman, 2008; Wong, 2010). ${ }^{191}$

Most RESP providers require that a subscriber also have a deposit account with a mainstream financial service provider (Schwartz \& Ben-Ishai, 2012). This allows the provider to set up automated electronic transfers for contributions into the RESP. Lowerincome Canadians often report feeling unwelcome, uncomfortable and often poorlyserved as clients (Buckland, Brennan \& Fikkert, 2010; Buckland, 2012; Robson, 2012). In a bank or credit union, front-line client service personnel are not always familiar with RESPs as a financial product and may not be able to give accurate information to clients about rules regarding the product or the government matching grants (Wong, 2010; Girdharry, Simonova \& Lefebvre, 2010). These are the same retail financial service providers that were expected to enter the RESP market after the 1998 budget.

A final critique points to the interaction with provincial means-tested benefits. Because RESP savings could be withdrawn with penalties, they would have been regarded by provincial social assistance policy-makers as a liquid asset that should be used before income support was provided. ${ }^{192}$ In 1998 through to 2004, RESP deposits were included

\footnotetext{
${ }^{191}$ Many group RESP providers now provide options for individual and more flexible contribution schedules. RESP providers also now are required to follow the Government of Canada's "Master List of Designated Educational Institutions", a list prepared in consultation with provincial and territorial governments and used for the administration of federal and provincial student loans programs.

${ }^{192}$ Author's review of provincial social assistance regulations and policy manuals in 2002 and 2006-2008.
} 
in most provincial means-tests for welfare and related programs (Robson, 2008). If a family was currently receiving, or anticipated that they might need to apply for, social assistance in the future, they might have greater incentive to save for a child's education in ways that could more easily be concealed from social assistance programs or the Canada Revenue Agency_-for example, cash savings kept at home.

\subsubsection{Effects of the 1998 launch of the CESG}

The success of the 1998 budget announcement on RESPs might be measured in a number of ways based on the stated goals: increased competition in the supply of RESPs, positive political reaction and household use of RESPs.

It does seem to have had the desired effects of increasing the number of RESP providers. From a list of 22 RESP promoters in 1997, the supply has increased now to 71 promoters. $^{193}$

It also seems that the government saw some positive public opinion in response to the budget. A Gallup Poll conducted in March 1998 asked Canadians about their awareness and perceptions of the federal budget. Overall, 55\% of Canadians reported that they were aware of the budget and $53 \%$ of those felt that it would, on balance, help their own family's financial situation. This positive assessment was more frequent among families with children under 10 . However, the poll also found a much stronger degree of support

${ }^{193}$ Personal communication with official in the Registered Plans Branch, Canada Revenue Agency, Spring 2013. 
among Canadians with higher incomes compared to lower incomes: $53 \%$ of those with household incomes over $\$ 80,000$ reported that the budget would be helpful to their family while only $20 \%$ of families with incomes under $\$ 20,000$ said the same thing (Gallup, 1998).

The proportion of Canadian children with an RESP and total RESP assets also increased. Less than two years later, the Finance Minister reported that RESP assets had doubled since the creation of the CESG in the 1998 budget (Martin, 1999). He stated:

The 1998 budget created the CESG, a forward- looking initiative designed to help families save for their children's post-secondary education. Canadians have responded overwhelmingly to that measure. During the first 25 years of Registered Education Savings Plans (RESPs), \$2.5 billion of savings were accumulated. In the short time since the CESG was introduced—only 21 months ago - private savings have doubled to $\$ 5$ billion. The fact is, thanks to the CESG, RESPs are becoming as essential and as valuable to saving for education as are Registered Retirement Savings Plans to retirement.

In 1998, when the CESG was introduced, $40 \%$ of Canadian children with any education savings had those savings in an RESP (SAEP, 1999). It is not possible, based on public data, to know how this compares to RESP coverage prior to the 1998 budget. By 2001, that proportion had increased to 54\% (Shipley, Ouellette \& Cartwright, 2003). 
From the available data, it is difficult to determine how the $14 \%$ increase in RESP coverage was distributed by household income. ${ }^{194}$ The question of equity has been raised by Don Drummond, who had been Assistant Deputy Minister of Tax Policy during the process to develop the CESG and 1998 budget. Drummond has observed that "it's probably not that far-fetched a statement to say that on the tax side, our financing of postsecondary education is now a transfer away from the less well-off to the better off" (The Calgary Herald, 2008). In other words, the method of delivering more of the assistance to household for post-secondary cost through tax-preferred account-based instruments has made for a more regressive approach.

In 2003, HRSDC conducted its first formative evaluation of the CESG/RESP program. The evaluation report concluded that, while the program had been successful in accelerating total education savings for children, take-up in the program was very weak among low-income families. In fact, most of the CESG, in dollar terms, was flowing to upper-middle and higher income households — those with incomes over $\$ 80,000 .{ }^{195}$ If the

${ }^{194}$ The public micro-data files for the 1999 and 2002 Surveys of Approaches to Educational Planning use different measures of RESP coverage. The 1999 survey does not, for example, include a measure of the dollar value of RESP savings but instead only reports whether households were saving and were doing so in an RESP. In both cases, the included weight is for each individual child. For portfolio analysis, the appropriate unit of analysis is more correctly the household rather than a single member of the household.

${ }^{195}$ This evaluation report is no longer available on the HRSDC website or through the archive of federal online content maintained by Library and Archives Canada. The findings cited here are based on a reference to the 2003 evaluation in a 2009 formative evaluation report (HRSDC, 2009), the author's recollections from reading the report when it was available and the author's conversations with several senior officials at HRSDC between 2002 and 2006. 
original private group education savings plans had been largely of benefit to uppermiddle income families, the first efforts to change the RESP — including increases to annual and total contribution limits and then the creation of the CESG-had not fundamentally changed the distribution of tax-preferred education savings. The department and outside stakeholders soon developed a set of proposals that were aimed at addressing this inequity.

\subsubsection{Amending the grant and adding the Canada Learning Bond}

On the heels of the above-mentioned evaluation report, officials at HRSDC launched a policy development process to find mechanisms to boost take-up of RESPs amongst lower and modest income families. ${ }^{196}$ The process included an environmental scan of savings programs targeted to low-income participants in Canada and abroad, key informant interviews and public opinion research on the RESP and CESG, consultations with outside stakeholders and advocates and a study tour to the United Kingdom to examine the design and early implementation of two savings incentive programs introduced by the UK government. ${ }^{197}$ Officials in the Department of Finance were not enthusiastic about RESPs. They viewed these as a problematic but thankfully low-cost aberration in the Income Tax Act (Martin, 2008). There was a real concern in HRSDC, if

\footnotetext{
${ }^{196}$ This section is heavily informed by the author's first hand knowledge of events as the Direct of Research for Social and Enterprise Development Innovations. She worked directly with political and senior public service officials in government as they developed the RESP changes for the 2004 federal budget and appeared as a witness at two Parliamentary Committees.

${ }^{197}$ Findings from that study tour are reported in Robson (2005). "Asset-based Policy in the United Kingdom: Lessons for Canada", Toronto: Social and Enterprise Development Innovations.
} 
the distribution of the take-up could not be addressed, the CESG and RESP would be at risk for termination. The department's arguments for preserving and improving the education savings programs were three-fold:

- Lower and modest-income Canadians had been shown to be interested in saving, particularly for their children's education. Further, when provided with incentives and account structures that were responsive to their needs, some were able to save amounts that would surprise many policy-makers. ${ }^{198}$

- The administrative costs of the matched education savings program were miniscule relative to the costs of administering the Canada Student Loans Program. ${ }^{199}$ If an incentive to promote early savings could reduce dependence on student loans over the medium-term, it was hoped that the overall education financing system could be made more efficient, effective and sustainable.

- Evidence from early commitment programs and the department's own analysis of the Survey of Approaches to Educational Planning suggested a positive effect on education savings and student motivation and performance in secondary school. The literature on early commitment programs was later reviewed in Currie, Leonard, Robson and Hunter (2009) who also concluded that early guarantees of

\footnotetext{
${ }^{198}$ At the time, HRSDC was also funding learn\$ave, a large scale demonstration of individual matched savings accounts for low-income Canadians interested in returning to school or starting a small business. Some members of the department, including the head of the learning branch and the Deputy Minister, were keenly interested in "asset-based" policy instruments as an alternative delivery mechanism for a wide range of programs and benefits. See Chapter 1 in Leckie et al. (2010) for a discussion of proposed advantages of asset-based instruments. ${ }^{199}$ Lenore Burton, Director General, Canada Education Savings Program, HRSDC, remarks to a national conference on financial capability, Ottawa, 2005.
} 
financial capital for higher education can have positive effects for some disadvantaged students.

By early 2003, there had been a substantial change in the political leadership of the government. Jean Chrétien had been forced into an early departure by long-time rival and former Finance Minister, Paul Martin. There was a perception among some HRSDC officials and external stakeholder that the new Prime Minister may be more inclined to spend federal money on RESPs, given his past record in the 1996 through 1998 budget.

Throughout 2003, officials in HRSDC and external stakeholders continued to press for changes to enhance the CESG. The preferred model was to introduce an income-tested government grant, to be deposited directly into individual RESPs. Unlike the CESG, the proposed income-tested deposit would not need to be matched with household savings. In addition to the new income-tested grant, officials and stakeholders proposed that the CESG be increased above a $20 \%$ match rate for low and modest-income families.

Officials in the Department of Finance were resistant, likely viewing the proposals as throwing good money after bad. Senior political advisors close to Martin expressed keen interest in the proposal but were unable to counter arguments from the Department of Finance that only a very costly program could have enough incentive effect to increase RESP savings and education participation and reduce future demand on student loan programs. If the dollar values of the income-tested government contribution were too low, the argument was that it would do little or no good in terms of promoting access to 
higher education. If the dollar values were too high, the program was rejected as too costly. Finding the right matching ratio that would be seen by lower-income families as sufficient to offset the costs and barriers to using RESPs proved equally difficult.

In late 2003, senior political advisors to Martin met directly with senior advisors to the (then Labour) government in the United Kingdom and discussed their experience in launching the Child Trust Fund. The Child Trust Fund was an endowment for all children in the U.K. born after a certain date with payment rates geared to income. A few months later, the Canadian government introduced its 2004 budget, including a commitment to create a new Canada Learning Bond and enhancements to the Canada Education Savings Grant.

Framed as "targeted measures to help low- and middle-income families save for their children to go to college or university", the 2004 budget promised:

- A one-time $\$ 500$ deposit into an RESP for all children receiving the National Child Benefit Supplement ${ }^{200}$ and $\$ 100$ deposits for each subsequent year that the same child continued to receive the supplement, referred to as the Canada Learning Bond (CLB). Payments of the bond would be made after the implementing legislation received Royal Assent but eligibility would be

\footnotetext{
200 The Supplement is a portion of the Canada Child Tax Benefit system that is targeted to low and very modest income families. For families with one child, it is reduced gradually as income rises above $\$ 24,683$ for 2013 . Annual income limits are adjusted for inflation (CRA, 2013).
} 
retroactive to children born from January 1, 2004 onwards. The total CLB payments for any one child were capped at a lifetime limit of $\$ 2,000$.

- Changes to the CESG so that the first $\$ 500$ of annual personal savings in an RESP for a child could be matched at $30 \%$ or $40 \%$ depending on household income, ${ }^{201}$ referred to as the Accelerated Canada Education Savings Grant (A-CESG). The annual limit on contributions to an RESP that could be matched by federal grants was kept at $\$ 4,000$ per year. Families earning up to $\$ 35,000$ could receive up to an additional \$200 for annual savings of \$500 and families earning between $\$ 35,000$ and $\$ 70,000$ could receive up to $\$ 150$ for the same savings. Households with incomes greater than $\$ 70,000$ would continue to get the $20 \%$ grant on all deposits and households in the other income groups would similarly get the basic $20 \%$ CESG on any savings they managed to make above the $\$ 500$ per year. In real terms this meant an additional $\$ 100$ per year to the lowest income families and an additional $\$ 75$ per year to the modest income families over and above what higher income families would be getting for doing the same amount of saving.

\subsubsection{Critiques of the new CLB and A-CESG}

In keeping with their opposition to other registered savings instruments, the NDP members argued against the CLB and A-CESG. They argued that it did nothing to help

\footnotetext{
${ }^{201}$ The dollar amounts of the thresholds are revised annually. Values reported here are as announced in the 2004 budget. Current values are up to $\$ 42,706$ for the $40 \%$ match rate and from $\$ 42,706$ up to $\$ 85,414$. It is important to note that income here refers to net family income, calculated after exemptions and deductions have been applied. Real market earned incomes are likely to be higher for many families.
} 
current Canadian students who were struggling with rising tuitions and mounting loan debts (McDonnough, 2004). Conservative M.P.s, while generally supportive of the measures, were reluctant to call for program measures that might contribute to a successful implementation, such as increased spending on outreach and communication to eligible families (VanLoan, 2004).

In Committee testimony, representatives of student associations argued against the CLB and enhanced CESG, taking a position very much aligned with the NDP. Representatives of RESP providers, particularly the largest and longest-standing group provider, the C.S.T. Foundation spoken strongly in favour of the measures (Lewis, 2004). Advocates for low-income Canadians were mixed in their response. Some argued against it as a distraction from more pressing needs for income support (NAPO, 2004) while others said the measures were a good start but called for detailed attention to implementation issues and openness to future investments (Robson, 2004; Shillington 2004).

Later, a 2009 formative evaluation conducted by HRSDC concluded that the financial incentive of the CLB and CESG likely needed to be increased to meet program goals but that implementation issues were more immediately pressing (HRSDC, 2009).

One other argument leveled against the CLB was that, given the target population, families receiving the bond would be too poor to save anything else out of their own money (HRSDC, 2009). Even in the best-case scenario in which an eligible child received the $\$ 500$ in his or her first year and then the $\$ 100$ bonds in each year up to the 
lifetime maximum of $\$ 2000$, the total value of the RESP by the end of secondary school may be worth between $\$ 3,200$ and $\$ 5,900 .^{202}$ These amounts are small relative to the full costs of a post-secondary diploma or degree. It is also unknown whether these amounts are sufficient to have the behavioral effects of other early commitment programs in terms of secondary achievement and aspirations towards higher education.

The critique that the CLB would not meaningfully increase the education savings of low and modest income households presumed that these families would not save their own money. However, $95 \%$ of RESP accounts receiving the CLB have also increased through personal savings deposits (HRSDC, 2011). In other words, the overwhelming majority of families who receive the CLB are also saving something themselves in RESPs. How much they are saving, relative to other similar families who are not using RESPs (and therefore not receiving the CLB), has not yet been examined in the published literature. If families receiving the CLB save more than CLB-eligible families who do not open an RESP, then it would be reasonable to conclude that the CLB has an incentive effect on household savings.

One way of estimating the difference between CLB-eligible families using and not using RESPs is to compare the annual average deposits into RESPs with the reports of annual savings earmarked for education outside of RESPs. The best available estimates of annual savings for education outside of RESPs among low and modest income families

${ }^{202}$ Author's calculations based on annual compound interest of 3\% and $8 \%$. 
likely to be eligible for the CLB suggest that they are saving approximately $\$ 485$ per year. ${ }^{203}$ HRSDC (2011) reports that the total value of RESP assets in CLB recipient accounts grew \$306 million in 2010, without including CLB amounts for that year. With 292,940 accounts in total, less the $5 \%$ who do not save anything on top of the CLB, this suggests that annual growth was, on average, $\$ 1,106$ per account in 2010 . This estimate does not include any CLB money paid into the account.

Some share of this growth is due to interest earned on savings deposits made in that year or previous but given low rates of interest this amount is likely to be small in dollar terms. HRSDC's public reporting is ambiguous on whether the increase in the value of accounts includes the matching CESG and A-CESG amounts. On the conservative presumption that it does, roughly $\$ 250$ might be deducted from the estimate of average RESP growth, suggesting that CLB-recipient accounts may have annual personal savings of $\$ 856$ - substantially higher than $\$ 485$ in CLB-eligible savings outside of RESPs. This estimate should be verified as survey and administrative data become available.

${ }^{203}$ This estimate is based on data in Shipley, Ouellette and Cartwright (2003) for the 2002 Survey of Approaches to Education Planning. Data in the more recent Canadian Financial Capability Survey were not usable for this analysis. The estimate of $\$ 485$ is based on a median annual savings outside of RESPs of $\$ 480$ for the lowest income families (earning less than $\$ 25,000$ ) and $\$ 490$ for the next quintile (earning between $\$ 25,000$ to under $\$ 45,000)$. All of the families in the first quintile are likely eligible for the CLB and many in the second may be as well. The similarities of the dollar values in median savings for the two groups is striking. Reports of average RESP contributions by all Canadian families suggest relative stability over time (see for example HRSDC, 2008; 2009; 2011). Adjusting for inflation (author's calculation using the Bank of Canada Inflation Calculator and based on Statistics Canada series V41690973) provides an estimate of $\$ 570$ for 2010 


\subsubsection{Concluding thoughts on the RESP}

Any effects on secondary achievement and post-secondary participation will not be known until 2022 when the first cohort of CLB-eligible students turns 18, the usual age for transitions out of secondary school.

Based on the most recent evaluation and statistical reports, it is clear that the expected effects of significantly boosting the use of RESPs by low and modest income families has not, at this time, been fully realized. Among all children eligible for the CLB, only $4.7 \%$ had received the bond by the end of 2006 (HRSDC, 2012). The government's own projections had been that the take-up of the program would be slower in the first two years but this result was well below their most conservative estimates. By late 2011, the take-up nationally was $23.4 \%$ with steady increases year over year since the program was launched (HRSDC, 2012). Recall that the rate of RESP use by Canadian families as a whole is over $50 \%$. However, other estimates suggest the take-up may be significantly higher in communities where there have been substantial efforts of RESP providers or community organizations to promote awareness and facilitate the application process for eligible families (Stapleton, 2013; Nayar Consulting, 2013). It seems these labourintensive, 'high-touch' programs do much to address the non-financial barriers to opening an RESP for some low-income families. These programs appear to work in two ways: first, by raising program awareness and understanding for products not generally marketed by providers to this target group; and second, by providing information and basic guidance to parents as they choose an RESP provider and product. Finally, by 
addressing administrative barriers such as helping with obtuse application forms, transportation and perceptions of financial exclusion (Wong, 2010; Robson, 2012; Nayar Consulting, 2013).

Other key obstacles to greater equity in take-up are apparent on the RESP provider side. While the number of overall providers has increased substantially, as many as one quarter may not be participating in the CLB and enhanced CESG programs (HRSDC, 2009b). ${ }^{204}$ There have been anecdotal reports that front-line staff of RESP providers are not always adequately informed about the nature of the product and the associated government incentives, sometimes discouraging or misinforming lower income clients looking to open an RESP and receive the CLB without committing to future savings of their own (Robson, 2012).

Various government departments and agencies including HRSDC, the Financial Consumer Agency of Canada, the Canada Revenue Agency, Canlearn.ca (a joint project of federal and provincial governments) and several provincial securities regulators have all invested in communications initiatives to try to address gaps in understanding and awareness on both the provider and consumer side. HRSDC has also spent approximately \$2 million per year to fund voluntary sector organizations through a

\footnotetext{
${ }^{204}$ From the available public information is not possible to determine whether these RESP providers have declared that they will not participate in the CLB and enhanced CESG, effectively stating that they do not plan to serve any clients below a certain income level, or whether it is rather that these providers have not yet had a client who is eligible for these income-tested programs.
} 
program called the Education Savings Community Outreach program (HRSDC, 2011). The program provides funding to cover up to $75 \%$ of the costs for community organizations to promote awareness of RESPs and government savings initiatives. At least one participating organization has concluded, on the basis of their experience, that while the CLB and A-CESG are policy changes that trend in the right direction, they do not, as currently designed, respond to the needs and preferences of the target population (SEDI, 2010).

The introduction of the CLB and increased CESG may not, at this time, have equalized accessibility of RESPs for lower income families. One, perhaps unexpected effect of the policy change has been on provincial policy-makers. Before CLB payments were made, governments in all provinces and territories had amended their social assistance rules to exempt RESPs for dependent children from the list of assets included in an assessment of a household's wealth (Robson, 2008). This now means both that families who apply for social assistance and those who want to remain eligible for benefits can use RESPs to save for a child's education without penalty to their income flows.

Furthermore, four provinces introduced complementary programs, promising provincial contributions into eligible RESPs. Alberta was the first with the Alberta Centennial Education Savings (ACES) program initially proposed by a backbench MLA and later included in the 2004 provincial Speech from the Throne. Positioned as a legacy initiative to mark the province's $100^{\text {th }}$ anniversary, the Alberta Speech from the Throne described the program as "more than an investment in individual children. It is an investment in 
our shared future as Albertans, in the generations who will inherit all that Albertans have worked hard to create" (Hole, 2004). Children born from January 1, 2005 onwards were to receive a $\$ 500$ deposit into an RESP as long as they were resident in Alberta. No conditions on household income or household contributions to the RESP were included in the design. The plan also included $\$ 100$ contributions for eligible children at age 8,11 and 14. Administration of the plan was uploaded to the Canada Revenue Agency, in collaboration with HRSDC and the Alberta ministry responsible for higher education.

In its 2013 budget, the Alberta government announced that the ACES program would be "winding down" and promised that information on final eligibility dates and other closing details would be forthcoming. Like the 1985 budget cutting the RHOSP, it appears as though the decision to phase out the ACES program is largely framed in terms of returning the province to a balanced budget. The actual dollars saved, however, are quite modest at \$11 million per year (Finance Alberta, 2013).

As of 2013, Quebec, British Columbia and Saskatchewan all have provincial RESP contribution programs that have recently been or are about to be implemented. The Quebec government launched its Quebec Education Savings Incentive in 2007 as a refundable tax credit paid directly into the RESP accounts of eligible children in the province. The basic benefit is a $10 \%$ matching credit on annual savings in the account (excluding amounts from federal savings incentives) to an annual maximum of $\$ 250$, $\$ 300$ for low-income families. The lifetime maximum of the QESI for any one child in Quebec is $\$ 3,600$ (Quebec Portal, 2013). In late 2012, the government of Saskatchewan 
launched a very similar program of a $10 \%$ matching grant to a maximum of $\$ 250$ per year but legislative authority to implement the program is still pending. Finally, in its 2013 budget, the government of BC announced a new BC Training and Education Savings Grant that would deliver a one-time $\$ 1,200$ grant into an RESP of eligible children in BC.

The impact of these additional federal and provincial savings incentives, on top of the favorable tax-treatment of RESPs, on the well-being of families with children and on the educational attainment of the beneficiary children is unknown and, until the first cohort of children transitions into early adulthood, likely unverifiable. It is clear, however, that as long as wealthier families remain more likely to open RESPs, they will reap a larger share of the benefit from the universal grant programs and a larger share of the benefit from matching savings incentives that, despite improvements, still reward larger savers more than small savers.

The 2004 change to the CESG that introduced income-tested matching rates is an interesting departure from the general policy trend. Previous tax-preferred savings instruments provided thinly-universal policy features that all offered, in practice, more financial benefit to wealthier households. But, it is unclear whether the dollar values involved in this policy shift from the CLB and A-CESG are meaningful for Canadian households. It is also unclear whether the net benefits from the program are sufficient to offset the complexity that could otherwise dissuade many target families. 
The 2004 income-tested CLB is also an interesting exception to past tax-preferred savings because it created an income-tested transfer of capital that did not depend on individual or household 'thrift'. As part of the overall CESG, the A-CESG remains part of a quasi-universal program to promote savings through tax-assisted accounts. But the CLB is unique in restricting a benefit associated with a registered, tax-preferred savings instrument to lower-income families. The rough estimates (discussed above) suggest that the CLB might be leading to an increase of nearly $\$ 400$ per year in education savings for participating families. But this estimate should be treated with caution until sufficient data is available for analysis.

Perhaps the strongest impacts of the additional savings incentives for RESPs are actually political. In the case of the federal CLB and A-CESG, as well as the four provincial programs mentioned earlier, the policy announcement was made by the governing party in the same year that they would call an election. In election years, promises of money for children's education might be appealing to a range of voters and, given the relatively small value per account, are fairly low-cost and low-risk commitments. Political attention to RESPs and education savings at the federal level has had an impact on provincial political and policy priorities too. Finally, the experiments with new incometested savings incentives may also have raised stakeholder awareness and understanding of both financial and non-financial barriers to opening and using RESPs.

The 1998 budget that brought in the CESG needed placeholders for a range of target populations - the Lifelong Learning Plan for working-age adults (see Chapter 5), changes 
to student loans and bursaries for current students, and improvements to RESPs for families with young children. Its lasting impact though may not be on post-secondary education and training in Canada, but rather increased attention to accessibility in registered savings instruments. The designs of the final two registered instruments introduced since 1998 have paid somewhat more attention to the needs of low and modest income Canadians. ${ }^{205}$ These are discussed in the next chapter. Whether this is a permanent and meaningful shift in tax-preferred account-based savings policy remains to be seen.

\footnotetext{
${ }^{205}$ In addition to the RDSP and TFSA discussed in the next chapter, the Government of Canada has also made available a new Pooled Registered Pension Plan starting January , 2013. The PRPPs are pooled defined contribution retirement savings plans for employees and self-employed persons who have not exhausted their RRSP/RPP contribution room. In design they are essentially similar to an RRSP but feature a group savings element to create a larger pool of capital and generate larger returns. At the time of writing PRPPs are only available to employees in federally-regulated sectors such as transportation and banking. Enabling legislation is required in each province. Given the limited scope and implementation experience to date, PRPPs are not discussed in this study.
} 


\section{Chapter 7: Completing the set: RDSPs and TFSAs}

This chapter concludes the retrospective analysis of the tax-preferred savings instruments by discussing the development and early evidence on the Registered Disability Savings Plan (RDSP) and Tax-Free Savings Account (TFSA). These were each introduced by the federal government within the very recent past and, as a result, there is very little evaluation data available as of yet. Like all of the other instruments discussed in Chapters 4, 5 and 6, the RDSP and TFSA are also instruments that: 1) require attachment to a mainstream financial services provider; 2) use the personal income tax system to deliver incentives in ways that confer larger benefits on those with larger taxable incomes; 3) normalize only certain kinds or goals for personal savings; 4) promote financial capital that is fungible and may be beneficial to the saver outside of the strict savings goal of the tax-preferred account.

This chapter finds that, like the RHOSP and RESP, the RDSP and TFSA have each been designed based on previous examples. These last two instruments to be created came after many decades of incremental change to RRSPs, experiments with instruments that were cancelled (compulsory savings and the RHOSP) and changes to the RESP aimed at increasing accessibility to low and modest income families. The RDSP was most heavily influenced by the RESP - as will be discussed in the current Chapter. The TFSA was developed as a complement to the existing RRSP. Like the RRSP, the RHOSP and the RESP before it, the RDSP was introduced following the advocacy efforts of outside stakeholders who wanted a change to tax policy to meet a savings goal that was personally important to them. Like these previous instruments, it seems that the creation 
of the instrument also owes something to the personal preferences of key decisionmakers. The TFSA, by contrast, came about following a largely theoretical and academic debate - making it similar in that respect to the wartime compulsory savings experiment that relied heavily on theory from Keynes.

This chapter begins with the retrospective analysis of the RDSP, then the TFSA and finally ends with some general conclusions across the six instruments discussed over Chapters 4 through 7.

\subsection{The Registered Disability Savings Plan}

In 1989 a small group of Canadian parents of children with disabilities formed a new organization they called Planned Lifetime Advocacy Networks (PLAN, 2013). Changes in the treatment and care of persons with disabilities meant that children with disabilities were being cared for outside of institutional settings and, at the same time, persons with physical and cognitive disabilities were living longer than before. PLAN was formed as a group of parents concerned with how to ensure the wellbeing of their son or daughter after they, as the primary caregivers, grew elderly and eventually passed away (PLAN, 2009).

The group emphasized the need for parents to plan ahead for the social and financial capital that their children with disabilities would need later in life. For example, they encourage parents to build personal networks of family members, friends and community members who can act as caring advocates for their child. Similarly, in the mid 1990's, 
the group launched a successful public advocacy campaign regarding discretionary trusts and provincial means-tested benefits for persons with disabilities. ${ }^{206}$ Beginning in 1998, PLAN also began to examine ways to better support parents in planning ahead and saving up for a child with a disability.

PLAN's goal was to find a way to allow other family members, in addition to parents, to contribute towards a savings plan for a child with a disability. They also wanted a mechanism that would enable parents and even grandparents to roll-over their RRSP savings, without penalty, into this new savings plan. It is notable that the group has stated that "independence from government funding was our first value" (PLAN, 2009). While this statement was made in reference to the funding for the group itself, it is indicative of an orientation towards self-sufficiency and using one's own money. A founding member of PLAN, Arthur Mudry, is quoted as follows, "if we earned our own money, we could advocate and hold government accountable" (PLAN, 2009). It is not difficult to see how the group might move from a focus on technical elements of discretionary trusts to a focus on longer-term parental, family and even community savings.

In early 2003, the federal government established the Technical Advisory Committee on Tax Measures for Persons with Disabilities (TACTMPD). The group included tax

\footnotetext{
${ }^{206}$ Discretionary trusts, also referred to as family trusts, are a form of flexible trust that allows a sponsor to determine the amount and nature of payments to beneficiaries within a group. The beneficiaries do not have any ownership over the trust and cannot change the terms of payment.
} 
experts (including many with experience in the Department of Finance), representatives of organizations serving persons with disabilities and was co-chaired by Sherri Torjman of the Caledon Institute. After several years of incremental reforms to disability and medical expenses tax credits, the Advisory Committee was asked to make recommendations that would "improve the fairness of the treatment of persons with disabilities under the income tax system, taking into account available fiscal resources" (TACTMPD, 2004).

In its 2004 final report, and among its many recommendations on tax credits and deductions, the Advisory Committee also recommended:

The government [should] examine ways to allow greater flexibility as to how the private savings of a caregiver can be used to provide ongoing support to a dependent child or grandchild with a disability in the event of the caregiver's death. This measure will help these families to ensure a better quality of life for their children or grandchildren with severe disabilities (p.7).

In the February 2005 budget, the federal government implemented several of the Committee's recommendations to expand and improve disability-related tax credits, provide more flexibility in the rules on RESPs for children with a disability. ${ }^{207}$ The federal government also committed to "reviewing rules" regarding the rollover of a

\footnotetext{
${ }^{207}$ Prior to 2005, an RESP account could only receive contributions for 21 years and had to be closed before the $25^{\text {th }}$ anniversary that the account was opened. In 2005, these deadlines were extended to 25 years and 30 years, respectively, for children with disabilities. The deadlines have also since been extended for the general population.
} 
parent or grandparent's RRSP savings to a child with a disability (Finance Canada, 2005, Annex 8). At the time, a parent or grandparent could, as part of the distribution of their estate after their death, transfer any unused RRSPs to a child with a disability but only through an RRSP in the child's name or by purchasing an annuity with the child as the named beneficiary. ${ }^{208}$ For parents of children with disabilities, there would have been three major concerns.

First, compared to discretionary trusts, the RRSP or annuity options gave parents less choice regarding the terms of payment to their dependent child and likely increased the transaction costs, at least in the case of the annuity. ${ }^{209}$ Second, and closely related to the first, while discretionary trusts could be set up to equip members of the social network supporting a person with a disability, ${ }^{210}$ a self-directed RRSP in the name of a child with a disability could create substantial legal difficulties. This would be unique to cases where an adult with a cognitive disability is unable to exercise competent decisionmaking or where periodic or degenerative illnesses similarly make it difficult for a person with a disability to exercise full control over their assets. Third, and perhaps most importantly, RRSPs and annuities, unlike discretionary trusts, are viewed by provincial social assistance administrators as assets owned by their beneficiaries. Particularly for

\footnotetext{
${ }^{208}$ The rules also permitted the transfer of funds from a Registered Retirement Income Fund, essentially a matured RRSP paying out retirement income.

209 The costs of the annuity to achieve some target level of payment would likely be high and the personal income tax costs of cashing out an RRSP would also be quite high, relative to a discretionary trust.

${ }^{210}$ See reference above to PLAN's model of a social network of support to provide lifelong assistance to a child with a disability.
} 
persons with disabilities who have limited attachment to the workforce, social assistance benefits are an integral part of their household income as adults (HRSDC, 2013). The assets transferred from a deceased parent or grandparent to a child with a disability could, in these circumstances, result in an immediate claw-back of the monthly social assistance income benefits that the adult child relies on. To paraphrase John Stapleton, while most Canadians would welcome an inheritance, for those on social assistance, the news is met with terror (Stapleton, 2009).

PLAN's 2003 submission to the Advisory Committee had, among other things, called for the federal government to create a new registered savings instrument that would allow for the roll-overs of the RRSP and RRIF funds while at the same time preserving the flexibility, and exemptions from means-tests, of discretionary trusts. "There is no incentive [in the tax system] for families to plan for the future", wrote PLAN in their submission (PLAN, 2003).

Their proposal for such an incentive was for a tax-deferred savings plan, very much like an RRSP. ${ }^{211}$ Contributions to the savings plan would accumulate tax-free during the

211 PLAN's 2003 proposal uses the term “deferral”, suggesting that taxes might be paid, even if at a reduced rate, at some future date. Recall that in the case of RRSPs, taxes are deferred until retirement when mandatory withdrawals begin. In the case of RESPs, taxes are deferred until withdrawals are made and taxed as income in the hands of the student. In both cases the applicable rate of taxation is generally presumed to be lower at the time of the withdrawal than at the time of contribution. Furthermore, in the case of RRSPs, there is a further incentive to contribute in the form of an annual deduction from taxable income. Details regarding the deferral and any additional incentives were not included in PLAN's proposal. It is not uncommon for advocacy organizations to make 
lifetime of a beneficiary with a disability. Withdrawals would be similarly tax-free as long as they could be shown to be for purposes that "enhanced the participation and citizenship" of the beneficiary. Notably, ownership of the registered account could be held by a trust and not just by an individual. Also, contributions to the savings plan would be permitted from the person with the disability and from family members either through cash deposits or through transfers of other financial assets. The aim was both to create an instrument that might reduce poverty of adults with disabilities over the longer term and, at the same time, catalyze a family to look ahead and take steps to plan financially and otherwise for their dependent child with a disability. Outside of the taxpreferred treatment however, the PLAN proposal did not envisage any direct financial benefits from government, in keeping with their philosophical orientation towards independence and self-reliance.

Not long after the 2005 budget, a political crisis ${ }^{212}$ and then a general election in 2006 caused a widespread bottleneck on nearly every federal policy front. Like proposals on many other issues, the idea of tax-preferred disability savings instrument was placed on hold. The Liberals lost the 2006 election and were replaced by the Conservatives who installed Jim Flaherty as the new Minister of Finance.

more general statements regarding their preferred policy option and to delegate the more detailed policy development to policy-makers inside of government departments and agencies.

${ }^{212}$ Justice John Gomery was appointed by Prime Minister Paul Martin to investigate political interference and misuse of public funds through the federal sponsorship program. 
Flaherty had previously served as provincial finance minister in Ontario and was familiar with the interaction of federal income tax measures and provincial income support programs. Flaherty, in keeping with the ideological perspective of the new government, also made clear that he was in favor of measures to reward individual effort and economy over reliance on government programs and spending (Flaherty, 2006). But perhaps most importantly, Flaherty himself is the father of a son with a disability and, as a personal mission, made the tax treatment of disability a key priority early on in the Finance portfolio (Curry, 2011).

\subsubsection{Considering options for the new instrument}

Flaherty was sworn in as Minister of Finance in early February 2006 and by May 2006, in his first budget, announced a new expert panel to advise the government on the financial security of children with disabilities (Finance Canada, 2006). ${ }^{213}$ The panel was named in 2006 with a mandate to "examine ways to help parents and grandparents save for the long-term financial security of a child with a severe disability" (Finance Canada, 2006c). Their final report was issued in December of that year and prepared the government for an announcement in the 2007 budget.

\footnotetext{
${ }^{213}$ Members of the panel included Laurie Beachell, head of the Council of Canadians with Disabilities who had also served on the 2003 Technical Committee as well as Quebec actor Rémy Girard (also a father of a child with a disability) and James Love, head of a private trust and a Toronto lawyer. The head of the secretariat at the Department of Finance was Ian Pomeroy, a long-time member of the Tax Policy Branch at Finance who had previously lead, with his then-colleague Keith Horner, a study of tax pre-paid savings plans.
} 
Meanwhile, PLAN had commissioned two studies, published by the Caledon Institute, to develop its proposal for a tax-benefitted savings plan for parents of children with disabilities. One study was a review of the relevant federal and provincial policy environment regarding disability savings conducted by Richard Shillington.

Shillington (2005) noted the range of restrictions against savings and assets for individuals and families receiving means-tested benefits and flagged this as a substantial issue to be considered and resolved in any disability savings plan. He also, very briefly, proposed three ways that a new savings plan might be constructed using existing tax policy precedent:

- In the first option, assets of a donor (such as a parent) would be given to a recipient child. The assets would have been accumulated using after-tax income and would receive no tax credit or other incentive. Investment interest on the savings would also be taxed in the hands of the donor until the asset is given away. Withdrawals after the transfer to the child would be taxed in the hands of the child - in a sense creating the same kind of double-taxation faced by the original group education savings plan members prior to the 1972 Tax Court decision.

- The second option was to employ an RRSP-like model in which savers would receive a deduction for their contributions and withdrawals by the recipient would be taxed at their (presumably lower) tax rate. Shillington raised the concern that, although the deduction created a greater savings incentive for the donor and avoided the problem of double taxation, it could create opportunities for families to avoid taxes by claiming deductions, paying reduced taxes when the recipient takes out the money 
and then using inter-familial transfers (which cannot realistically be tracked by the Canada Revenue Agency) to cycle the money back to the donor.

- Shillington's third model was a tax-prepaid model in which the contributions to the savings account would receive no special tax treatment and withdrawals would be taxed in the hands of the recipient. Shillington did not address the taxation of any investment income growth inside of the account prior to transfer or withdrawal by the beneficiary. ${ }^{214}$

Chapters 3 and Chapter 4 have already addressed some of the various trade-offs between deduction-deferral models and tax-prepaid models. In his review, Shillington argued in favor of the third model, the tax-prepaid model whose most similar precedent would be the RESP (discussed above). It had the advantage, according to Shillington, of eliminating double taxation without creating incentives to cycle funds within a family to take advantage of available tax deductions.

The second paper commissioned by PLAN was by Keith Horner, a former official at the Department of Finance. Horner had been asked by PLAN to examine its proposal for a tax-deferred savings instrument and to offer technical advice on how best to design a taxpreferred instrument to meet PLAN's goal of encouraging families to plan ahead for their dependent child with a disability using their own money. Horner (2005) examined two precedents for tax-preferred and registered savings - the RESP and RRSP, using each of

\footnotetext{
${ }^{214}$ Shillington's report did not address the taxation of investment income in the second option either.
} 
these as models for a potential new registered savings instrument for disability savings. The RESP, noted Horner, was more attractive than savings for education outside of an RESP because of the $20 \%$ grant on contributions, ${ }^{215}$ and, given his assumptions, of a reduced marginal tax rate when withdrawals were made. ${ }^{216}$

Horner modeled two competing policy options using two illustrative marginal effective tax rates for the family $(22.05 \%$ and $50 \%)$ and the same initial investment capital of $\$ 1,000$ with a constant compounding interest rate over 10 years. The RRSP-based model presumed that parents were able to contribute and receive a deduction from their annual taxable income (up to some un-named limit), investment income would be sheltered from income tax and the balance would only be taxed on withdrawal in the hands of the beneficiary — who, in Horner's model faced a $0 \%$ marginal rate. The tax-prepaid option offered no deduction for the contributions and sheltered the investment income from annual income tax paid by the contributor, it also sheltered withdrawals by the beneficiary but included the investment income portion of the balance as income for the purposes of income-tested or means-tested benefits. ${ }^{217}$

${ }^{215}$ His analysis did not present any information on the returns for families with the Canada Learning Bond and Accelerated Canada Education Savings Grant.

${ }^{216}$ Horner presumes a marginal tax rate of $29.6 \%$ in his model. This suggests a family income at or near the median level and does not included reductions in income-tested benefits such as rental or childcare subsidies that would be available to lower income household facing lower marginal tax rates but potentially much higher marginal effective tax rates.

${ }^{217}$ This decision seems unusual given that there would be reason to expect that taxation in the hands of the recipient would also result in benefits claw-backs under the RRSP-like model. By the time Horner was writing, provincial exemptions for RESPs benefitting dependent children were already in place. It would have been reasonable to model the 
Horner's analysis led to mixed results, ranging between $1.1 \%$ and $8.87 \%$ rates of return (after inflation and applicable taxes) over a 10-year period. He argued in favor, though modestly so, of the RRSP-like design option. This was largely on the basis, it seems, of an assumption that all parents would use any tax refund (or other increase in their disposable income) to reinvest in the disability savings plan. In fact, much of the evidence from behavioral economics suggests that people treat so-called 'found' money (such as tax refunds) very differently than earned money and are more likely to spend it than save it (Thaler \& Sunstein, 2008; Morrison \& Oxoby, 2011; Soman, 2011).

In his analysis of potential take-up and contribution rates, using the RRSP-like model, Horner projected that participation would be strongest among upper-middle and higher income households with greater income to save and higher tax liabilities_-leading to a relatively greater benefit from the deduction-deferral model). His model also projected relatively weak participation among modest-income families, but explained it in terms of substitution effects, rather than the design of the instrument itself. Horner's model of take-up presumed that families would face a substitution only between disability savings and saving for their own retirement through an RRSP.

Horner (2005) wrote: "people save primarily to replace earned income that will cease at retirement and the amount of saving needed by a family depends on the level of public pension income that it will receive" (p.17). In fact smoothing lifetime income or

RESP-like option for an RDSP to have a similar exemption and remove any effective tax through benefits claw-backs. 
consumption is just one of many possible motivations for saving, as discussed in Chapter 2. Furthermore, it is not clear that families use this kind of sophisticated calculation of life expectancy, projected income sources and levels and retirement planning needs. ${ }^{218}$

Both Shillington's and Horner's reports were cited extensively in the 2006 final report of the Expert Panel reporting to the Minister of Finance. Echoing a previous federal government's response to the Carter Commission, the report said "the Panel was tempted to clear new ground and make use of a modern approach to the fiscal policy framework. Upon reflection, however, the Panel was of the view that this was not the time or the subject matter for a dramatic, new and perhaps controversial approach" (Finance Canada, 2006b, p.11). The Expert Panel made a series of 15 often detailed and technical recommendations. Chief among them was that a new instrument be created and called a Registered Disability Savings Plan (RDSP). Notwithstanding the Panel's stated principle that "the first fundamental characteristic, then, of a Disability Savings Plan must be simplicity" (Finance, 2006b, p.15), the recommended new instrument was complicated. The description that follows is a much-simplified description of the Panel's recommendations.

\footnotetext{
${ }^{218}$ In fact public opinion and national survey research generally finds that most Canadian consumers report that they have no sense of how much income they will need in retirement and most do not even have a clear sense of which private or public sources of income they may have access to.
} 


\subsubsection{Recommendations from the Expert Panel}

The report noted that the Panel looked to each, the RHOSP, the RRSP and the RESP as potential models for a new registered and tax-preferred savings instrument. The RHOSP was dismissed since it had been cancelled over 20 years earlier and would no longer be familiar to Canadians. Between the RRSP and RESP models, and despite Horner's conclusion, the Panel concluded that the RESP model was preferable in light of their desire to ensure accessibility and benefit for lower income families. However, "by itself, the RESP provides a much lower incentive to saving than does the RRSP model", wrote the Task Force (Finance Canada, 2006b, p.20). To improve the incentives for lower and modest income families, the Panel recommended that the government introduce an income-tested bond, "broadly modeled after the Canada Learning Bond" (p.21), and a progressive matching savings grant, "broadly modeled after the Canada Education Savings Grant" (p.21). Both of these had been recommended to the Panel in a submission from an outside stakeholder group. ${ }^{219}$

\footnotetext{
${ }^{219}$ To my knowledge, the only submission to make this recommendation was from Social and Enterprise Development Innovations and was written by me. That submission was based on my own knowledge of RRSPs, demonstrations of matched savings for lowincome participants and my involvement in the Canada Learning Bond (CLB) and redesign of the CESG. For the income-tested Bond, the author had cautiously proposed a modest $\$ 500$ initial and $\$ 100$ annual contribution (identical to the CLB) but had recommended a higher income threshold of $\$ 30,000$. On the matching rates, I had proposed a rate of $20 \%$ to $40 \%$ based on income with the highest rate available on annual savings for families with up to $\$ 30,000$ in annual income, a $30 \%$ rate for those families between $\$ 30,000$ and $\$ 60,000$ and the $20 \%$ rate for those families with $\$ 60,000$ or more in annual income. This was a simplified method of determining the match rate compared to the Panel's stepwise approach by income and savings levels. However, it is notable that the Panel recommended a substantially richer bond and grant design. The learn\$ave project is cited by the Panel in its final report and contributions from PLAN and SEDI, my employer at the time, are also acknowledged.
} 
Only one RDSP could be opened per person, in contrast to both RESPs and RRSPs that allow multiple registered accounts all subject to the same annual and life-time limits. Eligibility for payments from an RDSP would be limited to Canadians who qualified for the Disability Tax Credit. ${ }^{220}$

The RDSP, as proposed by the Expert Panel, would be subject to a lifetime limit of $\$ 200,000$ but would have no annual contribution limit. The Panel further recommended that contributions be open to anyone but that only the beneficiary or his or her legal guardian (normally a parent) be entitled to open an RDSP. The Panel recommended that no restrictions be made on when withdrawals from the RDSP could begin but did suggest that the maximum annual withdrawal not be greater than the total market value of the plan divided by a beneficiary's projected life expectancy. Eligible investment vehicles were to follow section 146(1) of the Income Tax Act, the same section that applies to both RRSPs and RESPs. There were a number of other technical recommendations regarding rollovers from RRSPs and RESPs.

The disability savings bond was recommended at $\$ 1,000$ per year, for up to 20 years (or before a beneficiary's $50^{\text {th }}$ birthday) for eligible RDSPs where household income was

\footnotetext{
${ }^{220}$ The Disability Tax Credit is a non-refundable tax credit paid to Canadians who are able to meet a test requiring a medical doctor to certify their long-term, health, mobility or cognitive limitation. The credit may also be paid to an eligible caregiver. It has been the subject of much criticism because of the definitions of disability used, barriers to getting the medical examination and certificate and its limited value as a non-refundable credit for individuals and households with low or no taxable income.
} 
below $\$ 20,881 .^{221}$ The grant rate would be, like the A-CESG, tied to household income and would be paid at a higher rate on the first portion of dollars saved for lower and middle-income households, declining to a basic rate thereafter. Like the RESP, provisions regarding repayment of the grant and bond were included in the design. However, unlike the RESP, there would be no conditions placed on the use of the funds since the primary eligibility criteria of having a long-term disability would have already been met.

Like the RESP, contributions to the RDSP would not be eligible for a deduction and would not be included in the taxable income of the contributor. Unlike RESPs, these contributions would also be exempted as income in the hands of beneficiaries at the time of withdrawal although the beneficiary would pay tax on the portion of withdrawals related to investment income and government-sponsored bond and grants. In other words, in contrast to the RRSP in which all withdrawals are taxable (except in cases of the Homebuyer's and Lifelong Learning Plan repayable withdrawals), and in contrast to the RESP in which all withdrawals are taxable but in the hands of a much lower income student (who is likely to pay no net tax on the income), the RDSP was to have both a taxable and a non-taxable portion in the payments to beneficiaries.

${ }^{221}$ In 2006, according to the Panel's final report, this was the average total income of persons who received the Disability Tax Credit for themselves. Given the secretariat's access to tax-filer data at Finance, this is likely to be a very accurate estimate. 
There are trade-offs in program design between simplicity and sensitivity. A flat program delivering a set rate of benefit regardless of personal capacity or circumstance is likely to be simple but also to have large windfall gains by delivering benefits to those who do not need them. A highly progressive program is likely to be very sensitive to individual and household differences (in income, household composition, or even wealth) but is far more complicated and less transparent to users and stakeholders. It is debatable whether, in their final recommendations, the Panel succeeded in finding some reasonable balance between these two principles. It does seem as though they aimed for a balance, using language and assumptions that would have been familiar to those favoring progressive universalism. ${ }^{222}$

The final report of the Panel was also notable for making a formal recommendation to the government that it take steps to protect RDSP savings from provincial means tests for social assistance disability benefits. This would have been a key recommendation for families who expected that their dependent child would be reliant on public income support as an adult—including the stakeholders who had formed PLAN. But it would also have been a concern for some portion of the low-income families who would be eligible to receive the Disability Savings Bond.

${ }^{222}$ Progressive universalism was term used by the Blair government of the UK in the early to mid 2000's as part of a new focus on social exclusion. It has since been used in, again predominantly British, discourse on international development. At its core is a belief that, to reconcile multiple and often competing principles in public policymaking, the best route is to ensure that everyone gets something but that those with greater need get more. 
A final important element in the Panel's report was a discussion of the importance of communicating the RDSP design to prospective users and for the federal government to actively take a role in promoting its use. The Panel noted that the number of potential users of an RDSP was, relative to other registered instruments, very small and that, therefore, governments would be in the best position to directly identify (using administrative data) eligible families and directly inform them (outside of mainstream media or financial institutions) about the RDSP. ${ }^{223}$

In its 2007 budget, the Government announced that it would respond to the Panel and introduce legislation to create the new RDSP with an income-tested bond and matching savings grant.

\subsubsection{Government's response}

The budget promised to make the RDSP available in Canada by 2008-likely a wise move to allow time to reach agreements with financial institutions, provinces and between federal departments with roles in the implementation. The design was largely identical to the recommendations of the Panel report with a few notable exceptions:

- The income threshold for the income-tested bond was reduced but not eliminated as family income approached $\$ 37,178$ (to be adjusted annually with inflation).

${ }^{223}$ The Panel estimated that 225,000 Canadians might be eligible for an RDSP and modeled their cost estimates of their recommendations on a total uptake of just 180,000 per year at maturity. On the basis of projected average annual contributions by families of $\$ 600$, the Panel estimated the costs of the grant and the bond would be approximately $\$ 94$ million per year. 
- The budget projected the total cost of the program to include either a slightly higher take-up rate compared to the Panel's projections or to include the administrative costs that were not calculated by the panel and offered a total cost estimate of $\$ 111$ million per year, roughly $\$ 17$ million more than the Panel's estimate.

- The budget introduced a requirement that all bond and grant money in the Plan be locked-in for a minimum of ten years. If withdrawals were made before the tenth anniversary of the plan, all bonds and grant money deposited into the plan had to be repaid to the government. This is in direct contrast to the recommendation of the Panel that there be no time restrictions before a beneficiary might begin to receive payments out of the RDSP. This feature of the instrument has been justified by government sources as a measure to ensure that the RDSP is used "as a long-term savings plan". ${ }^{224}$

For low and modest income families caring for a child with a disability, the accumulated financial asset could be an important resource for large lump sum costs that cannot be paid out of income flows and for which there is no public funding available. For example, should a child's mobility decrease, requiring renovations or new equipment at home, the money in the RDSP might have been seen as a resource to help cover the cost. But the requirement to pay back the full grant and bond, not just some portion thereof,

${ }^{224}$ Source: Human Resources and Skills Development Canada (undated). "Registered Disability Savings Plan", webpage. Retrieved from: http://www.hrsdc.gc.ca/eng/disability/savings/index.shtml 
could be prohibitive, significantly reducing the family's asset. Compared to the RRSP, where early withdrawals (outside of tax-sheltered programs) are treated as income and taxed at source, the effective tax rate for early RDSP withdrawals is substantially higher and potentially upwards of $300 \%$ once the claw-back of all government savings grants are included.

Compared to the RESP, the ten-year minimum lock-in period is also much more restrictive than the repayment provisions for the Canada Learning Bond or Canada Education Savings Grant. The Bond and Grant for the RESP are payable up to a child's $17^{\text {th }}$ year and are, as per the design, available as early as the following year as part of payments to the beneficiary student. The Bond and Grant must only be repaid to the government if the RESP is terminated without the beneficiary child attending postsecondary education. ${ }^{225}$

Over the next year (2008), officials at the Office for Disability Issues at Human Resources and Skills Development worked closely with officials in Finance and the Canada Revenue Agency. Anecdotal reports suggest that officials in these departments, while loyally implementing the policy set by the government, were not entirely convinced of the value of the policy direction. The new savings instrument was seen as overly complex and likely to yield little benefit, particularly in light of targeted income

${ }^{225}$ The RESP does offer more flexibility in allowing transferability to another beneficiary while the RDSP, as a very targeted instrument, is non-transferable. 
support that might otherwise be offered using the same envelope of \$111 million per year. $^{226}$

A review of the Parliamentary debates following the 2008 federal budget suggests that the RDSP was viewed as a non-controversial item by Opposition parties in both the House and the Senate. In fact the only critique appears to have come from the Liberals who suggested that the government was moving too slowly on implementation, delaying the availability of RDSPs for families. ${ }^{227}$ The RDSP was formally launched in early December $2008 .^{228}$

\subsubsection{Implementation and early effects of the RDSP}

In 2011, three years later, the government conducted its first review of the RDSP. The data sources for the review included administrative data as well as consultations with external stakeholders, notably PLAN, the same organization that had been the original proponent of the RDSP. To launch the review, the government issued a public consultation paper in October 2011.

\footnotetext{
${ }^{226}$ Author's personal conversations with former officials in both Finance and HRSDC between 2007 and 2009. Presuming 225,000 Canadians were eligible for the Disability Tax Credit, \$111 million yields only a $\$ 493$ per person annual benefit so unless the income support were heavily income-tested, it is unclear that the dollar values involved would lead to a substantial increase in the annual incomes of most persons with disabilities in Canada.

227 Through 2007 and 2008, Judy Sgro, Liberal MP for York-West repeatedly placed written questions on the Order Paper to ask about the implementation of RDSPs.

${ }^{228}$ Media release, "Finance Minister, Jim Flaherty, announces the RDSP", December 3, 2008, Finance Canada, Ottawa.
} 
But even before the review began, the government made several changes to the RDSP instrument between 2009 and the fall of 2011 . These include:

- Securing the agreement of governments in all provinces and territories to exempt RDSP balances and withdrawals from means tests in social assistance programs, either fully or up to a dollar limit.

- Amending, in 2010, the RDSP rules to allow parents to carryover unused savings grants for up to ten years. ${ }^{229}$

- Changing the rules regarding repayment of the disability savings bond and grant (if withdrawn within ten years) to allow more flexible withdrawals, but only for RDSP beneficiaries with shortened life expectancies.

(Finance Canada, 2011b).

Participants in the review exercise were, through the government's consultation paper, invited to comment on: the basic parameters of the instrument, issues in opening RDSPs (in particular the question of legal competence and representation for persons with disabilities that impair decision-making), accommodating roll-overs of unused RESP funds into eligible RDSPs, reasonable exemptions to the rules requiring the locking in or

\footnotetext{
${ }^{229}$ This is in contrast to rules regarding RRSP and RESP contribution room. RRSP carry-forward rules allow unused deduction room (either because a deduction for eligible contributions was not claimed or because no contributions were made in a given year) to be carried forward in perpetuity up to age 71. RESP rules similarly allow subscribers to carry forward unused contribution room in perpetuity up to the life-time contribution limit of $\$ 50,000$ and, furthermore, unused entitlements to the Canada Learning Bond and Canada Education Savings Grant are carried forward up to a child's $17^{\text {th }}$ birthday or the lifetime limits. It should be noted, however, that the bond and grants for the RDSP are substantially richer than the RESP.
} 
repayment of bond and savings grants and any other administrative rules that might be improved. Around the time of the review there were only 59,000 RDSP accounts in place (McFeat, 2011), well below the Advisory Panel's projection but well above the take-up rates for RESPs with the CLB or CESG, relative to the eligible population.

PLAN launched its own separate consultation exercise at the same time, using on-line surveys and focus groups with families caring for a child with a disability. The government does not appear to have made public the findings from its RDSP review in 2011 but PLAN did.

PLAN's 2011 report on its consultations found that, the principal concern for families with an RDSP was the rigidity of the rules on withdrawals with families expressing a desire for greater flexibility. Not unlike the RESP, a substantial portion of eligible families found it challenging to open an RDSP given the complexity of the forms, limited information and a lack of awareness among front-line staff at financial institutions. On a more positive note, many families reported that, after opening the RDSP, they experienced a decline in stress and anxiety about the future and became more hopeful. This finding also suggests that motivations outside of long-term consumption smoothing are playing a role in the savings decisions of these families.

Another concern raised by families was that the RDSP rules required a subscriber to be either the parent of a child (under aged 18 and unable to enter into financial contracts) receiving the Disability Tax Credit, or to be the adult with a disability themselves. Some 
adults with certain forms of impairment may not be capable of entering into contracts (such as a contract to open an RDSP) but the legal mechanism to enable a caregiver to take over responsibility for contracting on behalf of that adult requires a legal declaration of incapacity. Families reported that this 'all-or-nothing' approach presented major difficulties emotionally but also practically since a declaration of incapacity effectively eliminates all legal rights to decision-making rather than being more sensitive a range of intellectual and cognitive abilities. PLAN's report suggested changes to the legal framework on representation for RDSPs and changes to the rules on withdrawals to allow, penalty-free, withdrawals for certain purposes such as essential health and medical supports or costs to buy or adapt a home (PLAN, 2011).

The government's response came in the 2012 federal budget. Following that budget, parents and married or common-law spouses would now be able to open an RDSP for an eligible adult who was unable to enter into legal contracts him or herself. The budget also changed the ten-year rule on RDSP to replace the full repayment of the bond and savings grants with a proportional repayment out of the total amount withdrawn (Finance Canada, 2012b). While not ideal, this was certainly an improvement and more aligned with the treatment of early withdrawals from RESPs or RRSPs.

\subsubsection{Concluding thoughts on the RDSP}

The RDSP is, of all of the registered instruments included in this study, the one with the smallest potential target population. It is not intended as a universal program. It is a niche program created to address the concerns of a very particular but politically 
mobilized subset of the population. While it shares this common origin with RRSPs, its niche status sets it apart from most other registered savings instruments. ${ }^{230}$

Although the RDSP was first proposed by an outside stakeholder organization, it was championed by a Finance Minister who had a deep and personal affinity for the file. The retrospective analysis of compulsory savings, RRSPs, RHOSPs and RESPs suggest that the personal experiences, perspectives and priorities of political and public-service policy-makers played some role in the observed policy outcomes. ${ }^{231}$

Of all the registered instruments reviewed in this thesis, the RDSP seems to have been the one developed with the greatest investment in stakeholder consultation. It is also the one instrument to have been modified reasonably quickly in response to those consultations. By contrast, the RRSP saw many decades before it was revised at all and RESPs operated essentially outside of the income tax system for over decade before the federal government took much notice. The RHOSP was introduced, tweaked the following year

\footnotetext{
${ }^{230}$ The RHOSP was targeted at aspiring first-time homebuyers but was available to the approximately $40 \%$ of Canadians who rent and do not own their home. The RESP, while largely aimed at families with children, is technically available to anyone for a beneficiary of any age - only the savings bond and grants are limited to children.

${ }^{231}$ For example, I argue in Chapter 4 that the list of credits to offset the new compulsory savings would have best aligned with the existing financial obligations of workers similar to federal public servants in the Department of Finance. Similarly, the change of Finance Minister seems to have played some role in the 1974 decision to amend the Income Tax Act to create RESPs (Chapter 6). And, as argued in the same chapter, the personal preferences and priorities of Paul Martin as Finance Minister and later PM seem to have had some role in shaping changes to RESPs starting in 1996.
} 
in response, it seems, to perceptions of unintended uses, and then largely forgotten for nearly a decade.

Finally, among all of the direct and indirect savings incentives associated with the registered instruments, the bond and grants tied to the RDSP are by far the most generous in proportion to the dollars saved by families and individuals. For an eligible family, even without any personal contributions, the RDSP could be worth up to $\$ 10,000$ plus investment interest earned in the plan. Furthermore, the transfers and investment income earned are all tax-free — generating a further public cost in foregone income tax revenues. Compared to the transfers of wealth through RRSPs and RESPs, this is a substantial amount.

Some authors have noted that differences in the benefits given to some low-income groups over others signal a distinction between 'the un-deserving and deserving poor' (Katz, 1989; Mink \& O’Connor, 2004;). The distinction often relates to some normative judgment on whether the individual could alter his or her own economic circumstancesor whether the individual is thought to be choosing to remain poor. It is a lens that echoes much of the $19^{\text {th }}$ Century moralists that were discussed in Chapter 2. Katz (1989) notes that persons with disabilities who are not able to work and generate employment income to be self-sufficient as well as children in low-income families are generally grouped under the heading of 'deserving poor'. It is possible, that some part of the explanation for the higher value of federal investment per RDSP account, compared to 
the other tax-preferred instruments, relates to this differentiation amongst low-income groups.

On the other hand, being eligible for an RDSP and the disability bond means living with the challenges of caring for a child with a long-term severe disability. It is not difficult to argue that these families are deserving of public support.

\subsection{The Tax-Free Savings Account}

The final and most recent instrument to be discussed is the Tax-Free Savings Account. It is the sixth instrument to be discussed in this retrospective analysis and represents the most true form of a tax-prepaid instrument. The developmental process, however, shares much in common with the first policy discussed—compulsory savings.

In the 2008 federal budget, the federal government announced that it would amend the Income Tax Act to allow adult Canadians to save up to $\$ 5,000$ per year ${ }^{232}$ in a new registered savings account called a Tax-Free Savings Account (TFSA). Those financial institutions already legally entitled to issue RRSPs would be able to issue TFSAs and the same rules regarding investment vehicles that apply to RRSPs would (like RESPs, RHOSPs and RDSPs) apply to TFSAs. Investment income earned on the capital in the account would grow tax-free and withdrawals would not be taxed. But, contributions into the account would not receive any direct incentive such as a tax deduction or a

${ }^{232}$ Indexed to inflation and rounded to the nearest $\$ 500$. The 2013 limit for new contributions is $\$ 5,500$. 
matching grant. Unused TFSA room could be carried forward indefinitely with no age limits on contributions (unlike RRSPs) and no lifetime limit on total contributions (unlike RESPs). Furthermore, TFSA investment income and withdrawals would be excluded from the calculation of taxable income and would not be included in the determination of eligibility for the income-tested portion of federal seniors' benefits. ${ }^{233}$

In his budget speech, the Minister of Finance, hailed it as "the single most important personal savings vehicle since the introduction of the RRSP", noting that while the RRSP was primarily a vehicle for retirement savings, the TFSA "is like an RRSP for everything else in your life" (Flaherty, 2008). After the budget implementation bill passed through Parliament, the first TFSAs were sold in in January 2009.

In 2012, the federal government committed to doubling the TFSA contribution limit to $\$ 10,000$ per person per year in or near a federal budget in 2015 . The commitment was conditional on eliminating the federal deficit (Finance Canada, 2012).

${ }^{233}$ Many provincial income-tested benefits, such as child supplements and senior's income and drug benefits, are calculated on the basis of either total or net taxable income. To give an example of how another registered instrument factors into these definitions of income, total income includes withdrawals from RRSPs but net income is reduced by allowable deductions for RRSP contributions. Most provinces and territories (outside of Quebec) use the federal calculations of total and net income even where they use their own calculation of taxable net income. Federal seniors benefits include the Canada Pension Plan (a social insurance program based on lifetime contributions), Old Age Security (a universal benefit based on residency) and the Guaranteed Income Supplement (an income-tested supplement for Old Age Security recipients). For Canadians with low lifetime earnings, the OAS and GIS are estimated to make up approximately $50 \%$ of retirement incomes (Mintz, 2009). 


\subsubsection{Origins in academic debate}

In contrast to the RRSP, the RESP and the RDSP, there was no outside group of selfinterested stakeholders calling on government to create a registered instrument to address their concerns regarding personal retirement savings or education savings. The origins of the TFSA have much more in common with the compulsory savings experiment of the Second World War.

In both cases, the design was heavily influenced by academic economists debating theoretical positions on the proper role of taxation on savings and the likely behavioral response by households. This debate leading up to the TFSA included several published pieces by academics and think tanks. For example:

- Poschmann and Kesselman (2001) called for the creation of a tax prepaid savings account for long-term (including retirement) savings alongside the existing RRSP. $^{234}$

- Poschmann and Robson (2004) renewed a call for a tax pre-paid account but with attention to the short and medium-term capital needs and barriers to saving for low-income households. This article drew heavily on Shillington's (2003) paper on marginal effective tax rates faced by low and modest income seniors with RRSP assets.

\footnotetext{
${ }^{234}$ According to Milligan (2009), this 2001 article and a similar version later the same year in the Canadian Tax Journal are "widely viewed as the precursors to the TFSA" (p.359, footnote 8).
} 
- Ragan $(1994 ; 1995 ; 1996)$ had argued that RRSPs should be abolished on the grounds that the increase in new personal savings was too small relative to cost of foregone income taxes. Instead of proposing the tax pre-paid alternative, Ragan's proposal was to replace registered savings with generous annual exemptions on investment income.

- The Economic Council of Canada (1987) had published a series of studies on the tax treatment of savings and had concluded that annual contribution limits on RRSPs should be increased substantially (from $18 \%$ to $30 \%$ of earned income). Daly and Naquib (1985) of the Council had gone one step further and proposed that an optimal tax system in Canada required both the deduction-deferral and the tax prepaid options to allow households adequate flexibility to smooth their lifetime consumption.

Notwithstanding the long history of study and debate among economists, the Department of Finance moved cautiously before introducing the TFSA in the 2008 budget. The original policy announcement signaling the federal government's interest in a new tax pre-paid registered savings instrument was actually made in the 2003 federal budget released by then Finance Minister John Manley. ${ }^{235}$ Towards the very end of the budget document was a brief commitment that: "The Government intends to review and consult with respect to these issues in order to assess whether TPSPs could be a useful and appropriate mechanism to provide additional savings opportunities for Canadians" in

${ }^{235}$ Finance Canada, Budget 2003, Annex 9 "Tax Measures: Supplementary information and Notice of Ways and Means". 
response to "numerous representations from individuals, researchers and businesses that Canada's tax system should be more conducive to saving", including but not limited to calls for a tax pre-paid savings plan (Finance Canada, 2003b, Annex 9).

Following the 2003 budget, the Department of Finance issued a consultation paper soliciting the views of interested parties on how the tax system could better promote household savings and whether and how a new tax pre-paid registered account might complement the existing mechanisms. Senior officials in the Tax Policy Branch, including Keith Horner (later author of one of the key policy development reports for PLAN) and Ian Pomeroy (later the head of secretariat charged with recommending the structure of the RDSP), met with outside stakeholders. ${ }^{236}$ The paper provided a basic review of the contemporary treatment of various forms of saving under the Income Tax Act, provided some factual information regarding the use of RRSPs and employer pensions in Canada and requested input on he design of a tax pre-paid savings account. The delay for another four budgets is likely due in part to another turn-over in government in 2006 and also to a lack of consensus inside or out of the department on the value of adding another registered and pre-paid savings account to the regime of taxpreferred instruments. $^{237}$

\footnotetext{
${ }^{236}$ The author participated in one such meeting and authored a submission to the Department as part of this consultation exercise.

${ }^{237}$ Horner, for example, has generally been of the view that the deduction-deferral model is preferable, as in his RDSP modeling paper for PLAN. Similarly, in 2011, Horner authored a study for the Institute for Research on Public Policy that suggested among possible retirement savings policy options, the best design is really a mandatory public
} 
Another common feature between TFSAs and war-time compulsory savings policy is that Canada seems to have waited until there was adequate proof of possibility through comparable policies in other countries. In fact, a 2007 study conducted by the OECD found that 10 countries already had one or more forms of tax pre-paid accounts in place, and this estimate is without counting tax pre-paid retirement savings (OECD, 2007). ${ }^{238}$ These are briefly discussed below.

\subsubsection{International precedents}

In the United States, Roth Individual Retirement Arrangements (Roth IRAs) had been introduced in 1997 as part of a package of federal tax reforms. While traditional IRAs operate on a deduction-deferral model, Roth IRAs are based on the tax pre-paid model. Unlike the TFSA, the Roth IRA only permits tax-free withdrawals of principal. Withdrawals of interest earnings are permitted only in cases of retirement or disability (IRS, 2012). In prescribed, but increasingly looser conditions, the U.S. government allows account owners to convert a traditional IRA to a Roth IRA.

defined benefit program, not another employer or individual-sponsored defined contribution instrument, which the TFSA represents.

${ }^{238}$ The OECD study included Canada in its list of countries with tax-prepaid savings instruments on the grounds that RESPs were largely consistent with the model. In fact, RESP withdrawals are taxable for beneficiaries but are not expected to generate tax liability because of limited sources of other income and education-related tax credits available to students in higher education. It is important to note that this analysis presumes full-time status as a student. 
Burman, Gale and Weiner (2001) looked at IRA contributors between 1982 and 1995 and concluded that many traditional IRA holders would have been better off, in terms of their after-tax increase in financial assets, using a Roth IRA. However, consumer surveys find that traditional IRAs remain more commonly-held than Roth IRAs, except among low-income households and that Roth IRA balances tend to be smaller by nearly $50 \%$ compared to traditional IRAs (Holden, Ireland, Chambers \& Bogdman, 2005). Adelman and Cross (2010) suggest that the best IRA option varies depending on individual circumstance, arguing in favor of ensuring both are available to consumers to make decisions that are optimal for their own needs.

The US also offers an added incentive to low and modest income earners through "the saver's credit" that delivers a refundable tax credit worth up to USD $\$ 1,000$ for individuals (USD $\$ 2,000$ for couples) on the first USD $\$ 2,000$ of annual personal contributions to an IRA account (IRS, 2013). In 2010, the IRS paid out a little more than $\$ 1$ billion through the savers credit to 6.1 million U.S. tax-filers.

In the United Kingdom, governments have experimented with various forms of tax prepaid savings since the mid 1980's (OECD, 2007). In 1986, the Thatcher government created Personal Equity Plans (PEP) that sheltered investment earnings and withdrawals from the plan from taxation up to an annual limit of up to $£ 6,000$ per year. However, all money in a PEP had to be invested in allowable stocks and shares-initially limited to stocks and shares in British companies and later expanded to include European companies as well. 
In 1990, Thatcher's successor, John Major, launched the Tax-Exempt Special Savings Account (TESSA) as a lower-risk complement to the PEP to allow savers to retain some of their capital in cash, term deposits and other vehicles outside of stocks and shares. However TESSA deposits, unlike PEPs, had to be locked-in for five years to maintain tax-free status, although withdrawals of investment interest were permitted without penalty. TESSAs were also subject to a maximum of five years or $£ 9,000$ limit on taxexempt status.

When the Labour government came to power in 1997 in the U.K., it brought with it a deep interest in promoting access to savings and assets for low and modest income Britons. In 1999, PEPs and TESSAs were replaced by Individual Savings Accounts (ISAs) that permitted the same tax-free growth of savings and investment income, within certain limits, but allowed more flexibility in withdrawals without penalty, creating a more pure tax pre-paid model. The availability of withdrawals was expected to be more attractive to lower-income savers who might feel more secure knowing their savings were both protected from tax but also accessible if needed. However, the annual limits and caps on various forms of investment were complicated and confusing to many consumers. Furthermore, financial service providers complained that the design was heavily skewed in favour of banks and building societies rather than treating all providers equally (Warland, 1999). 
In 2008 , the UK government aimed to simplify the policy and collapsed the distinction between so-called "maxi-ISAs" (accounts that allowed greater flexibility in portfolio allocations) and "mini-ISAs" (accounts that capped the share of money that could be held in cash). In 2011, a new form of ISA was introduced to allow accounts for British youth. Currently over 24 million Britons, nearly $40 \%$ of the population, hold an ISA (HMRC, 2013). As of 2011, very low-income earners, those with less than $£ 5,000$ in annual income, make up $12 \%$ of all ISA owners but higher income earners are likely to have much larger ISA balances and to contribute more per year to their account.

\subsubsection{Comparing the TFSA as a 'tax-prepaid' savings instrument}

The idea underlying the TFSA is actually much older than the Canadian academic debate and international precedent. Recall that that in 1945, the report of the Ives Commission on the tax treatment of annuities and pensions had considered a tax pre-paid model alongside a deduction and deferral model (Chapter 3).

The tax pre-paid model posits that an appropriate level of tax has already been paid on income and that savings are made out of after-tax income resources. No deduction against income tax is allowed for contributions to a tax pre-paid account and no tax is levied on the withdrawals since it is, in theory, simply stored-up after-tax income saved from one period to be used in another. In many respects, the tax pre-paid model is much like an informal way of saving - similar to how a child might save in a piggy-bank. One critical difference, is that, while a money in a piggy-bank earns no interest, money in a registered TFSA can grow through investment returns. These investment returns are also 
excluded from total and taxable income, and conversely investment losses cannot be deducted as a capital loss. Another critical difference is that assets in a TFSA are visible to a financial institution and will be considered in any assessment of credit worthiness or evaluations of total wealth for targeted products and services.

For the TFSA, unlike the RESP and RDSP, there is no income-tested bond or matching savings grant. The incentive to save comes instead through two parts. The first is a removal of a disincentive - the taxation of withdrawals. In RRSPs, the deductiondeferral model presumes that the value of the deduction now will be recouped through deferred taxation later on. Recall as well that, in the design of the RRSP, the Department of Finance held firm to the view that, over the long-term, the deduction-deferral model was revenue neutral and essentially equivalent to a tax pre-paid model. In fact, the federal budget documents for 2008 presented a table illustrating the equivalence between a TFSA and RRSP — as well as the relative advantage of each compared to savings in unregistered instruments. A copy of this table is reproduced below as Figure 7.1.

Figure 7.1: Federal budget 2008 table on equivalence RRSPs and TFSAs 
7.3 Concluding thoughts on the set of instruments

Source: Finance Canada (2008) Budget 2008, Annex 4, "Tax measures: Supplementary information”

The key feature to note in this table is that it presents a case in which the marginal tax rate remains unchanged between the time of contribution and the time of withdrawal. This assumption is possibly indicative of the perspective adopted by analysts within the Department of Finance and is likely unsupported by factual evidence.

Figure 7.2 below is reproduced from Laurin and Poschmann (2010) for comparison to Figure 7.1 above. It provides a partial ${ }^{239}$ illustration of the alternative cases in which marginal tax rates do not stay the same between the time of contribution and withdrawal for the RRSP and TFSA.

${ }^{239}$ Partial in the sense that the magnitude of the differences in marginal tax rates is modest and effective rates (to include changes in income-tested benefits) are not included. 
Figure 7.2 Laurin and Poschmann Table on TFSAs vs RRSPs

\begin{tabular}{|c|c|c|c|c|c|c|}
\hline & \multicolumn{2}{|c|}{$\begin{array}{l}\text { Same tax rate (40\%) on } \\
\text { labour income saved } \\
\text { and on retirement } \\
\text { income withdrawal }\end{array}$} & \multicolumn{2}{|c|}{$\begin{array}{l}\text { Tax rate on labour } \\
\text { income saved (40\%) is } \\
\text { higher than on } \\
\text { retirement income } \\
\text { withdrawal (30\%) }\end{array}$} & \multicolumn{2}{|c|}{$\begin{array}{l}\text { Tax rate on labour } \\
\text { income saved }(30 \%) \text { is } \\
\text { lower than on } \\
\text { retirement income } \\
\text { withdrawal }(40 \%)\end{array}$} \\
\hline & \multicolumn{6}{|c|}{ (dollars) } \\
\hline & RRSP & TFSA & RRSP & TFSA & RRSP & TFSA \\
\hline Amount saved for retirement & 1,000 & 1,000 & 1,000 & 1,000 & 1,000 & 1,000 \\
\hline Taxes & 0 & (400) & 0 & (400) & 0 & (300) \\
\hline Net amount saved & 1,000 & 600 & 1,000 & 600 & 1,000 & 700 \\
\hline $\begin{array}{l}\text { Value after } 20 \text { years } \\
\text { ( } 5 \% \text { annual rate of return) }\end{array}$ & 2,653 & 1,592 & 2,653 & 1,592 & 2,653 & 1,857 \\
\hline Taxes & $(1,061)$ & 0 & (796) & 0 & $(1,061)$ & 0 \\
\hline \multirow[t]{2}{*}{ Net income at retirement } & 1,592 & 1,592 & 1,857 & 1,592 & 1,592 & 1,857 \\
\hline & \multicolumn{2}{|c|}{$\begin{array}{l}\text { RRSP and TFSA are } \\
\text { equivalent }\end{array}$} & \multicolumn{2}{|c|}{ RRSP is superior } & \multicolumn{2}{|c|}{ TFSA is superior } \\
\hline
\end{tabular}

Source: Laurin, A. and Poschman F. (2010). "Saver's Choice: Comparing the Marginal Effective Tax Burdens on RRSPs and TFSAs", Toronto: C.D. Howe Institute. Reproduced with permission.

For middle and upper income Canadians making deposits and withdrawals in a registered account within a short time horizon, an assumption of continuity in marginal tax rates may be a reasonable assumption. In cases where, as a result of accumulated labour market experience and increases in employment income, pre-retirement withdrawals from RRSPs might actually face a higher marginal tax rate than at the time of contribution (creating a loss to the saver). ${ }^{240}$

For lower and modest income savers, a pre-retirement RRSP withdrawal may come at a time with the same marginal tax rate but at a much higher marginal effective tax rate than

${ }^{240}$ Withdrawals here would be outside of the sheltered programs for lifelong learning and buying a house. 
the value (if any) of the RRSP deduction (Laurin \& Poschmann, 2010). This is because of losses to income-tested benefits such as childcare, extended health, transportation and housing subsidies. Even in cases where withdrawal is postponed to retirement, some low and modest income Canadians actually see their incomes increase in retirement and therefore face higher marginal tax rates and marginal effective tax rates that can be excess of 100\% (Shillington, 2003; Stapleton \& Shillington, 2008).

As compared with RRSPs and unregistered savings, TFSAs may represent an important improvement for lower and modest income households. In fact, data released by the Department of Finance suggest that TFSA participation rates now meet or exceed participation in RRSPs, although like RRSPs, the frequency of TFSA participation rises with personal income. ${ }^{241}$ However, the distribution of all TFSA accounts and account balances is heavily skewed towards lower and modest-income Canadians. In 2011, Canadians with annual individual incomes below $\$ 40,000$ made up $49 \%$ of all TFSA account holders and made $46 \%$ of all contributions to a TFSA that year (Finance Canada, 2012). At least some of this is potentially explained by the age distribution of TFSA users: frequency of account holding and size of annual contributions rises with age, beginning at about age 50 and peaking for those aged 72 and older. Recall that this latter group is no longer eligible to contribute to an RRSP and must begin drawing down a minimum amount from a RRIF or annuity. For some portion of the low and modest-

\footnotetext{
${ }^{241}$ Approximately $20 \%$ of Canadians with incomes below $\$ 20,000$ have a TFSA compared to nearly $60 \%$ of those with incomes over $\$ 200,000$ (Finance Canada, "Tax Expenditures and Evaluations 2012", Part 2, Chart 3).
} 
income Canadians using TFSAs, the vehicle is likely a way to maintain assets in retirement rather than spending them down.

This use of TFSAs among the likely-retired raises what has become perhaps the key criticism of the TFSA: the potential for far greater fiscal costs from the TFSA in the future, particularly given Canada's aging population.

\subsubsection{Critiques of the TFSA}

Alarie (2009), Milligan (2012), Poschmann (2012) and Kesselman (2012) have all noted that the TFSA has the potential to lead to increased strain on the federal fiscal framework. One set of concerns is related to the exemption of TFSA withdrawals from the income test for Old Age Security and the Guaranteed Income Supplement. ${ }^{242}$ The chief concern for these authors appears to be the risk that some number of asset-rich but income-poor Canadian seniors will, in the future, be inclined to apply for and collect the GIS.

Kesselman (2012) cited a projection that by 2050 , GIS benefits may rise by $\$ 4.2$ billion due to the effects of the TFSA alone. In combination with the reduced income-tax recovery on OAS benefits, Kesselman projected that the TFSA may cost $\$ 5.5$ billion to

${ }^{242}$ Old Age Security is a universal income support payment made to seniors in Canada aged 65 and older. Eligibility is based on at least ten years of residence in Canada, not on social insurance contributions or past employment. OAS benefits are taxable income. The Guaranteed Income Supplement is an income-tested top-up added to the OAS for those seniors with low retirement income from other sources such as Canada Pension Plan benefits, workplace pension benefits and income from private retirement savings (such as RRSPs and RRIFs). TFSA withdrawals are not included in the income test for the GIS. 
the federal fiscal framework by 2050. As the TFSA contribution room grows, and particularly if it is doubled in 2015 as promised by the government in 2011 , it could “exacerbate an existing problem of providing federal income-tested benefits even to individuals with substantial TFSA balances”, wote Kesselman (2012, p.376).

Milligan (2012) raised a related concern about the long-run sustainability of the TFSA but based on the potential for the instrument to reduce future income tax revenues dramatically, all else being equal. Milligan developed a model of retrospective household response to the TFSA using 2005 survey data on past behavior. If families and individuals in 2005 had the opportunity to transfer any and all taxable assets into a TFSA, ${ }^{243}$ at a $\$ 5,000$ per adult annual limit, he projected that $89 \%$ of families would have been able to shelter all of their otherwise taxable savings after just five years (by 2010) and that, in turn, the federal tax base would have declined by $3.2 \%$. Using the same model, when families accumulate up to $\$ 300,000$ in TFSA contribution room, then the federal tax base would decline by $6 \%$.

\footnotetext{
${ }^{243}$ Milligan acknowledges that his assumption may over-estimate TFSA participation by assuming that households will direct all taxable capital into a TFSA over, for example, RRSPs and that they will do so up to the annual maximum contribution. In fact, not unlike RESPs, it may be that many TFSA savers are satisficers, saving a set (perhaps monthly) amount they prefer to contribute, rather than maximizers. Average per account TFSA contributions in 2009, the first year they were available were $\$ 3,926$, declining to $\$ 3,769$ and $\$ 3,727$ in the two subsequent years. The higher average contributions in the initial year are suggestive of some amount of swapping of existing savings into a new vehicle. Over time, a more constant rate of annual contributions to TFSAs may emerge, similar to RESPs, although doubling the contribution room would have a significant effect at the upper end of the distribution.
} 
The combined effects of potential increases in GIS payments, and to a lesser extent OAS payment, ${ }^{244}$ and potential reductions in federal income tax revenues led Kesselman (2012) to suggest that either the contribution limit should not be increased or that it should only be increased with companion reforms. These reforms would either restrict lifetime savings in a TFSA, or cap the exemption of TFSA withdrawals for GIS purposes, or reinstate a tax on withdrawals from a TFSA above some annual or lifetime amount. Poschman (2012) concedes that the implications of expanded TFSA contribution room create potential problems, but he argues these are "policy concerns with policy solutions, and not reasons to deny [Canadians] adequate, or even generous, tax-recognized savings opportunities" (p.399).

\subsubsection{Concluding thoughts on the TFSA}

It is likely still too soon to accurately project the real effect of the current or possibly doubled annual contribution limits of the TFSA on future tax revenues and transfers to individuals. Based on current tax expenditures (discussed in Chapter 3), the TFSA looks to be a very inexpensive instrument relative to the personal savings involved.

In 2011, the most tax year for which data is available, Canadians contributed $\$ 30.7$ billion to TFSAs and withdrew another $\$ 8.1$ billion (Finance Canada, 2012). However the projected cost to government, in foregone income taxes, was just $\$ 155$ million, an

\footnotetext{
${ }^{244}$ Because OAS benefits are taxable income, they are taxed at the effective rate for each individual beneficiary. As a beneficiary's total income from all sources increases so too should his or her tax rate, and therefore the income tax paid on OAS benefits.
} 
exceptionally small tax expenditure compared to the comparable annual cost of RRSPs. It is unclear, at this point, how much of the $\$ 30.7$ billion is new saving and how much of it is simply shifting from one asset to another.

Projections that assume rational actors will move all taxable assets into the TFSA as larger room becomes available may be overestimating the behavioral response. Previous studies find households do not always allocate their household portfolios to maximize their tax savings but that those who do are more likely to have larger incomes and greater wealth (Poterba \& Samwick, 2002; Amromin, 2003; Bergstresser \& Poterba, 2004; Alan, Atalay, Crossley \& Jeon, 2010). It is also worth noting that, not withstanding the higher participation of retirement-aged Canadians, only $6 \%$ of all TFSA holders are currently GIS recipients (Finance Canada, 2012).

The claims of a nightmare scenario in which tens of thousands of TFSA owners with hundreds of thousands in sheltered savings suddenly become eligible for the GIS are strikingly similar to arguments regarding asset limits in social assistance. Based on the Elizabethan Poor Laws principle of "less-eligibility", social assistance and other meanstested programs aim to make sure that participants truly have no other recourse but the publicly-funded support. Yet the available evidence finds no evidence that increases in asset-limits in social assistance meaningfully increase welfare case loads or even generate program savings sufficient to offset the administrative cost of verifying household assets. Furthermore, some evidence suggests that low-income households spend down assets or dis-save as they approach what they believe to be the applicable limit for a means-tested 
program they believe they may need in the future (Robson, 2008; Stapleton, 2009; National Council of Welfare, 2010). Yet, nearly one quarter (23\%) of current GIS participants have a TFSA ${ }^{245}$ suggesting, not unlike some social assistance recipients, some share of low-income seniors have a use for a safe but accessible savings vehicle.

There is the potential for a rash policy response to fears of projected increases to GIS program costs and windfall gains to asset-rich but income-poor seniors. One policy change would be to include all TFSA withdrawals in the income-test for GIS. Such a response could, regrettably, make it harder for low and modest-income seniors to keep their savings in any of the tax-preferred account-based instruments available to middle and upper-income seniors.

Another possible policy change would be to cancel the planned increase to the annual TFSA limit. This is a somewhat separate question from the issue of windfall access to the GIS. In pre-budget submissions to the government, a range of external groups have all called for increases to annual TFSA contribution room. ${ }^{246}$ In fact, one prominent actuary, Malcolm Hamilton, has even argued that the government should open up TFSA contribution room retroactively, to allow adults to contribute $\$ 5,000$ for each year that

\footnotetext{
${ }^{245}$ No data has been released to the public on the annual contributions or accumulated value of the TFSAs of current GIS recipients.

${ }^{246}$ Pre-budget submissions from the Investment Funds Institute, to the Chartered Accountants of Canada, to the Canadian Association of Retired Persons to the Federation of Canadian Music Festivals for the 2013 budget all included a request to increase TFSA contribution room.
} 
they were older than 18 in 2008 to effectively reduce any disadvantage for older Canadians (Hamilton cited in Chevreau, 2009 and Kesselman, 2012).

While potentially politically popular, the increases in TFSA room may well replicate the pattern in RRSPs where annual increases in available room are used only by a limited number of higher income savers. After RRSPs were introduced in 1957, contribution limits remained unchanged for 14 years. As the limits increased and public awareness of the program grew, participation expanded but the original purpose, to provide a niche program to self-employed workers saving for their own retirement, was effectively lost and instead taxable income became the better predictor of a claim for an RRSP deduction. It should be of no surprise if the distribution in the number of TFSA accounts and dollars should start to swing towards the upper end of the income distribution if and when the annual limits are raised.

The ability to move money in and out of TFSAs and the absence of age or use limits on withdrawals also serve as reminders that the TFSA was not introduced as a retirement savings instrument but rather as the instrument "for everything else in your life" (Flaherty, 2008). Considering the impacts of the TFSA on retirement income programs alone misses much of the point of the TFSA in the first place.

One of the unique features of the TFSA is that the purpose of the savings is unrestricted. Recall that RRSPs are notionally for retirement (with the exception of sheltered uses for homeownership and adult learning), RESPs are for education, RHOSPs were for 
homeownership and the RDSP is tightly restricted to families coping with a severe longterm disability. Each of these instruments invites critiques and evaluation in comparison to some other mechanism to promote retirement security, affordable homeownership, participation in higher education and financial security for persons with disabilities and their caregivers. Because each of these other instruments has such a specific use in mind, and not always uses more relevant to the top of mind concerns for low and modest income Canadians, they also have tended to obscure attention to their common features, origins and potential impacts on households.

The TFSA on the other hand was supposed to make no assumptions about how Canadians would or should use their own savings and was not going to actively penalize lower income or lower wealth Canadians for doing the same thing as other groups—saving. Canada's compulsory savings experiment failed in large part because it did not do in implementation what it had promised in theory - to meet a macroeconomic policy goal while delivering proportionally more the direct benefit (in refunded savings with interest) back to low and modest-income households. The next phase in the TFSA will decide whether it suffers a similar fate.

\subsection{Overall conclusions from the retrospective analysis}

In Chapter 1, I proposed the following as my first research question: Do the instruments [of interest in this thesis] hold together as a coherent set, with sufficient shared policy history and design that they should be examined together, rather than only in isolation? 
Based on the analysis presented in Chapters 4 through 7, I conclude that tax-preferred and account-based savings instruments in Canada, past and present, have too many common characteristics in their origin, design and implementation to not be considered as a coherent set. While there is value in continuing to examine, for example, RRSPs in comparison to other retirement income security instruments, there is much to be gained in looking holistically across savings instruments.

First, it is clear that all of the current instruments share four important features. All of them:

1) Require attachment to a mainstream financial services provider. RRSPs, mortgage loans to facilitate home equity, RESPs, RDSPs and TFSAs can only be obtained by purchasing a financial product from a federally-recognized provider. The extent of convergence in providers is outside of the scope of this thesis, but I speculate the convergence is high though imperfect and may have implications for the conduct of financial markets in Canada. More importantly, at the microeconomic level, the convergence means that households who are already able to access one tax-preferred savings instrument are more likely to be encouraged, by their financial service provider, to access another one. The difficulties faced by poorer consumers trying to open an RESP and RDSP are very real. For those households outside of, or only marginally attached to, the financial mainstream, these savings instruments must appear to be a system that is largely out of reach to them. 
2) Use the personal income tax system to deliver incentives in ways that confer larger benefits on those with larger taxable incomes. All of the instruments in question rely on some form of tax-preferred treatment—deductions, deferrals and exemptions. The value of the preferential tax treatment rises with tax liability and taxable income making these instruments highly regressive in terms of direct microeconomic effects on households. ${ }^{247}$ The deduction-deferral model of the RRSP appears to have the strongest incentive effect for higher income households (who expect a decline in future incomes) while tax-prepaid models (the RESP and TFSA) seem to be marginally more equitable for households with lower and modest incomes and savings. The instruments that offer direct cash transfers, on top of the tax incentive for saving, may again be marginally more equitable as long as that transfer is progressive. However, the value of the income-tested portions of the cash transfers, while better than nothing, are currently too small to balance the much larger value of the incentives flowing to higher income and higher wealth households.

3) Normalize only certain kinds of or goals for personal savings. The one potential exception to this is the TFSA that places no restrictions on the purpose of the withdrawals. However, even the TFSA has been positioned by advocates, critics and policy-makers as a complementary instrument to RRSPs for long-term

${ }^{247}$ As noted in Chapters 2 and 3, I do not discount the possibility that the net economic effects of these instruments may be more equitable once the full costs and benefits to households, the private sector and government are considered. That level of analysis is outside of the scope of this thesis and likely not quantitatively feasible. 
retirement savings. All of the other registered, tax-preferred account-based instruments reviewed in Chapters 4 to the present have some reasonably clear goal associated with the savings instrument—retirement savings, homeownership, higher education and care of adults with severe disabilities. In each of these cases, governments have made choices about which motives or goals for saving they will public sanction. There is a reasonable possibility this is influencing the savings choices of individuals in two ways. First, to echo Sen (Chapter 2), normative effects of these instruments may direct more household savings towards these goals than towards others. Second, those individuals and households who do not see their own priorities and preferences reflected in these normalized goals may still accumulate assets, but they may be more likely to do so using other instruments that do not receive the generous public subsidies of tax-preferred account-based savings instruments.

4) Promote financial capital that is fungible and may be beneficial to the saver outside of the strict savings goal of the tax-preferred account. Although, as I have argued above, each of the instruments is intended to serve a certain sanctioned savings purpose, in practice, these instruments create positive externalities for households that are generally overlooked in the policy discourse. First, accumulated saving in all of the instruments is, because of the mandatory attachment to mainstream private sector financial service providers, recognized as part of a household's total capital by financial service providers. For example deposits and accumulated balances in RESPs made by a parent may be intended 
for future use by a child, but in the interim, the parent benefits from recognition as the owner of the capital. This can in turn increase their total net worth and improve access to financial products and services such as preferential rates on credit and more personalized portfolio management services. A second way the accumulated capital has a fungible value is that all instruments provide for some mechanism to transfer or terminate the restricted savings. For example, money in RRSPs can be withdrawn for housing or education, tax-free, or with a tax penalty for any reason. Similarly, unused RESP balances can be transferred into an RRSP and RRSP amounts can be transferred into an RDSP. The effect of this fungibility is to improve the ability of those financially secure households already included in the system of tax-preferred account-based instruments to use and move around pools of liquid capital in ways that best meet their own needs. But for financially insecure households, fungibility ensures that assets are included in means tests for income support and other benefits such as extended health benefits, housing and childcare subsidies. For poorer Canadians, even small savings in these fungible assets can mean a reduction in overall welfare. The few exemptions for registered savings in means-tests have been made in an ad hoc manner and without prejudice for other tax-preferred account-based instruments.

In addition to these four shared characteristics, my retrospective analysis of the taxpreferred account-based instruments has revealed that they share at least two more shared features from their origins. 
The first is that each instrument responded to outside policy advice or policy advocacy. They were not first conceived of by policy-makers inside of government. The initial work to set the parameters on the design of each instrument was done by or with stakeholders outside of government. The outsourcing of government policy is not unique to the treatment of household savings and assets, but the trend towards outsourcing appears to have started much sooner in this field of policy-making than might otherwise be presumed. The stakeholders involved were generally people with more elevated socio-economic status, and sometimes stakeholders who might personally or professionally gain from the creation of a new savings instrument.

A second shared feature in their origin and development has been a tension between the role of tax-preferred savings as instruments for microeconomic policy and their role as instruments to meet macroeconomic policy gains. Compulsory savings promised to reconcile the macroeconomic goal of financing the war effort with the microeconomic goal of promoting greater post-war equality and shared prosperity. In practice, the policy was weighted more heavily to the former than the latter, leading to a collapse of political and public support. RRSPs were likewise used as instruments to promote domestic investment in Canadian firms. Similarly, TFSAs have been judged less on their ability to improve the welfare of individuals and households, and more on the projected future costs to the federal fiscal framework from a declining tax base and increased program costs. Promoting general economic stability is a widely recognized goal for welfare systems, alongside promoting the well-being of individuals and households (Daniels \& 
Trebilcock, 2005). In addition to being a recognizeable set of instruments, I argue that tax-preferred account-based instruments are a system within Canada's liberal welfare regime.

There has been a remarkable convergence of policy-making across these six tax-preferred policy instruments - each new instrument referencing and replicating something from past examples. Like other systems of welfare, these policy instruments have effects on regulating public morality (by prioritizing certain forms of saving and assets over others) and insuring individual risk (by supporting households in building and maintaining new resources that can prevent, mitigate or manage risks to wellbeing). Whether these instruments also promote an equitable distribution of resources is an open question

Because my concern is with the microeconomic goals and effects of the instruments, my evaluation of this system of welfare centers on the direct effects for households. Owing to financial and non-financial features, these instruments confer far larger benefits on wealthier households. While notionally available to anyone in Canada, this system is notionally universal but in practice it delivers more direct benefit to households with more private wealth and less benefit to households with less private wealth. More recently, incremental changes over the past decade show some greater attention to poorer Canadians but may not be sufficient to alter the dominant direction of federal taxpreferred, account-based policy-making. Based on the retrospective analysis, there is good reason to believe the direct effects of Canada's current system of welfare through tax-preferred account-based savings instruments is regressive, giving greater benefit to 
the wealthy and less to the poor. In the next chapter, I use data on household savings and assets to support this assertion. 


\section{Chapter 8: Survey data on household use of tax-preferred savings}

\subsection{Aims and overview of the study}

In the previous chapter I addressed my first research question - whether or not the Canadian collection of separate tax-preferred account-based savings instruments can and should be regarded as a system for welfare policy. Having concluded that the evidence from their policy origins and designs supports a system-oriented analysis, I speculated that the direct effects on households from this system are largely regressive. This chapter uses survey data on household wealth to verify that claim. Here I address the second research question in this thesis, posed in Chapter 1: If tax-preferred account-based savings instruments form a coherent set of policy instruments and indeed a system for delivering social welfare to households, is it a progressive or regressive system?

I begin by reviewing the literature on redistribution and progressive policy in liberal welfare regimes. That literature defines "progressive" as delivering more direct benefit to poorer households compared to wealthier households and "regressive" as its opposite. I then return to two studies, previously discussed in Chapter 1, by Kerstetter (2002) and by Morissette and Zhang (2007), respectively, on household net worth and the composition of household wealth in Canada. Both studies presented cross tabulations based on bivariate analysis. This study replicates and then extends their methodology. I adopt a simplified form of portfolio analysis, similar to Milligan (2004) and to Meh, Terajima, Chen and Carter (2009), examining the difference in the proportion of total household assets inside the tax-preferred account-based instruments in place in 1999 and 2005. 
Consistent with the studies by Kerstetter and by Morissette and Zhang, I find that the incidence of tax-preferred instruments is heavily skewed towards wealthier households in both measures of how many households own the asset the average household value of the asset. I expand on the two previous studies by both dis-aggregating these assets from the categories used by other authors and by restricting the sample according to the intended target population of the policy. For example, although RESPs are available to all Canadians, they are heavily targeted towards families with children. I also expand on previous studies by taking a closer look at the sub-sample of 'owners' - those households who do, across the wealth distribution, own that tax-preferred asset. This is approach is more consistent with government evaluation and monitoring on specific policy instruments and has previously been used by Milligan (2004). I find that the relatively small number of low-wealth households who participate in the tax-preferred accountbased instruments may have accumulated larger sums in these instruments than might be expected from the aggregate estimates (Kerstetter, 2002; Morissette \& Zhang, 2007). This has implications for future policy change.

Finally, consistent with Milligan (2004), I examine the portfolio share of total assets that are held in tax-preferred account-based instruments in both 1999 and 2005. I find that half of the total assets of the wealthiest quintile of Canadian households are held in these 
instruments that provide them with generous tax advantages and fungible capital. ${ }^{248}$ The median portfolio share held in these assets declines substantially with net worth quintile and reaches $0 \%$ by the bottom quintile. I suggest, consistent with literature on dependency on income transfers, that households at the top (but not uppermost) end of the wealth distribution are more reliant on and gain more direct benefit from the taxpreferred savings instruments. This effect is largely driven by the portfolio share from equity in a principal residence and to a lesser extent, RRSPs. I conclude that, in terms of the direct benefits from the system of tax-preferred savings instruments, the system is highly regressive.

\subsection{Literature review}

In a liberal welfare regime, such as Canada, redistribution is more often handled through targeted policy measures (Myles, 1998; Kato, 2003; Esping-Andersen, 2006; Mkandawire, 2005). Policy instruments may be targeted on the basis of need, or income or means-testing or other criteria to identify those who are deemed to deserve assistance through public spending. As Mkandawire (2005) noted, "the choice between targeting and universalism is couched in the language of efficient allocation of resources subject to budget constraints" (p.1). While other welfare regimes may offer large universal benefits, in a liberal regime the total value of social transfers is smaller in the aggregate and will form a smaller share of total resources for most households (Myles, 1999). Just

${ }^{248}$ As discussed at Section 1.2 in Chapter 1, money in these instruments is imperfectly fungible but is more fungible than in the past and far more fungible than benefits awarded under other welfare state instruments. 
as a tax system is deemed to be progressive if the tax rate rises with taxable income, targeted social transfers in a liberal regime are expected to rise as other household resources fall. Targeted programs that deliver a greater benefit to those in greater need are considered both more efficient but also more progressive (Myles, 1999; Battle \& Torjman, 2001).

Previous Canadian studies have considered the relative importance of targeted income transfers to low-income households and income inequality (Myles \& Picot, 2000; Picot, Morissette \& Myles, 2003; Zuberi, 2004; Morissette \& Ostrovsky, 2005; Frenette, Green \& Milligan, 2009). This literature finds that income transfers have some effect on the intensity of low-income (how far a household falls below a benchmark for low-income), household income instability, and on the inequality of total household incomes. While the size and timing of the effects differ substantially across studies, they are consistent in pointing to changes in the "relative importance" of government transfer income as share of total household income from all sources (Coward, Gellaty \& Moussaly, 2012).

Those households for whom transfer income is 'relatively more important' are more dependent on the welfare state. Whether this relative dependence is a good or bad thing is a matter of value judgment and not empirical fact. In the Esping-Andersen typology, those regimes that provide relatively larger shares of household income through government transfers provide greater decommodification - the ability to secure individual or household wellbeing outside of paid employment markets (Esping-Andersen, 1990 \& 2006). However, in a liberal regime, there is a social value given to self-sufficiency and 
independence from the welfare state—consistent with the discussion of 'thrift' and $19^{\text {th }}$ century moralist approaches to saving, discussed in Chapter 2. Particularly when associated with residual social assistance, reliance on transfers for wellbeing in Canada's liberal welfare regime is characterized as a highly negative form of dependence (Myles, 1998; Battle \& Torjman, 2001; Esping-Andersen, 1990, 2006; Hunter \& Miazdyck, 2004).

However, the present thesis is concerned with household wealth and the role of public policy in shaping observed outcomes in savings and asset accumulation. I adopt the perspective that, just as in income transfers, households for whom tax-preferred assets are relatively more important to their total wealth may be more dependent on a form of welfare system compared to households for whom these assets are a small or even nonexistent part of their total wealth. Just as the above-mentioned studies on the importance of transfer income have examined differences across the income distribution, an examination of the relative importance of tax-preferred savings instruments should consider differences across the distribution of household wealth in Canada.

Three previous studies have described the household distribution and use of several taxpreferred instruments. ${ }^{249}$ Using bivariate analysis of the 1999 Survey of Financial Security, Kerstetter (2002) presented several cross tabulations of household wealth in

${ }^{249}$ The discussion of the studies by Kersetter (2002) and Morissette \& Zhang (2006) that follows has been repeated from Chapter 1 for ease of reference by the reader. 
Canada using a definition of wealth that included housing ${ }^{250}$ and registered savings such as RRSPs. ${ }^{251} \mathrm{He}$ reported that, in 1999 , the poorest $20 \%$ of households with the least wealth owned less than $1 \%$ of all registered financial assets, ${ }^{252}$ and less than $1 \%$ of the total stock (measured as market value) of all owner-occupied homes in Canada. By contrast, the richest $20 \%$ of Canadians in 1999 owned $72 \%$ of all registered financial assets and $48 \%$ of the total stock (again measured as market value) of all owner-occupied homes. He asserted that "the tax policies of the federal government and some provincial governments have conferred huge financial benefits on the very wealthiest people, the one group capable of fending for themselves" (p.60). Kerstetter also offered comparisons on the distribution of net worth in 1999 to the distributions in each 1977 and 1984.

Kerstetter's study did not look at the details of tax-preferred savings instruments to describe the mechanisms through which they encourage asset-accumulation or why, in their design, they principally benefit wealthier households. Kerstetter's data also do not differentiate between the three different registered accounts that were included in the 1999 Survey of Financial Security - Registered Retirement Savings Plans (RRSPs),

${ }^{250}$ Kerstetter included the market value of any owner-occupied housing in his definition of household assets - not adjusted for the value of any outstanding mortgage debt or other debt secured against the value of the home.

${ }^{251}$ Kerstetter noted that his cross tabulations were created by analysts within Statistics Canada and purchased as a custom data product on a fee for service basis.

${ }^{252}$ Kerstetter reported these as "RRSPs and other registered plans" but did not give a further explanation of which other registered savings are included in this category. In the 1999 survey, RRSPs, RESPs, RHOSPs and Registered Retirement Income Funds were included as well as the imputed value of registered workplace pensions. Kerstetter reported (p.7) that the data he used excluded workplace pensions. 
Registered Education Savings Plans (RESPs) and residual amounts in Registered Homeownership Savings Plans (RHOSPs). Yet each of these is aimed at different savings goals and delivers incentives in different ways through the tax system. His analysis also does not include net home equity among those registered instruments despite the similarities between tax-preferred account-based instruments. Since 1999, there have been changes to these tax-preferred registered savings instruments that should be examined using the more recent data from the 2005 Survey of Financial Security.

Morrisette and Zhang (2007) conducted a similar bivariate analysis of both the 1999 and 2005 Survey of Financial Security. Like Kerstetter, they reported on the overall distribution of net worth in Canada and on the rates and mean values of ownership of certain categories of assets for households across net worth quintiles. Like Kerstetter, these authors did not report separately on each of the tax-preferred savings instruments or on net housing equity and only report on the mean amounts owned by households in three of the five quintiles. It is important to acknowledge that the chief objective for Morissette and Zhang was to provide more up-to-date information on wealth inequality in Canada and to present findings on a proposed measure of severe financial vulnerability households living in low-income with no financial assets or financial assets that, if liquidated would not raise them above low-income. It was not to verify Kerstetter's claims regarding the role of tax incentives in the savings and assets of wealthy Canadians. 
Milligan (2004) provided bivariate analysis of the 1999 Survey of Financial Security and compared it, like Kerstetter, to earlier survey data for 1977 and 1984. Milligan, however, reported on the separate values for each RRSPs, RESPs and RHOSPs but also included Registered Retirement Income Funds (RRIFs) and Deferred Profit Sharing Plans (DPSPs) in his definition of tax-preferred savings. These latter two are outside of the definition used in this thesis. ${ }^{253}$

Milligan's cross tabulations reported, for 1999, on the unconditional mean (the mean value for the population as a whole), the share of total assets held in each of the specific assets and the percentage of households reporting a positive balance. His tables also presented the mean values of tax-preferred assets for the bottom and the top quartile of households by net worth. He found that, using his definition of tax-preferred assets, $12 \%$ of total households assets were held in tax-preferred instruments in 1999, the largest share (9.8\%) in RRSPs. ${ }^{254} \mathrm{He}$ reported a substantial gap between the poorest $25 \%$ of households who held just $6.2 \%$ of their total assets in RRSPs and the richest $25 \%$ of households who held $10 \%$ of their total assets in RRSPs.

${ }^{253}$ As argued in Chapter 5, RRIFs are not properly a savings instrument, but rather a taxpreferred vehicle for accommodating matured RRSP assets in retirement. Deferred Profit Sharing Plans may be offered by some firms in lieu of a workplace pension or as a form of additional compensation making more appropriate comparisons with workplace pensions or non-wage compensation mechanisms rather than tax-preferred, accountbased policy instruments for household saving.

${ }^{254}$ Milligan's Table 1 suggests that RESPs and RHOSPs are negligible as a share of total assets. After RRSPs, the next largest share of assets are in RRIFs in his set of taxpreferred instruments. 
Milligan further estimated that the market value of a primary residence makes up 31.4\% of all households assets, but this figure was not adjusted for mortgage or equity loans against the asset and was not included in his category of tax-preferred assets. Perhaps as a result, his estimates suggest that a primary residence is actually more important in the household portfolios of the poorest quartile (at 39\% of all assets) compared to the richest quartile $(25.1 \%)$

Milligan noted that for many forms of assets, a large number or even a majority of households report that they do not own the asset. The presence of large numbers of zeros in the distribution of wealth is common in nearly all studies of household wealth and can present challenges for descriptive and analytical statistics (OECD, 2013). Indeed many of the statistical methods employed with income (on the basis that income is almost always higher than $\$ 0$ ) are not applicable to wealth. For example, when household net worth is zero, statistics that use net worth as the denominator will not be meaningful. On the other hand, if households with zero values on specific assets are excluded from analysis this can substantially restrict the sample and in ways that are very uneven across the distribution of household net worth. Milligan's approach was to instead report both the unconditional mean (for all members of a given category) as well as the mean conditional on having the asset of interest. This approach is broadly consistent with the federal policy evaluation and monitoring reports cited in Chapters 5 through 7 where the question of interest is, once take-up is known, how users of the policy instrument are behaving. Milligan's approach leads to a very interesting finding that, at the bottom quartile, mean RRSP assets increased substantially from unconditional mean of $\$ 1,500$ to 
a conditional mean of $\$ 6,000$. Again it is important to note that Milligan's principal aim in his study was not to evaluate the role of tax-preferred savings instruments in household wealth but rather to use three years of cross-sectional data to model cohort changes in lifecycle asset accumulation and allocation patterns.

Finally, Meh, Terajima, Chen and Carter (2009) conducted a more up-to-date analysis of the composition of household portfolios in Canada. Based on descriptive statistics, they noted that some Canadian households displayed particular dependence on one form of asset that may be of concern in the near future to policy-makers. Using data from the 1999 and 2005 Surveys of Financial Security, they calculated the mean share of household assets held in each real estate, financial assets, retirement assets, vehicles, business equity and "other" assets. It is not clear from their description of their methodology exactly what was included in each of these categories. They found that households in the bottom quintiles were more dependent on vehicles and "other" assets than other households and had, between 1999 and 2005, seen the largest increase in their dependence on real estate assets. Households in the top quintile had portfolios that were most evenly balanced across the authors' asset categories, making them more resilient to a drop in the values of any one category of asset. For households in the middle quintiles, housing assets made up more than half of the total portfolio leading the authors to caution that shocks to real estate markets could have large effects of the welfare of these households and their ability to manage household debt. This question of household financial stability was of primary importance to Meh and his colleagues, not the role of tax-preferred assets in observed household portfolio allocations. 
The current study adopts a bivariate analysis strategy, similar to that used by Kerstetter (2002), Milligan (2004) and Morissette and Zhang (2007). I limit my data to describe only those tax-preferred assets that are the subject of this thesis.

Like Milligan (2004), I am interested in a set of tax-preferred instruments but differ in my definition. As argued in Chapter 1, equity in a primary residence is, thanks to new financial products, now more like a household savings account, allowing owners to liquidate some of their savings through reverse mortgages and home equity loans. I include net equity (but not the total market value) of owner occupied primary residences in my set of tax-preferred savings instruments. Like Milligan, I include RRSPs, RESPs and, for 1999 only, residual amounts in RHOSPs. I also exclude deferred profit sharing plans and RRIFs for reasons noted at footnote 249 above and footnote 252 below. ${ }^{255}$

The studies by Kerstetter, by Milligan and by Morisette and Zhang each compared data to studies of wealth in Canada conducted in the 1970's and 1980's. Data on household wealth prior to 1999 did not include any estimates of the value of workplace pensions. These can be an important asset for those households with one or more members of a pension plan and, in the present context, may influence household allocation choices, particularly with regard to RRSPs. To make data for 1999 and 2005 comparable to

${ }^{255}$ At the time of the 1999 and 2005 surveys, neither RDSPs nor TFSAs were yet available and as a result the data used in this chapter does not include these two instruments. 
earlier wealth data, previous authors have had to exclude the value of workplace pensions from their definition of wealth. I limit my study to data for 1999 and 2005 and include workplace pensions in the calculation of total household net worth.

I expand on previous studies by also reporting results on each of the tax-preferred assets for relevant subpopulations. Like Meh and his colleagues (2009), I am interested in identifying differences in household reliance on certain forms of assets by net worth quintile. This analysis is similar to Milligan (2004) who reported on the share of total assets in RRSPs and RESPs. My analysis represents a first effort to illustrate the distribution of direct benefits from a largely hidden system of welfare aimed at promoting household saving and asset accumulation.

\subsection{Methodology}

I conduct a bivariate analysis of tax-preferred account-based savings instrument by household net worth. Where appropriate, as discussed immediately above, I also control for certain household variables to focus on the primary target population for each instrument. Mulivariate analysis could have been used to generate the same findings as this study but is not necessary for the purposes of this thesis-namely quantifying the inequalities discussed in Chapters 4 through 7. The bivariate approach used by Kerstetter (2002) and by Morisette and Zhang (2007) is adequate for the present purposes.

While each tax-preferred instrument is notionally available to all Canadians, each has some feature that signals a target population. In the case of RRSPs, the original policy 
intent was to provide Canadians who did not have a pension with a tax-sheltered way to save for their retirement. According to Mousally (2010), 18\% of all employed workers in Canada have only an RRSP and no workplace pension. Employer-sponsored pensions cover approximately $32 \%$ for all employees in Canada but a higher percentage of workers in public sectors compared to the private sector. I report on the average value of RRSP assets for all households and for only the subsample of households with only RRSPs and no workplace pension assets. I expect that those households who have RRSPs but no workplace pension will save more in RRSPs than those households combining both RRSP and workplace pensions in their retirement income plans. Some number of households may also have previously had an RRSP that has been liquidated before retirement. Furthermore, as discussed in Chapter 5, pre-retirement withdrawals from RRSPs are encouraged under the Homebuyer's Plan (HBP) and the Lifelong-Learning Plan (LLP). I report on past RRSP ownership and early withdrawals.

In the case of RESPs, the savings incentives are available only to families with children under 18. I report on average values (both unconditional and conditional) for all households as well as only the subsample of households with dependent children under age 18 .

In the case of home equity, the tax-sheltered asset is, by definition, conditional first on owning one's residence and second on having positive equity in the house, after mortgages and other debts secured against the property are deducted. I derive and report on a measure of net tax-exempt housing equity for only households who own their 
primary residence as well as the unconditional median value for the population as a whole.

Some studies of wealth have reported on housing wealth by reporting separately the value of the estimated market price of a home and then the mortgage debt outstanding on a home (Kerstetter, 2002; Milligan, 2004; Morisette, Zhang \& Drolet, 2002; Morisette \& Zhang, 2007). Others have reported on the equity held in a principal residence as the net of the estimated resale value less the outstanding mortgage balance (see for example CGA, 2011). For the purpose of this study, neither of these approaches would be adequate. Since the aim of the study is to look at how households across the wealth distribution allocate whatever resources are at their disposal in the tax-preferred vehicles of registered accounts and housing, it would be incorrect to add housing to a sum total without first adjusting it to a net value by subtracting debts that would legally be paid out first upon realization of the sale of the home. This means that both mortgage and home equity loan amounts should be deducted to arrive at a true value of the termination value of the housing assets belonging to an economic family.

I report the share of total household assets held in each of RRSPs, RESPs, residual RHOSP balances and home equity, and for the sum of these as a measure of dependence on tax-preferred assets. In the calculation of the portfolio shares in each type of taxpreferred asset, I remove those previous control variables and report the result for the 
population as a whole, by net worth quintile. ${ }^{256}$ Because each instrument has a different primary target population, the control variables cannot be combined and conditional medians cannot be aggregated. Furthermore, the aim in this study is to consider the direct household impacts of a thinly-universal system of welfare - therefore a population-wide analysis is appropriate.

Because of the size and potential interaction effects from workplace pensions, I report on the portfolio shares of assets in tax-preferred instrument where the value of assets first includes and then excludes pension assets. As discussed throughout this thesis, pension assets can be large but they are an asset over which an individual or household exercises very little direct control and almost no liquidity until retirement age. Nevertheless, their size and tax-preferred treatment mean they cannot be ignored.

Median values are reported rather than means because they are less sensitive to extreme values in the distribution (OECD, 2007). In many cases, mean values are substantially different, suggesting an even more steeply skewed distribution both across and within net worth quintiles (OECD, 2007). Means are not reported but are available on request.

Results from cross-tabulations are presented in Tables and Figures at Section 8.5 later in this chapter. Inter-quintile differences and the sample sizes of the surveys are large

${ }^{256}$ I do repeat the portfolio share analysis with controls for the age of the primary income earner in the economic family to limit the sample to working age households. I also repeat the analysis with controls to eliminate the wealthiest $5 \%$ and then $1 \%$ of economic families on the basis that these may be outliers in their behavior and portfolio allocations. 
enough that I expect all differences will be statistically significant. Statistical testing for significance is limited to inter-quintile differences in portfolio shares held the taxpreferred instruments.

Analysis began by constructing the quintiles for net worth. I first calculated a measure comparable to Morissette and Zhang (2007) before calculating quintiles that included pension wealth. Results are reported at section 8.5. A household's net worth quintile is constant across all tables.

I employ Milligan's (2004) approach to deal with large numbers of zero values and report both the unconditional average value of the asset and the average value of the asset conditional on a non-zero balance or other reasonable indication of ownership.

Because of efforts to fill any missing values (through follow-up with respondents, use of administrative data and imputation) there are no missing values in the SFS files for 1999 or 2005. The data file has also been processed and cleaned to remove any values entered to questions that should have been skipped based on responses to prior questions. For example, if a respondent said that no one in the household owned a vehicle then any nonzero values entered as the dollar value of vehicles were removed by Statistics Canada prior to releasing the master data file. In these two survey years, the best interpretation of a $\$ 0$ entry for any asset or debt is that the economic family does not have this component of net worth. 
Nevertheless and as noted above, it is possible for net worth to be zero or negative. Morisette and Zhang (2007) reported that $12.3 \%$ of economic families in 1999 and $14.1 \%$ of economic families in 2005 had a negative or zero net worth. However their definition of net worth excluded pensions. Including pension assets increases the average net worth of the bottom quintile. For the purpose of this study, net worth quintile is used only as a categorical variable and is constant for a household in all bivariate analyses. A negative or zero net worth will place them in the bottom quintile but is otherwise not important to the analysis.

In the tables on portfolio shares, a finding of $0 \%$ means that the household has none of its total assets in the tax-preferred instrument. If none of a household's assets are held in the tax-preferred then the instrument is not important to their total assets or the contribution of wealth to their overall wellbeing. As the ratio rises above zero, household reliance or dependence on tax-preferred savings increases. This approach is only possible as long as the household has some positive assets. Because pension assets are included, no household in the sample has $\$ 0$ in assets.

\subsection{Data}

Analysis of household wealth was done using the master file for the Survey of Financial Security (SFS) for each 1999 and 2005. The SFS was a national cross-sectional survey conducted by Statistics Canada to measure the assets and debts of Canadians but also 
included questions regarding household income and selected financial behaviors. ${ }^{257}$ The unit of analysis is the economic family defined, according to the SFS and other Statistics Canada surveys, as all persons related by blood, marriage (including common law), or adoption who live in one residence. This definition presumes that related members of a household will share costs and financial resources and as, a result, data on wealth was collected only for the economic family as a whole. This assumption is potentially problematic in presuming equitable access to household assets, and conversely responsibility for household debts, without attention to the wide variation in family and household formation and reformation. Nevertheless, this is the only microeconomic wealth data available in Canada. Further details on the data used are available in Appendix A and a discussion of the unit of analysis appears at pages 474-477.

Wealth in this discussion, as in the literature, is used interchangeably with the term net worth (Zyblock, Webber Shields \& Maser, 1997; Kerstetter, 2002; Milligan, 2004, Morissette \& Zhang, 2007; Bascand, Cope \& Ramsay, 2006; Meh et al., 2009). Both refer to the value of a stock of resources less liabilities, and are seen as distinct from income flows such as employment earnings, social assistance benefits or interest earned from investments. I calculate net worth as the total of all assets less all debts. Assets include physical or tangible assets (such as real property, vehicles and personal possessions), business assets (such as equity stakes in a business including claims on its current assets income), financial assets (such investments and other savings), pension

${ }^{257}$ Efforts to use the 1984 wealth data used by Kerstetter (2002), by Milligan (2004) and by Morisette and Zhang (2007) found that the confidential file was not available. 
assets and outstanding debts owed (such as loans and credit debts). Debts include all personal liabilities including mortgage debts, personal loans, credit balances, installment debt (such as store cards) and other outstanding liabilities. Business debts are not reported separately but are instead deducted against the valuation of the related business as part of the valuation of a respondent's equity in the business. This was the approach adopted in the design of the 1999 and 2005 SFS questionnaires (Zyblock et al., 1997). Table 1 in Appendix A summarizes the components of net worth for the 1999 and 2005 SFS data.

The value of pension assets for 1999 and 2005 SFS were all imputed by Statistics Canada. Survey respondents were asked a series of questions about the current and past membership in workplace pensions and the nature of the pension plan (for example, defined contribution in which current employer and employee contributions are guaranteed but final benefits depend on the rates of return on the invested capital, or defined benefit in which the employer commits to meeting a specific future benefit level for retired members and contribution rates are adjusted to adequately fund the future liability). This information, along with administrative records where consent was given, was used by Statistics Canada to generate both "going concern" and "termination" estimates of the value of employer pension (see below). The estimates consider the age and income of the pension member, the nature of the workplace pension, the contribution rates of the employer and member and the duration of the membership in the plan. A full discussion of the pension valuation methods used by Statistics Canada appears in a paper by Cohen, Franken and Maser (2001). 
Assets are valued on a termination rather than going concern basis. In fact, most assets covered in the SFS dataset are valued on the termination basis meaning that the value is assessed by asking respondents for to report the market value if sold or liquidated on the date of the survey. Most debts are similarly measured (Statistics Canada, 2010). The termination approach is adopted in the current study because it is reported across many classes of assets and therefore allows for the greatest comparability among assets.

My definition of tax-preferred assets in this thesis includes RRSPs, RHOSPs, RESPs, RDSPs, TFSAs and equity in a principal residence. The 1999 and 2005 SFS datasets predate the creation of the RDSP and TFSA therefore these are excluded in my analysis of survey data. As new data becomes available these can be added in future analysis. The total amount of economic family wealth held in this class of assets is defined, for 1999 and $2005^{258}$ below.

\footnotetext{
${ }^{258}$ This definition is broadly consistent with Milligan's (2004) definition of a class of taxpreferred assets. The current analysis builds on Milligan's approach by including a measure of housing equity. The exclusion of RRIFs in contrast to Milligan is addressed in an earlier footnote. The exclusion of deferred-profit-sharing-plans from the class of taxpreferred assets is justified on the basis that these explicitly preclude employee contributions (CRA, 2008) and so cannot attract personal or household savings out of new or existing assets. Also, DPSPs are taxable at the time the share in the profits is exercised by the holder in such wide-ranging circumstances as sickness, long-term disability, parental leave or lay-off. Earnings on the investments in a DPSP are exempt from tax but the final tax impact on the beneficiary is highly uncertain depending on when and how the benefit is exercised.
} 


$$
\begin{aligned}
& \text { RRSPs }+ \text { RESPs }+ \text { Residual RHSOP balances }+ \text { Equity in a principal residence } \\
& =\text { Tax-preferred assets }
\end{aligned}
$$

The variable for Registered Retirement Savings Plans includes RRSPs as well as lockedin variants such as Locked-in Retirement Savings Plans (LRSPs) and Locked-in Retirement Accounts (LIRAs) but does not include any Registered Retirement Income Funds (RRIFs). ${ }^{260}$ Contributions to these accounts may include some combination of economic family members and employers but this division cannot be ascertained from the way the information was collected. Amounts held in RRIFs are included in all estimates of total assets and total net worth but are not addressed separately in the analysis since they are financial products intended to be conversions from RRSPs which are the key taxpreferred instrument.

The value of RESPs in 1999 and 2005 is the value of all RESPs held by a member of the economic family. Given the wording of the questions asked of survey respondents, it is possible that this estimate includes amounts held as a subscriber (someone who opened and contributes to an RESP, such as a parent or grandparent) or as a beneficiary

259 The net value of equity in a principal residence is calculated by the author and is discussed later in the chapter.

${ }^{260}$ As per the discussion of RRSPs in chapter 3, RRSPs must be converted to RRIFs or annuities in the year that the account owner turns 71 . 
(someone who is named as the intended user of the account upon enrolment in a postsecondary education program). ${ }^{261}$

The variable for household savings in Registered Homeownership Savings Plans is available and reported only for 1999. As discussed in Chapter 5, RHOSPs were introduced as a federal tax instrument in 1974 and were later repealed in 1985 (with sunset provisions for existing accounts). While some remaining accounts may have been existence in 1999, by 2005, these would all have, been required to be closed by federal law. The inclusion of RHOSPs in 1999 only is expected to have little or no impact on the findings since the proportion of the sample with an RHOSP is very low and the median dollar values of RHOSPs is $\$ 0$ across the distribution of households by wealth quintile.

I have derived an estimate of home equity for each 1999 and 2005, as the net of an economic family's market value of an owned (versus rented) principal residence, less the family's and mortgage debts and home equity loans outstanding against the property. This is expressed as:

Imputed market value of the home ${ }^{262}$ - Outstanding mortgage debt on the home + Outstanding home equity loans $=$ Home equity

${ }^{261}$ A respondent and a beneficiary may be the same person in the case that an adult opens an RESP to save for their own education. The incidence of this kind of use is unknown from public data and RESPs are generally presumed to be vehicles to save for the higher education of a child related to the subscriber.

${ }^{262}$ Imputations were done by Statistics Canada. 
The SFS files include a file for the individual respondent and a separate file for the respondent's economic family. ${ }^{263}$ The selected respondent from each household was the person who self-identified as being the most knowledgeable about the family's financial circumstances (Statistics Canada, 2006) and who was asked to respond on questions of income, assets and debts on behalf of the entire economic family. While data on basic demographic characteristics, income, workplace pensions and labour force participation are available separately for each member of the household, data on non-pension assets and debts was collected for the pooled amounts for all members of the economic family. The unit of analysis in the present study is the economic family - also referred to as the household for ease of discussion.

The sample size and overall response rates for each of the 1999 and 2005 SFS are summarized in table 8.1 below. The sample size for 1999 is large enough to permit detailed analysis without suppression. The 2005 data is more recent but more limited in the size of the sample. I opt to include both in this study, recognizing this has restricted the number of control variables that can be used.

Table 8.1 SFS sample size and response rates, 1999 and 2005

${ }^{263}$ Economic family is defined by Statistics Canada as "the members of a household who are related by blood, marriage or adoption" (Statistics Canada, 2012). Single persons would be considered to be in an economic family of "one". 


\begin{tabular}{l|ll}
\hline Survey & Sample & Additional sample, if any \\
\hline SFS 1999 & $\begin{array}{l}23,000 \text { dwellings } \\
\text { Overall response rate: } 75.7 \%\end{array}$ & $\begin{array}{l}2,000 \text { dwellings in high } \\
\text { income areas } \\
\text { Response rate: } 59.9 \%\end{array}$ \\
SFS 2005 & $\begin{array}{l}7,500 \text { dwellings } \\
\text { Overall response rate: } 67.7 \%\end{array}$ & $\begin{array}{l}1,500 \text { dwellings in high } \\
\text { income areas } \\
\text { Response rate: } 51 \%\end{array}$ \\
\hline
\end{tabular}

The sampling frame for the surveys used is a complex and multi-stage frame using the data from another survey (the Labour Force Survey), and where results are weighted based on national Census data to adjust for age, gender, household size, province of residence and income data from administrative sources (Statistics Canada, 2009, 2010), adjusting the results to be representative of the Canadian population as a whole, including those households who refused to participate in the survey. Weighting procedures in surveys of wealth presume that the characteristics included in the weights will adequately reflect diversity in the population and lead to representative estimates of assets and debts. In addition to a complex, multi-stage weighting scheme, to try to compensate for expected non-response among higher income and higher wealth household, the SFS oversampled households living in neighbourhoods identified as being "high income". 264 All bivariate analysis was conducted using the standard weight included in the master file.

${ }^{264}$ Using Census data, it is possible to identify average household income by postal code tracts. In the 1999 and 2005 samples, the additional higher income sample was drawn from postal code tracts with average household incomes of $\$ 200 \mathrm{~K}$ or more. 
The dollar figures for 1999 were adjusted to 2005 constant dollars in the standard way based on the Consumer Price Index. ${ }^{265}$

Further detail on data sources, data quality, definitions of variables and notes on use of the master data files that may be of interest to future researchers is available at Appendix

A.

\subsubsection{Defining net worth quintiles}

I first adjusted all 1999 dollar values to constant 2005 dollars and to create estimates of median net worth by quintile using the author's definition of net worth (described earlier in this chapter). I report the results in Tables 8.2 and 8.3 below. The net worth quintile of the household, as described in these tables, is used as the grouping variable in all of the other stages of the analysis with the SFS data.

Table 8.2: Upper limits for net worth quintile, including pensions, median and mean net worth, 1999 (\$2005)

\begin{tabular}{r|rrr}
\multicolumn{1}{l|}{ Quintile } & $\begin{array}{r}\text { Upper limit of } \\
\text { quintile }\end{array}$ & Median net worth & Mean net worth \\
\hline Bottom 20\% & 11,600 & 5,568 & 5,485 \\
2 & 76,191 & 57,072 & 56,849 \\
3 & 193,140 & 159,964 & 159,811 \\
4 & 432,164 & 344,520 & 349,299 \\
Top 20\% & NA & $1,041,486$ & $1,427,967$ \\
\hline
\end{tabular}

${ }^{265}$ The adjustments were calculated based on the on-line "Inflation Calculator" provided by the Bank of Canada. It in turn relies on the monthly Consumer Price Index for Canada, 1914-2006 (CANSIM V41690973 series). For reasons that cannot be determined by the author, the adjustment for 1999 to 2005 in this study differed slightly from the constant used by Morissette and Zhang (2006). 
Table 8.3: Upper limits for net worth quintile, including pensions, median and mean net worth, 2005 (\$2005)

\begin{tabular}{r|rrr}
\multicolumn{1}{l|}{ Quintile } & $\begin{array}{r}\text { Upper limit of } \\
\text { quintile }\end{array}$ & Median net worth & Mean net worth \\
\hline Bottom 20\% & 10,852 & $-2,382$ & 1,000 \\
2 & 86,700 & 41,098 & 37,282 \\
3 & 234,776 & 153,163 & 148,350 \\
4 & 537,700 & 367,585 & 361,226 \\
Top 20\% & NA & $1,264,158$ & 862,850 \\
\hline
\end{tabular}

The change in the upper limits, after adjusting for inflation is noteworthy, as they fell between 1999 and 2005 for the bottom quintile only and rose substantially for the top two quintiles. This is consistent with findings from Morissette and Zhang (2007) that wealth inequality increased during the same period.

Results from the bivariate analyses using these net worth quintiles are presented in the next section.

\subsection{Results}

In the subsections below, I discuss the incidence and then unconditional and conditional median values for each of RRSPs, RESPs, RHOSPs and housing equity. After the results for each instrument, I present the data on the portfolio shares held across the taxpreferred assets.

\subsubsection{RRSPs}

Tables 8.4 and 8.5 below show data on the incidence of RRSPs by net worth quintile for 1999 and 2005 respectively. I report the percentage of households with various 
combinations of RRSPs and workplace pensions (RPPs). I also report the percentage of households who state that they have ever had an RRSP - including those who do not currently have an RRSP. For those households reporting that they have or have previously had an RRSP, I report the percentage who state they have used the taxsheltered Homebuyer's Plan (discussed in Chapter 5) and the percentage who have made taxable pre-retirement withdrawals from an RRSP.

Table 8.4: Incidence of RRSPs by net worth quintile, 1999

\begin{tabular}{|c|c|c|c|c|c|c|c|}
\hline Quintile & $\begin{array}{r}\% \text { with } \\
\text { RPP only }\end{array}$ & $\begin{array}{r}\% \text { with } \\
R P P \\
\text { and } \\
R R S P\end{array}$ & $\begin{array}{r}\% \text { with } \\
\text { RRSP } \\
\text { only }\end{array}$ & $\begin{array}{r}\% \text { with } \\
\text { neither } \\
R P P \text { nor } \\
\text { RRSP }\end{array}$ & $\begin{array}{r}\% \text { ever had } \\
R R S P\end{array}$ & $\begin{array}{r}\text { if yes, \% } \\
\text { withdrawal } \\
\text { under } H B P\end{array}$ & $\begin{array}{r}\text { if yes, \% } \\
\text { taxable } \\
\text { withdrawal }\end{array}$ \\
\hline Bottom 20\% & 6.4 & 4.5 & 12.2 & 76.9 & 23.1 & 1.5 & 9.4 \\
\hline 2 & 14.1 & 20.3 & 29.8 & 35.7 & 58.3 & 8.5 & 16.9 \\
\hline 3 & 15.2 & 38.9 & 27.0 & 19 & 70.7 & 11.2 & 18.8 \\
\hline 4 & 13.4 & 51.7 & 25.2 & 9.7 & 81.6 & 6.8 & 22.7 \\
\hline Top 20\% & 6.1 & 65.6 & 23.5 & 4.8 & 91.1 & 4.3 & 18.7 \\
\hline
\end{tabular}

Table 8.5: Incidence of RRSPs by net worth quintile, 2005

\begin{tabular}{r|rrrr|rrr}
\hline Quintile & $\begin{array}{r}\text { \% with } \\
\text { RPP only }\end{array}$ & $\begin{array}{r}\text { \% with } \\
\text { RPP } \\
\text { and } \\
\text { RRSP }\end{array}$ & $\begin{array}{r}\text { \% with } \\
\text { RRSP }\end{array}$ & $\begin{array}{r}\text { \% with } \\
\text { onither } \\
\text { RPP nor } \\
\text { RRSP }\end{array}$ & $\begin{array}{r}\text { \% ever had } \\
\text { RRSP }\end{array}$ & $\begin{array}{r}\text { if yes, \% } \\
\text { withdrawal } \\
\text { under HBP }\end{array}$ & $\begin{array}{r}\text { if yes, \% } \\
\text { taxable } \\
\text { withdrawal }\end{array}$ \\
\hline Bottom 20\% & 8.5 & 3.3 & $\mathbf{1 1 . 2}$ & 77.0 & 23.2 & 1.3 & 10.4 \\
2 & 15.4 & 19.0 & $\mathbf{2 6 . 5}$ & 39.1 & 53.9 & 10.8 & 15.4 \\
3 & 15.9 & 36.5 & $\mathbf{2 7 . 1}$ & 20.5 & 70.3 & 16.3 & 20.5 \\
4 & 15.5 & 56.4 & $\mathbf{2 1 . 9}$ & 6.2 & 82.9 & 15.3 & 20.1 \\
Top 20\% & 8.3 & 64.3 & $\mathbf{2 2 . 4}$ & 4.9 & 89.0 & 6.9 & 17.4 \\
\hline
\end{tabular}

Not surprisingly, the poorest $20 \%$ of Canadians are most likely to report that no one in the economic family had either a workplace pension or RRSPs in 1999 and 2005 respectively. This does not necessarily mean these same families and individuals are not 
saving anything for their retirement. For example, Schellenberg and Ostrovksy (2010) find that households often report other forms of assets such as home equity, a small business or expectations of future earned income as part of their retirement preparation. This is also very likely the case for the small percentage (4.8\% and $4.9 \%$ in 1999 and 2005 respectively) of the wealthiest $20 \%$ who do not report having either a pension or RRSPs. The most obvious conclusion is that estimates of wealth and net worth that remove pension wealth from the model are likely to under-estimate wealth inequality in Canada.

The small increase, and across all net worth quintiles, in the percentage of households reporting they are saving only through a workplace pension is somewhat surprising given that pension coverage rates in Canada have been modestly declining since the mid1970 s. $^{266}$

The tables above also suggest that the opportunity for (and impacts of) substitution between pensions and RRSPs (discussed in Chapters 3 and 4) is not evenly distributed by net worth. As household net worth rises, so does the likelihood of having both a workplace pension and RRSP savings. For wealthier households, the ongoing increases to contribution limits will be more important as a mechanism to spread a larger share of

\footnotetext{
${ }^{266}$ Author's analysis of Statistics Canada Survey of Labour and Income Dynamics, CANSIM Table 282-0002. Pension coverage rates among all members of the labour force fell from $37 \%$ to $32 \%$ between 1976 and 2006. The declines were most sharp among men in the private sector (where rates fell from $27 \%$ to $20 \%$ in the same time period) but were partially offset by increases in pension coverage among women (climbing from $27 \%$ to $33 \%$ ).
} 
their savings between pensions and private, tax-preferred RRSPs. But it seems highly unlikely that policy to continuously increase contribution room will, on its own, do much for those in the bottom two net worth quintiles.

Given all the possible combinations of RRSPs and pension, the poorest $40 \%$ of households are most likely to have only RRSPs, making them closest to the original target population for the policy - Canadians without an employer-sponsored pension. This is a stark contrast to the historical data presented in Chapter 4 showing that the early adopters of RRSPs were largely self-employed professionals with higher incomes. Today, wealthier households are more likely to be able to count on both a pension and RRSPs, facilitated by generous contribution limits while less wealthy households are more likely saving for retirement independently in RRSPs. In short, those who are most reliant on self-financed retirement savings are less likely to benefit from the current policy design.

The tables above also suggest that many more low wealth households have had an RRSP at some time than those who currently have an RRSP. Among households in bottom quintile, $14.5 \%$ had an RRSP in 2005 but another $8.7 \%$ had had one at some point. Some share of these closed RRSPs will have been as a result of conversions to Registered Retirement Income Funds. However, Tables 8.4 and 8.5 also show the percentage of households reporting that they had made pre-retirement withdrawals, either using the taxsheltered Homebuyer's Plan or as a taxable withdrawal of cash. 
In all net worth quintiles, it appears that an important share of households are making taxable pre-retirement withdrawals from RRSPs. In other words, RRSPs may have become more medium term savings vehicles in which funds cycle in and out, rather than being held for long-term retirement needs. Looking specifically at the policy-sanctioned tax-sheltered mechanism of the HBP, the tables above suggests it is almost totally irrelevant to households with low net worth. Consistent with the discussion in Chapter 5, HBP withdrawals rise with net worth but peaks for households in the middle quintile and $4^{\text {th }}$ quintile. It is also noteworthy that HBP use increased between 1999 and 2005 for all net worth quintiles save for the poorest $20 \%$.

Figures 8.1 and 8.2 present the median values of RRSPs for all households and the conditional median values of RRSPs. In this case the conditioning variable is the ownership of only RRSPs (and no workplace pension assets) - replicating the original target population of the policy when it was created. The frequencies of RRSP-only households by net worth quintile are listed in bold in the Tables 8.4 and 8.5 above.

Figure 8.1: Unconditional and conditional median RRSP values, 1999 


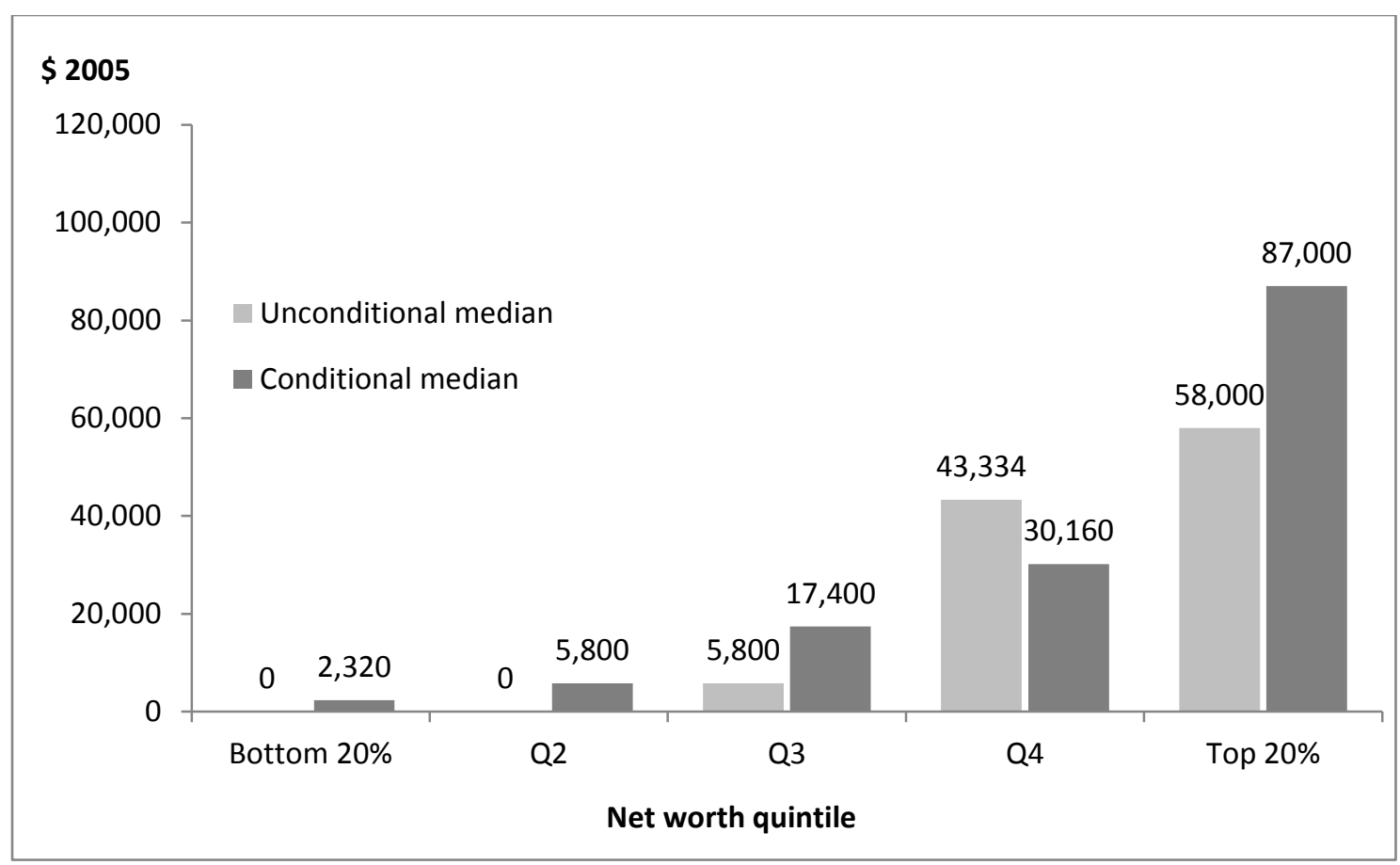

Figure 8.2: Unconditional and conditional median RRSP values, 2005

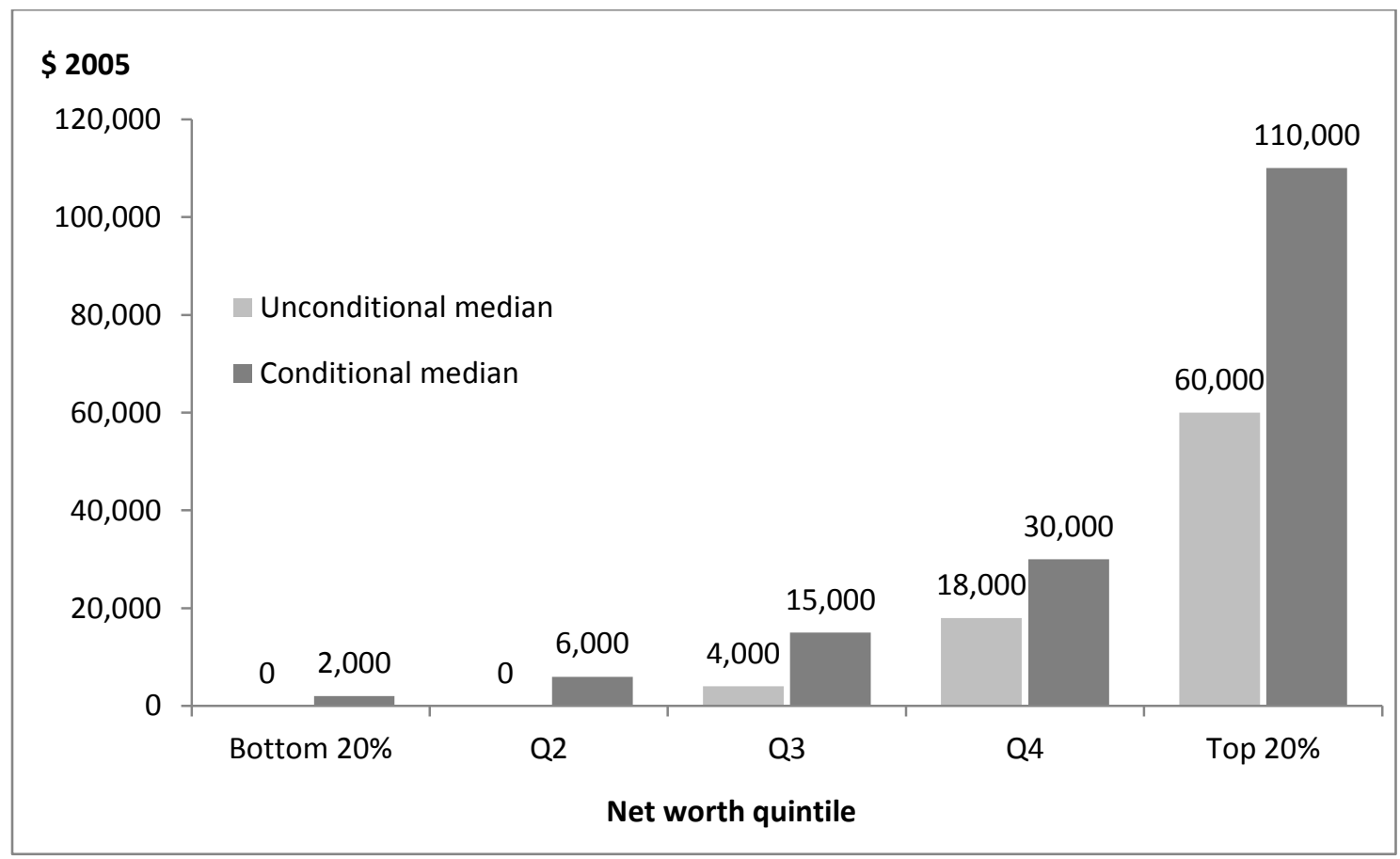


The unconditional median value of RRSPs for the poorest $40 \%$ of households is $\$ 0$ in both 1999 and 2005. However, when the sample is restricted to households with only RRSPs, the conditional medians are substantially higher. The $12 \%$ of households in bottom quintile in 1999 (11\% in 2005) who had only RRSP retirement savings had $\$ 2,320$ in RRSP assets in $1999, \$ 2,000$ in 2005 . The increase between the unconditional and conditional medians is even larger for the next quintile, where $29.8 \%$ in 1999 and $26.5 \%$ in 2005 had only RRSP retirement assets.

The estimates of the conditional median RRSP assets for the middle and highest net worth (Q3 and Q5) in the figures above are also higher than the unconditional medians. These quintiles have greater access to workplace pensions and it is likely that these economic families might be saving less in their RRSP because of substitutions with workplace pensions. However the magnitude of the difference is smaller than for the poorest quintile. These results suggest that policy decisions regarding RRSPs that overlook effects on low wealth households on the assumption that that they have no RRSPs may be overlooking a group of small savers.

The fourth quintile in 1999 (Figure 8.1, above) is notable because the median value of RRSP assets for households in that net worth group without a workplace pension is actually lower than the median for all households in the same quintile. The explanation appears to be that households in this band, in 1999, had actually saved more in RRSPs when they held them in combination with a pension. The difference disappears in the 2005 data. 
Between 1999 and 2005, there were few policy changes to RRSPs. Annual contribution limits increased just $\$ 3,000$ in that period (CRA, 2013b). It is difficult to ascribe any direct effect from policy in the observed changes median RRSP values among the economic families using only RRSPs for their retirement savings. The unconditional median value of RRSP assets increased only for the richest $20 \%$ of households. Looking at the conditional median — for the subsample of RRSP-only retirement savers—RRSP assets increased for both the second and top quintiles. The increase for the second quintile was very small.

The period of 1999 to 2005 saw large losses followed by large gains in investment markets. ${ }^{267}$ These market gains were probably not evenly shared by RRSP investors with different levels of net worth. Wealthier investors would have had greater access to personalized, strategic financial advice and portfolio management leading, possibly, to better returns compared to smaller investors. Because of the structure of the generous deductions and exemptions for RRSPs, these unequal market gains are not smoothed out, as they occur, by the tax system. Whether, over the long-run, the tax system captures these gains in higher RRSP withdrawals is an unanswered question. In the short and medium term, periods of high market returns coupled with the design of tax-preferred RRSPs that we have is likely to mean that wealthier RRSP users are able to build and keep more RRSP assets.

${ }^{267}$ For example, the S\&P/TSX Composite Index rose through 1999 to a peak in September 2000 before plummeting through to the autumn of 2002. After that, the Index grew steadily and had doubled in value by autumn 2005 . 


\subsubsection{RESPs}

Table 8.6 below reports the incidence of RESP assets by net worth quintile for each 1999 and 2005. I report the incidence for the population as a whole and for the subsample of economic families with children under age $18^{268}$-replicating the primary target population for RESPs, particularly since the Canada Education Savings Grant and Canada Learning Bond were added (discussed in Chapter 6).

Table 8.6: Unconditional and conditional incidence of RESPs, 1999 and 2005

\begin{tabular}{r|rrrr}
\hline Quintile & \% with RESP & \% with RESP & families with & families with \\
& 1999 & 2005 & children, \% with & children, \% \\
& & & 1999 & with RESP \\
& & & & 2005 \\
& & & & \\
\hline Bottom 20\% & 1.4 & 1.9 & 10.5 & 9.0 \\
2 & 4.6 & 7.1 & 14.7 & 18.0 \\
3 & 7.1 & 15.4 & 14.1 & 47.4 \\
4 & 6.3 & 16.0 & 23.5 & 50.9 \\
\hline
\end{tabular}

The data set did not permit me to identify families with dependent children over 18 who were currently attending post-secondary education. Table 8.6 therefore should be viewed as an estimate of the frequency of families using RESPs to actively save. Some proportion of economic families would also own RESPs from which they were making withdrawals to support one or more adult children (or other adult family members) in higher education - these families are not captured in the conditional estimates above.

${ }^{268}$ This includes children by birth, adoption, family re-formation and foster children. 
From the data in Table 8.6, there are three overall trends worth highlighting. First, there is a substantial increase in the frequency of RESP ownership when the sample is constrained to families with children. As described in Chapter 6, while RESPs are not restricted to saving for a child, families with children have been the primary target market for RESPs since the first group plans were created in the 1960s. The addition of the agerestricted grants and bonds in 1998 and 2004 substantially reinforced the perception that RESPs are intended only for families with children. Data in the table above might reflect RESP ownership with some immediate impact of the 1998 introduction of the basic Canada Education Savings Grant Rates but would not reflect the introduction of the Canada Learning Bond and enhanced CESG. ${ }^{269}$

Second, RESP ownership is higher for families with children, but not evenly so by net worth. In both 1999 and 2005, families in the bottom quintile of households had a rate of RESP ownership roughly one fifth that of families in the top quintile. This disparity is, however, smaller than the disparity in RESP ownership by net worth quintile in the overall population.

Finally, between 1999 and 2005 there was a substantial increase in RESP ownership for all but the poorest $20 \%$ of economic families. The increase in RESP ownership for the sub-population of economic families with children was shared by all net worth quintiles but not evenly so. Rates of RESP ownership roughly doubled for the bottom $40 \%$ and

${ }^{269}$ Although the CLB and enhanced CESG were announced in 2004, the first payments were not issued until 2006. 
top $20 \%$ of families with children between 1999 and 2005 but it roughly tripled for the middle $40 \%$ of families with children (those in the $41^{\text {st }}$ to $79^{\text {th }}$ percentiles by net worth). This faster rate of increase in the middle is no doubt related to the expansion of the role of banks in the delivery of RESPs. Despite gains across quintiles, RESP ownership remained polarized in 2005. The frequency of RESP ownership reached more than half of the wealthiest families with children by 2005 but less than a tenth of the poorest $20 \%$ of families with children.

The unconditional median gives an estimate of the distribution of RESP assets across the whole population — in all cases it is $\$ 0$. The median conditional on having a dependent child, gives an estimate of the distribution of RESP assets among Canadian families with children - this is the better estimate of distribution within the target population for the policy instrument. It too is $\$ 0$ in all cases with one exception—-the wealthiest families with children under 18 had median RESP assets of $\$ 400$ in 2005 only. Finally, the median condition on having an RESP gives an estimate of the distribution of savings among RESP users. In Figures 8.3 and 8.4 below, I report the median RESP asset by net worth quintile for each 1999 and 2005, conditional on those families with children under age 18 who have an RESP.

Figure 8.3: Conditional median RESP assets, 1999 


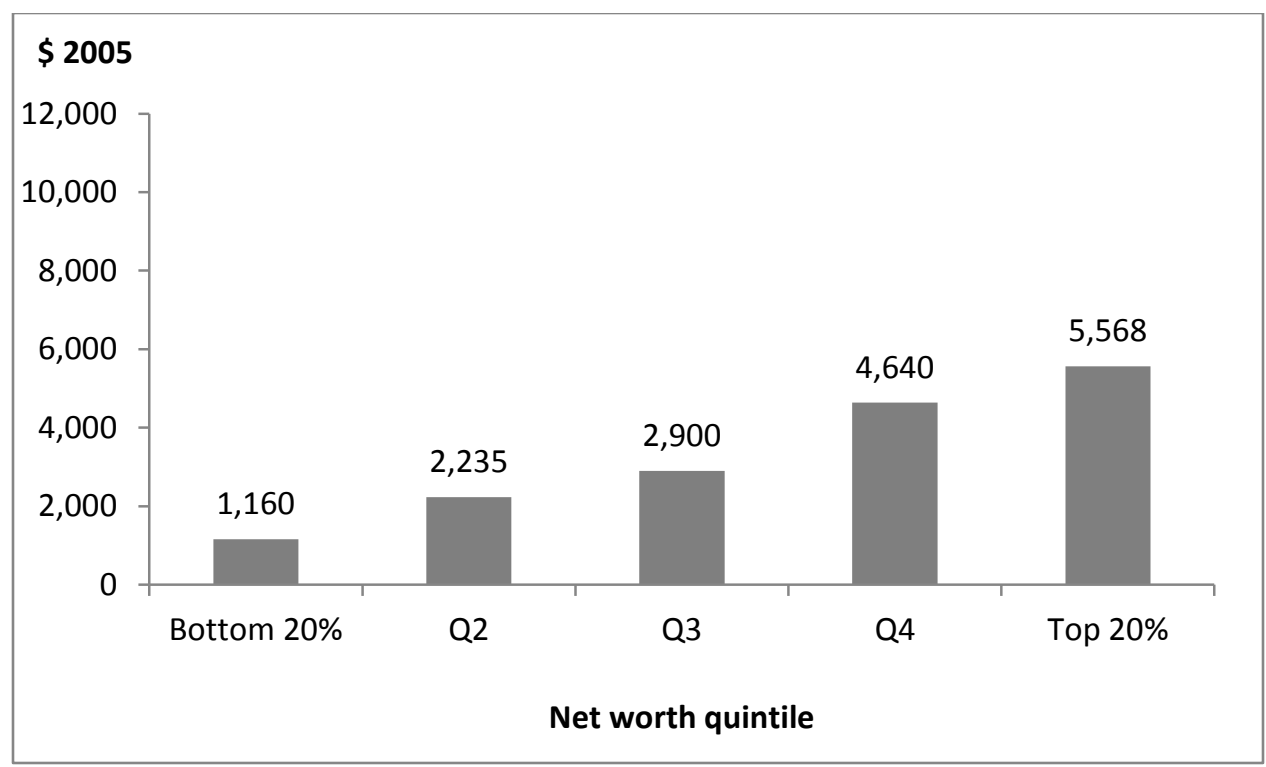

Figure 8.4: Conditional median RESP assets, 2005

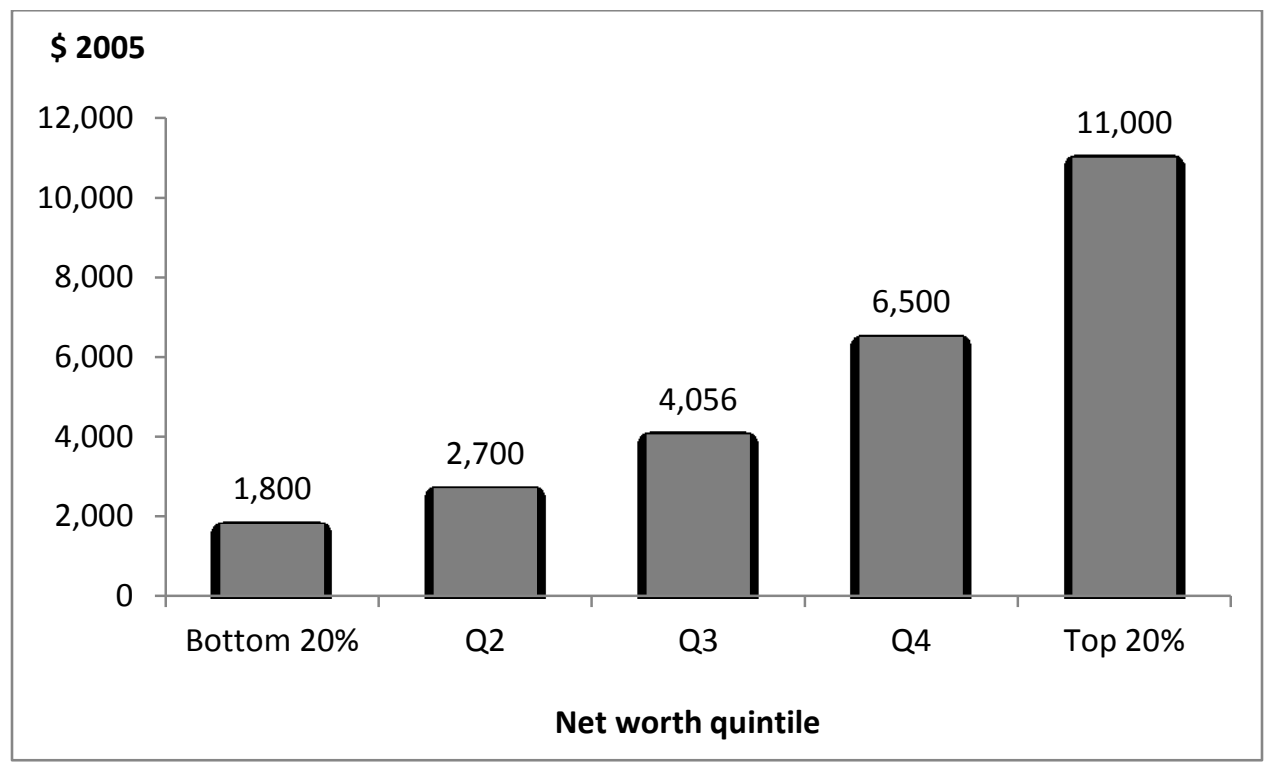

Previous studies of RESP use in Canada have looked at the distribution of savings by household income but not net worth. Lefebvre (2004) reported that in 2002, among 
RESP owners, median RESP annual contributions were $\$ 700$ in households with incomes below $\$ 15,000$ and $\$ 1,200$ for households with incomes above $\$ 40,000$. This does not tell us anything though about the value of the accumulated tax-sheltered assets in the RESP. The government's own annual statistical review on RESPs (HRSDC, 2013b) states that the total value of accumulated RESP assets was \$35.6 billion in 2012 up from \$31.6 the year before but has no information on how those accumulated assets are distributed amongst households.

The distribution of median RESP assets by net worth quintile is flat at $\$ 0$ for all economic families and even among all economic families with children, for both 1999 and 2005-with one notable exception. At the top quintile in 2005, the median value of RESPs conditional on having children is $\$ 400$ - the only quintile of target families for the RESP to have a non-zero median value. RESP assets are the exception for most economic families and even most economic families with children (see Table 8.6 above) but a slim majority of the wealthiest economic families with children have an RESP.

Looking at the median values of those families with RESPs, the values of RESP assets increase substantially for all quintiles over the other estimates of medians in both 1999 and 2005. For the bottom quintile, the target sample shrinks from $20 \%$ of the full population, to the $9 \%$ within that quintile who have an RESP in 2005 . However, their RESP assets were $\$ 1,160$ in 1999 and $\$ 1,800$. This suggests that, among economic families who have chosen to open an RESP, accumulated savings may be substantially larger, even among lowest and modest net worth families, than population-wide estimates 
would reveal. Like RRSPs, this suggests that discourse on policy change that overlooks the education savings of the poorest economic families with children may be ignoring an important group of small savers.

As discussed above and at length in Chapter 6, the period 1999 to 2005 covers the period in which the Canada Education Savings Grant (CESG) and changes to expand the number of RESP providers were introduced. For RESP users in all quintiles, Figures 8.3 and 8.4 above show a substantial increase in median RESP assets. The magnitude of the increase is, however, extremely unequal. The median value of RESP assets for the wealthiest RESP users nearly doubled while increases for other quintiles were more modest, at between $20 \%$ and $55 \%$ from 1999 to 2005 . Did the same policy changes induce RESP users to save more knowing that their deposits would be matched by the federal government? Because this is cross-sectional data, the RESP-users in 1999 are not necessarily the RESP-users in 2005 so it is not possible to say with certainty. As a general conclusion though, although the smaller savings of poorer RESP owners should not be under estimated, it seems likely that the principal effects, by 2005, of the 1998 introduction of the CESG were on the wealthiest families. After the CESG, both the RESP participation of families with children and the median assets of families with RESPs in the top net worth quintile nearly doubled. As future data becomes available, it may be possible to evaluate whether this inequality has persisted after the Canada Learning Bond and Accelerated CESG were introduced.

\subsubsection{RHOSPs}


Table 8.7 below shows the frequency and average values of RHOSPs in 1999. I give the unconditional median and the median conditional on having a non-zero RHOSP balance. The policy was originally designed for Canadians who were not already homeowners. The RHOSP was cancelled in 1985 but allowed existing RHOSPs to remain in place until they expired (at the end of 20 years from the date of opening the account.

Table 8.7: Frequency, unconditional and conditional average values of RHOSPs, 1999

\begin{tabular}{r|cc}
\hline & \multicolumn{2}{|c}{ All net worth quintiles } \\
\hline Mean value of RHOSP assets & All economic families & $\begin{array}{c}\text { Only RHOSP } \\
\text { owners } \\
\end{array}$ \\
Median value of RHOSP assets & 66 & 23,537 \\
& 0 & 11,600 \\
\hline Quintile & Frequency of RHOSP assets (\% of all economic \\
& families \\
\hline Bottom 20\% & .1 \\
2 & .2 \\
4 & .4 \\
Top 20\% & .4 \\
.3
\end{tabular}

As illustrated earlier in this chapter, only a tiny fraction of Canadians still had RHOSP assets in 1999. In fact the number of account holders is so small (less than $0.5 \%$ of all economic families), that it was not possible to derive estimates of the unconditional or conditional median value of RHOSP assets by net worth quintile. As an alternative to detailed distributional data, I report the unconditional mean and the mean conditional on having an RHOSP in 1999. The substantial increase from the median to the mean values suggests that the distribution of RHOSP balances is very skewed. In summary, the tiny fraction of Canadians who still had an RHOSP in 1999 had substantial mean and median assets in those tax-benefitted accounts. 


\subsubsection{Home equity}

Tables 8.8 and 8.9 below show the incidence of homeownership in each 1999 and 2005 by net worth quintile. Owning a primary residence is the first condition to be able to take advantage of the exclusion of both imputed rental income (the estimate of the return to the owner from living in a home they own versus renting a comparable dwelling) and capital gains when the asset is sold.

Table 8.8: Incidence of homeownership by net worth, 1999

\begin{tabular}{r|rrr}
\hline Quintile & $\begin{array}{r}\text { Own without a } \\
\text { mortgage }\end{array}$ & $\begin{array}{r}\text { Own with a } \\
\text { mortgage }\end{array}$ & Do not own \\
\hline Bottom $20 \%$ & $\mathbf{0 . 3}$ & $\mathbf{2 . 8}$ & 96.9 \\
2 & $\mathbf{6 . 6}$ & $\mathbf{3 2 . 2}$ & 61.2 \\
3 & $\mathbf{2 1 . 7}$ & $\mathbf{5 5 . 2}$ & 23.1 \\
4 & $\mathbf{4 4 . 5}$ & $\mathbf{4 4 . 3}$ & 11.3 \\
Top 20\% & $\mathbf{6 5 . 4}$ & $\mathbf{2 9 . 1}$ & 5.5 \\
\hline
\end{tabular}

Table 8.9: Incidence of homeownership by net worth, 2005

\begin{tabular}{r|rrr}
\hline Quintile & $\begin{array}{r}\text { Own without a } \\
\text { mortgage }\end{array}$ & $\begin{array}{r}\text { Own with a } \\
\text { mortgage }\end{array}$ & Do not own \\
\hline Bottom $20 \%$ & $\mathbf{0 . 5}$ & $\mathbf{3 . 5}$ & 96.0 \\
2 & $\mathbf{7 . 1}$ & $\mathbf{2 9 . 5}$ & 63.4 \\
3 & $\mathbf{2 4 . 6}$ & $\mathbf{5 7 . 0}$ & 18.5 \\
4 & $\mathbf{3 9 . 2}$ & $\mathbf{5 1 . 5}$ & 9.4 \\
Top 20\% & $\mathbf{6 7 . 7}$ & $\mathbf{2 9 . 2}$ & 3.1 \\
\hline
\end{tabular}

Overall rates of homeownership in Canada (not shown in the tables) were 63.3\% in 1999 and were $60.3 \%$ in 2005 . The majority of homeowners had a mortgage against the property (51.7\% in 1999 and $66 \%$ in 2005$)$. 
Not surprisingly, rates of homeownership, and particularly homeownership free of mortgage debt, rise steeply with net worth. For the lowest quintile, overall rates of homeownership were largely unchanged, between 1999 and 2005. For the next quintile, there was a slight increase in the rates of ownership without a mortgage but a slight decline in overall ownership over the same time period. The third and fourth quintiles saw an increase in homeownership rates but mostly through mortgage-financed ownership, a finding that makes good sense in the context of rising housing prices over the period in most real estate markets across Canada. Finally, the wealthiest quintile saw a small increase in homeownership without a mortgage.

The distinction between ownership with and without a mortgage can be important. Owner-occupied housing is the most valuable asset for most households but mortgage debt is also generally the largest source of household debt. Households who own without a mortgage are more likely to have substantially higher net worth, regardless of their other assets and debt.

In Figures 8.5 and 8.6 below, I present the unconditional median value of housing equity for all economic families and then the median conditional on owning the family's principal residence. These figures include owners both with and without mortgage debts, as reported (in bold) in Tables 8.8 and 8.9 above.

\section{Figure 8.5: Unconditional and conditional median housing equity, 1999}




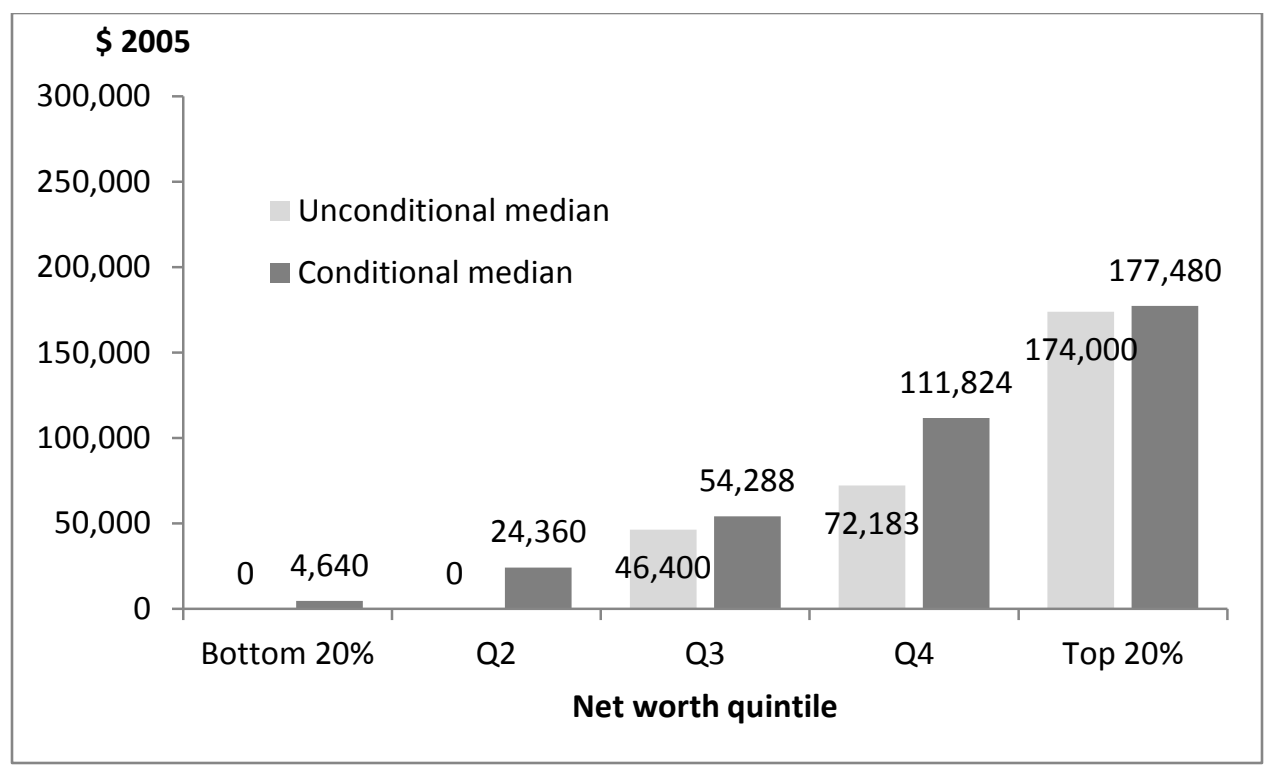

Figure 8.6: Unconditional and conditional median housing equity, 2005

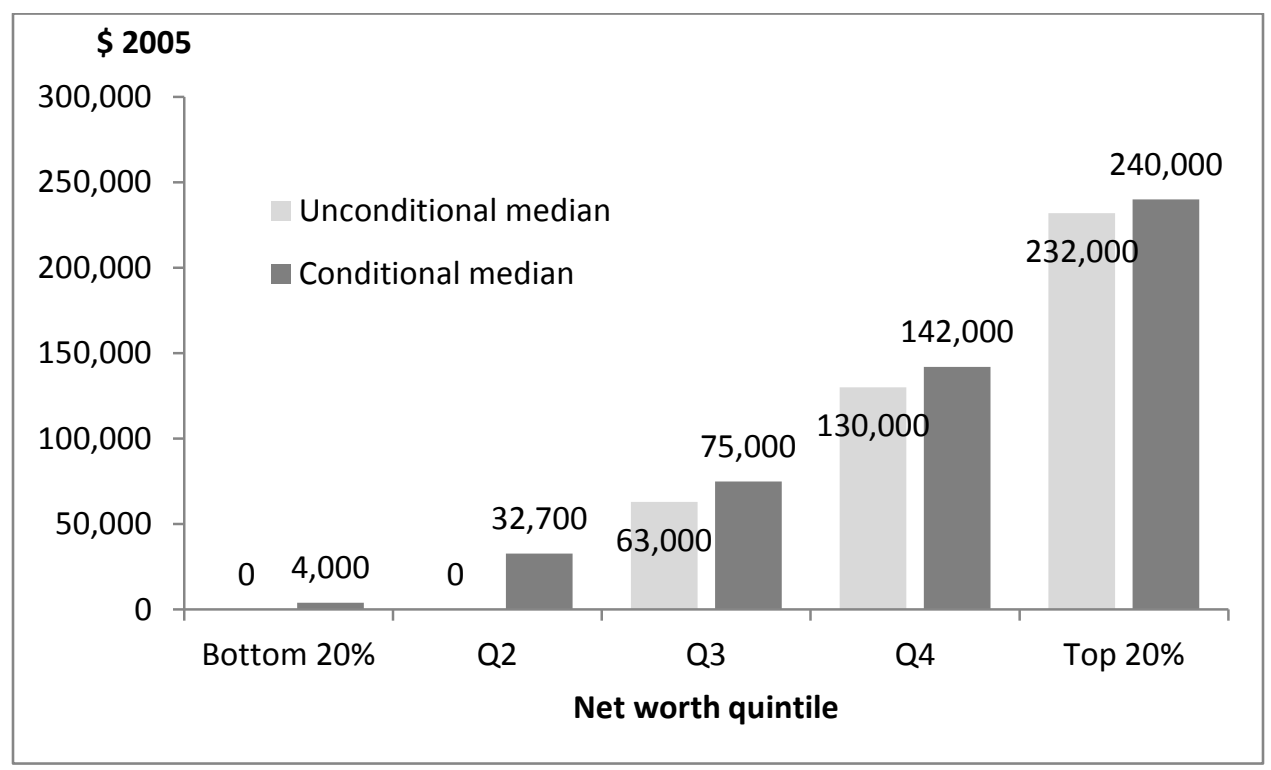

Previous studies of changes to the distribution of housing assets and total household net worth over time have generally included all households, including renters with $\$ 0$ in housing equity (Kerstetter, 2002; Morissette \& Zhang, 2007). The difficulty with these studies is that conclusions about the distribution of gains from housing values are 
confounded by large differences in housing tenure across net worth groups. If low net worth households do not realize gains in housing assets, the authors reasonably suggest, it is because they do not own homes. Kerstetter (2002) and Engeland, Lewis and Shillington (2006) also compared gains in housing assets and total net worth between owners and renters within the same age group, with the same household income and with the same household composition. In those studies the goal was to see how homeownership affects net worth compared to renting, other relevant factors being ostensibly equal. Instead my goal is to compare how tax-sheltered gains in the housing market are shared amongst all Canadians who have an ownership stake in the market but have different levels of total assets and debts.

Within the lowest two quintiles, the vast majority of economic families rent and do not own their own home, thus making the unconditional median value of housing equity to $\$ 0$. The medians in these same quintiles, conditional on homeownership, are substantially larger. However, in both 1999 and 2005, among only homeowners, the distribution of home equity is highly unequal across net worth quintiles. This seems to be result of two separate factors.

First, (reported in Table 8.8 and 8.9) over half of the highest net worth economic families own their homes outright with no mortgage to reduce their equity in the market value of the home. By contrast, less than $1 \%$ of households in the bottom quintile own their homes without a mortgage — which means that whatever the market value of their home, the fungible tax-sheltered asset is reduced by mortgage debt. 
A second important factor is that wealthier homeowners own more expensive houses. In 1999, the median market value of a home (not shown) owned by a household in top quintile was $\$ 208,800 .^{270}$ In 2005 , this figure was $\$ 275,000$. Among homeowners in the bottom quintile, the median market value of their home was substantially smaller: $\$ 75,400$ in 1999 and $\$ 100,000$ in 2005 . Furthermore, the median market value of owneroccupied housing was, in 2005, equal across the bottom two quintiles, suggesting a stepwise progression in the value of homes owned by the bottom $40 \%$ versus remaining $60 \%$ of economic families by net worth. This suggests that even if low and modest net worth households are able to get a toehold in the housing market in Canada, they may not see the same kinds of gains as middle and higher net worth homeowners.

Indeed increases in housing equity between 1999 and 2005 were not equally shared by households in different net worth quintiles. The period between 1999 and 2005 was one of large increases in real property values in Canada (Bank of Canada, 2012; CMHC, 2012). However, while the conditional median values of net equity increased for four of the net worth quintiles, it did not for homeowners in the bottom net worth quintile.

Increases in property values will increase the positive asset for owners, but it will also drive up the size of mortgages for most new buyers. Because the data are cross-sectional and not longitudinal it is impossible to know what level of mobility took place for

${ }^{270}$ Data on market values, mortgage debts and home equity loan debts is available from the author on request. 
households in moving from one quintile to another between 1999 and 2005, perhaps in part due to gains in their home equity. But comparing the cross-sectional data, from 1999 to 2005 , the homeowners in the top quintile saw an increase of $35.2 \%$ to their median net home equity while the owners in the bottom quintile experienced a decrease of $-13.6 \%$. The strongest gains in median net housing equity were actually in the middle quintile at $38.2 \%$ but this is only slightly above the gains for the top quintile.

None of the households who owned their homes in either 1999 or 2005 paid tax on the imputed rental income or on any capital gains to their equity in the property. The generous tax treatment of housing wealth, combined with sharp growth in housing prices and relaxed lending practices would all play a role in shaping the net contribution of housing to household net worth in the 1999 to 2005 period. Previous Canadian studies (Kerstetter, 2002; Morissette \& Zhang, 2007; CMHC, 2010) have all concluded that housing plays a key role in observed differences and changes in household net worth. The above data further suggest there are good reasons to expect that housing is playing a different role for households in different relative positions along the net worth distribution. As future data become available, it may be possible to develop models for these differential effects, taking into account the components of housing values, mortgage amounts and home equity loans.

\subsubsection{Portfolio shares in tax-preferred account-based savings instruments}

In Figures 8.7 through 8.10, below, I report the median total portfolio share of household assets that are held in all tax-preferred account-based savings instruments for 1999 and 
2005. Again, these are the median percentages of total household assets, from all sources, that are held in the total of RRSPs, RESPs, RHOSPs and home equity. I report the percentage shares of assets that are held in tax-preferred assets, first including and then excluding pension assets in the total of household assets.

Figure 8.7: Median portfolio (with pension assets) shares in tax-preferred assets by net worth, 1999

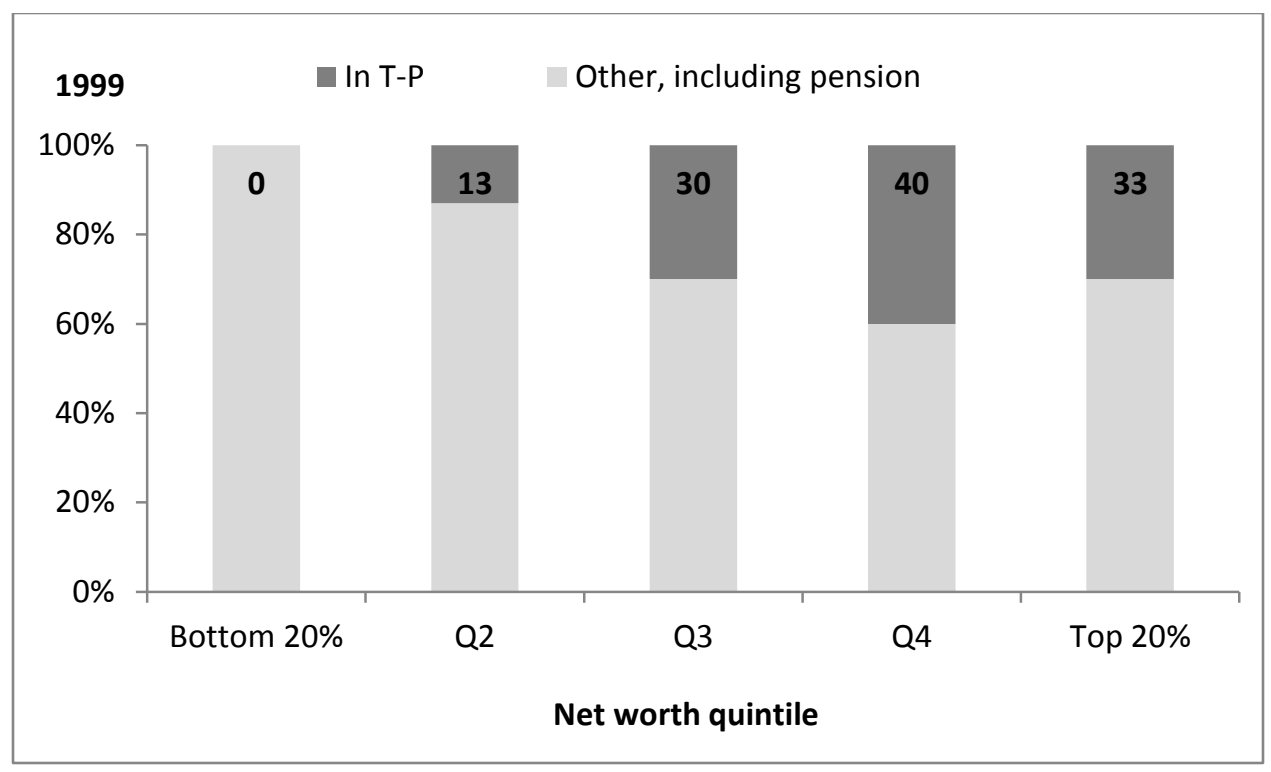

Figure 8.8: Median portfolio (with pension assets) shares in tax-preferred assets by net worth, 2005 


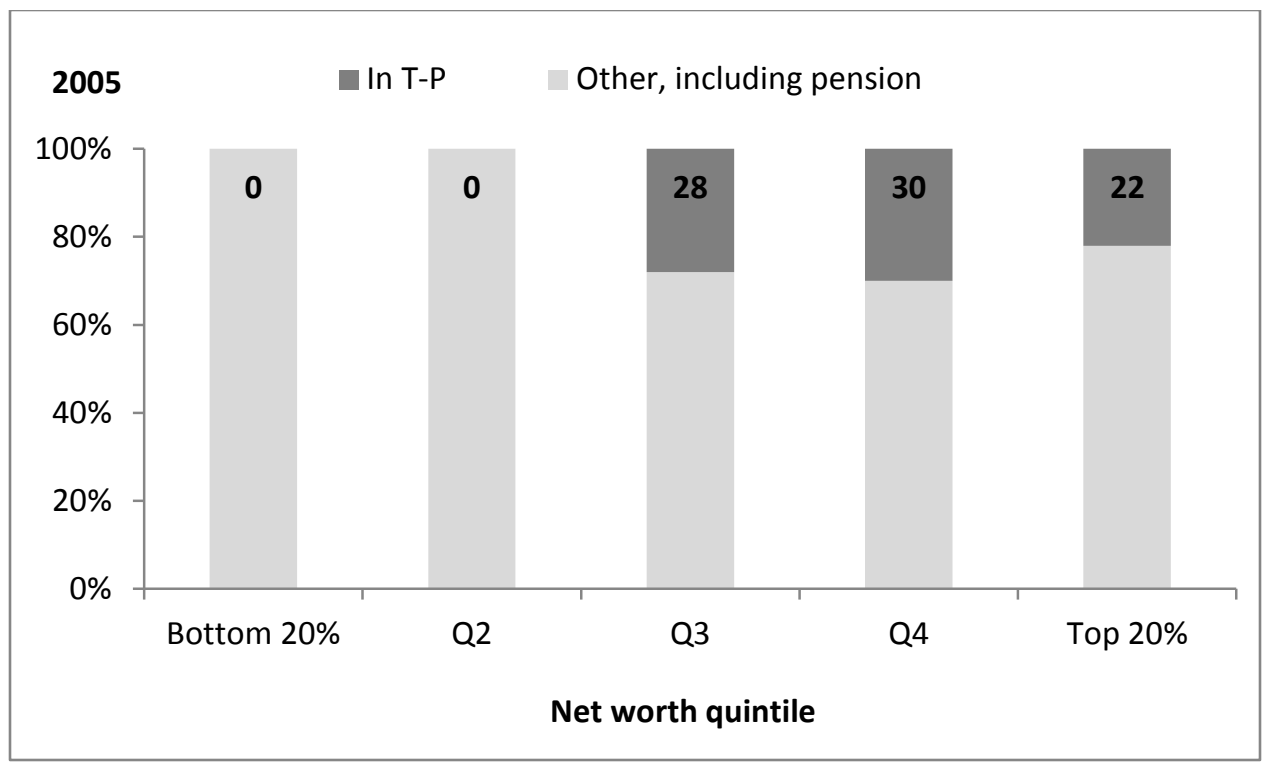

Figure 8.9: Median portfolio shares in tax-preferred assets by net worth, 1999

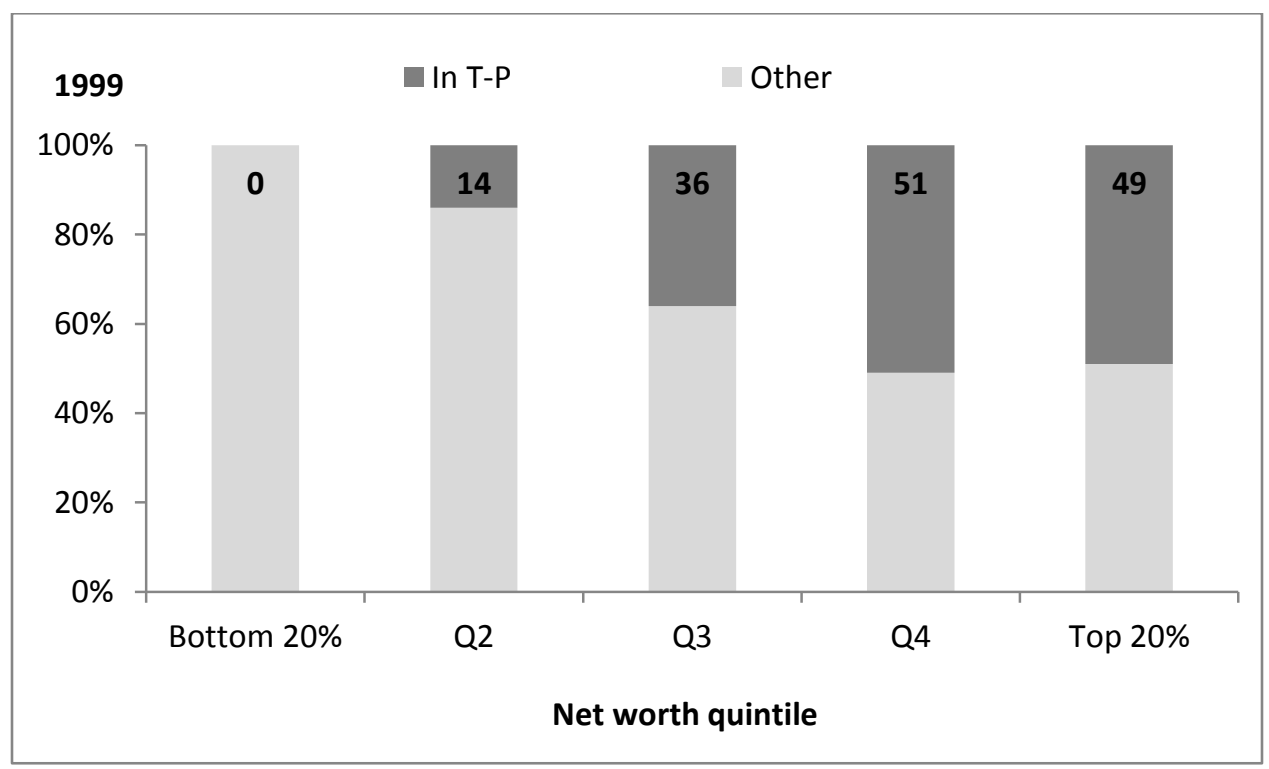

Figure 8.10: Median portfolio shares in tax-preferred assets by net worth, 2005 


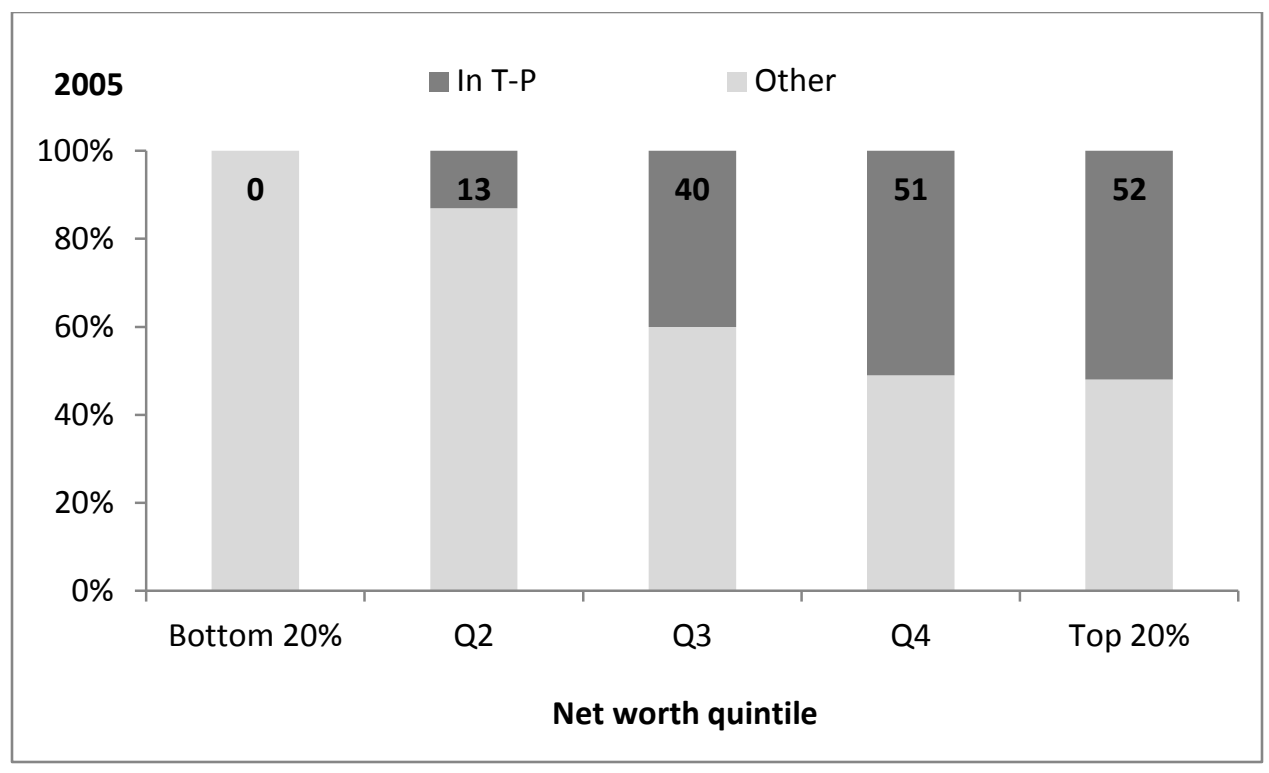

The four figures above suggest that households in the top two quintiles have much larger shares of their household assets in the four tax-preferred savings instruments covered by the dataset—RRSPs, RESPs, RHOSPs and home equity. This is true in all cases, for 1999 and 2005 and when pensions are included or excluded from the valuation of total household assets. As a measure of dependence, this suggests that higher wealth households are more reliant on the account-based, fungible, tax-sheltered instruments.

The lower portfolio shares—-for all but the bottom net worth quintile—of tax-preferred assets when pensions (valued on a termination basis) are included is noteworthy. What it suggests is that pension assets are large enough to have a substantial influence over the portfolio shares of any other class of asset. It is also consistent with the data reported in Tables 8.6 and 8.7 earlier in this chapter. Households in the bottom net worth quintile are less likely to have a workplace pension, households in the fourth quintile are most likely to have only a workplace pension in their retirement savings and households in the top 
quintile are most likely to have both a workplace pension and RRSPs in their retirement savings.

I emphasize the results in Figures 8.9 and 8.10, showing the portfolio shares without pension assets, for two reasons. The first is that the distribution of pensions - with and without other retirement assets - is so uneven across net worth quintiles that it is likely to be exerting effects on the allocation decisions of households in a complex way. The second, as emphasized throughout this thesis, is that households have limited capability to control whether they have a workplace pension or to control the value of that pension asset. The set of assets over which households have more direct choice and over which they can demonstrate capability is the set that excludes pension assets.

When pension assets are excluded, the portfolio shares of household assets in the taxpreferred instruments rise steeply with net worth. This finding is broadly consistent with studies of portfolio allocations in the U.S. that find that household allocations are closer to optimal as household wealth, income and marginal tax rates increase and as their exposure to labour market risk declines (Bergstresser \& Poterba, 2003; Poterba \& Samwick, 2003; Amoromin, 2003; Zhou, 2009). It is also generally consistent with the portfolio shares reported by Milligan (2004) and with a study of Canadian portfolio allocations by Alan, Atalay \& Crossley (2006). While each of those studies used a different definition of tax-preferred assets than the current study, they each find that the relative importance of tax-preferred assets increases with household wealth (Milligan, 2004) and with marginal tax rate (Alan, Atalay \& Crossley, 2006). 
The changes in portfolio reliance over time is also notable. Between 1999 and 2005, the portfolio shares in tax-preferred assets also increased for the middle and top quintile. In 1999, the fourth quintile had just over half (51\%) of their portfolios in the tax-preferred assets - a proportion that stayed the same in 2005 . However, by 2005 , the wealthiest $20 \%$ of households held the largest shares $(52 \%)$ of household assets in tax-preferred account-based instruments. The middle quintile saw their portfolio shares increase but there was no change for the bottom quintile and a decrease for the second quintile in portfolio shares between 1999 and 2005 . In short, the richest $40 \%$ of households are most reliant on the instruments that are heavily subsidized through public policy.

The portfolio shares are not substantially different when the sample is limited to only households with a primary income earner aged 65 or younger. Nor are the shares substantially different for the top quintile when the sample excludes the top $1 \%$ or even $5 \%$ of households. This suggests that the dependence on tax-preferred instruments is concentrated among the wealthy, but not über-wealthy in Canada.

Significance testing ${ }^{271}$ confirmed the obvious conclusion that the median share of taxpreferred assets in all household assets is very different across the net worth quintiles.

${ }^{271}$ Kruskal Wallis test, $\mathrm{H}=.000$ at both $\mathrm{p}<0.05$ and $\mathrm{p}<0.01$ for within table and within year comparisons of medians. 
Post-hoc tests ${ }^{272}$ also confirmed that the differences in median share of tax-preferred in total household assets in in Q4 (51\%) is significant and not due to error Q5 (52\%). The differences remain significant when total assets include pension assets, when the sample is restricted by excluding the top $1 \%$ and $5 \%$ of households, and finally when the sample is restricted to only working-age adults.

In Table 8.10 below, I report the portfolio shares of each of the four tax-preferred account-based savings instruments separately. This table illustrates the large effect of housing equity in the portfolio share analysis. The table presents data for assets excluding pensions, for the reasons described above.

Table 8.10: Median portfolio shares in tax-preferred assets by net worth, 1999 and 2005

\begin{tabular}{r|cccc|cccc}
\hline \multicolumn{1}{l|}{ Quintile } & \multicolumn{4}{|c|}{1999} & \multicolumn{4}{c}{2005} \\
\hline & RRSP & RESP & RHOSP & $\begin{array}{c}\text { Home } \\
\text { equity }\end{array}$ & RRSP & RESP & RHOSP & Home \\
equity
\end{tabular}

For the bottom two quintiles, none of the individual tax-preferred instrument had, at the median, any positive share of total household assets. The portfolio shares of RRSPs for the top three quintiles remained stable between 1999 and 2005. The portfolio share from housing was higher for the fourth quintile in both 1999 and 2005 suggesting that this

${ }^{272}$ Mann-Whitney test, $\mathrm{U}=.000$ at both $\mathrm{p}<0.05$ and $\mathrm{p}<0.01$ for within table and within year comparisons of medians of Q1 to Q2 and Q4 to Q5. Bonferroni correction is used to reduce Type I error. 
group is perhaps most dependent on housing wealth. Consistent with the portfolio analysis by Meh, Terajima and Chen (2009), the wealthiest $20 \%$ of households show the greatest diversification in the household portfolios, although in this table the diversification is only between RRSP assets and housing equity. For all of the top three quintiles, housing equity grew as a share of total household assets between 1999 and 2005. This is likely due to the increase in the market value of homes discussed in the previous section of this chapter.

\subsection{Conclusions}

Three findings are worth highlighting from the data discussed above. First, households with low net worth are less likely to use tax-preferred savings instruments but it is not true that they do not use them at all. On measures of incidence and aggregate estimates of average account values, low net worth households are less likely to own any taxpreferred savings instruments and their average assets in any one or the total of these instruments is quite low—often $\$ 0$. However, for each instrument, the incidence of using the tax-preferred assets is greater than zero for the poorest quintile. These small numbers of households - sometimes $10 \%$ of the bottom quintile — have assets in these taxpreferred instruments that should not be discounted (Kerstetter, 2002; Morissette \& Zhang, 2007). For authors focused on describing wealth inequality, it may be simpler to use unconditional averages and show a stark contrast between $\$ 0$ assets at the bottom and quite large assets at the top. However, this kind of analysis could be misleading for policy analysis purposes because it ignores the sub-populations of users of the savings instruments. When policy on any of the tax-preferred savings instruments is changed, its 
impact will be different across households but it is not true that it will have no effect on the poorest households. Researchers and policy-makers alike should aim for a more nuanced understanding of the perceptions and behaviors of the users (versus non-users) of tax-preferred savings instruments at different levels of household wealth.

A second conclusion is about the importance of housing assets. The role of housing assets in household portfolios has already been widely acknowledged in the literature. For example, Meh and his colleagues (2009) noted "over the 1999-2005 period, the most important change in household assets was a dramatic increase in the portfolio weight assigned to real estate, likely driven by the strong house prices" (Meh, et al., p.10). The authors further concluded that "household finances have become more sensitive to the state of the housing market" (p.15). This is certainly true for those households for whom housing equity represents roughly a third of their total assets (excluding pensions). The growth of housing market values has, as discussed earlier, had a very uneven effect for households at different levels of total wealth. Households with lower total wealth who managed to purchase a home did not enjoy the same increase in their housing equity as wealthier households. The increase in property values for them seems to mean an increase in mortgage debt.

For wealthier households, tax-sheltered housing equity has increased substantially between 1999 and 2005. For these households, financial products now allow them to withdraw and spend that equity in ways that were not previously possible. At the same time the generous tax treatment of housing assets has meant they have gained far more 
from homeownership than perhaps from any other tax-preferred instrument. One possible policy response, for those concerned with redistribution of wealth in Canada, might be to consider ways to promote homeownership for greater numbers of lower and modest wealth households — similar to the efforts of federal policy in the 1970s (discussed in Chapter 5). But if this means exposure to larger mortgage debts, it is not clear this is a preferred strategy.

The final conclusion from this chapter addresses my research question on the regressive or progressive nature of Canada's current system of tax-preferred account-based savings instruments. The earlier studies by Kerstetter (2002) and by Morisette and Zhang (2007) suggested that many forms of household assets in Canada are concentrated among higher wealth households - they own more of the individual assets and the assets they own are more valuable. However, previous authors did not look specifically at the concentration of the tax-preferred instruments that are of interest in this thesis.

Data from Chapters 4 through 7 from annual reports of tax returns and policy monitoring and evaluation reports might be another source of evidence. However, these sources show a more mixed and confusing picture that does not allow for clear conclusions on whether, as a system for enhancing household welfare, tax-preferred instruments are regressive or progressive. Annual reports on RRSP claims show, for example, that for every dollar of RRSP deductions claimed in 2009, 21 cents of that dollar were claimed the very richest by taxpayers (Table 5.2, Chapter 5). But, like the other administrative data on RESPs and TFSAs cited in this thesis, these sources only illustrate the 
concentration by household income - they are not helpful for understanding the impacts of a system on household wealth. ${ }^{273}$

As a system for encouraging household savings and asset accumulation, Canada's set of tax-preferred instruments cannot necessarily be deemed regressive just because higher income Canadians are more likely to own the tax-preferred assets and to own more valuable quantities of the same tax-preferred assets. As long as Canada's system of income taxation is progressive, it can be argued that income taxation will have addressed inequalities either before income is saved, or when money is withdrawn as taxable income. This approach treats the assets as stored income, rather than as capital that may have welfare effects independent of effects on smoothing consumption.

An assessment of tax-preferred account-based instruments as a system for encouraging household savings and asset-accumulation should instead consider how reliant households are on these instruments for the assets they have-whatever those might be. This approach is philosophically consistent with the literature on portfolio analysis although the approach used in the current study has been more similar to Milligan's (2004) work looking at differences in portfolio shares.

From this perspective, I see a collection of instruments that share common features and common policy paths that should be addressed as a system, and a system that aims to

${ }^{273}$ Overall, the correlation between an economic family's net worth and their income is .557 using the 2005 SFS data, which is significant at the 0.01 level using a 2-tailed test. 
promote the asset accumulation of Canadian households. Given the generous contribution limits and breadth of individual instruments included in this system, it would be reasonable to expect that smaller and modest savers actually have a larger share of their portfolios sheltered in tax-preferred instruments. But this is not the case. Households in the bottom $40 \%$ of net worth see, at the median, no real benefit from these instruments to their household portfolio. Some low wealth households have these assets, but in numbers and amounts too small to balance the generous benefits for the higher wealth and wealthiest households.

The richest $20 \%$ of Canadians, the same households with the most diverse portfolios, the least exposure to market risk on any single class of asset, and the most valuable portfolios to allocate, those households are able, under the current system, to shelter half of their assets in tax-preferred instruments. These households receive generous deductions for contributions to RRSPs, their investment income grows tax-free and they benefit from generous tax reductions or full exemptions when they do withdraw money from these assets. As described in Chapter 3, the amount of foregone federal income tax revenue related to these benefits is substantial— - likely far more than Canada currently spends directly on traditionally recognized systems of welfare, such as residual income support.

If a similar study found that Canada's system of income supports had somehow become the source for half of the household incomes of the richest $20 \%$ of Canadian households, there would be no question that it was regressive and need of fundamental reform. However, we have a system of asset-based welfare that is, as Kerstetter (2002) alleged, 
subsidizing the wealth - indeed half of the assets - of the richest $20 \%$. There should be no question that it is regressive and in need of fundamental reform. 


\section{Chapter 9: Qualitative study on perceptions of, motivations for and policy impacts on saving}

\subsection{Aims and overview}

To complement the findings from the retrospective policy analysis in Chapters 4 through 7 and the analysis of the survey data on household wealth and portfolio compositions in the previous chapter, this chapter presents the results of an exploratory qualitative study.

I have already argued that the set of tax-preferred savings instruments should be examined as a system for delivering welfare within Canada's liberal welfare regime. I have further argued that, based on the design of the instruments in this system, it is largely regressive. There is good reason to believe that, because these instruments: a) give proportionally greater benefit to larger savings by those with higher marginal tax rates, b) require attachment to mainstream financial services, c) recognize some goals or motives for saving but not others, and d) create fungible pools of capital, they will be less accessible to poorer Canadians.

For the four factors listed above to be important in understanding the regressive nature of tax-preferred savings instruments, I would expect that, compared to wealthier citizens, poorer citizens might:

a) Show differences in their financial behavior and allocations that reflect weaker incentives.

b) Show differences in their comfort and familiarity with mainstream financial services and with the design of the account products involved. 
c) Show goals and motivations that do not necessarily conform to those sanctioned in the system of public policy instruments.

d) Express concern regarding asset limits in means-tested welfare programs that might penalize them for having fungible capital.

The data in Chapter 8 show the household outcomes from the system, at two points in time. Consistent with an expectation that households receiving greater incentive will allocate a larger share of their assets to the tax-preferred instruments, I find that the proportion of assets in these instruments rises with net worth quintile. The wealthiest $40 \%$ of Canadian households have more than half of their assets in tax-preferred instruments while the poorest $20 \%$ have none. In sum, wealthier Canadians benefit more from this system while poorer Canadians, on average, do not benefit at all. But, in addition to the financial effects from tax incentives and differences in household tax rates, the list above suggests that non-financial barriers are also important in shaping outcomes.

This chapter explores a further source of evidence regarding the regressive nature of Canada's current system of tax-preferred and account-based instruments by presenting the results of seven focus groups conducted in Ottawa in 2012. I find that the participants with limited or modest resources do, compared to the participants with moderate or better levels of resources, show differences in their comfort and familiarity with the financial services and products involved in tax-preferred savings instruments, differences in their 
preferences and goals for saving and accumulating assets and many do express concern about the effects of asset-limits on means tests.

The participants in the focus groups with more limited means were keenly aware of the existence of a system of tax-preferred accounts-however, they did not view it as a system available to them. By contrast, participants with greater means were more familiar with the system of tax-preferred instruments - many on the basis of personal experience. However, many of these participants expressed concerns about the complexity and fairness of the system of tax-preferred instruments.

I conclude that, in addition to the financial incentives from generous tax treatment, the three other factors listed above each seem to have some salience. The retrospective analysis suggested that these factors - attachment to mainstream financial services, normalizing some goals but not others and fungibility of the assets-likely matter. While further research is required, I believe these focus groups have provided some preliminary evidence that these factors are important and worthy of further consideration.

\subsection{Approach, methodology and limitations}

Qualitative research is useful for examining variables that cannot or should not be measured using quantitative methods, for conducting initial explorations of concepts and theoretical constructs that might later be examined using quantitative means, or for adding nuance and context to the interpretation of related quantitative findings (Sofaer, 1999; Denzin \& Lincoln, 2005, Yin, 2011). In the current study, focus groups are used 
for all three reasons. There are, in Canada, no current and adequate surveys of public opinion research on factual understanding, perceptions and preferences regarding taxpreferred public policy instruments to encourage saving.

Broadly, the focus groups aimed to explore:

1) The attitudes of poor and non-poor adults on saving, including preferences for active or passive approaches and preferences on different savings goals (such as motivations and expected uses of savings).

2) The awareness of poor and non-poor adults of three different policy instruments related to household savings: non-taxation, tax-deduction, savings grants.

3) The perceived impact of different policy instruments on personal/household financial decision-making.

A total of 42 adults took part in the seven focus groups between February 8 and February 27, 2012. ${ }^{274}$ All sessions were held at the Centretown Community Health Centre in Ottawa.

All focus groups followed a consistent series of exercises designed to elicit opinions and observations about public policy instruments for promoting savings by Canadian households and individuals. I acted as the facilitator for all of the groups using the same

${ }^{274}$ Ethics clearance was granted by Carleton University's Research Ethics Board for data collection between January and May, 2012. 
guidelines for each group. ${ }^{275}$ My role as facilitator was to explain the purpose of the focus group to participants, pose questions for discussion, ensure that each group member had adequate opportunity to speak, record responses, and, if necessary, prompt participants to add detail or clarify points they had made.

Each focus group lasted a total of 90 minutes, including a brief informed consent procedure at the beginning. Each group consisted of between 4 and 11 participants.

Focus groups were conducted entirely in English and results were recorded through a mix of participant and facilitator writing and digital audio recordings. Copies of the written papers were retained and used in the analysis and were cross-referenced against the audio-recording of sessions. Analysis of the data was conducted using grounded theory methodology, a standard technique in qualitative research (Charmaz, 2005; Morrow, 2007; Ponterotto \& Grieger, 2007, Yin, 2011). Grounded theory approaches inductively “develop increasingly abstract ideas about research participants' meanings, actions and words", while referencing against data points to "fill out, refine and check emerging conceptual categories" (Charnaz, 2005, p.208). I do not adopt the constructivist revisions to grounded theory but rather emphasize objective descriptions of the statements as they were made by participants, an approach perhaps more associated with the postpositivist tradition of grounded theory. Data analysis proceeded in a repeated series of coding and re-coding efforts, beginning first with the audio recording of participant discussions, and

${ }^{275}$ A copy of the facilitator guide is available at Appendix C. 
then extending to include notes written on flip-chart paper (visible to participants during the group discussions) as well as written responses of participants. The aim of each subsequent re-coding effort was to synthesize the responses of participants without eliminating thematic responses. Grounded theory, as the name implies, supposes that theories to describe or explain phenomena are derived using a bottom-up approach, rather than a positivist top-down perspective of analysis (Yin, 2011). Given that the focus groups provided multiple sources of data for analysis, and given the objective of comparing responses from more marginalized consumers with those of other consumers, this analytical offered the best approach.

There was good evidence for redundancy of responses suggesting that the sampling was adequate for the purposes of the research questions, notwithstanding heterogeneity of many participant characteristics outside of those used for screening.

\subsubsection{Participants}

Participants volunteered to participate in the study and received an honorarium of $\$ 40$ paid at the end of the session. All participants were over the age of 18 and, while exact ages were not recorded, the groups showed a mix of participants from their early 20s through to age 65 . The majority of participants were between 30 and 45 years of age.

Recruitment was conducted using a variety of methods. Staff at the Centretown Community Health Centre informed clients and partnering agencies about the focus groups. These agencies included drop-in centres for low-income adults with health and 
housing needs. In addition, I also posted recruitment notices in public venues in downtown Ottawa such as coffee shops, retail outlets and lobbies of office towers. Interested participants volunteered for the study by contacting me by telephone and completing a basic screening for their age ${ }^{276}$, permanent residence in $\mathrm{Canada}^{277}$ and household income.

Although this thesis has been principally concerned with household wealth, screening on wealth would have been prohibitively difficult. As discussed in Appendix B, surveys of wealth often find that participants have little direct knowledge of the true value of their assets and liabilities. By contrast, participants usually have much better information about their regular flows of income. Income levels in Canada are highly correlated with household wealth in the aggregate. I find an overall correlation between an economic family's net worth and their income is .557 using the 2005 Survey of Financial Security which is significant at the 0.01 level using a 2-tailed test. As illustrated at Table 9.1, below, at the lower end of the distribution, the association between low-income and lowwealth is stronger. ${ }^{278}$ While household income is not my preferred criteria for identifying participants with low and more average resources, it is more feasible and is a reasonable screening variable for poverty versus economic stability.

Table 9.1: Cross-tabulation of household income and net worth in Canada (2005)

${ }^{276}$ To be eligible for the study, volunteers had to be between 18 and 65 years of age.

${ }^{277}$ I did not record the immigration status, ethnic or national origins of participants. The focus groups included participants from diverse ethnic backgrounds some of whom were likely immigrants to Canada.

278 These data are available on request. 


\begin{tabular}{|r|c|c|c|c|c|}
\cline { 2 - 6 } \multicolumn{1}{c|}{} & \multicolumn{5}{c|}{ Net worth quintile } \\
\hline $\begin{array}{r}\text { Income } \\
\text { quintile }\end{array}$ & $\begin{array}{c}\text { Q1 (bottom } \\
20 \%)\end{array}$ & Q2 & Q3 & Q4 & $\begin{array}{c}\text { Q5 (top } \\
20 \%)\end{array}$ \\
\hline $\begin{array}{r}\text { Q1 (bottom } \\
20 \%)\end{array}$ & $53.6 \%$ & $22.2 \%$ & $14.0 \%$ & $6.6 \%$ & $3.7 \%$ \\
\hline Q2 & $28.1 \%$ & $28.3 \%$ & $21.1 \%$ & $15.1 \%$ & $7.5 \%$ \\
\hline Q3 & $12.0 \%$ & $25.4 \%$ & $22.5 \%$ & $20.4 \%$ & $20.0 \%$ \\
\hline Q4 & $5.6 \%$ & $18.0 \%$ & $24.8 \%$ & $28.4 \%$ & $23.0 \%$ \\
\hline $\begin{array}{r}\text { Q5 (top } \\
20 \%)\end{array}$ & $0.8 \%$ & $6.2 \%$ & $17.7 \%$ & $29.4 \%$ & $45.9 \%$ \\
\hline
\end{tabular}

Source: Author's calculations from the 2005 Survey of Financial Security.

In this study, a very simplified screening procedure was used for income. Volunteers were asked whether their economic family income ${ }^{279}$ fell above or below the applicable cut-off. Cut-offs were based on the after-tax Low-Income Cut off (LICO) published by Statistics Canada. ${ }^{280}$ Eligible participants had either a household income at or below $120 \%$ of the LICO or at or above $250 \%$ of the LICO. The dollar figures for these amounts are presented in Table 9.1 below.

${ }^{279}$ All persons related by blood, marriage or adoption who live in the same household. Discussed in Chapter 8.

${ }^{280}$ Statistics Canada. (2011). "Low income lines 2009-2010", Ottawa. Catalogue no. 75F0002MWE. 
Table 9.2: Focus group income cut-off levels

\begin{tabular}{|l|l|l|l|}
\hline Household Size & LICO & $\begin{array}{l}120 \% \text { LICO } \\
\text { (Low-income) }\end{array}$ & $\begin{array}{l}250 \% \text { LICO } \\
\text { (Middle and upper- } \\
\text { middle income) }\end{array}$ \\
\hline 1 & $\$ 18,759.00$ & $\$ 22,510.80$ & $\$ 46,897.50$ \\
\hline 2 & $\$ 22,831.00$ & $\$ 27,397.20$ & $\$ 57,077.50$ \\
\hline 3 & $\$ 28,430.00$ & $\$ 34,116.00$ & $\$ 71,075.00$ \\
\hline 4 & $\$ 35,469.00$ & $\$ 42,562.80$ & $\$ 88,672.50$ \\
\hline 5 & $\$ 40,388.00$ & $\$ 48,465.60$ & $\$ 100,970.00$ \\
\hline 6 & $\$ 44,791.00$ & $\$ 53,749.20$ & $\$ 111,977.50$ \\
\hline $7+$ & $\$ 49,195.00$ & $\$ 59,034.00$ & $\$ 122,987.50$ \\
\hline
\end{tabular}

Based on these limits, I identified participants with low or modest income- those at or below the $120 \%$ of LICO. For participants at or above the $250 \%$ of LICO I cannot identify whether they were of average or higher income or resources, only that they had at least enough household income to be well above the LICO. In my discussion I refer to these participants as having middle or upper incomes.

Among the 42 participants, 15 had middle or upper household incomes and the remainder (27) had low or modest household incomes. The 15 middle or upper income participants took part in three different focus groups. Participants with lower incomes were distributed across four focus groups.

A little less than half of the participants were men (19). In the low-income groups, one group was composed of only men and two were composed of only women. Same-sex focus groups can provide insurance that socialized gender roles will not dissuade female participants from expressing their views, particularly for more vulnerable groups of 
women. Same-sex groups were not possible among the middle and upper income as these participants proved more challenging to recruit compared to the lower and modest income participants. I do not see any indication in the data that the mix of gender in the room proved important in the results.

\subsubsection{Limitations}

The results below should be interpreted with attention to at least the following two limitations. First, participants in these focus groups may not be representative of the broader population or even subpopulations from which they are drawn since selection was purposive and non-random. Qualitative studies are based on purposive rather than random or representative samples. The aim is not to recruit a sample that is representative of all other participants sharing relevant characteristics. Instead, the aim is to explore perspectives of participants who have some breadth of opinion on an issue of interest.

For voluntary focus groups, all participants self-select. The participants who elect to take part are more likely to have greater interest in the subject matter, to have fewer other demands on their time or some combination thereof. The aim of focus group research is not to sample for representative opinions but instead to identify thematic responses from participants that might suggest areas for further research using representative samples (Denzin \& Lincoln, 2005). Alternatively, qualitative research can be useful for identifying explanatory variables that will add depth to results from quantitative research, 
particularly when traditional sampling frames are likely to leave out particular subpopulations.

A second important limitation in qualitative research is the risk of biased responses from participants. For example there may be exaggerated in-group agreement owing to social desirability bias or researcher demand. In a group setting, some of this can be offset (but not fully eliminated) through the facilitator's own conduct and by including individual, written exercises.

The focus groups were not able to examine the role of household composition, life events, luck, participant age and life stage, initial endowments, income flows and perceptions of belonging and inclusion. Likewise, participants were not asked to divulge any information about their own financial circumstances as part of the group discussion. The questions did not ask for information on their own wealth holdings, product decisions or current use of tax-preferred savings instruments. These variables would be better explored through (for example, confidential depth interviews with individual participants) future research.

\subsection{Results}

\subsubsection{Associations with the term "saving"}

To open the focus group, participants were asked to perform a written free-association exercise, starting with the term "saving" and writing down other words or phrases that 
came to mind. Participants took turns discussing as many of their word associations as they felt comfortable.

Word association exercises are frequently used in marketing research to develop campaign themes, product brands and other elements of strategy (MacDaniel, 1998). The associations in this case may shed light on the perceptions of focus group participants towards "saving" more generally as a construct and elements of the theoretical model of individual saving outlined in Chapter 2.

The types of associations raised by participants fell into several different categories, suggesting that for them, saving is multidimensional construct and not simply a "loss" as it has been treated in much behavioral research (Bernartzi \& Thaler, 1995; Morrison \& Oxoby, 2011).

First, there were associations that reflect a motivational dimension. For example, participants mentioned "freedom”, "security”, "retirement”, "house”, “trips”, "emergency", "hobbies" reflecting goals or reasons for saving. The range of motivations or reasons for saving is discussed at length in section 9.3.2 below.

A second theme or dimension of associations was related to effort. For example, participants used words such as "difficult", "challenging" and "hard to do" reflecting a view that saving feels like something that requires exertion and overcoming obstacles. Interestingly, these terms were used by participants both income groups. By contrast, 
participants also used terms such as "not yet", "doable" and "difficult and easy", suggesting that the perceived degree of effort involved likely varies considerably. Women in both groups were somewhat more likely to make reference to these more positive or hopeful terms suggesting, perhaps, a more positive overall orientation towards the topic.

A third dimension concerned the behavioral strategies associated with saving, in fact this was the category most frequently apparent in the participant responses. Participants mentioned a range of behaviors including:

- "finding money"

- "budgeting"

- "cut spending", "spending less" and "don't spend"

- "plan ahead"

- "keeping track"

- automating behaviors such as " $10 \%$ of paycheck", "automated withdrawal", "discipline", "regular deposits" and "habit"

- behaviors to increase available income such as "borrowing", "investing", "make money" and "good paying job".

Participants with lower-incomes were somewhat more likely to mention behaviors that involved reducing consumption or increasing income through employment. Participants in the middle to upper-middle income groups were more likely to mention behaviors that 
reflected a habitual or automated behavior. Men in both groups were somewhat more likely to refer to increasing income through employment or investing.

Both lower and middle to upper income groups made reference to behaviors of planning ahead, keeping track and making ends meet, that are part of the model of financial capability developed by Kempson, Collard \& Moore (2005) often in exactly the same wording used in that model (discussed in Chapter 2). This may be further evidence for the construct validity of Kempson et al's model. An observation that someone is making regular savings deposits, economizing on their expenditures and accumulating assets may be an indication of a number of aspects of financial capability but is unlikely to be a sufficient indication of any one of them alone.

Participants also made normative associations with saving. They used terms such as "necessary", "wise", "good thing", "responsibility" and "recommended". Here again, participants from both income levels used these kinds of normative terms. This suggests that, not withstanding some effort involved, participants perceive saving as having value beyond its economic value. In Chapter 2, I proposed that motivation, perception and psychological variables such as self-efficacy and inclusion might all play a role in shaping differences in observed assets, alongside institutional variables. It is possible that participants" use of normative words such as "wise" and "good thing" indicated perceptions of saving as an accepted social norm and also normative motivations to conform to that view. Those with a greater sense of self-efficacy (including a more internalized locus of control) may be more willing to not conform to those norms while 
persons with a stronger sense of belonging and inclusion may be more likely to conform to those norms. However, these variables are outside of the current research design.

Finally, a fourth type of association made by participants was with various instruments specific products or programs or references to places or ways to keep savings. These references included mentions of "piggy-bank", "gold", "bank", "bonds" and "where to keep?" But more importantly, several participants made reference to the tax-preferred savings instruments that have been the focus of this study: "TFSA", "RRSP" and "RESP". The first two (TFSAs and RRSPs) were mentioned only by participants in the middle and upper-middle income groups while the latter (RESPs) was the only reference to a tax-preferred registered instrument in the word associations of any of the low-income participants. Recall that this exercise offered no direction to participants other than to write down what came to mind after writing the word "saving" in the middle of a blank piece of paper. This suggests that there may a very powerful association between the family of tax-benefited registered accounts and the general construct of "saving".

If these programs have become synonymous for Canadians with the very idea of saving itself then this may be the public policy equivalent of what marketers describe as a brand becoming generic (Manning, 2009). In marketing, a product brand name is said to have become generic when it becomes synonymous with the category of products and, in a 
sense, indistinguishable from the concept of the product itself. ${ }^{281}$ Generally market researchers believe this "genericization" takes place only when a brand name product has dominated a market for an extended period of time. In the case of registered, taxpreferred savings instruments in Canada, only RRSPs have been available and wellknown for long enough to have achieved that kind of prolonged dominance. That other instruments (including TFSAs and RESPs) were also mentioned suggests that, for participants, first, there is something that has made these other instruments strongly associated (or perhaps even synonymous) with "saving" and that they are seen as a generic group of products that are associated with one another. ${ }^{282}$

\subsubsection{Motivations for saving}

The review of the literature on motivations for saving in Chapter 2 had proposed the following seven categories:

- Precautionary motives (saving to smooth consumption during life-course)

- Bequest motives (saving to pass on wealth)

- Life-cycle motives (saving to smooth consumption for known transition to retirement)

- Instrumental motives (saving up for large purchases)

- Normative motives (conforming with social norms)

\footnotetext{
${ }^{281}$ Well-known examples include "Kleenex" as a generic term for facial tissue, "Jell-o" for flavoured gelatin or "Hoover" for vacuum cleaners.

${ }^{282}$ The position or order of these terms on participants' pages suggests that they wrote down one and then subsequently others. The train of thought for many participants seems to have been: saving $=$ RRSP + some other tax-preferred instrument.
} 
- Speculative motives (saving to invest for a return).

Results from the discussion on savings goals and motives with focus group members (see Table 9.3 below) suggest some refinements to these categories may improve understanding of what drives and shapes savings behavior. Focus group participants were asked to collectively brainstorm reasons or goals for saving that they had personally experienced or had witnessed in people they know personally. There was strong support for precautionary motives with participants in all groups citing goals such as "rainy day", “a cushion” or "stability". Other responses, such as "independence”, "freedom”, "less stress" and "better future", suggest an aspirational dimension to this motivation for saving. Most literature on precautionary motives suggests that savers are motivated to forego current consumption so that they build a stock to supplement future consumption needs if ever income flows decrease. The presumed economic goal is to equalize consumption and well-being over time. Instead, references in the focus groups suggested that their forward-looking or precautionary savings can also have aspirational qualities, in hoping for a "better future". In this case, saving and forgoing consumption now may not necessarily be experienced as an economic loss but rather (or concurrently) as an increased sense of personal agency. If this is true in representative samples, this could have important implications for economic models on saving that attempt to offset loss aversion (see for example Bernatzi \& Thaler, 1995; Thaler \& Sunstein, 2008; Morrison \& Oxoby, 2011). 
Some focus group participants also cited motivations that might broadly fit within the category of bequest motives, with at least one response of "to leave an inheritance". However, there were many more references to a desire to pass on wealth during one's life-time, rather than at death. For example, participants spoke about saving money "to donate", "to help others" and for "helping family". Similarly, many participants cited children as motivations for saving, most often specifically a child's future education 
Table 9.3: Goals and motivations for saving

\begin{tabular}{|c|c|c|c|c|c|c|}
\hline \multicolumn{4}{|c|}{ Low-income groups } & \multicolumn{3}{|c|}{$\begin{array}{c}\text { Middle/Upper-middle income } \\
\text { groups }\end{array}$} \\
\hline Group 1 & Group 2 & Group 3 & Group 4 & Group 5 & Group 6 & Group 7 \\
\hline $\begin{array}{l}\text { Women } \\
\text { only } \\
n=4\end{array}$ & $\begin{array}{l}\text { Women only } \\
n=6\end{array}$ & $\begin{array}{l}\text { Men only } \\
n=6\end{array}$ & $\begin{array}{l}\text { Mixed } \\
n=11\end{array}$ & $\begin{array}{l}\text { Mixed } \\
\mathrm{n}=7\end{array}$ & $\begin{array}{l}\text { Mixed } \\
n=4\end{array}$ & $\begin{array}{l}\text { Mixed } \\
n=4\end{array}$ \\
\hline $\begin{array}{l}\text { House } \\
\text { Vacation } \\
\text { Short trip } \\
\text { Education } \\
\text { for children } \\
\text { Less stress, } \\
\text { not } \\
\text { worrying } \\
\text { about } \\
\text { money in } \\
\text { the bank } \\
\text { Healthier } \\
\text { foods } \\
\text { Fitness and } \\
\text { exercise } \\
\text { Costs of a } \\
\text { car } \\
\text { Security } \\
\text { Jacket / } \\
\text { clothing } \\
\text { Seasonal } \\
\text { clothes }\end{array}$ & $\begin{array}{l}\text { House } \\
\text { Education } \\
\text { Retirement } \\
\text { Car } \\
\text { Vacation } \\
\text { Medical } \\
\text { Emergency } \\
\text { money } \\
\text { Business start- } \\
\text { up } \\
\text { Wedding } \\
\text { Divorce } \\
\text { Funeral } \\
\text { Transportation } \\
\text { Going back to } \\
\text { school } \\
\text { Training } \\
\text { Christmas gifts } \\
\text { Pets } \\
\text { Social life } \\
\text { Extra curricular } \\
\text { activities } \\
\text { (recreation) } \\
\text { Hobbies } \\
\text { Tools }\end{array}$ & $\begin{array}{l}\text { Better future } \\
\text { Stability } \\
\text { World travel } \\
\text { Old age } \\
\text { Reach goals } \\
\text { Stuff (toys) } \\
\text { Children/family } \\
\text { Tuition for kids } \\
\text { Medical } \\
\text { operation } \\
\text { Funeral } \\
\text { Rent } \\
\text { Party } \\
\text { Helping family }\end{array}$ & $\begin{array}{l}\text { Retirement } \\
\text { Rainy day } \\
\text { Trip } \\
\text { To help } \\
\text { others } \\
\text { Child's } \\
\text { education } \\
\text { To buy } \\
\text { goods } \\
\text { Family } \\
\text { medical care } \\
\text { Pets } \\
\text { To buy } \\
\text { insurance } \\
\text { For } \\
\text { recreation } \\
\text { To travel to } \\
\text { family } \\
\text { To feel good } \\
\text { Have a } \\
\text { cushion } \\
\text { Security } \\
\text { Funeral } \\
\text { Wise to do } \\
\text { To pay bills } \\
\text { To pay off } \\
\text { debts } \\
\text { To live } \\
\text { more } \\
\text { comfortably } \\
\text { To leave an } \\
\text { inheritance } \\
\text { To donate } \\
\text { As a buffer }\end{array}$ & $\begin{array}{l}\text { Freedom } \\
\text { Retirement } \\
\text { A pillow, } \\
\text { cushion } \\
\text { Vacation } \\
\text { Things } \\
\text { Education } \\
\text { Home } \\
\text { Plastic } \\
\text { surgery } \\
\text { Independence } \\
\text { Old bills } \\
\text { Wedding } \\
\text { Second home } \\
\text { Funeral } \\
\text { Down- } \\
\text { payment } \\
\text { Just in case } \\
\text { Rainy day } \\
\text { Dad not there } \\
\text { anymore } \\
\text { Bank } \\
\text { Birthday } \\
\text { present } \\
\text { A car } \\
\text { Boat, } \\
\text { snowmobile } \\
\text { Property } \\
\text { Restaurant } \\
\text { Health, } \\
\text { medical } \\
\text { Raising kids } \\
\text { Second career }\end{array}$ & $\begin{array}{l}\text { Retirement } \\
\text { Security, just } \\
\text { in case } \\
\text { Emergency } \\
\text { Feel secure } \\
\text { Children's } \\
\text { education } \\
\text { Travel } \\
\text { Car } \\
\text { House } \\
\text { (down- } \\
\text { payment) } \\
\text { Education } \\
\text { Habit } \\
\text { Good idea }\end{array}$ & $\begin{array}{l}\text { Sense of security } \\
\text { Rainy day } \\
\text { Kid's education } \\
\text { House } \\
\text { Holiday/vacation } \\
\text { Save for } \\
\text { everything } \\
\text { before you buy it } \\
\text { Christmas } \\
\text { To invest to } \\
\text { make more } \\
\text { money } \\
\text { Wedding } \\
\text { Security for } \\
\text { disability } \\
\text { (accident or } \\
\text { retirement) } \\
\text { Avoiding } \\
\text { fraudulent } \\
\text { investments } \\
\text { Just because } \\
\text { Raised that way } \\
\text { Taxes and HST } \\
\text { if self-employed }\end{array}$ \\
\hline
\end{tabular}

Participant's responses to the question: "Thinking about your own experience, or people you know, what are some of the things you've saved for? Or maybe you're saving for a goal now? Or maybe it's something you would like to save for."

costs. Bequest motives may be a subset of altruistic motives that are not limited to end-

of-life giving. It is also noteworthy that while children and children's education were

mentioned in all but one focus group, more general altruistic motivations were only

volunteered by low-income participants. 
Life-cycle motives were in evidence across all seven focus groups. In six out of the seven groups, participants of all age ranges mentioned "retirement" or "old-age" as reasons or goals for saving. However, other life-course stages or events were also mentioned including: "wedding", "divorce", "funeral" and "raising a child". Women in both income levels were slightly more likely to mention motivations related to child rearing. Participants' own ages and likely life-stages did not seem to influence their responses.

While the literature on life-cycle motivations for saving has a strong focus on the transition to retirement, it may be that in practice, people consider retirement to be one of a number of life-events with associated costs. This is also consistent with the work of McKay and Kempson (2003) who found that life events such as family formation and divorce had large effects on savings behaviors. On the other hand, the costs of a wedding or a funeral could also be understood as part of a set of instrumental motives for saving, that is, saving-up to buy something or otherwise cover a lumpy cost that could not be afforded out of income flows alone. But given the social (as well as economic) significance attached to family formation, dissolution, parenthood and death, they may have much overlap with retirement savings as life-course transitions.

Instrumental motives for saving were in evidence as well across all seven groups. Lowincome participants tended to list more instrumental goals and to be more specific in describing those goals, listing, for example "seasonal clothes", "tools", "better food" and 
"a jacket", items that many outside of low-income would not consider to be unaffordable from income flows. Both income groups referenced financial transactions among reasons for saving including "pay old bills", "buy insurance", pay "taxes if self-employed”, and "pay off debts". Both income groups also universally cited housing-related costs (for example saving for "a house", "a down-payment"), generally home-purchase but saving for the costs of a rental deposit was cited in one low-income group. Housing represents one of the largest on-going expenses for most households and is, in most cases, the largest purchase individuals will ever make in their lifetimes. As a savings goal, whether for purchase or rental, it may be worth separating housing from other instrumental goals in efforts to see how motivation may impact savings behavior.

Participants did mention motives for saving that could be understood as normative. For example, some participants mentioned that saving is "wise to do" or "a good idea". Among participants in the middle and upper-middle income groups, there was slightly more frequent reference to socialization, describing saving as "habit" or as something they were socialized to do by parents or family. While the early theorists and moralists had argued that low-income individuals needed intervention to value thrift and saving (see discussion in Chapter 2), there is little reason to believe that low-income persons do not recognize a social, normative value to saving. It may be that middle or upper-middle income participants were more likely to volunteer that their upbringing or experience had influenced their view of saving. The effects of family and life experience for low and modest income persons on perceptions of saving has not been studied in Canada. 
Finally, participants did not often mention goals that might reflect a traditionally speculative motivation. Only one mention was made regarding saving to start a new business venture or to make a financial investment. However participants across all groups did mention goals such as "travel", "vacation", "training", "a second career", "education", "health or medical", "fitness" and even "plastic surgery". What these goals have in common is that they are investments in self-care or self-improvement that extend beyond basic needs for food, clothing and shelter. In one sense these could be understood as purely instrumental savings goals, however investments in human capital or small business start-up are clearly expected to generate a long-run return. The investments in medical costs, fitness and plastic surgery appear to be very similar, leading to an improvement over the long term in health, wellness and perhaps employability. The aspirational quality to the discussion around saving for a vacation and travel suggested that participants may view these in a context of self-care or selfimprovement as an investment. In fact, research in psychology generally treats vacation, exercise and optional health care as measureable self-care behaviors (Mahoney, 1997; Wasco, Campbell \&Clark, 2002; Stevanovic \& Rupert, 2004).

In summary, the savings goals and motivations reported by participants are broadly consistent with categories from previous theory and research and support the need for multi-dimensional views of motives for saving. The degree of overlap between participants of different income levels is also striking, though so too were a handful of marked differences. Participants in all groups spontaneously mentioned the same goals to which federal instruments have been linked (namely retirement savings, saving for a 
home, saving for a child's education) but also extended well beyond this more limited range.

\subsubsection{Public perceptions of policy instruments}

In another exercise, focus group participants were asked to brainstorm a list of government programs that they had heard of where the aim was to help Canadians save. Table 9.3 below presents the full list of instruments as volunteered (both in terms of order and terminology) by participants.

One or more of the registered tax-preferred instruments that have been the focus of the previous chapters were mentioned in each and every group. This suggests that awareness of these instruments (though not necessarily confident knowledge of their details) is reasonably widespread, regardless of income levels. In fact, a registered instrument was the top-of mind example cited in each group suggesting that the association between the goal or value of saving and registered instruments as a type of intervention is very for consumers. In many cases, participants cited the acronyms for the registered instruments, suggesting perhaps that they are aware of the instruments in much the same way as a brand-name consumer product. This possibility is explored further in the discussion later in this chapter on the perceptions of these instruments.

It is also possible that the mix of instruments listed by groups may be, at least in part, related to their characteristics, including levels of income and wealth. For example, groups composed of lower-income participants were somewhat more likely to mention 
the Registered Disability Savings Plan (mentioned in two out of four low-income groups but none of the middle/upper-middle income groups) while groups composed of middle and upper-middle income participants were more likely to name the Tax-Free Savings Account (mentioned by all such groups but in just one of four low-income groups). Some of the lower income participants may have been recipients of the Ontario Disabilities Support Program who may have heard about the RDSP through a caseworker or social service provider. ${ }^{283}$ By contrast, the middle and upper-middle income participants may have had more exposure to marketing for the TFSA.

This relationship between the instruments and income-levels of participants shows up as well in the mentions of other programs. Lower-income participants were much more likely to name programs that provide income-support (for example, social assistance, ODSP, child tax credits, seniors supplements) or reduce out of pocket expenses (for example, subsidies for housing, public transportation or recreation). Participants in both groups did make reference to social insurance programs such as Employment Insurance and the Canada Pension Plan. In one sense, these latter could be framed as collective, compulsory savings programs to which all employees must contribute through payroll $\operatorname{taxes}^{284}$. However, unlike the registered instruments that are the focus of this

${ }^{283}$ For example, at least one low-income participant referred to having taken part in an information workshop on RDSPs through a social service agency.

${ }^{284}$ Self-employed workers may contribute to the Employment Insurance program if they have entered into an agreement with the Government of Canada to do so. Self-employed workers are required to contribute to the Canada Pension Plan out of their net annual earnings. 
Table 9.4 Public programs for saving named by participants

\begin{tabular}{|c|c|c|}
\hline \multirow{4}{*}{$\begin{array}{c}\text { Low-income } \\
\text { groups }\end{array}$} & Group 1 & $\begin{array}{l}\text { Registered Disability Savings Plans } \\
\text { Children's Grant (Education savings) } \\
\text { ODSP } \\
\text { Social Assistance }\end{array}$ \\
\hline & Group 2 & $\begin{array}{l}\text { RESPs } \\
\text { RRSPs } \\
\text { Life insurance } \\
\text { Subsidies (bus pass, housing, recreation programs) } \\
\text { Energy Star Initiative } \\
\text { EI Program }\end{array}$ \\
\hline & Group 3 & $\begin{array}{l}\text { Registered Retirement } \\
\text { Canada Savings Bonds } \\
\text { RRSPs or RIFFs } \\
\text { Investments/Stock market } \\
\text { Old Age Security / Canada Pension } \\
\text { Registered Disability Savings Plan } \\
\end{array}$ \\
\hline & Group 4 & $\begin{array}{l}\text { RRSPs } \\
\text { RESPs } \\
\text { Canada Savings Bonds } \\
\text { Tax-free Savings Account } \\
\text { Donations, tax credit } \\
\text { Subsidies } \\
\text { Child Tax Credits } \\
\text { Charities } \\
\text { Seniors Supplements } \\
\text { GST/HST } \\
\end{array}$ \\
\hline \multirow{3}{*}{$\begin{array}{l}\text { Middle/upper } \\
\text { income } \\
\text { groups }\end{array}$} & Group 5 & $\begin{array}{l}\text { Tax-free Savings Account } \\
\text { Canada Savings Bonds } \\
\text { Tax breaks (clean energy, kids in sports) } \\
\text { RRSPs } \\
\text { RESPs } \\
\text { Taxes } \\
\text { Pension, OAS } \\
\text { EI }\end{array}$ \\
\hline & Group 6 & $\begin{array}{l}\text { RRSPs } \\
\text { TFSAs } \\
\text { RESPs } \\
\text { First-time Home buyer } \\
\text { Government bonds (federal and provincial) } \\
\text { CPP, government pensions }\end{array}$ \\
\hline & Group 7 & $\begin{array}{l}\text { RESPs } \\
\text { RRSPs } \\
\text { TFSAs } \\
\text { Canada Savings Bonds } \\
\text { Provincial Bonds } \\
\text { Ontario Housing Savings Plan } \\
\text { Government websites - information } \\
\text { Government insurance on savings accounts } \\
\text { Eco-energy efficiency } \\
\text { Feed-in tariff }\end{array}$ \\
\hline
\end{tabular}


thesis, contributions into these programs are only part of the method for determining potential benefits (or withdrawals, in the most flexible us of the term) and any notional "assets" accumulated in the program cannot be transferred. In other words, these programs are not truly aimed at encouraging individual savings and asset-accumulation.

But it is very interesting that they may be perceived by some Canadians to do just that and suggests that, in lived experience, the lines between various instruments in a social welfare policy framework can be very blurry for citizens. Similarly the income-support subsidy or cost-reduction programs mentioned by the lower-income groups are not really aimed at encouraging individual asset accumulation but rather to improve well-being (through purchasing power) for households with limited income. The reference to these kinds of instruments may be reflective of a view of "saving" that emphasizes thrift, or reducing expenditures, rather than building up wealth. This would be consistent with references to more short-term, consumable goals (described in the previous section) and suggests that "saving" may need to be conceptually divided between thrift (including “saving on") and forward planning (including "saving up" or "saving for").

\subsubsection{Confidence and understanding re: existing instruments among lower income participants}

After brainstorming a list of policies or programs, participants were asked, as a group, to offer any information they had about up to three instruments on the group's own 
brainstormed list. ${ }^{285}$ This section presents the findings among the low-income participants. The following section presents the findings among the middle and upper income participants. There was imperfect overlap in the instruments named by the participants at the two income levels. Instruments that were raised in all groups for the same income level are discussed below. It is notable that none of the groups cited homeownership as a form of tax-preferred savings although it was cited as a goal for saving.

Before turning to the group discussions on each RESPs, RDSPs and RRSPs, there are two general observations to note. The first is that participants at both income levels generally exhibited behaviors suggesting that they hold financial knowledge in esteem. Not infrequently, if a participant spoke with any confidence about an existing program, other participants quickly turned towards him or her to ask additional questions or used expressions of positive regard mixed with surprise. For example, one low-income male participant described a program with which another was unfamiliar and said: "It's a need to know basis but your caseworker should inform you about it". He was able to demonstrate some confidence in his own description of the program, prompting others in the group to begin chattering with interest. Another low-income male even excitedly exclaimed "Wow!" and, addressing his question to his peer in the group, asked: "can I save money with that?" A similar exchange took place between low-income males in a

${ }^{285}$ The instruments were selected on an ad hoc basis by the facilitator to include one or more registered instrument and one other program that had been named by more than one participant in the room. 
separate group in which one asked the other for additional program details and about where he could get further information.

Another general observation is that, with one exception, participants in the low-income groups viewed government as the main supplier of the registered instruments they discussed. In all but one discussion, participants made no mention of banks or other financial service providers as the point of sale for RRSPs, RESPs and RDSPs. This may be, at least in part, a reflection of some degree of financial exclusion. For example, one female low-income participant stated: "I think 'how much money I have' all the time and sometimes I think about if I save the money where I'm gonna' put it? Sometimes I feel the banking is not safe. ${ }^{286}$ Similarly, another (male) participant expressed the view that life on low-income is often rife with obstacles to mainstream sources of well-being: "At the lower end of the income spectrum, we have to look at all venues and all options that we can because we're just trying to get by with dignity and respect just like anybody else.”

\section{RDSPs}

Participants were generally aware that the RDSP is a savings program for persons with disabilities. Similarly, participants were aware of the existence of an age limit and annual contribution limit on the account but were not confident about the details. For example, in one group a participant asked "it's only until 40 years, isn't it?" and another responded

\footnotetext{
${ }^{286}$ Note that here, as in all quotes in this report, the participants' words are written verbatim from the digital audio recording.
} 
uncertainly, "no, [pause], I don't think so...". In another group, a participant suggested maybe it is "up until the age of 45, I believe". Similarly, in a discussion on the RDSP, a participant said: "I'm not sure of the amount, if it's $\$ 3,000$ or what. [...] I'm not sure."

Participants expressed a great deal of uncertainty about the interaction between the RDSP and social assistance benefits for persons with disabilities. There were questions about whether RDSP contributions were deducted directly from monthly social assistance income, whether RDSP contributions might be clawed-back from social assistance income and whether being in receipt of social assistance was necessary to qualify for an RDSP. For example, one participant asked: "Do you have to be collecting disability before you can do that?" and another responded "I don't know. I don't know much about it really."

Finally, participants generally expressed a great deal of uncertainty and confusion about the RDSP. For example, one female low-income participant said: "What I understand is that [pause] you could put money aside into that plan with the government. That's really all I understand about it." Another (male) participant was aware that there was a government-paid matching grant on personal savings in an RDSP but was uncertain about which level of government paid the grant. Another low-income male stated: "It's a pretty new program, I think.. just in the last year I think maybe it came in." 


\section{RESPs}

Some participants were aware of RESPs as a savings instrument for a child's education and others were broadly aware of the existence of such program but expressed no direct knowledge of them. However, even among participants who knew of the RESP, there was a general level uncertainty about the program details. One participant commented: "I can't remember what the exact numbers were. I don't know the exact ratios." Another participant was uncertain of the program name but was aware that, if a parent were to withdraw his or her education savings deposits early that the government grants would be lost.

\section{RRSPs}

Like RESPs, many participants were broadly aware of the existence of RRSPs but were not directly familiar with the details of the program. Participants raised questions of each other about whether RRSPs were the same or different than the Canada Pension Plan. 'I'm not sure", replied on male participant. "I don't know anything about these things" remarked another low-income male. Another participant noted that RRSPs are sometimes available through employers which prompted much interest and questioning among other participants. And, in a separate group discussion, one participant expressed the view that RRSPs were not intended for people who did not already have money: "It takes money to make money" he said. The same participant then observed that, in his view, the rules for this (and perhaps related programs) were frequently subject to change for Canadians with low incomes and little savings. 
But perhaps most strikingly, the discussion on RRSPs revealed that many participants viewed RRSPs as potentially harmful, quite on top of viewing them as inaccessible. “I know somebody who owes money on RRSPs" said one female participant. "I don't know how that works, but she went into RRSPs and something not good happened. I don't understand it." Another female participant stated "you're not really supposed to go into them" and noted that having RRSPs can affect eligibility for certain program targeted to low-income Canadians.

\section{A question of emphasis}

Although low-income participants had somewhat limited information about registered tax-preferred instruments and expressed little confidence in the information they did have, this was not universally true of all programs discussed by groups of low-income participants. During discussions of Ontario's social assistance programs (including both Ontario Works and the Ontario Disability Support Program), participants were able to explain, to the exact dollar value, the amount of basic income benefit as well as related top-up amounts for transportation and special dietary requirements. Participants were similarly able to describe the refundable tax credit for the Goods and Services Tax or Harmonized Sales Tax with considerable accuracy on details such as frequency of payment, how to apply and the maximum qualifying annual income. Perhaps more importantly participants expressed a great deal of confidence regarding their own knowledge and there was general agreement amongst participants regarding program details, in contrast with expressions of surprise or uncertainty in the discussions on the registered savings instruments. 
Discussions regarding the registered instruments and social assistance also revealed that participants paid considerable attention to perceived risks. For example, in the discussion on RESPs, participants were quick to point out the risk of losing the government's matching grant in cases of early withdrawals. The discussion on social assistance in at least two focus groups included detailed descriptions of provincial means tests. And, as mentioned above, provincial means tests were also raised as questions or concerns in the discussions on RDSPs and RRSPs. Similarly the participants' remarks regarding RRSPs revealed a general perception that they are something that low-income people "are not supposed to go into" and can even result in increased debt.

Taken together, along with the results from the earlier exercises regarding associations and motivations for saving, it suggests that low-income participants in these focus groups have considerable financial capability. They have detailed knowledge of, and are confident in their understandings of, the public programs with which they most often and directly interact. Given their present vulnerability, low-income participants appear to be keenly attuned to indications of risk or potential for loss (including harsh penalties) in mainstream programs. ${ }^{287}$ It is not that the low-income participants believe they are legally not entitled to hold a registered savings account but rather that they, not

${ }^{287}$ One potential question for future research may be to evaluate differences in loss aversion between subjects with low or modest incomes, including differences in loss aversion by income source (for example comparing subjects with primarily or exclusively modest market incomes and those with primarily or exclusively transfer incomes). Many existing studies on loss aversion appear to deal with circumstances in which participant income is either removed as a variable or where lifetime income may be at or above the population average. 
inaccurately, perceive that the accounts have been designed in ways that tend to exclude them either directly or indirectly.

\subsubsection{Confidence and understanding re: existing instruments among middle and upper-middle income participants}

In contrast, middle and upper-middle income participants were much more specific and confident in their program descriptions. Participants did not discus the RDSP but did have very lengthy, very rich discussions of RRSPs, TFSAs and to a lesser extend RESPs.

\section{RRSPs}

Participants were all aware that RRSPs offered a tax deduction against current income and would be taxed on withdrawal. Many were able to confidently and clearly explain the deduction-deferral model and even made clear observations about the presumed tax benefits. "The tax you would have paid on that money, you get it back now. You just pay it later on when you retire and in the meantime you can lower your tax bracket," said one male participant. "When you retire, you assume that you're going to be taxed at a lower tax bracket so it's better", said another. One female participant observed "your tax break depends on your income so if you earn more income you get a better break after you pay your taxes, not when you put it in your RRSP so you have to have the money first."

Participants were able to discuss, with considerable detail and confidence, various rules regarding annual contribution limits, roll-overs to RRIFs, spousal RRSPs and even the 
interactions between these provisions. Participants were also able to discuss the treatment of pre-retirement withdrawals, including normal tax withholding rates at source and shelters for withdrawals for both home purchase and adult education or training. They described "pros and cons to taking the money out early" depending on personal circumstances, such as purchasing first home, although some expressed somewhat less confidence on the exact details of the Homebuyer's Plan. For example, in one group, a participant suggested it was a simple withdrawal while another cautiously responded "I thought it was that you could borrow from your RRSP, right?" Participants also demonstrated an understanding of the policy rationale for taxing pre-retirement withdrawals, stating "it's all to deter you from doing that I guess because it's supposed to be for your retirement".

Whereas participants in the lower-income groups tended to focus on the role of government in the instruments they discussed, participants in the middle and uppermiddling income groups demonstrated an awareness of interactions with markets in their registered savings. For example, several participants cautioned that registered savings might grow or shrink depending on market returns. In the words of one participant: "You can be at the mercy of the market". Participants in these groups also generally noted, and favorably so, the availability of various types of investments (including stocks, term deposits, bonds and more) that might be held in an RRSP. As one male participant remarked: "there's a bit of freedom there to choose exactly how you want to earn money". Another participant related her own experience with discovering what could and could not be included in RRSP investments: "I was trying to invest in something that 
didn't qualify. I didn't know! My friend had a really neat business. Sure I'll in invest in it! Didn't fly. I don't know what the rules are." Finally, a female participant in another group urged that the best practice was to check what could and could not be included in RRSPs with the financial institution selling the registered investment.

\section{TFSAs}

In all three focus groups with middle and upper-middle income participants, the conversation on TFSAs tended to flip back and forth between TFSAs and RRSPs, with similarities and distinguishing features being highlighted. For example, participants noted that the TFSA was better suited than the RRSP for short and medium term savings goals compared to long-term retirement planning. Other participants named income levels, prior savings and even age as important factors in selecting between RRSPs and TFSAs and debated the merits of each instrument:

- "I think this one is aimed at people who have a lot of money because what are you saving in that unless you've maxed out your RRSP there's no real advantage to using this one"-Female participant.

- "I agree that it's better for younger savers". - Female participant.

- [In response to the above] 'Yeah, not the older ones except if they've maxed out their RRSP." - Male participant.

- "At some point you can use both [RRSPs and TFSAs]. If you have enough saving you can actually max out both" - Male participant. 
Participants also demonstrated confidence and clarity in their understanding of the difference between the deduction-deferral model of RRSPs and the tax pre-paid model of TFSAs:

- “The difference, it's like, you pay your taxes, you don't get your taxes back now, instead you're just not paying taxes on the revenues that you're getting out that amount of money." - Male participant

- "You've already paid the tax on the money when it went in, unlike RRSPs you pay the tax when you take it out." - Female participant

- "They [RRSPs and TFSAs] are different ways of having tax shelters." - Female participant

At the same time, participants also demonstrated considerable detailed knowledge on the exact annual limit of TFSA contributions, the accumulation of contribution room from one year to the next and even the year in which it had been introduced. They were aware that, like RRSPs, only certain investments would qualify for registration under a TFSA. Participants also spoke, in all three groups, about rules penalizing TFSA account-holders for replacing withdrawn money and exceeding their annual contribution limit. One female participant noted that she thought many TFSA users had been penalized for withdrawing and contributing money in the same year. She felt that the rules on withdrawals and deposits were too restrictive: "Even when you go to the bank and the credit union they encourage you to do it but it's money that sits in that account for a year. So you do it and then you get stuck!" Another female participant added: "That's a problem with the name, TFSA. It's not really a savings account." 
There was also some debate about the return on the investment to an individual TFSA holder. While on female participant argued that, in nearly all cases, an RRSP with a deduction was preferable, another noted, energetically "say over 50 years, $\$ 5,000$ a year, and then all that tax, even if it's a one percent interest rate, you're not going to pay tax on it!" In general participants agreed that, under current market conditions, investment returns in either RRSPs or TFSAs were likely to be poor, prompting one participant to say that, in his view, the "problem with both [RRSPs and TFSAs] if you take a loss you cannot write off your losses for both". In response, another participant advised saving outside of registered instruments and claiming investment losses as capital losses.

\section{RESPs}

Compared to RRSPs and TFSAs, the participants expressed much less certainty regarding their understanding of RESPs.

It is unknown how many participants in the focus groups have children, as this information was not collected, but the general perception was that RESPs are taxsheltered savings accounts intended for parents to save for a child's higher education. For example, one participant stated that she was "not sure if you can contribute for someone other than a child" adding "probably" after a pause. While RESPs are technically available for beneficiaries of all ages, their origins (see chapter 4) and certainly the policy emphasis through, for example the Canada Education Savings Grant, may have successfully branded the instrument as a children's education product only. 
Participants expressed a range of views on the design of RESPs, in some cases describing them as similar to RRSPs, with a deduction for contributions, and in others as similar to TFSAs with a tax pre-paid model. Participants were generally confident in their knowledge that eligible withdrawals were taxed as income in the hands of a beneficiary student, although there were questions regarding the minimum age and post-secondary enrolment to be able to make such withdrawals. For example, one participant stated "you may have to be an adult to be able to withdraw, but I'm not $100 \%$ sure on that." Another suggested that RESP money might not be able to be withdrawn at once but was unsure while several participants had questions about what happens to RESP savings in cases where a beneficiary child does not pursue higher education. Finally, participants were aware of a government top-up for deposits into RESPs but were less confident of the precise details, noting that it was "a $20 \%$ bonus", in the words of one participant, "but I don't know up to what limit" in the words of another.

\subsection{Conclusions}

There are three key conclusions from this exploratory research - all of which should be verified in future research.

The first is that there was remarkable overlap between the associations and reported motivations for savings in both the low-income and middle or upper income groups. These more attitudinal and even affective orientations towards the act of saving and accumulating assets may be important for understanding observed outcomes. Both 
groups of participants were likely to name goals for saving that conformed to the prescribed goals of tax-preferred instruments. Both groups used terms that suggested an attitudinal orientation towards saving as a positive or desirable behavior.

Furthermore, both groups made unprompted associations between the term "saving" and specific examples of tax-preferred instruments, suggesting a strong association or even genericization of these instruments. However lower income participants had more limited associations - naming, unprompted, just one tax-preferred instrument - compared to middle and higher-income participants. Furthermore, lower income participants also named goals or motivations for saving that were distinct from either those associated with existing tax-preferred instruments or those named by higher income participants. I believe there is value to exploring further research to see whether the attitudinal orientations and associations with saving differ between those with lower and greater personal financial resources. I believe that the current qualitative findings suggest that differences in goals and motivations for saving may be part of the full explanation for observed differences in household use of the system of tax-preferred savings instruments.

A second key conclusion is that there seemed to be important differences in the comfort and familiarity of participants with regards to the tax-preferred account-based savings instruments as financial products and with regards to the private sector providers of those financial products. There is no question that, on the registered tax-sheltered savings instruments of interest in this study, middle and upper-middle income focus group participants were far clearer and more confident in their knowledge compared to low- 
income participants. Middle and upper-middle income participants demonstrated a broad knowledge of various aspects of each of the three registered instruments discussed above and, even where precise details were outside of their immediate knowledge, they were aware of the general characteristics or components of the registered instruments.

The discussions in these groups also revealed that the middle and upper-middle income participants were able, with some facility, to compare and contrast one registered instrument with others, noting similarities and drawing on earlier descriptions to succinctly describe another instrument. As consumers, they appear to be very aware of the key aspects in the policy design that have been replicated or incrementally altered as new instruments are introduced. Participants even frequently used specialized or semitechnical terms in their conversation, such as "marginal tax rate", "return on investment" and "eligible investments". Participants in these groups also did not shy away from offering guidance or even advice on the optimal use of the instruments being discussed, a dynamic that only emerged once in the discussions of the low-income participants. Their greater willingness to offer advice or insights into the best use of registered instruments, further suggests a sense of confidence, familiarity and accessibility of these savings vehicles for the middle and upper-middle income participants. In many cases, participants made references to their own direct experiences of having used or currently using one or more of the registered instruments under discussion. If they felt familiar with these instruments and able to discuss them confidently, often it appeared to be because they had learned about them through their own financial choices and savings behaviors. 
It is important to note that low-income participants generally did not discuss the role of financial institutions or expressed some skepticism regarding banks, however, middle and upper-middle income participants frequently showed a recognition and acceptance of the role of a range of financial service providers. For example, in response the question about explaining RRSPs in plain language, one participant replied "I would say go talk to your accountant. That's the best way to get it right". Other participants readily made reference to banks, credit unions and financial advisors. There appeared to be a recognition that the private sector had specialized or technical information that they lacked (see for example the discussion above regarding investments eligible for inclusion in an RRSP) but that the providers of this technical knowledge were available to them as consumers. This is a striking contrast with discussions in the low-income group that tended to refer to government and, less frequently, community organizations, as providers of savings and income programs or at least technical information on those programs.

Not withstanding the higher level of clarity and confidence in the knowledge of the middle and upper-middle income participants, there was also a general sentiment that the instruments were too complex. Asked to describe an RRSP, one participant replied "I think 'confusing"'. Following a lengthy and quite detailed discussion of several different registered savings vehicles, another participant jokingly remarked, "so why do people not understand these? I mean like.... Come on! And if you actually get into it there's more than that, right? The rules are just crazy!" 
The above findings are consistent with prior the research on financial exclusion in Canada (Buckland, Brennan \& Fikkert, 2010; Buckland, 2012; Robson, 2013) and suggest another potentially promising area for future research. To understand differences in financial behaviors under conditions of different tax incentives, I do not believe it is sufficient to look only at the incentive through the tax system itself-mainstream financial service systems that are integral to the delivery of tax-preferred savings instruments also generate different impacts for consumers with different levels of resources.

A third and final key conclusion is that, for low-income participants, fungibility of capital in tax-preferred assets is deeply problematic when scrutinized by means-tests in residual welfare benefits. Many low-income participants were able to describe, in detail, the clawback rates enforced on savings. Others spoke of being rejected for means-tested benefits such as income support or extended medical assistance because while their incomes were very low, their assets put them over the applicable means-test. Finally, some participants indicated that, while they were not confident in their knowledge of the details of one or more tax-preferred, account-based instruments, they were confidence in their belief that they personally were not expected to own one.

Even though the low-income participants clearly shared the social norm of saving and had overlapping goals with the middle and upper-income participants, it was clear they are at a severe and multifaceted disadvantage in using any of the tax-preferred registered instruments currently available. These participants were aware of the existence of a 
system tax-preferred savings but suggested that these instruments are not available or meant for low-income participants, a perception that is not without factual basis given their design, intended savings goals, requirements for interactions with private sector intermediaries and severe penalties through interactions with social assistance or exposure to investment risk.

The retrospective analysis from Chapters 4 through 7 highlighted various features of various tax-preferred account-based savings instruments. Canada currently has in place five such instruments: tax-sheltered equity in owner-occupied housing, RRSPs, RESPs, RDSPs and TFSAs. I have concluded that these form a system for conferring welfare to households in the form of subsidies for saving and accumulating certain forms of assets. My expectation, from the retrospective review in Chapters 4 through 7, is that this system is largely regressive because of the dominant features of each of the instruments in question. I confirmed, in Chapter 8, that in fact, upper and high wealth households are more dependent on these instruments in their portfolios and derive greater benefit from them towards their total wealth. The findings in this chapter offer preliminary evidence that citizens may be aware of this system of welfare but they may not, depending on their resources, feel included in it. 


\section{Chapter 10: Conclusions}

The central aim of this thesis is to argue that Canada's collection of tax-preferred, account-based savings instruments should be examined as a coherent and related set of policy instruments that, taken together, form what amounts to a hidden welfare system. I also set out to make a clear case that several features in the design of these instruments mean that they disproportionately benefit wealthier Canadians compared to poorer Canadians, even when this latter group complies with the policy objective and uses these instruments to save and build household assets.

This concluding chapter begins with a short discussion of what the thesis has contributed by way of new knowledge. Then I review, briefly, the evidence from the preceding chapters that leads me to conclude that yes, Canada does have a hidden welfare system for household savings and assets and that, yes, it is a regressive system that benefits wealthier households who do not need government assistance to be financially secure. Although each individual instrument is not unknown as a financial product, the sense in which these instruments form a system, and their directly observable distributional effects, are not well studied or transparent to the public. I conclude with some views on what the conclusions of this thesis imply for future research and policy-making in Canada.

\subsection{Primary contributions of this thesis}

This thesis offers some new research that may have academic as well as applied value. First, this thesis provides the first detailed historical account of the design and evolution 
of each the Registered Retirement Savings Plan, the Registered Homeownership Savings Plan and the Registered Education Savings Plan. It also appears to be only the second written discussion of Canada's experiment with the compulsory savings regime during the Second World War and adds to the study published by Barnett (2001). This thesis is also the first work to demonstrate that, as new registered instruments have been created, policy-makers have frequently replicated older registered instruments so that the set of instruments share common features and faults.

Second, while other authors in Canada (Kerstetter, 1999; Morissette \& Zhang, 2007) have used large-scale survey data to illustrate the disparity in net worth in Canada, this is the first study to illustrate the disparity in tax-preferred assets in Canada, not only in terms of frequency and prevalence but also in terms of prominence in household assets portfolios.

Finally, while other academic researchers have called for greater attention to the costs and policy effects of tax expenditures (Maslove, 1978; PBO, 2011; Lester, 2012) and at least one American academic has called similar expenditures in the United States a hidden welfare state (Howard, 2007), this thesis appears to be the first to argue that Canada also has a system of welfare that promotes household wealth accumulation through the tax-benefitted instruments I have examined. 


\subsection{A cohesive set of instruments}

My first question was whether current tax-preferred and account-based instruments share sufficient features and policy origins that they might be considered as a set of instruments should be examined together. As described in Chapters 4 through 7, RRSPs, RESPs, RDSPs and the TFSA share many common features. As argued in Chapters 1, 3 and 8, housing equity also belongs in this category of tax-preferred instruments. Below I review and reiterate the arguments in support of viewing the five instruments as a cohesive set of policy instruments.

First, all are instruments that rely on the tax system to deliver a public incentive for private household savings. Each instrument has one or more tax benefits - whether in the form of deductions, exemptions, exclusions or deferrals. The RRSP, because it offers a deduction against current income, appears to be the least equitable in terms of the tax benefit for poorer versus wealthier Canadians, a finding that is supported by the differences in household reliance on RRSPs (see Table 8.10, Chapter 8).

Other instruments have seen cash transfers added to the tax incentive - as in the savings grants and bonds - with the most generous cash incentives targeted to parents of children with disabilities using the RDSP. However, the rate at which the incentives increase as household resources decreases is fairly low, meaning that these benefits are only somewhat progressive. The flat rate Canada Education Savings Grant, for example, seems to principally have increased the RESP savings of wealthier families with children. The income-tested Canada Learning Bond seems to be having a strong and positive 
impact on the education savings of poorer families with children, as estimated by the comparisons of eligible families with and without RESPs. However, these gains among poorer families appear to be far weaker than the benefit accruing to high wealth families.

Second, all instruments demand some attachment to mainstream financial services. Although the compulsory savings experiment as well as the past sale of government annuities demonstrate that it has been possible for governments to be direct providers of savings and asset-accumulation instruments, the practice, since at least the creation of the RRSP in 1957, has been to rely on delivery by private sector financial services providers. Each of the tax-preferred savings instruments, including home equity, requires consumer interaction with a private sector provider to be able to open the desired savings vehicle, make deposits and obtain the publicly-paid benefit. Governments have been able to outsource much of the marketing, the implementation and the ongoing administration of savings instruments. The result is that the instruments reach the target markets of financial services providers — not necessarily those who might benefit most from public assistance to save and acquire assets.

Third, all of the instruments are account-based and create some fungible source of capital that can be transferred, cashed-in or otherwise create positive externalities for the household. The registered accounts—RRSPs, RESPs, RDSPs, TFSAs—are based on recognized financial assets in prescribed types of accounts. The policy and legislation explicitly permit transfers between instruments and early withdrawals—often without penalty. In the case of housing equity, the value of equity in a primary residence grows 
without taxation and exactly like TFSAs, can be withdrawn (either through sale or through financial products such as home equity loans and reverse mortgages) without taxation. Regular mortgage payments act, in many respects, as a kind of forced savings, requiring borrowers to repay some part of their debt and improve their equity stake in the asset. Survey data also suggest that Canadian homeowners perceive their homes as investments and part of their long-term savings (Schellenberg and Ostrovsky, 2010).

The ability to make these pools of capital fungible may be, for many households, a valuable way to manage risk — shifting capital from instrument to instrument as needs change to maintain a diverse portfolio. However, for households who rely or expect to rely on means-tested benefits for income, housing, extended health care and more, fungibility of these assets justifies the policies that see them clawed-back before any residual assistance is given.

Fourth, each instrument is linked to some normative and policy-sanctioned goal for saving. For example, RRSPs are widely understood to be intended for retirement savings and RESPs for the education savings of a dependent child. It is possible to imagine a policy regime in which there is only one all-purpose type of tax-preferred savings account intended for any or all savings goals, without judgment. Even the TFSA that places no restrictions on the use of withdrawals is now principally viewed by policymakers and researchers as an alternative to RRSPs for retirement savings. By limiting and labeling separate vehicles for separate purposes, policy-makers have created a choice architecture that mimics the kinds of mental accounting described by behavioral 
economists, creating distinct pockets of money into which savers can deposit money for those goals which appeal to them. When real accounts match the architecture of an individual's own internal mental accounts, there is likely to be an increase in saving and asset accumulation (Thaler \& Shefrin, 1981; Thaler, 1999; Finnie \& Davies, 2011). There is also the distinct possibility that the labels attached to each separate savings vehicle serve a signaling function to savers, normalizing certain kinds or reasons for saving over others.

There may be a wide range of goals or motivations for households to save and build assets but not all of these are supported through tax expenditures and public policy. Saving and assets for retirement, homeownership, disability and education are. Some households with goals outside of these norms may be disadvantaged in trying to reach a comparable level of saving and assets without the benefit of tax assistance. It is also unclear how much the labeling of these instruments may be influencing the stated preferences and motivations of households. I cannot know, for example, whether participants in my focus groups consistently listed "retirement" as a reason to save because they genuinely see their financial security in old age as a pressing concern or, alternatively, whether it is because they have absorbed so much advertising and marketing from RRSP-providers that they have come to believe retirement is a key reason to save. 


\subsubsection{A set of instruments with policy advantages}

Each of the goals that are highlighted by these tax-preferred instruments could be supported through policy instruments outside of personal savings. Individual savings instruments contrast with, for example, social insurance systems, universal income entitlements or public provision of goods and services. Social insurance systems pool social risk by requiring that everyone pay into the pool but only draw benefits in times of needs. Universal income entitlements provide benefits on the basis of citizenship and are insensitive to different capacities to pay, different levels of exposure to risk or different capacities to manage risk. Public delivery of goods and services rely on revenue from taxation and aims to deliver the goods or services to eligible populations with ongoing efficiency struggles to avoid deadweight losses and free-rider problems.

Compared to other choices of policy instrument, individual savings instruments have certain advantages. In individual savings programs, there are no free-rider problems since public benefits (in either the form of tax benefits or direct grants) can only be triggered by some contribution on the part of the individual saver. Individual savings instruments also respond to individual differences in risk and capacity to pay - whether they do so progressively or regressively is a separate matter of policy design.

Individual savings instruments also avoid the problem of opaqueness in social insurance systems. Insurance premiums are set in response to actuarial calculations that are not well understood or necessarily accepted by contributors. Similarly, premiums paid into the system are not directly related to benefits received, if benefits are ever claimed at all. 
In the case of savings instruments, individual savers have greater control over their own payments and the direct return (for example as a tax deduction, tax refund, or as a matching grant) is far more transparent to the saver. Even in the case of housing equity, homeowners can monitor the value of their property and any mortgage debt (for example through regular statements from their lender and local real estate information) and derive some estimate of the value of their equity that is directly related to their actions to reduce their mortgage or invest in the value of the home.

In short, there are many practical and political advantages to pursuing policy goals through individual savings instruments notwithstanding the problems in Canada's current tax-preferred savings accounts.

\subsection{From a "set" to a "system" of welfare}

My second research question in this thesis was whether, beyond forming a set of similar instruments, tax-preferred and account-based savings instruments form a system for delivering welfare. As a corollary, I asked whether the system is generally progressive or regressive.

In his 2007 book The Welfare State Nobody Knows, Howard argued that a complete snapshot of the American welfare state must include the large number of expensive tax expenditures that tend to be ignored by mainstream welfare policy analysis. Worse, argued Howard, these same "tax expenditures negate a lot of the redistribution accomplished by traditional anti-poverty programs" (p.206) and, he therefore concluded, 
"a large and growing portion of the American welfare state does little to reduce poverty or narrow the gap between rich and poor" (p.205).

Sherraden (2005) echoed this sentiment when looking at the more narrow set of U.S. tax expenditures on individual or household savings, and observed that "public policies for asset-building are making the comfortable more comfortable, the rich richer and leaving the poor as they are." Could these authors have as easily made the same observations about Canada?

The evidence thus far supports the claim that tax-preferred savings instruments should be examined as a set. But is this tantamount to finding a hidden welfare system? Neither Howard nor Sherraden offer definitions of their uses of the terms 'hidden' or 'welfare state'.

As acknowledged earlier in this thesis and supported by the findings in Chapter 9, these individual instruments are not unknown to Canadian consumers as programs to facilitate household saving. Not all of them are familiar with the features of each instrument, but Canadian consumers are not unaware of the existence of these programs. Similarly, the academic literature has tended to focus on point-in-time examinations of one instrument at a time, relative to some savings goal (for example, retirement savings or education savings). There are three important elements that remain largely concealed or at least unexamined: 1) the relationship between these instruments; 2) their incremental expansion over time; and, 3) the degree to which wealthier Canadians have come to rely 
on them to capture and protect their assets, while poorer Canadians draw far less benefit even when they make use of the same system. This is the sense in which I argue that this set of instruments is 'hidden'. It is a perspective on transparency that is similar to earlier analyses of transfers to individuals that noted the important, cumulative, but largely unexamined, impacts of incremental changes to social policy in Canada (Battle, 1998).

Here I turn my attention to clarifying a definition of 'welfare system'. Esping-Andersen $(1990 ; 2006)$ proposes three criteria for the definition of a welfare state:

1. First, it involves some expenditure of the state. Esping-Andersen does not discuss tax expenditures in his work but, as discussed at length in Chapter 3, it is clear that expenditures in the form of tax exemptions or deductions, as well as direct savings grants (such as the Canada Education Savings Grant) are forms of public spending. The foregone tax revenues reduce the available pool of resources to which the state has access to fund other goods and services. Those revenue losses must be made up in some way and while only a subset of taxpayers will claim and benefit from the tax expenditure, all taxpayers bear the cost through reduced public spending or increased taxation. ${ }^{288}$

${ }^{288}$ If the costs result in reduced spending on other redistributive programs then it is likely that the costs are borne largely by those with lower and modest incomes who rely most on these programs. If instead the costs result in an increase to tax rates, the incidence will depend in part on whether the increases are to personal or corporate income taxes or consumption taxes. If there is a perfect association between household income and household wealth and, the progressive income tax rates rise (by household income or wealth) at the same rate as the total benefits of the tax-preferred instruments, then the 
2. Second, Esping-Andersen argues that all welfare state programs have some residual or institutional quality, that is they are targeted to those in need after market forces have been considered or are institutionalized and available to all. The exact balance between targeted and universal qualities will vary from state to state, he argues and therefore welfare policy analysis must look beyond expenditures to examine the substance of the policies in question. Again, the taxpreferred instruments offer a thin universality in that they are, notionally, available to all Canadian households. A closer inspection of the history and current features of each reveals that they have a quasi-residual quality in almost exactly an inverse pattern compared to more traditional welfare policies such as income support. In Esping-Andersen's typical use of the term, a residual welfare state is one in which citizens who are unable to secure their well-being through competitive markets are able to turn to public programs as a last (or near to last)

redistribution will be simply within the group of upper income and wealth households. They will receive a greater share of the benefits from the system but also pay a greater share of the costs. I suspect this may not be the case for at least two reasons. First, is that in many of the instruments reviewed in this thesis, there are benefits that are not or cannot be recovered through the tax system. For example, RRSP deferrals appear to lead to a reduction of total lifetime taxation for the many households who see a reduction in their marginal tax rates during retirement. Second, household wealth allocations into the tax-preferred instruments rise so sharply for the top $60^{\text {th }}$ to roughly $95^{\text {th }}$ percentile that it would have to be demonstrated that this same subset of households pays a comparably larger share of total taxation in Canada. In fact studies of taxation suggest that the greatest single share of income taxes are paid by the top 1\% of income earners (Statistics Canada, 2013) - and they seem to be outside of the group who derive the greatest benefit to their household wealth portfolios. Source: Statistics Canada (2013). The Daily, January 28, available online at: http://www.statcan.gc.ca/daily-quotidien/130128/dq130128aeng.htm 
resort. In the case of the tax-preferred savings instruments, they first demand engagement with competitive markets and then provide a residual public benefit to top-up or complement (by sheltering investment market earnings) the effects of the market. In both the residual and institutional welfare regimes, EspingAndersen argues that the state "encourages the market, either passively by guaranteeing only a minimum, or actively by subsidizing private welfare schemes" (p.167). In the case of the tax-preferred savings instruments examined in this thesis, it seems clear that they provide quite generous direct subsidies to private households saving and building assets for their own welfare. ${ }^{289}$

3. Third, according to Esping-Andersen, each welfare state gives expression to a conception of social citizenship, conferring (or denying), enhancing (or moderating) certain social roles, rights and particularly (in his framework) relationship with labour markets. As the discussion at section 10.2 suggests, the set of instruments does seem to belie certain assumptions about acceptable reasons for saving and even the social roles and relationships of Canadians with different degrees of wealth. The histories of each instrument suggest that poorer Canadians have not been part of the constituencies of the policy and are not presumed to have the same entitlement to the benefits of the instrument as

\footnotetext{
${ }^{289}$ As noted earlier, the total economic costs and benefits from the system of taxpreferred accounts will depend on a wide range of behavioral responses from governments, markets and private households. Estimating these is outside of the scope of this thesis. The immediate benefits are still largely those going to wealthier households with larger shares of tax-preferred assets in their portfolios.
} 
wealthier Canadians. The current designs of each instrument confer greater social rights, in practice, on Canadians with greater means. Finally, Esping-Andersen is concerned with the degree to which welfare programs in practice decommodify workers and enable them to secure their well-being outside of paid labour. In the case of tax-preferred savings instruments, it seems clear that there is a decommodifying effect for those able to save enough (with tax assistance) to generate capital income that reduces their reliance on labour income and in retirement when they plan to withdraw from labour income and live off their accumulated savings.

Daniels and Trebilcock (2005) have also noted that systems within welfare states may have different, sometimes even competing policy goals. These include goals to:

- promote economic stability,

- regulate public morality, promoting certain socially-preferred activities and discouraging others;

- build social solidarity, maintaining a sense of shared identity and willingness to engage in collective action;

- insure individual risk, protecting citizens from risks they cannot manage alone and for which market solutions are inadequate;

- provide equitable distribution of resources, reducing the risks faced by the most destitute citizens. 
As discussed in Chapters 1 and 2, there is good theoretical and growing empirical support for the importance of savings and assets in individual and household well-being not just as stored income for later use. Tax-preferred savings instruments are currently used to promote a range of micro-economic policy goals, from retirement security to participation in higher education. By prioritizing certain forms of saving and assets over others - the normative effect of the instruments discussed above - these instruments fulfill the welfare goal of regulating public morality. The labels attached to each account type communicate something about the importance of saving and about which goals or motivations will be publicly sanctioned and subsidized.

The access to the public subsidy-in the form of generous tax treatment or direct spending-also enables households to self-insure against risk. The savings and assets in these accounts can enable households to prevent poverty in retirement, mitigate the effects of disability or manage risks from changing demands for education and skills in labour markets. The evidence in Chapter 8 suggests that the very same households who are best able to manage these risks with their own resources are the ones who are sheltering more than half of their household portfolios in tax-preferred savings instruments.

Finally, I note that tax-preferred savings instruments have frequently been used as instruments for broad goals of fostering macroeconomic growth. For example, compulsory savings were expected to generate sufficient federal revenues to finance an unprecedented war effort. In the 1970's, RRSP investment rules were changes to 
promote investment in Canadian firms over international competitors. Similarly, during the recessions of the 1970's and 1990's the federal government saw saving for homeownership as a potential stimulus measure. It is not clear how these measures influenced the improvement in the well-being of those households doing the saving. My retrospective review of the compulsory savings suggests that higher income households who paid any compulsory tax (after savings credits) were likely to have benefitted most from post-war windfalls of unexpected refunds. The evidence on the RHOSP similarly suggests that the stimulus effect rose with marginal tax rate. The evidence on the Homebuyer's Plan suggests that many program users are not keeping up with their repayment schedules and are incurring additional tax liability as a result.

As discussed in Chapter 2, when macroeconomic concerns are primary in discourse on household savings and asset accumulation, the policy choices may be less sensitive to differences in household capability. If the policy goal is to generate a large pool of domestic investment capital, then the most efficient policy measure may target an incentive at a group of taxpayers most able to generate that capital in a short period of time - upper-middle and upper income and wealth taxpayers. The effects on the distribution of net worth and the effects of this incentive on household wellbeing will be of less concern. Nevertheless, this constitutes a form of welfare system even if it is at odds with microeconomic policy goals.

In short, the set of tax-preferred savings instruments of interest to this thesis do meet Esping-Andersen's criteria for inclusion in welfare state analysis. This does not, to my 
mind, imply that they from a welfare state, separate and apart from the more traditional programs included in welfare policy analysis (namely income security programs delivered through social insurance and means-tested or universal transfer programs). Instead, I suggest the set of instruments form a system within Canada's liberal welfare state (or regime to adopt Esping-Andersen's terminology). Howard (2007) is absolutely correct in arguing that tax expenditures too rarely, if ever, receive the attention in welfare analysis that they deserve. Tax expenditures, whether for household saving or otherwise, do deserve far greater research attention and inclusion in welfare policy theory and analysis. But, just as Esping-Andersen (1990), argues that different welfare regimes have systems for addressing pension income, health care and income insurance, I argue that different welfare regimes might also have systems for addressing household savings and assets.

Canada's current set of tax-preferred savings instruments is broadly consistent with its categorization, in Esping-Andersen's framework, as a liberal welfare state in that wealthier citizens derive more of their welfare from the market (for example private RRSP savings) and poorer citizens are left more dependent on residual benefits (for example income-tested seniors' benefits). But it may also present certain challenges to the Esping-Andersen typology.

First, as described above, the tax-preferred savings instrument have a superficial institutional quality in that they are, notionally, available to anyone in Canada who is willing to open a registered account with a financial institution and make deposits (or 
take out a mortgage and purchase a home). Institutional or universal systems are not generally associated with liberal regimes in the Esping-Andersen approach.

Second, the real value of the state contributions (in the form of tax benefits and direct savings grants) is actually larger for wealthy savers - the exact opposite of what would normally be expected in residual programs of a liberal welfare state.

Third, Esping-Andersen calls for attention to the decommodifying effects of welfare state programs, that is, the degree to which they enable citizens to opt out of the paid labour force while maintaining some acceptable standard of well-being (Esping-Andersen, 1990; 2006). Here the likely effects are somewhat more complicated. Among wealthier households, the savings instruments almost certainly enable them to build greater assets than they would if those assets were subject to annual taxation. These assets in turn generate positive effects on their well-being, including offering these households greater security in times of withdrawal from the paid labour market (for example saving for retirement through RRSPs or TFSAs or withdrawing tax-free RRSP funds to support a return to education or training).

For households with low or very modest resources, means-tests and claw-backs in income support programs mean that they must choose between decommodification, relying on residual welfare programs, and saving. Those who enter the decommodifying but highly stigmatizing income support programs then must forego the positive benefits of accumulating assets (see Chapter 1). 
One female participant in a focus group I facilitated as part of my thesis research spoke passionately about how she had saved diligently, slowly and painstakingly for years to be able to send her son to university. ${ }^{290}$ When her son's long-term disability later required medical treatment not covered by public health insurance, she applied for the meanstested provincial health benefits program. She was denied because her household assets were too high and was advised to cash-in her education savings for her son—-forfeiting any capital she had accumulated over the years and spending it as income and choosing between her hope for her son's long-term education and his immediate need for extended health services. This case is illustrative of many others in which low-income savers have faced conflicts between conforming to the social norm of saving for sanctioned goals and using the traditional, residual welfare systems that demand income and asset poverty before public benefits will be given. In short, low-income and low-wealth savers are stuck in a losing position between two competing welfare systems, neither of which has truly been designed with their well-being mind.

My final corollary question was whether this welfare system of tax-preferred savings instruments is progressive or regressive. Esping-Anderson $(1990,2006)$ has noted that all welfare systems involve some degree of redistribution by gathering resources through taxation and spending them elsewhere through public welfare policies. This redistribution does not, however, have to be progressive — taking greater resources from

${ }^{290}$ It was not clear from the participant's statements whether these savings were held in an RESP and I did not press her to divulge personal information in a group setting. 
those who have more wealth from markets and redistributing it, through public policy, to those who have less (Esping-Andersen \& Myles, 2011).

The retrospective analysis in Chapters 4 through 7 highlighted a number ways in which the process for developing each instrument and the final design of the instruments themselves was heavily skewed in favour of Canadians with more rather than less wealth. This does not necessarily negate their potential value to other users who were not already represented by the promoting stakeholder, but it does shed light on the imagined constituency when each instrument was first created. The exact policy designs in each case appear to have been crafted largely by officials in the federal public service who would all be Canadians with better than average incomes and better than average longterm savings (in the form of the Public Service Superannuation Plan). The leading advocates for each of the registered instruments were also themselves people likely to have above average incomes and capital (including social capital): doctors, dentists, senior professionals in accounting, university professors, think-tank researchers and heads of non-governmental organizations. The new instruments were not created it seems, by or for the super wealthy in Canada, but by and for those of above average income and wealth.

The instruments were not designed with the participation of lower income and lower wealth Canadians or, until very recently, much attention to their concerns and preferences. I do not negate the value of more recent efforts to accelerate savings grants and bond for lower and modest income savers, or to exempt TFSA and RESP savings 
from means-tests for some income support programs. These are incremental improvements but, on balance, the system remains heavily dominated by the interests of higher wealth households.

My conclusion that the system is heavily skewed is reinforced by the analysis of the survey data in Chapter 8. I find that higher wealth households are more likely have taxpreferred savings instruments and likely to have more valuable tax-preferred savings instruments, compared to households with lower or middle levels of net worth. I also find that households in the top $40 \%$ of the distribution have more than half of their total assets, using the most flexible and inclusive definition of marketable assets under direct control of a household, in tax-preferred instruments. Furthermore, the top quintile by net worth has the largest share, of any quintile, of their assets in these tax-preferred instruments.

Much of this difference might be explained by the fact that the higher wealth households are more likely to also have higher incomes, and therefore both greater capacity to save and higher tax liabilities. Instruments, such as those currently in place in Canada, that deliver more benefit for larger savings by those with higher marginal tax rates, will necessarily benefit these wealthier Canadians. Yet, I believe the situation is more complex. First, I note that there are, for each tax-preferred instrument, small subgroups of low wealth households who have surprising large savings in these instruments. Second, from the retrospective analysis, I believe there are factors outside of tax incentives that matter to the observed distribution of tax-preferred assets. 
The evidence from a preliminary set of focus groups conducted with poor and non-poor participants, ${ }^{291}$ suggests that these non-financial factors identified in the retrospective analysis - outsourcing of delivery to private sector financial institutions, selection of certain sanctioned savings goals over others and fungibility of assets - may be important variables for future research. The focus group participants at different levels of household resources showed very different patterns in their perceptions of the existing set of tax-preferred savings instruments.

For the middle or upper income groups, the tax-preferred savings instruments were strongly associated with the act of saving, were familiar and, while seen as flawed and complex, were recognized as forms of government assistance for their own efforts to save and build assets. For the lower income groups, the same savings instruments were seen as foreign and inaccessible. The barriers cited by these participants had nothing to do with insufficient tax incentives. Neither did the discussions of the lower income focus group participants suggest that they were a) less interested in building assets or b) less capable of making financial choices and decisions or less able to demonstrate a detailed understanding of the public welfare state programs which they viewed as accessible to them. I acknowledge again that these qualitative findings are directional and not conclusive. They require far more study than is possible in this thesis but this

${ }^{291}$ Note that in these focus groups, household resources were measured in terms of proximity to the Low Income Cut Off rather than household wealth, savings or assets. This is discussed in Chapter 9. 
preliminary research suggests that further incremental fiddling with tax incentives is unlikely to be enough to change the current system from a regressive into a progressive welfare system.

The research for this thesis found no explicit official policy statement that lower and modest income or wealth Canadians should not or must not use RRSPs, RESPs, RDSPs, TFSAs or buy homes. In fact, in the case of the RESP, the federal government is actively engaged in promoting take-up among low-income families with young children. In the case of the TFSA, the government took the modest but important step of excluding savings from the income test in the Guaranteed Income Supplement for low-income seniors. Finally, in the case of the RDSP and RESP, the federal government has introduced accelerated savings grants and bonds for lower income households. If anything, these examples suggest that there is policy in some quarters of the federal government to ensure that poorer Canadians are not excluded from a system of taxpreferred savings and opportunities to acquire assets.

However, from a capabilities perspective (discussed in Chapter 2), there is a gap between the assertion that poorer Canadians could make use of one of more tax-preferred savings instruments and a closer examination of whether they can or $d o$ in practice. As Howard (2007) noted on similar American instruments, "while all these programs are theoretically available to all, in practice they are $[\ldots]$ a thin but politically attractive version of universalism" (p.206). In sum, the cohesive set of savings instruments do not work as well for poorer Canadians as for richer ones, even among the non-trivial numbers of 
poorer households and individuals trying to make use of them. If Canada's welfare system to redistribute income saw those households with upper-middle and high incomes receive more than half of their total income from this system, there would be no question that something was terribly wrong.

\subsection{Does having a hidden welfare system matter?}

In the section above, I have briefly argued that tax-preferred savings instruments ought to be included in welfare regime analysis in recognition of the fact that they form a system for delivering benefits to citizens. I have also noted at least three ways in which including the tax-preferred instruments in welfare analysis may raise new questions about the theory and typologies in the work of Esping-Andersen and others in his tradition. But apart from new questions or puzzles for academic theory, are there real world implications of attention to this hidden welfare system of tax-preferred savings? I suggest there are at least two: first, better data and more research, and second, a set of principles for future policy reform.

\subsubsection{More and better data for research}

First, and perhaps least surprisingly, I suggest that Canada needs more and better data and research on the full set of instruments discussed in this thesis and on household savings more generally. At the time of writing, Statistics Canada has conducted but not yet released another cross-sectional national survey of household finances in a 2012 followup to the 1999 and 2005 Surveys of Financial Security. When the micro-data becomes 
available to researchers, it may offer an opportunity to conduct evaluations of policyimpact using a pre-post design for the 2005 changes to RESPs as well as the creation of the TFSA and RDSP. ${ }^{292}$ In other countries, including the United States and the United Kingdom, household wealth data is collected at regular intervals and in panel, rather than cross-sectional data sets. Canada's more sporadic and cross-sectional data collection severely limits the ability of researchers to look, at a household level, at changing trends in savings behavior and asset-holding or to examine responses to policy. Other sources of data, as discussed in Chapter six, such as the annual National Accounts dataset or proprietary private sector surveys, are inadequate either because of the level of detail or the population covered. Questions regarding the take-up, use, value to households and distribution of the various tax-preferred policy instruments can only be addressed using national surveys of households. While estimating individual and household assets, debts and net worth is difficult to do, particularly compared to estimating annual income, these are critically important to understanding well-being and inclusion of Canadian families and individuals. Canada has already invested substantial time and expertise in developing a methodology and questionnaire in the Survey of Financial Security. Although the survey is imperfect, its chief defect is a lack of political will to ensure it is fielded regularly and with sufficient samples to produce useful data at regular intervals.

${ }^{292}$ For example, it may be possible to measure policy effects on total household assets, total net worth and portfolio asset shares from policy measures by examining variables at a point prior to a policy change and then afterwards. 
The research and writing of this thesis also revealed how little academic research in Canada is conducted on questions of wealth inequality, households savings and policy instruments to promote household savings and wealth. A review of the literature found a small number of Canadian researchers who have published on these topics. In the academic community, the trend has been generally to conduct econometric studies of aggregate savings and wealth without attention to the components or distribution of these, or conversely, to conduct studies or evaluations of specific tax-preferred instruments in isolation without attention to the existence of the other related instruments in the set described in this study. Within both of these communities, there is even less attention to the savings and assets of poorer Canadians, in contrast to the volume and breadth of Canadian research on income. There must certainly be a relationship between the supply of data on wealth in Canada and the supply of research on this topic but it is unclear if an increase in demand for data from researchers would, or has ever, lead to an increase in data supply.

The quantitative data on household wealth should also be supplemented through efforts to better understand the perspectives and preferences of households at different levels of resources. Further surveys on knowledge, attitudes and preferences as well as qualitative methods including focus groups and depth interviews might help to enhance our understanding of how households make decisions on saving in the presence of incentives and constraints from public policy. Finally, behavioral experiments, particularly those that include participants from populations targeted by policy instruments (for example, parents with children) could be important for testing responses to policy change while 
controlling for the large number of other factors that could be influencing the observed savings or wealth outcome.

\subsubsection{Policy principles and options for reform}

As noted throughout this thesis, governments may have both microeconomic and macroeconomic rationales for encouraging their citizens to save and build personal assets. In macroeconomic terms, the primary concern is the efficient and effective way to stimulate a sector, direct flows of capital or incentivize an aggregate amount of saving. For macroeconomic goals, the distribution of saving within the population may be of far less concern than reaching some aggregate target level of capital. But in microeconomic terms, particularly in looking at the distribution of overall well-being and inclusion, with attention to the unique effects of assets separate from income flows, the different impacts of policies on households with different levels of capability should be of central importance.

As Bradford (2000) notes "any effort to analyze the effect of U.S. federal tax rules on the accumulation of wealth and the stock of capital used in production confronts the fact that there is, as yet, no consistent policy towards saving" (p.141). He might just as well have been writing about Canada. Absent any such consistent policy towards saving are there some principles or alternative policy options that should be considered? Here, I hasten to add that "should" implies that a policy-maker first has an interest in promoting savings and asset accumulation and second is in general agreement with the concerns regarding the distributional effects of the current system that have been raised in this thesis. 
I suggest that one principle ought to be that savers should receive preferred treatment over non-savers in any policy framework to promote savings and asset accumulation. This much seems fairly non-controversial in proposing that people who comply with a desired policy goal should receive the benefit while those who do not comply should not be entitled to the same benefit.

In the current system, for each of the given tax-preferred savings instruments, there are already non-trivial subgroups of low net worth Canadians who have opted in, even if they are saving small amounts. However, I further argue that savers with lower resources should also receive proportionally greater benefits compared to savers with larger resources. This demands that smaller savers with less money to save and fewer other assets should get a larger share of the public expenditure—or at least at an accelerated rate - compared to higher income and higher net worth households.

It may be difficult, practically speaking, to adjust a public benefit in response to both the income (and deposits out of said income) at a point in time and the accumulated value of an asset. However it is not impossible or completely foreign even in the current tax system. For example, the Canada Revenue Agency is able to track annual and lifetime deposits into RRSPs to calculate available contribution room from one year to the next. It would be a modest change to use the same information to calculate, not just available contribution room, but also a progressive rate of savings incentive. Furthermore, RRSP annual contribution limits could be reduced or at least do not have to increase each year. 
Similarly, tax-exemptions and matching savings grants could be restricted to household with incomes below a certain threshold. The cancelled Ontario Homeownership Savings Plan was available only for taxpayers with incomes below a certain level and phased out benefits as account holders approached their lifetime maximum. There are trade-offs between simplicity and responsiveness in policy design but these are not impossible to overcome.

A second suggestion is that public policy should try to reduce inequalities in capability to save and build assets, or at the very least, policy should not increase these inequalities in capability. The principle above points towards restructuring incentives so that they increase inversely with income and with accumulated wealth. This likely implies a system of conferring benefits outside of tax-deductions and tax-exemptions but could, for example, be delivered through a more progressive system of matching savings grants or a new system of refundable tax credits. But this second principle of considering inequalities in capability also argues for a system of savings instruments that is outside of competitive and mainstream financial services. Tying the publicly-financed incentive inversely to income and/or wealth would only address one form of inequality in capability—disposable income out of which to save. To address the non-financial barriers, particular the barriers of awareness, accessibility and efficacy in interacting with mainstream financial markets and service providers, public policymakers should give greater consideration to instruments that allow for direct and public delivery of savings instruments. 
One very modest way to implement this approach would be through automatic defaults that open a no-frills savings account for a member of a target group and deposit the income-tested savings incentives to which he or she is entitled. This automatic opt-in approach has been tried repeatedly in workplace pension schemes and is widely viewed as a powerful option in choice architecture by behavioral economists (Thaler \& Sunstein, 2008). It is also an approach that was tried in the United Kingdom in the implementation of the universal Child Trust Funds.

Under the Trust Fund policy, eligible families received a voucher that could be redeemed at any participating British financial institution. In cases where the voucher was not redeemed within a prescribed time limit, a default basic Child Trust Fund Account was opened on behalf of the beneficiary child with a private sector provider, based on a rotating roster (HM Treasury, 2009). Families with these default accounts continued to receive public benefits and investment growth, were provided regular updates on the status of their accounts and were allowed to take over direct control of the account (including transferring the balance to a preferred provider or account type) at any time. An interim evaluation of the Child Trust Fund concluded that the automatic enrolment option was used by as many as one in five of all eligible children, with higher rates of default (government-opened) accounts for children in low and modest income families, children of lone-parents, children whose parents had lower levels of formal education and children in families without other forms of saving (Kempson, Finnie and Davies, 2011). This approach to automated opt-in mechanisms has already been called for in the case of 
RESPs (SEDI, 2010; Schwartz \& Ben-Ishai, 2012) and RRSPs but could equally be applied across the existing tax-preferred savings instruments.

One potential downside of this approach is that it would likely result in a larger proportion of low-income and low-asset households holding default, basic accounts that would passively accumulate only some modest transfer or grant. Households with larger incomes and more savings would continue to reap the majority of the benefits from actively engaging with their accounts, making deposits and seeking returns from investment markets. Perhaps having a government opened, private-sector held, small account is preferable to having no savings at all and no stake in an otherwise hidden savings-based welfare system. But there is a more potentially impactful policy option not just direct enrolment by government, but direct delivery by government.

At the start of Chapter 4, I noted that it would be difficult to imagine today that a Canadian government might require, by law, that its citizens save some portion of their incomes. It is also unimaginable that a Canadian government might deliver some of the same deposit-taking financial services as private sector banks, credit unions and other financial institutions. And yet, Canada has had policies of universal compulsory savings held on deposit by the federal government and universal access to (government-held) savings accounts through the Postal Savings Office ${ }^{293}$ and Dominion Annuities. In

${ }^{293}$ Postal Savings were in place prior to confederation. Deposits were accepted at postal stations and credited to individual interest bearing savings accounts with regional and 
design and implementation, the government made several critical errors on the compulsory savings scheme, making it refundable for all rather than just to lower-income Canadians and failing to take account of the other ways that poorer and modest income Canadians were likely to save. In response to the political backlash, the government withdrew the policy less than two years after it had been announced. In the post-war period, the government also cancelled the Postal Savings program on the basis that it was no longer justifiable given the expansion of private sector service providers. Another example, to be explored in future research, was the system of Net Income Stabilization Accounts (NISA), available to Canadian farmers until the late 1990's as governmentmonitored and managed savings accounts. Canadian farmers were expected to make deposits into their personal NISA out of annual net profits, deposits that were in turn matched by the federal government, and were expected to make withdrawals from the same account to offset losses to income in other years. The program was modified and later replaced by the Canadian Agricultural Income Stabilization program that pays benefits only when participating farmers report an eligible loss of income. These examples do not argue for the view that government cannot and should not be a direct provider of progressive savings instruments. Rather they argue for future policy informed by past mistakes to deliver something better.

The modest changes to accelerate incentives in RESPs and RDSPs to poorer savers combined with investments in programs to promote outreach and awareness are not

later the national postal service. As private sector financial services expanded, the federal government reduced and eventually cancelled the program in the late 1950's. 
sufficient to reduce the inequalities that are built in, as part of the fundamental and largely unquestioned designs, of Canada's system tax-preferred savings. Perhaps a system of direct delivery and of progressive benefits might overcome these. In Chapter 9, I found that the participants in with lower and modest income Canadians saw government in the role of direct provider of savings incentives and felt excluded from the mainstream financial service providers to whom governments have outsourced the administration of tax-preferred savings. It is not clear that the administrative cost savings from the outsourcing of delivery are large enough to warrant, in economic terms, the exclusion of the very same Canadians who could most benefit from direct assistance to save and accumulate assets. Bringing the direct delivery and administration of policypreferred (since the incentive need not necessarily be delivered through the tax-system) back into government could very well be a more efficient way of reaching desired savings goals, particularly if the costs of the system were reduced by severely constraining or eliminating the tax expenditures in the current system. This is not so radical an approach. Since Ambachtsheer (2009) proposed a supplementary Canada Pension Plan to enhance the retirement savings of Canadians with limited or no workplace pensions, the idea has now gained traction with some financial institutions and even leading neo-conservative Canadian economists (McCaughey, 2013; Wilson \& Mintz, 2013).

A supplementary CPP would demonstrate that it is possible for governments to play an enhanced and direct role in the delivery of at least one form of household saving. Could a consensus on a role for government in pension savings be expanded to include other 
types of household savings? Other examples from international systems in New Zealand and Singapore ${ }^{294}$ suggest that more direct and directive government delivery systems can be applied to other savings goals such as housing. It remains an open question whether and how such a direct delivery system could be applied for more short-term savings, particularly the types of goals articulated by lower and modest income Canadians but not currently recognized by public policy.

As a very early and achievable policy goal, governments in Canada should aim to reduce, and wherever possible eliminate, barriers to saving in the form of claw-backs and meanstests in more traditional residual welfare programs. The available evidence strongly suggests that their dissaving effects and administrative costs far outweigh any reductions in welfare caseloads (Robson, 2008; NCW, 2010).

A final principle to be considered is that particular attention is needed on housing assets. As I found in Chapter 8, net housing equity is the single largest tax-preferred asset in the portfolios of Canadian households. Among the upper-middle and higher wealth households, owner-occupied housing is responsible for well-over one third of the portfolio shares of households and receives a full exemption under federal and provincial personal income taxes. In fact much of the inequality (by net worth) in the household portfolio shares held in tax-preferred instruments can be explained by housing. As noted in Chapter 8, for wealthier households, increasing housing prices mean an increase in

${ }^{294}$ For a good overview of these systems, see Sherraden (2005). 
their net worth. For poorer households, increasing housing prices seem to be more likely to mean an increase in their mortgage debts.

Housing prices in Canada may not rise indefinitely. When the market correction eventually takes place, some households in Canada will be at risk of seeing a substantial decline in their household net worth. Yet, studies continue to find that, over the medium and longer-term, Canadian homeowners grow richer than Canadian renters, despite cyclical market trends (Engeland, Lewis \& Shillington, 2006).

To make the current hidden welfare system of tax-preferred instruments more progressive, governments have several housing-related options. First, for some households, accelerating a transition from renting to ownership may prove beneficial to their net worth and overall wellbeing. The status quo only offers Canadians an opportunity to borrow from their own RRSPs to finance a downpayment-it is a policy that presumes beneficiaries already have money, just in the wrong instrument. The RHOSP seemed to have some impact in this regard but was most successful among wealthier Canadians. The Ontario Homeownership Savings Plan may have been a more progressive option given that benefits were gradually eliminated at a certain income and savings level.

Second, housing markets in Canada are currently structured around full ownership or rental options. However, there are many other options that might meet a wider range of housing and welfare needs, including shared equity options, life-lease, affordable 
cooperative housing and more. More flexible options might allow more Canadians to build assets and maintain affordable housing. Competitive housing markets do not appear able, without government policy intervention, to create and sustain these more housing options.

Finally, the full exclusion of imputed rent and capital gains on a principal residence bears reconsideration. Although Canada has never taxed housing as a part of personal income taxes, I am not certain this exclusion is justified given the evidence of the role of housing in household welfare and economic inequalities. Taxation on the benefits accrued from ownership could be implemented in a progressive way, even applying only to households with higher marginal tax rates or very large housing assets.

\subsection{Summary}

There are three key conclusions in the thesis. First, the collection of tax-preferred savings instruments (RRSPs, RESPs, TFSAs, home equity and RDSPs as well as the former compulsory savings and RHOSPs) have so many features in common and share so much of their policy design and heritage that they merit future consideration as a cohesive set of policy instruments. The second key finding is that there is reason to view this set of instruments as a welfare system and to question their consistency with Canada's overall liberal welfare regime. While it is more common in the analysis of welfare regimes and policy to question how much of a household's income is derived from government transfers, the results of this thesis suggest that we should also question how much of a household's savings and assets are benefitting from costly tax incentives 
and shelters. Finally, a detailed examination of the history, features and public perceptions of these instruments is reveals that they are regressive, by design. While a cursory and largely intuitive review of these instruments suggests that they are regressive and confer more benefit on wealthier Canadians, this detailed examination suggests that the degree of the inequality is more pronounced and that reasons for the inequality in the policy are more complex.

From these key findings, I suggest two implications for future research and policy. The first is a call for more and better Canadian data and research on household savings and wealth. The second implication is that other and likely much better methods for delivering incentives for household saving are available. They include more progressive methods of calculating incentives, outside of tax deductions and exemptions, and a greater role for government as a direct provider of financial services — both in administering savings accounts but also in removing asset-tests from the income support programs it provides. 


\section{Appendix A: Wealth data in Canada}

This appendix provides greater technical detail on the survey data used in Chapter 8 . Technical issues with the Canadian Survey of Financial Capability are also discussed to emphasize why this dataset was ultimately rejected for the study.

\section{Data selection}

Analysis of household wealth in this thesis was done using the master file for the Survey of Financial Security (SFS) for 1999 and 2005. The SFS is a national cross-sectional survey conducted by Statistics Canada to measure the assets and debts of Canadians but also included questions regarding household income and selected financial behaviors. The 1999 SFS had been the first effort to measure personal assets and debts in Canada since 1984 when a special version of the Survey of Consumer Finances (SCF) was fielded.

From 1955 to 1984, Statistics Canada collected asset and debt data for families and individuals through the Survey of Consumer Finances on a handful of occasions in 1955, 1970, 1977 and 1984. Over time, the surveys broadened their coverage from non-farm private households to all private households in Canada. Also, the categories of assets covered by these surveys gradually broadened over time. The 1955 survey focused mainly on liquid asset holdings; by 1984 coverage had expanded to include holdings of fixed and longer-term assets but excluded certain assets later included in 1999 and 2005 surveys. These include the contents of the respondent's home, valuables or collectibles and annuities. 
My application for access to pre-1999 data was met with the response that only the public use micro-data file is available for 1984 and, for that reason, the 1984 cannot be compared with the 1999 and 2005 master file. Public use files generally see multiple variables collapsed and potentially identifying information on individuals or households removed from the file. For wealth surveys this can be particularly problematic.

Brzozowski, Gervais, Klein and Suzuki (2009) conducted an analysis of household wealth in Canada using both the master file and the public use data for the SFS and found considerable differences between these two, suggesting that analyses relying on the public use files may underestimate the concentration of wealth at the upper end of the distribution by as much as 5 to $6 \%$. Statistics Canada's own report on the difference between estimates generated using the public use file and master files for just the 2005 SFS data found a difference of just over $2 \%$ in the estimates of median net worth and differences of as much as $20 \%$ in the estimates of various components of net worth (Statistics Canada, 2010).

In addition to the SFS data for 1999 and 2005, I also considered using the 2009 Canadian Survey of Financial Capability (CFSC), a cross-sectional survey by Statistics Canada of individual and household financial behaviors, attitudes, knowledge and resources. While the CFSC did collected basic self-reported data on household assets and debts, it did not go to the same efforts as the SFS to record detailed estimates of the asset-holdings and debts of respondent households. It is not possible, for example, to get an estimate from the CFSC of the value of a principal residence owned by a household separate from the 
dollar value of all tangible assets including other real estate, vehicles and the contents of the home. It is therefore not possible to use CFSC data to replicate the same work completed with the 1999 and 2005 SFS. Nor is it possible to compare and test the significance of differences in the results between SFS and CFSC because of important differences in the data collected in each survey.

Statistics Canada has collected data on a 2012 version of the SFS. Data are not expected to be available until at least December 2013.

A final point on the selection of the data sources concerns the use of microdata versus aggregate estimates of wealth from the National Balance Sheet Accounts. The National Balance Sheet Accounts, part of the National Accounts System for Canada, is a set of estimates of the values of assets, debts and outstanding financial claims for three different sectors of the Canadian economy: governments, incorporated businesses and private households. The estimates, released quarterly, are based on a complex economic model with input variables drawn from multiple survey and administrative sources. While the NBSA data do make it possible to, for example, describe the average net worth for Canadian households ${ }^{295}$, these same data cannot tell us anything about the distribution of assets across the population and has limited information about the specific components of net worth. For studies such as this one where distribution and allocation are both of interest, only micro-economic data are adequate (Bascan, Cope and Ramsay, 2006).

295 As of summer 2012, NBSA data estimated average total net worth in Canada at $\$ 185,800$ per capita (Statistics Canada, 2012, The Daily, June 15). 


\section{General problems when studying wealth with survey data}

In their 1997 discussion paper, Zyblock, Webber Shields and Maser (1997) describe a number of issues in measuring net worth. These can be broadly summarized as follows:

1. Defining wealth

2. Problems of non-response

3. Under-reporting of assets

4. Response burdens.

The next section discusses each of these before turning attention to more specific issues with and limitations of the three surveys used for this study.

\section{Defining wealth}

Wealth in this discussion, as in the literature, is used interchangeably with the term net worth (Zyblock et al, 1997; Frick, Graba \& Sierminska, 2007; Morissette \& Zhang, 2007; Bascand, Cope \& Ramsay, 2006). Both refer to the value of a stock of resources less liabilities, and are seen as distinct from income flows such as employment earnings, social assistance benefits or interest earned from investments. However there is an area of overlap between income and wealth. Income is a flow that can be spent on basic consumption, invested for future consumption or invested for bequests or other motives (Modigliani, 1986; Sherraden, 1993). However, income in excess of consumption is defined as savings, at least in the National Balance of Accounts approach, and therefore crosses over from income flow to resource stock. Similarly, entitlements to future income flows (such as a future pension or expected cash settlement or loan repayment) may constitute a resource stock at the time of measurement. In fact, Sherraden (1993) suggests that it is more accurate to think of income and assets as lying on a continuum 
according to liquidity, where more liquid assets begin to approach the form of income and more fixed forms of income begin to approach the form of assets. Nevertheless, for researchers interested in wealth, stocks of wealth do have to be delineated from flows of income.

To some degree, the divide between income and assets is largely determined by the point in time at which information is gathered by the researcher. In the case of cross-sectional surveys such as the SFS, questions are set to gather information about the flow of income over a set time period (the calendar year prior to the date of collection in the case of the SFS) but questions regarding assets and liabilities are phrased to gather "point in time information.' This raises the question of how to value assets that may be difficult or impossible to realize in the near-term. For example, the value of a private pension may be vastly different if the valuation is done at a pre-retirement point in time, compared to the expected total value of the asset if contributions ceased immediately (the termination value), or compared to a the expected value when the pension member retires (the going concern value). The question of "termination" versus "going concern" methods of valuation for inputs into net worth are limited to a fairly small number of types of assets or liabilities such as expected pensions, certain forms of life insurance and installment debts. In fact, most assets are valued on the termination basis by asking what is the market value if sold or liquidated on the date of the survey and most debts are similarly measured (Statistics Canada, 2010). I use the termination approach in the current study given that it most often used across asset-types and in previous studies. Using a termination basis for valuation also suggests something about the boundary between what 
is classified as income and what is classified as an asset. Having accepted the principle of taking a value based on what could be sold or liquidated in the present, income can be more easily differentiated from assets as the financial resources that could be spent in a given period without changing the present value of assets or incurring new liabilities (Atkinson, 1983). Having determined questions of time and differentiation from income, a researcher is still left with several problems in defining wealth. Decisions must be made about what should be included and, perhaps more importantly, excluded from the components of net worth on both positive and negative sides of the balance sheet.

While the definition of liabilities seems to be relatively straightforward to previous authors (Zyblock et al), the definition of resources or assets proves to be more challenging. In the broadest sense of the term, assets or capital might include human capital assets (such as the stock of education and skills held by an individual), natural capital (such as access to clean air and potable water), social capital (such as the networks of interpersonal relationships with family, friends and neighbors) or cultural capital (the accumulated value of belonging to a defined cultural group) (Sen, 1973; Atkinson, 1983). A similarly broad definition of liabilities might also include, for example, obligations to provide unpaid caregiving to dependent children or elderly parents, obligations to participate in one's community and local organizations, or obligations to offset personal carbon emissions. The difficulty, for researchers and policy-makers, of such far-reaching definitions is that they are difficult to measure, as long as dollar values remain the primary unit of measurement, in any meaningful and precise way and very hard to attribute to individuals or households with different characteristics. For instance, does a 
family of four living near a pulp and paper mill have the same access to clean air as a form of natural capital as a family of four living in a residential neighborhood with lots of greenspace? How should this difference be valued in dollar terms? How much of the difference is already captured, at least by proxy, through calculating the differences in household income that change purchasing power for residential location choice, or through differences in household real property values that would show a difference in market value based on location?

Zyblock and her colleagues, in discussing the framework for the 1999 Survey of Financial Security, suggest that the definition of assets and liabilities be more constrained to include only those elements of a household's current and marketable portfolio. In other words, wealth includes those assets that can be readily converted to a market price, over which households exercise some control and that might influence their decisions about saving out of current income. In this case the reach of assets (and liabilities for that matter) is more constrained to include physical or tangible assets (such as real property, vehicles and personal possessions), business assets (such as equity stakes in a business, including claims on its current profits) and financial assets (such investments and other savings) or liabilities (such as loans and credit debts). This is the approach adopted in the 1999 and 2005 SFS designs, as well as the 2009 CSFC design and therefore also in the current study. However this more constrained definition has merits beyond the realistic approach of taking what data is available. 
First, given that the aim of the overall thesis is to explore the role of selected federal policy instruments in wealth outcomes for Canadians, it may be advantageous to limit the examination of wealth outcomes to those forms of wealth over which governments have greater or more direct influence - namely financial and tangible wealth. Another argument for restricting the definition of wealth to exclude social security entitlements is that the most recent evidence for effects of later social security entitlements on current financial behavior in Canada is not strong. Looking at awareness and expectations of Canada Pension Plan (CPP) benefits, Schellenberg and Ostrovsky (2010) found that nearly one in five Canadians did not include CPP (or its Quebec equivalent) in their retirement income projections and fewer than one in five Canadians expected public pension benefits to be their primary source of income in retirement. In fact, the proportions of working-age adults expecting to rely heavily on CPP is low even among low-skilled and low-wage workers who are most likely to derive the majority of their retirement incomes from public pensions (if current trends continue). Social security wealth is opaque to individual beneficiaries and changeable through mechanisms outside of the control of individual Canadians, such as legislation, federal-provincial agreements and rates of return on CPP investments. It is not a helpful form of wealth to include for the purposes of this study and would not be consistent with Zyblock et al's definition of wealth as the marketable resources over which a household has control and which may influence their current savings behaviors. 


\section{Problems of non-response}

Surveys of all kinds on all topics suffer from difficulties of non-response - that is refusals to take part in the survey or to answer questions in the survey. In the case of surveys on personal finances, it may be the case that non-response is even higher given interpersonal and cultural sensitivities about discussing private details of one's personal financial circumstances. There are two concerns with non-response as it relates to data quality:

1. If refusal to take part is systematic in one or more subgroups of the population who share a characteristic of interest to the study, then the survey will suffer from sampling error and will not be representative of the population as a whole.

2. If respondents do not answer all questions, and particularly if response rates to particular questions are lower, then researchers have lower confidence intervals for portions of the data and are more likely to encounter difficulties with confidentiality and data suppression.

The general consensus among researchers conducting national surveys of wealth seems to be that non-response is principally an issue of getting adequate representation of higher income or higher wealth individuals and households in the survey (Zyblock et al. 1997; Marks, Heady and Wooden, 2005; Bascand, Cope and Ramsay, 2006; Frick, Grabka and Sierminska, 2007). This is certainly one aspect in which the National Balance Sheet Accounts, which do not use a sampling frame but instead take inputs from a wide range of surveys and administrative sources, have a real advantage over household wealth surveys. If no one has to answer new questions about income, assets and debts to derive 
your estimates of household wealth then the risk of non-response bias is small or at least no greater than the weighted average of all the input data sources. For the SFS and CFSC, the sampling frame is complex and multi-stage, using the data from another survey (the Labour Force Survey). Results are weighted based on national Census data to adjust for age, gender, household size, province of residence and income data from administrative sources (Statistics Canada, 2009 and 2010), adjusting the results to be-it is assumed - representative of the Canadian population as a whole, including those households who refused to participate in the survey. Weighting procedures in surveys of wealth presume that the characteristics included in the weights will adequately reflect diversity in the population and lead to representative estimates of assets and debts. In addition to a complex, multi-stage weighting scheme, to try to compensate for expected non-response among higher income and higher wealth household, the SFS oversampled households living in neighbourhoods identified as being "high income". ${ }^{296}$ The sample size for the surveys used is discussed in greater length later in this chapter.

No similar oversampling was done for the Canadian Survey of Financial Capability. However, it is arguable that there is an equal or greater risk of under-representation of households and individuals at the lower end of the income and wealth distribution. Surveys conducted by phone or even in person require that a respondent can be contacted by the statistical agency. In the SFS, survey sample households were contacted in writing

${ }^{296}$ Using Census data, it is possible to identify average household income by postal code tracts. In the 1999 and 2005 samples, the additional higher income sample was drawn from postal code tracts with average household incomes of $\$ 200 \mathrm{~K}$ or more. 
before a member of the Statistics Canada data collection team arrived for an in-person interview. In the CSFC, participants were called by telephone using random digit dialing that includes only landline telephones in private dwellings. For households with insecure housing, more limited literacy in the languages used for communication and individuals or households without a private landline telephone, they are unlikely to be reached by Statistics Canada and are, arguably, also more likely to have low incomes and less wealth. This is even setting aside the exclusion of certain types of households and regions from the SFS and CFSC as in most major Statistics Canada surveys. ${ }^{297}$ It is not clear that, where wealth researchers use strategies to oversample high wealth households, these surveys are immune to problems of non-random non-response among certain subgroups that are more marginalized and vulnerable.

The other type of non-response is partial non-response, in which respondents agree to take part in the survey but decline to answer certain items on a survey questionnaire. Even if the overall survey response rate is acceptable,${ }^{298}$ missing information on specific

${ }^{297}$ The two surveys discussed in this chapter excluded households on reserve lands and Canadian Forces Bases, all households in the three northern territories and any individuals living anywhere other than a private dwelling (for example residents in temporary and shelter housing, residents of institutions and inmates).

${ }^{298}$ It is not clear whether there are firm guidelines for response rates in Statistics Canada surveys. Response rates to phone surveys conducted by the agency have been declining over the last decade to a degree that the agency is now exploring on-line and even incentive methods to boost participation (author's own participation in an interdepartmental meeting, 2010). An advisory report to Statistics Canada on data quality in telephone surveys claimed that response rates to most phone survey items were $70 \%$ or better (Statistics Canada, 2007), however this does not correspond well to the reported overall response rates for the surveys used in this study or to the observed response rates to many questionnaire items in the CFSC discussed later in this chapter.2 
question items can mean that variables in the dataset are of lower quality (Statistics

Canada, 2007) or even un-useable by researchers subject to minimum cell count limits. ${ }^{299}$

The ways to address non-response on individual questionnaire items are through survey design, the order of questions asked, the use of administrative data to replace selfreported information and imputation. Each has its own advantages and challenges.

Changes to the survey design may mean, for example, eliminating questions or entire sections that are expected to be sensitive or uncomfortable for respondents. However this constrains the scope of surveys to the territory believed (based on prior assumption or, less frequently, on cognitive or field testing) to target respondents will be willing to answer rather than the questions that researchers really want to ask. The risk is that researchers will be overly conservative and omit questions or topics that target respondents might be otherwise willing to respond to. Another possibility is to supplement survey data with other sources of data such as qualitative (as in this dissertation) or administrative data.

The order of survey questions can be an important determinant of a respondent's willingness to share information. Having already shared several, less sensitive answers to questions, respondents may feel more relaxed and willing to disclose more personal information. For example, in the design of the Canadian Survey of Financial Capability,

${ }^{299}$ To preserve confidentiality of survey respondents, Statistics Canada suppresses the release of any data where the unweighted number of respondents falls below a threshold thought to otherwise risk making respondents personally identifiable. 
the decision to place income and wealth questions in the middle of the survey was deliberate as a tactic to boost response rates to these questions. ${ }^{300}$ Similarly, a pilot test of a compressed set of CFSC questions found that answers to self-assessment questions, for example, about self-assessed proficiency in areas of financial behavior) may be more relaxed (and perhaps truthful) when they come after more discrete questions about financial habits and behaviors (Robson, 2012).

For certain forms of financial information related to income and wealth, it may be possible to verify or replace respondent data with administrative data from tax return information (also called the T-1 Taxfiler Database), social assistance case files and Employment Insurance administrative records. Access to this administrative data can be difficult for researchers outside of government and require careful attention to respondent consent (particularly where records are needed for more than one household member) and security of data.

Finally imputation can be used to fill in missing values. A set of donor values is defined and then used to fill in gaps in the data set. The key issue is how to define the donor values and how to select them for each missing record. In the UK's Survey of Financial Capability, missing values were imputed through "hot-decking" in which the missing value is taken from a randomly selected similar record. In the case of the Survey of Financial Security, missing values were first imputed deterministically, by collecting

\footnotetext{
${ }^{300}$ Based on the author's own knowledge from participation in many of the federal interdepartmental meetings to develop the survey questionnaire.
} 
sufficient details to be able to determine an estimated value. For example, if respondents were unable to give an estimated value for their vehicle, information was collected on the make, model and year of the vehicle to determine an estimate using other reference sources (Statistics Canada, 2003). Where deterministic methods could not be used, a form of "hot-decking" was used and donor values were taken from individuals or families thought by Statistics Canada to have the most similar characteristics based on a composite score. Where multiple donors were tied in their matching score, a value was chosen at random from among these. The Canadian Financial Capability Survey similarly used method of "hot-decking" imputation but only for missing income data, not for components of net worth or other survey questions. Unfortunately no public information is available on the characteristics used to create the matching scores for donors in the imputation process. All imputation methods introduce some degree of error into the final estimates but are generally viewed as preferable to simply deleting or omitting records with missing data from the analysis (Statistics Canada, 2009).

\section{Problems of under-reporting assets}

Even once the survey designer has addressed the definition of wealth and missing values, there are still other challenges to the quality of the data. According to the literature, a major issue in surveys of wealth is the under-reporting of assets (Zyblock et al., 1997; Statistics Canada, 1999; Statistics Canada 2003; Johansson \& Klevmarken, 2006; Frick, Graba \& Sierminska, 2007). Logically the same concern should also apply to survey data on debts. 
Survey respondents may not have full information about the assets and debts of other household members or even their own assets and debts. For example, a respondent in a couple relationship may be unable to accurately answer questions about the value of investments held by their spouse or partner. Similarly, a respondent may have difficulty accurately answering questions about the value of their own investments if they do not regularly check account balances. In fact, the CFSC found that a little more than one in five Canadians checks their bank account balances only once a month (Arrowsmith \& Pignal, 2010).

The SFS aimed to address the potential for under-estimation by:

- Providing households in the survey sample with advance notice of the survey and allowing them opportunities to gather financial records in advance or even during the in-person interview.

- Following up with respondents or other household members after the initial interview to check information or complete responses.

- Checking estimates against results from the National Balance Sheet Accounts (NBSA).

Statistics Canada reported on its own internal efforts to compare SFS survey data with the NBSA and noted that the SFS "appears to underestimate some net worth components, particularly financial assets and consumer debt" but that the "quality of estimates of real assets (e.g. owner-occupied homes, vehicles) is much better than that of financial assets" (Statistics Canada, 2007, p.23). The lower estimates of average net worth may be related to the under-representation of the wealthiest families that are captured by the models 
underlying NBSA. However, as Statistics Canada points out, the NBSA models are unable to separate assets and debts belonging to individual Canadians from those belonging to unincorporated businesses so may in fact be somewhat inflated. Johansson and Klevmarken (2006) report on a similar effort to compare survey and administrative data from Sweden. They point out that even register data from tax returns may be subject to problems of under-reporting if taxable assets are self-assessed since people may be motivated to reduce their tax liability.

By contrast, I think there is reason to believe that survey respondents might over-value certain assets such as the value of their principal residence, collectibles and vehicles. The questionnaires in both the 1999 and 2005 SFS asked respondents to evaluate the market price of non-financial assets if they were to be sold today. Much of the behavioral economics literature suggests that people in possession of a good over-value it relative to its actual market value (Kahneman \& Tversky, 1979; Kahneman, Knetch \& Thaler, 1990; Thaler \& Sunstein, 2008). The SFS may reduce this potential for error to the extent that it uses deterministic imputation for the valuation of houses, vehicles and businesses, but not for valuables, collectibles and the value of a home's contents. Given that housing assets are, alongside pension assets, the largest asset class for nearly all households, a deterministic approach to setting housing values may be the best approach for reducing risks of over-estimation of assets. 


\section{Response burden}

A final general consideration in wealth surveys raised by Zyblock and her colleagues is that of response burden - that is, the time and effort required of participants to complete the survey. As respondent burden increases, response rates to the total survey or to specific questionnaire items are likely to decline, particularly in the context of a telephone interview. In the case of the 1999 and 2005 SFS files, participant burden was mediated by conducting interviews in person, making it potentially more difficult for respondents to end the interview prior to completing all questions. It was also reduced by asking for the consent of respondents to access administrative data to complete income information $^{301}$ and asking more discrete questions to allow for deterministic imputation of housing, vehicle and business assets. In the case of the CFCS, the interviews were conducted by telephone and without access to administrative files so the principal way to handle respondent burden was to constrain the overall length of the telephone interview and, therefore, the number and level of detail of survey questions. For example, while the SFS questionnaires asked for separate valuations of each an owner-occupied principal residence, other real estate owned in Canada and other real estate owned outside of Canada, the CFSC asked only whether any real properties were owned in or outside Canada and their estimated total value combined with other tangible assets (Statistics Canada, 2009). This latter approach is likely to lead to less accurate, less detailed and less useful information for researchers interested in net worth. However wealth researchers always face tradeoffs in survey data between increasing respondent burden

\footnotetext{
${ }^{301}$ Statistics Canada reports that $85 \%$ of respondents in the 1999 sample and $80 \%$ of respondents in the 2005 sample gave their consent to use administrative data sources.
} 
(and likely resulting in higher non-response) and getting the accurate and detailed estimates of various inputs into net worth that might be most desirable for research purposes. Furthermore, the four types of problems associated with surveying wealth discussed above are not, as is evident from the discussion, independent of one another and a decision to address one type of challenge can substantially increase the difficulty of another. Perhaps this goes some way to explaining why it is that the collection of net worth data has been so sporadic in Canada. ${ }^{302}$

\section{Specific issues with the survey data selected}

Having discussed the general issues of surveying wealth at all, this next section addresses the specific issues or considerations raised by working with the data sets chosen for this study: the 1999 and 2005 Surveys of Financial Security (SFS) and the 2009 Canadian Financial Capability Survey (CFCS). Given the constraints, discussed below, analysis using the CFCS was severely limited and is not reported. For ease of reference, specific issues with the surveys used will be addresses in a similar order to the discussion above, starting with the definition of net worth and its components and ending with considerations in the quality of data not already specified above.

\footnotetext{
302 As of the time of writing, Statistics Canada has eliminated the asset and debt module from its National Household Survey but is currently anticipating a 2012 repeat of the Survey of Financial Security (Statistics Canada PPR, 2012-13).
} 


\section{Unit of analysis}

The SFS files include a file for the individual respondent and a separate file for the respondent's economic family. ${ }^{303}$ The selected respondent from each household was the person who self-identified as being the most knowledgeable about the family's financial circumstances (Statistics Canada, 2006) and who was asked to respond on questions of income, assets and debts on behalf of the entire economic family. While data on basic demographic characteristics, income, workplace pensions and labour force participation are available for each member of the household, data on non-pension assets and debts was collected for the pooled amounts held by all members of the economic family. The CFSC also collected data on assets and debts for all economic family members pooled together. The CFSC survey collection randomly selected an adult member of the economic family to respond, rather than the most-knowledgeable person. ${ }^{304}$

Kerstteter (2002) relied on previously published estimates from 1970, 1977 and 1984 Surveys of Consumer Finances and would have been subject to the definition implicit in those surveys. The surveys from 1970 and 1977 excluded, for example, the value of workplace pensions, real property other than a principal residence or the contents of the home. Similarly, the 1970s surveys have no measure of mutual funds or asset-backed

${ }^{303}$ Economic family is defined by Statistics Canada as "the members of a household who are related by blood, marriage or adoption" (Statistics Canada, 2012). Single persons would be considered to be in an economic family of "one".

${ }^{304}$ Surveys of wealth in other countries often instead household members as the unit of analysis, regardless of their relationship and may end up pooling together the assets and debts of roommates with little ongoing financial relationship outside of their monthly rent. 
securities because these financial products simply didn't exist then. The 1984 survey also excluded the value of workplace pensions. Osberg (2007) used data from the public use microdata files for 1977 through 2005 and issues with the comparability of the public use files with the master files have already been discussed. It is worth noting that Osberg does exclude the value of employer pensions for all survey years but it is unclear what other adjustments were made to enable the data to be comparable from year to year. LaFrance and LaRochelle-Côté (2012) noted that the 1970 and 1977 surveys also exclude Registered Education Savings Plans (RESPs) and the value of any real estate owner by the economic family, other than the principal residence. Chawla (1990) also pointed out that the cash value of life insurance policies would similarly be excluded from net worth estimates using a 1970 or 1977 definition.

Among the studies comparing 1984 and 1999 or 2005 wealth data (Morrissette, Zhang \& Drolet, 2002; Kerstetter, 2002; Milligan, 2004; Morrissette \& Zhang, 2007), the common practice has been to make the newer data backwards comparable by eliminating components of net worth that were not collected for 1984: workplace pensions, the contents of the home, valuables and collectibles and annuities. This approach reduces the likelihood of exaggerating increases in net worth or wealth inequality over time by making the portfolios of the economic families as comparable as possible regardless of time period. However, workplace pensions can have substantial value for third of households with at least one current or past member of a pension plan (Schellenberg and Ostrovsky, 2012). For poorer households, the contents a home and modest valuables may be among the few assets they own and may sometimes be managed as more liquid assets 
than in households with more and more valuable financial and tangible assets. ${ }^{305}$

Excluding workplace pensions and the other assets excluded in the studies listed above may substantially lower final estimates of the assets and net worth of poorer households. The rationale of collecting and analyzing wealth data at the economic family rather than individual level is based in part on the difficulty of splitting the value of several and often very large assets among family members. Among the largest household assets, the value of a principal residence is, under all provincial family laws legally owned equally between members of a married couple, regardless of the contribution towards the downpayment or maintenance costs. However couples in a common law relationship are not subject to this legal framework and are free to divide the asset of the principal residence as they see fit. In this case it would be difficult and potentially distorting to apply an individual level valuation for an owner-occupied dwelling. Similar problems arise in thinking about how to apportion a value of the home to dependent children aged 15 and over who are classified as "adults" for the purpose of the SFS and most Statistics Canada surveys, but are unlikely to hold any equity (or liability) in the house belonging to their parent(s) or guardian(s).

The collection and analysis of household level financial data also presumes that members of an economic family will share resources (and obligations) as a result of their legal, social and emotional ties through birth, marriage or adoption. Unfortunately, no national

\footnotetext{
305 Although the overall rates of use of pawnshops in Canada is very low, households with lower income and lower net worth are much more likely to report using a pawnshop one or more times in the previous 12 months (based on tabulations provided to the Task Force on Financial Literacy from the Canadian Financial Capability Survey, 2010)
} 
level estimates on patterns of household financial behaviors could be identified to verify this assumption and it is an assumption with important implications. At least one study comparing individual and household estimates of wealth found that household wealth is much less unequally distributed than individual and that estimates of individual wealth show a substantial increase in the top decile (Frick, Graba \& Sierminska, 2007).

Research on household financial decision-making suggest that there can be important differences in the power and access to resources of household members (Levy \& Lee, 2004) and at least one study has concluded that those with greater incomes and power in a relationship will also end up with larger amounts in retirement assets (Babiarz, Robb \& Woodyard, 2012). However these intra-household financial relationships appear to retain some amount of interdependence, even if decision-making power is not shared if only because of applicable legal or social norms and, more importantly, these power dynamics and roles can shift over time (Goode, 2010). For cross-sectional surveys such as the SFS and CFSC, the risks associated with an assumption of household resource pooling may be preferable to the risk of capturing only a single point in time estimate where the collected values of individual assets and debts may depend on many unobserved and unstable variables.

\section{Components of net worth}

As discussed above, the SFS and CFSC collected information about a more constrained set of financial and tangible assets with a marketable value, leaving out estimates on the value of human and other forms of capital. All researchers using these data sets are 
therefore subject to the restrictions arising from what was actually collected and recorded. However, previous studies using the SFS data ${ }^{306}$ have adopted slightly different definitions of marketable net worth, determined at least in part by the time periods they are examining.

Table A.1, below, summarizes the components of net worth for the 1999 and 2005 SFS data. In the interests of space and clarity only those variable names from the relevant master file are included for the specific assets that were selected for separate analysis or transformation.

${ }^{306}$ Very little work has been so far published using the CFSC and none of the studies (Arrowsmith and Pignal, 2010; McKay, 2010; Buckland, 2011) have focused on estimates of net worth. 
Table A.1: Components of net worth for SFS 1999 and 2005, with variable names from master file

\begin{tabular}{|c|c|c|}
\hline Survey year & SFS 1999 & SFS 2005 \\
\hline $\begin{array}{l}\text { Financial assets } \\
\text { (non-RRSP) } \\
{[W A S T F I N P]}\end{array}$ & $\begin{array}{l}\text { - } \text { Cash in deposit accounts } \\
\text { - } \text { Term deposits (such as } \\
\text { - } \text { Mutual funds } \\
\text { - Canadian Savings Bonds } \\
\text { - Other bonds } \\
\text { - Stocks } \\
\text { - Shares } \\
\text { - RESPs [WARESP] } \\
\text { - RHOSPs [WAHOSP] } \\
\text { - T-bills } \\
\text { - Trusts } \\
\text { - Mortgage-backed } \\
\text { - } \text { securities } \\
\text { - } \text { Othertgage loans given } \\
\text { - Other, non-RRSP } \\
\text { investments not listed } \\
\text { above }\end{array}$ & $\begin{array}{ll}\text { - } & \text { Cash in deposit accounts } \\
\text { - } & \text { Germ deposits (such as } \\
\text { - } & \text { Mutual funds } \\
\text { - } & \text { Canadian Savings Bonds } \\
\text { - } & \text { Other bonds } \\
\text { - } & \text { Stocks } \\
\text { - } & \text { Shares } \\
\text { - } & \text { RESPs [WARESP] } \\
\text { - T-bills } \\
\text { - Trusts } \\
\text { - Asset-backed securities } \\
\text { - Mortgage loans given } \\
\text { - Other loans given } \\
\text { - Income trusts } \\
\text { - Other, non-RRSP } \\
\text { investments not listed } \\
\text { above }\end{array}$ \\
\hline $\begin{array}{l}\text { Pension assets } \\
\text { [WASTPENT] }\end{array}$ & $\begin{array}{ll}\text { - } & \text { RRSPs [WARRSPL] } \\
\text { - } & \text { Registered Retirement } \\
& \text { Income Funds [WARRIF] } \\
\text { - } & \text { Deferred profit sharing } \\
& \text { plans [WADPSP] } \\
\text { - } & \text { Annuities [WAANUITY] } \\
\text { - } & \text { Imputed value of } \\
& \text { workplace pensions } \\
\text { - } & \text { Imputed value of foreign } \\
& \text { pensions } \\
\end{array}$ & $\begin{array}{ll}\text { - } & \text { RRSPs [WARRSPL] } \\
\text { - } & \text { Registered Retirement } \\
& \text { Income Funds [WARRIF] } \\
\text { - } & \text { Deferred profit sharing } \\
& \text { plans } \\
\text { - } & \text { Annuities } \\
\text { - } & \text { Imputed value of } \\
& \text { workplace pensions } \\
\text { - } & \text { Imputed value of foreign } \\
& \text { pensions }\end{array}$ \\
\hline Real property & $\begin{array}{l}\text { Resale value of an owner- } \\
\text { occupied principal } \\
\text { residence, excluding farm } \\
\text { land where applicable } \mathrm{e}^{307} \\
\text { [WAPRVAL] }\end{array}$ & $\begin{array}{l}\text { - Resale value of an owner- } \\
\text { occupied principal } \\
\text { residence, excluding farm } \\
\text { land where applicable } \\
\text { [WAPRVAL] }\end{array}$ \\
\hline
\end{tabular}

${ }^{307}$ Real estate belonging to a family-owned farm would be captured as an asset or liability under other categories in the 1999 and 2005 surveys. The purpose of separating the house from the farm is to make equivalent the definitions of a principal residence for both urban and rural economic families. Just as the business assets and liabilities of an urban economic family engaged in an activity other than farming would be recorded 


\begin{tabular}{|c|c|c|}
\hline & $\begin{array}{ll}\text { - } & \text { Other Canadian real estate } \\
\text { - } & \text { Foreign real estate }\end{array}$ & $\begin{array}{ll}\text { - } & \text { Other Canadian real estate } \\
\text { - } & \text { Foreign real estate }\end{array}$ \\
\hline $\begin{array}{l}\text { Other tangible assets } \\
\text { [WASTNFIN] }\end{array}$ & $\begin{array}{l}\text { - } \text { Cars, trucks, vans, etc. } \\
\text { - } \text { Boats, RVs, etc. } \\
\text { - } \text { Contents of the home } \\
\text { - } \text { Valuables and collectibles } \\
\text { - } \text { Other non-financial assets } \\
\text { not reported above such as } \\
\text { patents }\end{array}$ & $\begin{array}{l}\text { - } \text { Cars, trucks, vans, etc. } \\
\text { - } \text { Boats, RVs, etc. } \\
\text { - } \text { Contents of the home } \\
\text { - } \text { Valuables and collectibles } \\
\text { - } \text { Other non-financial assets } \\
\text { not reported above such as } \\
\text { patents }\end{array}$ \\
\hline $\begin{array}{l}\text { Business assets } \\
\text { [WBUSEQ] }\end{array}$ & $\begin{array}{l}\text { Imputed equity in a } \\
\text { business }\end{array}$ & $\begin{array}{l}\text { Imputed equity in a } \\
\text { business }\end{array}$ \\
\hline Total assets & $\begin{array}{l}\text { 1. WATOPT: Sum of the } \\
\text { above assets on a } \\
\text { termination basis } \\
\text { 2. WATOTAL: Sum of the } \\
\text { above, on a termination } \\
\text { basis less imputed value of } \\
\text { workplace and foreign } \\
\text { pensions }\end{array}$ & $\begin{array}{l}\text { 1. WATOPT: Sum of the } \\
\text { above assets } \\
\text { 2. WATOTAL: Sum of the } \\
\text { above, less imputed value } \\
\text { of workplace and foreign } \\
\text { pensions }\end{array}$ \\
\hline Mortgage debts & 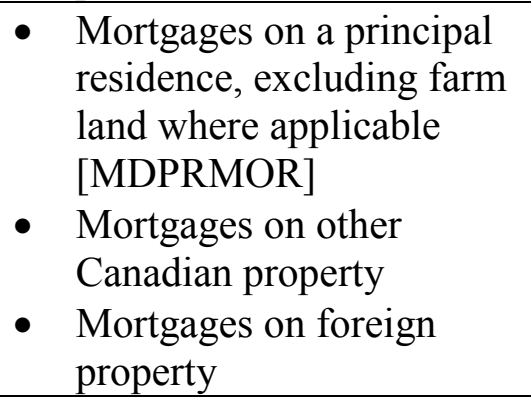 & 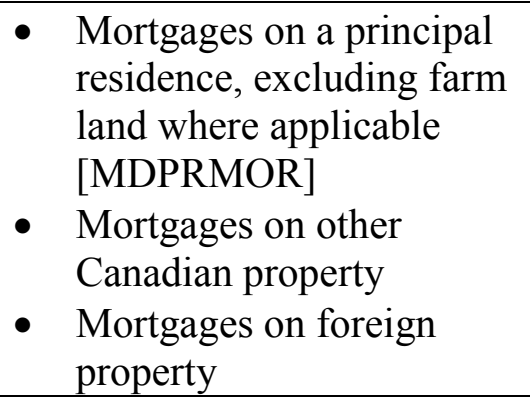 \\
\hline Other personal debts & $\begin{array}{l}\text { - Balances on credit cards } \\
\text { Balances on store charge } \\
\text { cards and other consumer } \\
\text { cards } \\
\text { - Balances on deferred } \\
\text { payment and installment } \\
\text { plans } \\
\text { - Balances on student loans } \\
\text { - Balances on loans for cars, } \\
\text { trucks and vans } \\
\text { - Balances on loans for }\end{array}$ & $\begin{array}{l}\text { - Balances on credit cards } \\
\text { Balances on store charge } \\
\text { cards and other consumer } \\
\text { cards } \\
\text { - Balances on deferred } \\
\text { payment and installment } \\
\text { plans } \\
\text { - Balances on student loans } \\
\text { - Balances on loans for cars, } \\
\text { trucks and vans } \\
\text { - Balances on loans for other }\end{array}$ \\
\hline
\end{tabular}

separately from the housing assets and liabilities, the 1999 and 2005 surveys took care to use this same separation of "work" and "home" for economic families living and working on a farm in 1999 and 2005. 


\begin{tabular}{|c|c|c|}
\hline & $\begin{array}{l}\text { other vehicles } \\
\text { Balances on a home equity } \\
\text { line of credit } \\
\text { [WDSTLOC] } \\
\text { - Balances on other lines of } \\
\text { credit } \\
\text { - Balances on other loans } \\
\text { from financial institutions } \\
\text { - Other money owed }\end{array}$ & $\begin{array}{l}\text { vehicles } \\
\text { - Balances on a home equity } \\
\text { line of credit [WDSTLOC] } \\
\text { - Balances on other lines of } \\
\text { credit } \\
\text { - Balances on other loans } \\
\text { from financial institutions } \\
\text { - Other money owed }\end{array}$ \\
\hline Total debts & $\begin{array}{l}\text { Sum of all mortgage and all } \\
\text { personal debts [WDTOTAL] }\end{array}$ & $\begin{array}{l}\text { Sum of all mortgage and all } \\
\text { personal debts [WDTOTAL] }\end{array}$ \\
\hline Net worth & $\begin{array}{l}\text { 1. WNETWPT: net worth, } \\
\text { including pensions, on a } \\
\text { termination basis } \\
\text { [WATOPT - WDTOTAL] } \\
\text { 2. WNETWTH: net worth, } \\
\text { excluding pensions on a } \\
\text { termination basis } \\
\text { [WATOTAL - } \\
\text { WDTOTAL] }\end{array}$ & $\begin{array}{l}\text { 1. WNETWPT: net worth, } \\
\text { including pensions, on a } \\
\text { termination basis } \\
\text { [WATOPT - WDTOTAL] } \\
\text { 2. WNETWTH: net worth, } \\
\text { excluding pensions on a } \\
\text { termination basis } \\
\text { [WATOTAL - } \\
\text { WDTOTAL] }\end{array}$ \\
\hline
\end{tabular}

Net worth in the present study is defined as all marketable assets less all marketable debts on a termination basis, and reports, for 1999 and 2005, on both net worth including [WNETWPT] and excluding [WNETWTH] workplace pensions.

Total pension assets for the 1999 and 2005 SFS [WASTPENT] include an imputed value for workplace pensions calculated by Statistics Canada. Survey respondents were asked a series of questions about the current and past membership in workplace pensions and the nature of the pension plan (for example, defined contribution in which current employer and employee contributions are guaranteed but final benefits depend on the rates of return on the invested capital, or defined benefit in which the employer commits to meeting some future benefit level for retired members and contribution rates are adjusted to adequately fund the future liability). This information, along with 
administrative records where consent was given, was used by Statistics Canada to generate both going concern and termination estimates of the value of employer pension. The estimates consider the age and income of the pension member, the nature of the workplace pension, the contribution rates of the employer and member and the duration of the membership in the plan. A full discussion of the pension valuation methods used by Statistics Canada is offered in a paper by Cohen, Franken and Maser (2001). As previously discussed, the current study uses the termination value and reports findings in the following chapter both with and without pension assets.

Tax-preferred assets include RRSPs, RHOSPs, RESPs, RDSPs, TFSAs and equity in a principal residence. The amount of economic family wealth held in this class of assets is defined, for 1999 and $2005^{308}$ as:

WARRSPL + WARESP + WAHOSP + Equity in a principal residence ${ }^{309}$

${ }^{308}$ This definition is broadly consistent with Milligan's (2005) definition of a class of taxpreferred assets. The current analysis builds on Milligan's approach by including a measure of housing equity. The exclusion of RRIFs in contrast to Milligan is addressed in the text of the chapter. The exclusion of deferred-profit-sharing-plans from the class of tax-preferred assets is justified on the basis that these explicitly preclude employee contributions (CRA, 2008) and so cannot attract personal or household savings out of new or existing assets. Also, DPSPs are taxable at the time the share in the profits is exercised by the holder in such wide-ranging circumstances as sickness, long-term disability, parental leave or lay-off. Earnings on the investments in a DPSP are exempt from tax but the final tax impact on the beneficiary is highly uncertain depending on when and how the benefit is exercised.

${ }^{309}$ Equity in a principal residence is calculated by the author and is discussed later in the chapter. 
Had the CFSC been used to develop estimates for 2009, the amount of economic family wealth held in this class of assets could not have been defined as a sum given the parameters of the survey questionnaire. For example, neither the prevalence nor the value of equity in a principal residence can be computed using 2009 CFSC data. Similarly, data on the dollar values of many tax-preferred instruments have such low cell counts that results could not be released.

For 1999 and 2005, the variable for Registered Retirement Savings Plans [WARRSPL] includes RRSPs as well as locked-in variants such as Locked-in Retirement Savings Plans (LRSPs) and Locked-in Retirement Accounts (LIRAs) but does not include any Registered Retirement Income Funds (RRIFs). ${ }^{310}$ Contributions to these accounts may include some combination of economic family members and employers but this division cannot be ascertained from the way the information was collected. Amounts held in RRIFs are included in all estimates of total assets and total net worth but are not addressed separately in the analysis since they are financial products intended to be conversions from RRSPs which are the key tax-preferred instrument.

The value of RESPs (WARESPs) in 1999 and 2005 is the value of all RESPs held by a member of the economic family. Given the wording of the questions asked of survey respondents, it is possible that this estimate includes amounts held as a subscriber (someone who opened and contributes to an RESP, such as a parent or grandparent) or as

\footnotetext{
${ }^{310}$ As per the discussion of RRSPs in chapter 3, RRSPs must be converted to RRIFs or
} annuities in the year that the account owner turns 71 . 
a beneficiary (someone who is named as the intended user of the account upon enrolment in a post-secondary education program). ${ }^{311}$

The variable for household savings in Registered Homeownership Savings Plans is available and reported only for 1999. As discussed in Chapter 4, RHOSPs were introduced as a federal tax instrument in 1974 and were later repealed in 1985 (with sunset provisions for existing accounts). While some remaining accounts may have been existence in 1999, by 2005 , these would all have, been required to be closed by federal law. The inclusion of RHOSPs in 1999 only is expected to have little or no impact on the findings since the proportion of the sample with an RHOSP is very low and the median dollar values of RHOSPs is $\$ 0$ across the distribution of households by wealth quintile.

\section{Sample size and response rates}

The sample sizes and response rates for the surveys used are summarized in Table A.2 below. In 1999 and 2005, the sample sizes are adequate to provide national-level estimates for all of the variables of interest. However in 2009 the sample size and response rates resulted in suppression of certain data on prevalence of the specific assets included in this study and as a result, the author elected to exclude the CFSC data from further analysis.

${ }^{311}$ A respondent and a beneficiary may be the same person in the case that an adult opens an RESP to save for their own education. The incidence of this kind of use is unknown from public data and RESPs are generally presumed to be vehicles to save for the higher education of a child related to the subscriber. 
As mentioned above, the 1999 and 2005 surveys included an additional sample of higherincome households.

Statistics Canada reports that the coefficients of variation for national level estimates (in the 2005 SFS) of total assets including pensions [WATOPT] is 2.75 , for net worth including pensions [WNETWPT] is 3.07 and for RRSPs [WARRSPL] is 4.19, all of which are well below the agency's recommended cut-off of 16.5 for acceptable estimates (Statistics Canada, 2005). Coefficients are not reported by Statistics Canada for the 1999 SFS or 2009 CFSC data and were not computed separately by the author. Given the much larger sample sizes for the 1999 and 2009, similar national estimates are expected to be at least as or more reliable compared to 2005. Response rates were higher for 1999 than the subsequent survey years, consistent with the downward trend in response rates more generally and were lower in any additional samples of higher income households. However the overall response rates are still sufficiently high to permit analysis for the current study.

Table A.2 Survey response rates

\begin{tabular}{|l|l|l|}
\hline \multicolumn{1}{|c|}{ Survey } & \multicolumn{1}{c|}{ Sample } & \multicolumn{1}{c|}{$\begin{array}{c}\text { Additional sample, if } \\
\text { any }\end{array}$} \\
\hline $\begin{array}{l}\text { SFS 1999 } \\
\text { Overall response rate: } \\
75.7 \%\end{array}$ & $\begin{array}{l}23,000 \text { dwellings } \\
\text { Response rate: } 77.3 \%\end{array}$ & $\begin{array}{l}2,000 \text { dwellings in high } \\
\text { income areas } \\
\text { Response rate: } 59.9 \%\end{array}$ \\
\hline $\begin{array}{l}\text { SFS 2005 } \\
\text { Overall response rate: } \\
67.7 \%\end{array}$ & $\begin{array}{l}7,500 \text { dwellings } \\
\text { Response rate: } 71.2 \%\end{array}$ & $\begin{array}{l}1,500 \text { dwellings in high } \\
\text { income areas } \\
\text { Response rate: } 51 \%\end{array}$ \\
\hline CFCS 2009 & $\begin{array}{l}27,500 \text { households } \\
\text { Response rate: } 56.3 \%\end{array}$ & None \\
\hline
\end{tabular}




\section{Imputation}

In the 2009 CFSC, only missing or incomplete income data was imputed but since this variable is not used in the current study no further discussion is needed of imputation for that study.

In both the 1999 and 2005 SFS a mix of "hot-decking" and deterministic imputation were used for components of net worth. As described in Table A.3, below, a quarter of all the values for assets was imputed and a much smaller share of debts. Overall, the rate of imputation does not, according to Statistics Canada, interfere with the reliability of the estimates, particularly at the national level, as is the case in this study (Statistics Canada, 1999 and 2005).

Table A.3: Imputation in 1999 and 2005 SFS master files (Statistics Canada 1999 and 2005)

\begin{tabular}{|l|l|l|}
\hline \multicolumn{1}{|c|}{ Variable } & \multicolumn{1}{|c|}{$\%$ imputed in 1999 } & \multicolumn{1}{c|}{ imputed in 2005 } \\
\hline Net worth & Not published & $28 \%$ \\
Total assets & $24 \%$ & $25 \%$ \\
RRSPs & $10 \%$ & $9 \%$ \\
Principal residence & $4 \%$ & $3 \%$ \\
Debts & $4 \%$ & $3 \%$ \\
\hline
\end{tabular}

The higher rates imputations for total assets and net worth are more likely to reflect the fact that some respondents gave partial responses to the series of questions on the value of specific assets. The slightly higher rates of imputation for RRSPs than principal residence, for example, may not be a concern if the imputation was informed by access to 
administrative records but this cannot be confirmed from published Statistics Canada sources. $^{312}$

\section{Comparability of data across survey years}

The dollar figures for 1999 were adjusted to 2005 constant dollars in the standard way based on the Consumer Price Index ${ }^{313}$.

Interestingly the 2005 data file included total asset and net worth variables labeled and described in the data dictionary as allowing comparisons between each the 2005 survey and the 1999 and 1984 surveys.

The variable for net worth intended to be comparable to 1999 is labeled [W05AS99] and is described by Statistics Canada as all assets less all debts where the total of assets

\footnotetext{
312 The 1999 and 2005 SFS is now considered to be an un-supported survey by Statistics Canada, meaning that no new staff or agency resources are invested to facilitate use of the data. The survey files provided to the Research Data Centre do not include a user guide for the master file and the data files were not yet "mounted" or prepared for import into a statistical program. Information on imputation rates and methods, response rates and other issues related to the survey design and data quality have been taken from published reports or from the user guides for the Public Use versions of the SFS surveys which are the best available source of information. Where possible, the author consulted with Statistics Canada staff who were familiar with the surveys used for this study. However, even the agency lead on a survey may not have full information about the data processing conducted elsewhere in the agency after data collection.

313 The adjustments were calculated based on the on-line "Inflation Calculator" provided by the Bank of Canada. It in turn relies on the monthly Consumer Price Index for Canada, 1914-2006 (CANSIM V41690973 series). For reasons that cannot be determined by the author, the adjustment for 1999 to 2005 in this study differed slightly from the constant used by Morissette and Zhang (2006).
} 
excludes the contents of the home and collectibles or valuables. But in fact these components should be included in any comparison of net worth using the variables for total assets [WATOPT or WATOTAL] and net worth [WNETWPT or WNETWTH]. Furthermore, the formula provided in the 2005 data dictionary for how Statistics Canada derived [W05AS99] reveals that they have also excluded annuities and RRIFs, two more components of net worth that were collected in 1999 and included in the 1999 estimates of assets and net worth. Researchers conducting analysis of the 2005 to compare to 1999 values should not use the [W05AS99] but should instead use the standard total asset and net worth variables listed in Table A.1 above (these have the same labels from 1999 to 2005).

Similarly the variable for net worth intended to be comparable to 1984 is labeled [W05AS84]. The formula used by Statistics Canada to derive this variable is identical to the formula for the variable [W05AS99], but a quick review of the data itself finds that the values are not. Subtracting the difference between the values for these two finds that:

$$
\text { [W05AS99] }-[\text { W05AS84] }=\text { WAFINOT }
$$

In other words, the value intended to support comparisons of 2005 to 1984 data omits "other financial assets not listed elsewhere", such as the value of patents and copyrights (see Table A.1) which were collected in 1984 and should be included in a comparable model of wealth. The provided variable should not be used by researchers for comparisons to 1984 data without first adding back in the [WAFINOT] values to arrive at measures of comparable total assets and net worth. The most likely explanation for the 
above is simple error in compiling and organizing both the data file as well as the data dictionary.

There are two final notes about the comparability of the definitions of net worth between survey years 1999 and 2005. First, the survey in 2005 added a measure of household assets held in income trusts that were not included in the 1999 survey. Similar to the differences in including RHOSPs described above, it is likely that income trusts gained in popularity in the intervening years between surveys and so were added to the 2005 questionnaire. Second, the 2005 survey also includes the value of assets in "asset-backed securities" while the 1999 survey describes "mortgage-backed securities". Based on a review of the structure of the questionnaire, it seems this is a simple re-labelling of an existing form of asset between survey years. However these and the other differences described above highlight the changeability of definitions of wealth as financial markets introduce or eliminate financial products.

\section{Replicating Morissette and Zhang's (2007) estimates of net worth by decile}

My work with the SFS data files for each 1999 and 2005 began with an effort to replicate the results of Morisette and Zhang who reported on the median net worth of Canadian economic families by net worth decile. To make values for net worth comparable, a new variable of total assets was created for each 1999 and 2005 to replicate the definition of total assets used by Morissette and Zhang. Again this meant excluding workplace pensions, annuities, valuables and collectibles and the contents of the home. No exclusions were needed to the variable for total debts. Dollar values for 1999 were 
adjusted to constant 2005 dollars using the same measure of inflation as used by Morissette and Zhang. Results are reported below in Tables A.4 and A.5 below.

Table A.4: Median net worth by decile for 1999 using Morissette and Zhang (2007) method, $(\$ 2005)^{314}$

\begin{tabular}{|c|c|c|c|}
\hline Decile & Results for 1999 & $\begin{array}{c}1999 \text { results published by } \\
\text { Morissette and Zhang } \\
\text { (2007) }\end{array}$ & $\begin{array}{l}\text { Percentage } \\
\text { difference }\end{array}$ \\
\hline Bottom 10\% & $-6,676$ & $-6,570$ & $1.6 \%$ \\
\hline 2 & 115 & 120 & $-4.0 \%$ \\
\hline 3 & 6,797 & 6,820 & $-0.3 \%$ \\
\hline 4 & 26,163 & 26150 & $<0.01 \%$ \\
\hline 5 & 57,141 & 57,120 & $<0.01 \%$ \\
\hline 6 & 93,852 & 93,850 & $<0.01 \%$ \\
\hline 7 & 148,613 & 148,610 & $<0.01 \%$ \\
\hline 8 & 221,826 & 221,770 & $<0.01 \%$ \\
\hline 9 & 344,889 & 344,890 & $<0.01 \%$ \\
\hline Top 10\% & 724,631 & 723,590 & $0.1 \%$ \\
\hline
\end{tabular}

${ }^{314}$ Data here and throughout are rounded to the nearest dollar. 
Table A.5: Median net worth by decile for 2005 using Morissette and Zhang (2007) method (\$2005)

\begin{tabular}{r|rrr}
\hline \multicolumn{1}{l|}{ Decile } & Results for 2005 & $\begin{array}{c}\text { 2005 results published } \\
\text { by Morissette and Zhang } \\
\text { (2007) }\end{array}$ & $\begin{array}{c}\text { Percentage } \\
\text { difference }\end{array}$ \\
\hline Bottom 10\% & $-8,500$ & $-9,600$ & $-11.5 \%$ \\
$\mathbf{2}$ & 40 & 10 & $300.0 \%$ \\
$\mathbf{3}$ & 6,318 & 6,000 & $5.3 \%$ \\
$\mathbf{4}$ & 27,994 & 25,500 & $9.8 \%$ \\
$\mathbf{5}$ & 65,500 & 63,250 & $3.6 \%$ \\
$\mathbf{6}$ & 115,300 & 109,050 & $5.7 \%$ \\
$\mathbf{7}$ & 183,237 & 173,590 & $5.6 \%$ \\
$\mathbf{8}$ & 276,500 & 263,000 & $5.1 \%$ \\
$\mathbf{9}$ & 434,500 & 413,750 & $5.0 \%$ \\
Top 10\% & 949,000 & $1,194,000$ & $-20.5 \%$ \\
\hline
\end{tabular}

The replication for 1999 was more successful than for 2005 with differences of less than $1 \%$ from the results reported by Morissette and Zhang. In 2005, differences are larger and persisted even after checking the replication process three times and re-entering commands. The difference could not be explained by the omission or inclusion of particular assets or debts. It may be that some of the difference is due to rounding of values or perhaps to the weight variable in the version of the data file released to the Research Data Centre. Discrepancies in descriptive wealth data are not uncommon in the Canadian literature, even when studies use the same survey data and same master files. A table summarizing these is available at Sub-Appendix A.1. 


\section{Sub-Appendix A: Summary of discrepancies in published wealth data in Canada}

The following Table A.6 summarizes descriptive data on household net worth in Canada as reported in four prior studies. The reference to each study is included in the far left column. These studies include:

- Summary data from the 2005 Survey of Financial Security as published by Statistics Canada with dollar values in 2005 dollars.

- Kerstetter (2002) with dollar values in 1999 dollars.

- Morissette and (2007) with dollar values in 2005 dollars.

- Morissette, Zhang and Drolet (2002) with dollar values in 1999 dollars. 
Table A.6: Summary of wealth data from four studies

\begin{tabular}{|c|c|c|c|}
\hline & \multicolumn{3}{|c|}{ Household Net Worth Reported } \\
\hline & 1984 & 1999 & 2005 \\
\hline All Household: SFS 2005 summary data & na & $\$ 120,500$ & $\$ 148,400$ \\
\hline All Households, Kerstetter (2002) & & $\$ 81,000$ & na \\
\hline $\begin{array}{l}\text { All Households Morissette, Zhang \& Drolet } \\
(2002)\end{array}$ & $\$ 58,392$ & $\$ 64,600$ & na \\
\hline Decile 1: Morissette \& Zhang (2006) & $-\$ 2,100$ & $-\$ 6,570$ & $-\$ 9,600$ \\
\hline Kerstetter (2002) & na & $-\$ 2,050$ & na \\
\hline Morisette, Zhang \& Drolet (2002) & $-\$ 1,824$ & $-\$ 5,700$ & na \\
\hline Decile 2: Morissette \& Zhang (2006) & $\$ 780$ & $\$ 120$ & $\$ 10$ \\
\hline Kerstetter (2002) & na & $\$ 3,137$ & na \\
\hline Morisette, Zhang \& Drolet (2002) & $\$ 674$ & $\$ 101$ & na \\
\hline Decile 3: Morissette \& Zhang (2006) & $\$ 7,770$ & $\$ 6,820$ & $\$ 6,000$ \\
\hline Kerstetter (2002) & na & $\$ 14,000$ & na \\
\hline Morisette, Zhang \& Drolet (2002) & $\$ 6,743$ & $\$ 5,920$ & na \\
\hline Decile 4: Morissette \& Zhang (2006) & $\$ 24,630$ & $\$ 26,150$ & $\$ 25,500$ \\
\hline Kerstetter (2002) & na & $\$ 35,525$ & na \\
\hline Morisette, Zhang \& Drolet (2006) & $\$ 21,380$ & $\$ 22,700$ & na \\
\hline Decile 5: Morissette \& Zhang (2006) & $\$ 52,260$ & $\$ 57,120$ & $\$ 63,250$ \\
\hline Kerstetter (2002) & na & $\$ 64,678$ & na \\
\hline Morisette, Zhang \& Drolet (2006) & $\$ 45,365$ & $\$ 49,580$ & na \\
\hline Decile 6: Morissette \& Zhang (2006) & $\$ 83,130$ & $\$ 93,850$ & $\$ 109,050$ \\
\hline Kerstetter (2002) & na & $\$ 101,540$ & na \\
\hline Morisette, Zhang \& Drolet (2006) & $\$ 72,155$ & $\$ 81,466$ & na \\
\hline Decile 7: Morissette \& Zhang (2006) & $\$ 120,690$ & $\$ 148,610$ & $\$ 173,590$ \\
\hline Kerstetter (2002) & na & $\$ 152,550$ & na \\
\hline Morisette, Zhang \& Drolet (2006) & $\$ 104,764$ & $\$ 129,000$ & na \\
\hline Decile 8: Morissette \& Zhang (2006) & $\$ 170,210$ & $\$ 221,770$ & $\$ 263,000$ \\
\hline Kerstetter (2002) & na & $\$ 220,760$ & na \\
\hline Morisette, Zhang \& Drolet (2006) & $\$ 147,751$ & $\$ 192,500$ & na \\
\hline Decile 9: Morissette \& Zhang (2006) & $\$ 256,740$ & $\$ 344,890$ & $\$ 413,750$ \\
\hline Kerstetter (2002) & na & $\$ 338,051$ & na \\
\hline Morisette, Zhang \& Drolet (2006) & $\$ 222,861$ & $\$ 299,373$ & na \\
\hline
\end{tabular}




\begin{tabular}{|l|r|r|r|}
\hline & & & \\
\hline Decile 10: Morissette \& Zhang (2006) & $\$ 534,980$ & $\$ 723,590$ & $\$ 1,194,000$ \\
\hline Kerstetter (2002) & na & $\$ 703,500$ & na \\
\hline Morisette, Zhang \& Drolet (2006) & $\$ 464,376$ & $\$ 628,100$ & na \\
\hline
\end{tabular}




\section{Appendix B: Facilitator Guide}

The following outline was used as guide to facilitate the focus groups discussed in

Chapter 9.

As participants arrive, confirm their names on the participant list.

1) Welcome (1 min)

Welcome participants and thank them for their time.

Script: "This is a focus group being conducted to understand how Canadians think about saving. It's part of a larger research study on saving and government policy that I am conducting as part of my PhD research at Carleton University. We're going to keep tonight's discussion to no more than 90 minutes. Thank you for being here."

2) Informed consent (10 mins)

Distribute paper copies of the informed consent form.

Script: "Before we being, it's important that you are all clear on how your input will be used in my research and that you are sure you want to be part of this study. I'm handing out copies of a consent form and need a few minutes of your time to read through it with you to make sure we are all on the same page. If you have any questions please jump in anytime."

Read through informed consent allowing time for any questions and responding to these as needed.

3) Exercise 1: Ice-breaker (4 mins)

Show participants 3 questions (written on poster paper in displayed at the front of the room) from a modified version of the Proust questionnaire and invite them to introduce themselves using their first name only and offering one answer to one of the 3 questions.

3 Questions:

"What sound or noise do you love?"

"What is your favorite word?"

"If you could try any job or profession, what would it be?" 
Exercise 2: Individual written (10 mins)

Distribute blank paper to participants as well as pencils.

Script: "In the middle of your paper I'd like you to write this phrase: Saving money. Then I'd like you to write down the next word that comes to mind, and then the next one, until you feel like you've run out of words or until I say we've run out of time for this one exercise. There are no right or wrong answers. The best thing to do is to let yourself relax and write down the words that come to mind. I'll let you know when it's time to stop. Also, don't worry about spelling."

After 5-7 minutes ask participants to stop writing and invite them each to share 1 or 2 words they wrote on their paper. Use the opposite order as for exercise 1.

Collect participants' papers at the end of this exercise and set them aside.

Exercise 3: Group discussion (10 minutes)

Script: "Thinking about your own experience or people you know, what are some of the things you've saved up for? Or maybe you're saving for a goal now? Or maybe it's something you would like to save up for?"

Record participant answers on the flip chart paper. Note which ones are current and which ones are hoped for.

Exercise 4: Group discussion (15 minutes)

Script: "Sometimes governments have programs to help Canadians save. Can you think about any government programs like this that you've heard of? For now, just give me the names of any programs you've heard of."

Invite participants to offer names of programs. Record participant answers on the flip chart paper. Select the first, third and last program named and underline them, whether they are real policy instruments or not.

Script: "Let's pick out three of these you've listed and talk for a few minutes about how they work. If you were trying to explain them to a friend or neighbor, what would you say?"

Exercise 5: Individual written and group discussion (20 minutes) Display flip chart page with the following terms written on it large enough to be visible to the entire group: tax deduction, tax pre-paid account, matching grant, interest rate, compound interest. 
Distribute worksheets to participants.

Script: "These are some terms that governments use when talking about savings programs. I'd like you take a minute to look at the list. Based on what you know of them, I'd like you give each a number in the order of how much help you feel it would give you or other Canadians in saving up. Let's use 1 to mean the most helpful and 5 to mean the least helpful."

Give participants 1 minute to record their answers. Collect the sheets and set them aside.

Script: "Ok, let's take a look at this list and go through each one. Let's talk about what these things are, how they work and how much help they give people for saving. What can you tell me about tax deductions?" Prompt, if necessary "What have you heard about tax deductions? How do they work? There are no bad answers. We can just have an open discussion." Record contributions in point-form on a flip chart page.

After a few minutes, move to the next item on the list and record points. After each tem has been discussed, "Ok, now that we've talked about these things as a group. Let's go back to the numbering we used to say how helpful they were in trying to save money. Again, we'll use 1 for the most helpful and 5 to mean the least helpful. How helpful would you say tax deductions are?" If participants disagree, ask them to vote and record the majority answer as well as dissenting answers. Repeat this process for each of the terms on the list.

Exercise 6: Group discussion (8 minutes)

Script: "We've talked about ways to save, things to save for and government programs. If you had 30 seconds with the right person in government, what would you tell him/her about how to make better programs to help Canadians save up?"

Record key words on a flip chart.

Exercise: Closure (2 minutes)

Script: "Is there anything else anyone would like to add or feels they really want to say that we haven't touched on? This is the end of the focus group so I want to make sure I get down anything else you want to add."

Allow for discussion

"Thank you so much for all your input - it's been really helpful for my research. Again, if you have any questions about the project please give me a call or send me an email - it's on your copy of the consent form. Again, everything from tonight is anonymous, private and for the research project only. I have your honorarium for each of you in these envelopes. Thank you again for being here." 


\section{References}

Ackerman, B. \& Alstott, A. (1999). The stakeholder society. New Haven, CT: Yale University Press.

Adelman, S. \& Cross, M. (2007). Comparing a traditional IRA and a Roth IRA: Theory versus practice. Risk Management and Insurance Review, 13(2), 265-277.

Alan, S., Atalay, K., Crossley, T. \& Jeon, S. (2010). New evidence on taxes and portfolio choice. Journal of Public Economics, 94, 813-823.

Alarie, B. (2009). Assessing tax-free savings accounts: Promises and pressures. Canadian Tax Journal, 57(3), 504-532.

Altshuler, R. \& Dietz, R. (2008). Tax expenditure estimation and reporting: A critical review. NBER working paper no. 14263, National Bureau of Economic Research, Inc. Retrieved from www.nber.org.

Altus Group (2008). Promoting the tax-free savings account for homeownership. Discussion paper prepared for the Canadian Homebuilders' Association. Toronto:ON.

Ambachtsheer, K. (2009). Pension Reform: How Canada Can Lead the World. Discussion paper. Toronto, ON: C.D. Howe Institute.

Amromin, G. (2003). Household portfolio choices in taxable and tax-deferred accounts: Another puzzle? European Finance Review, 7, 547-582.

Axworthy, T. (2006). Getting a stake: The history of asset-based social policy in Canada. In Robson, J. \& Nares, P. (Eds.). Wealth and wellbeing / Ownership and opportunity: New directions in social policy for Canada. Toronto, ON: Social and Enterprise Development Innovations.

Ballentine, G. (1992). The structure of the tax system versus the level of taxation: An evaluation of the 1986 Act. Journal of Economic Perspectives, 6(1), 59-68.

Bank of Canada (2012). Indicators of capacity and inflation pressures for Canada. Data series. Retrieved from http://www.bankofcanada.ca/rates/indicators/capacity-andinflation-pressures/.

Barnett, E. (2001). Keynes's how to pay for the war in Canada: The story of compulsory savings. Kingston, ON: Harbinger House.

Barr, M. \& Sherraden, M. (2005). Institutions and inclusion in saving policy. In Retsinas, N. \& Belsky, E. (Eds.). Building assets, building wealth: Creating wealth in lowincome communities. Washington: Brookings Institution Press. 
Barr, M., Mullanathian, S. and Shafir, E. (2012). Behaviorally informed financial regulation. In Barr, M. (Ed.). No slack: The financial lives of low-income Americans. Washington, D.C: Brookings Institute Press.

Barr-Telford, L., Cartwright, F., Prasil, S., \& Shimmons, K. (2003). Access, persistence and financing: First results from the Postsecondary Education Participation Survey (PEPS). Ottawa, ON: Statistics Canada.

Bascand, G., Cope, J. \& Ramsay, D. (2006). Selected issues in the measurement of New Zealand's saving(s). Paper prepared for Reserve Bank of New Zealand Workshop on Saving, November 14.

Battle, K. (1998). Transformation of Canadian social policy since 1985. Social Policy and Administration, 32(4), 321-340.

Battle, K. \& Torjman, S. (2001). The post-welfare state in Canada: Income-testing and inclusion. Toronto, ON: Caledon Institute of Social Policy. Retrieved from www.caledoninst.org.

Baum, C. (2009). The effects of vehicle ownership on employment. Journal of Urban Economics, 66(3), 151-163.

Benson, E. (1971). The budget. The Debates of the House of Commons. June 18.

Bentham, J. (1787). Defence of usury. Reprinted 1818. London, UK: Payne and Foss. Retrieved from http://www.econlib.org/library/Bentham/bnthUsCover.html

Bergstresser, D. \& Poterba, J. (2004). Asset allocation and asset location: Household evidence from the survey of consumer finances. Journal of Public Economics, 88, 1893-1915.

Benartzi, S. \& Thaler, R. (1995). Myopic loss aversion and the equity premium puzzle. The Quarterly Journal of Economics, 110(1), 73-92.

Benartzi, S. \& Thaler, R. (2004). Save more tomorrow: Using behavioral economics to increase employee saving. Journal of Political Economy, 112(1), S164-S187.

Blair, D. (1971). The budget. The Debates of the House of Commons. June 23.

Blenkarn, D. (1986). The budget. The Debates of the House of Commons. January 15.

Boadway, R. \& Kitchen, H. (1984). Canadian tax policy. Toronto, ON: The Canadian Tax Foundation. 
Boshard, R. (2001). Building assets - A report on the asset-development and IDA field. Washington, DC: Corporation for Enterprise Development.

Bostic, R., Gabriel, S. \& Painter, G. (2009). Housing wealth, financial wealth and consumption: New evidence from microdata. Regional Science and Urban Economics, 39, 79-89.

Brewer, G. \& DeLeon, P. (1983). The foundations of policy analysis. Pacific Grove, CA: Brooks/Cole Publishing Co.

Brison, S. (1998a). The budget. The Debates of the House of Commons, March 26.

Brison, S. (1998b). The budget. The Debates of the House of Commons, March 31.

Brown, F., Gibson, J. \& Plumptre, A. (1940). War finance in Canada. Toronto, ON: The Ryerson Press.

Browning, M. \& Lusardi, A. (1996). Household saving: Micro theories and micro Facts. Journal of Economic Literature, 34(4), 1797-1855.

Brundtland, G. (1994). The challenge of sustainable production and consumption patterns. Natural Resources Forum, 18(4), 243-246.

Buckland, J. (2010). Are low-income Canadians financially literate? Placing financial literacy in the context of personal and structural constraints. Adult Education Quarterly, 60(4), 357-376.

Buckland, J., Brennan, M. \& Fikkert, A. (2010). How well are poor people served by Canadian banks? Research working paper \#48. University of Winnipeg, Institute of Urban Studies.

Buckland, J. (2012). Passing the buck? Examining Canadian banks' approaches to financial exclusion. Research working paper \#49. University of Winnipeg, Institute of Urban Studies.

Burman, L., Gale, W. \& Weiner, D. (2001). The taxation of retirement savings: Choosing between front-loaded and back-loaded options. National Tax Journal, $54,689-702$.

Burman, L., Toder, E. \& Geissler, C. (2008). How big are total individual income tax expenditures, and who benefits from them? Discussion paper No. 31, Tax Policy Centre. Retrieved from http://www.taxpolicycenter.org/UploadedPDF/1001234_tax expenditures.pdf

Bynner, J. (2001). The effect of assets on life chances. In Bynner, J. \& Paxton, W. (Eds.). The asset effect. London, UK: Institute for Public Policy Research. 
Canada Mortgage and Housing Corporation (2006) Canadian housing observer 2006, Ottawa, ON.

Canada Mortgage and Housing Corporation (2010). Changes in household net worth 1990-2009. Socio-economic series 10-018. Ottawa, ON.

Canada Mortgage and Housing Corporation (2012). Canadian Housing Observer. Ottawa, ON.

Canada Revenue Agency (2010). Taxation statistics: Final universe data for the 2008 tax year. Retrieved from www.cra-arc.gc.ca.

Canada Revenue Agency (2013a). Tax Folio S1-F3-C2: Principal residence. Retrieved from www.cra-arc.gc.ca.

Canada Revenue Agency (2013b). RRSPs and other registered plans for retirement T4040(E) Rev. 12. Retrieved from www.cra-arc.gc.ca.

Canada Revenue Agency (2013c). Registered education savings plans. RC4092(E) Rev. 12. Retrieved from www.cra-arc.gc.ca.

Canada Revenue Agency (2013d). Registered disability savings plans. RC4460(E) Rev. 12. Retrieved from www.cra-arc.gc.ca.

Canada Revenue Agency (2013e). Tax-free savings account (TFSA): Guide for individuals, RC4466(E) Rev. 13. Retrieved from www.cra-arc.gc.ca.

Canada Revenue Agency (2013f). Contributing to your spouse's or common-law partner's RRSPs. Retrieved from www.cra-arc.gc.ca.

Canadian Medical Association (2007). As RRSP turns 50, CMA marks one of its greatest lobbying victories. Bulletin, March 27. Retrieved from http://www.cma.ca/multimedia/CMA/Content Images/Inside cma/CMA Bulletin /English/2007/bulletinmar27.pdf

Canadian Tax Foundation (2013). The finances of the nation, 2012 edition. Toronto, ON: Canadian Tax Foundation.

Canova, L., Rattazzi, A. M. M., \& Webley, P. (2005). The hierarchical structure of saving motives. Journal of Economic Psychology, 26, 21-34.

Capuano, A. \& Ramsay, I. (2011). What causes suboptimal financial behavior? Discussion paper. University of Melbourne. 
Carnegie, A. (1900). The gospel of wealth and other timely essays. Reprinted 1962. Cambridge, MA: Harvard University Press.

Carroll, R., Joulfaian, D. \& Mackie, J. (2008). Income versus consumption tax baselines for tax expenditures. National Tax Journal, June.

Carter, M., \& Barrett, C. (2006). The economics of poverty: Traps and persistent poverty, an asset-based approach. Journal of Development Studies, 42(2), 178-199.

Case, K., Quigley, J. \& Shiller, R. (2013). Wealth effects revisted: 1975-2012. Working paper No. 18667, National Bureau of Economic Research. Retrieved from: http://www.nber.org.

Certified General Accountants (2011). A driving force no more: Have Canadian consumers reached their limits? Research report. Burnaby, BC.

Charmaz, K. (2005). Grounded theory in the 21st Century: Applications for advanced social justice studies. In Denzin, N. \& Lincoln, Y. (Eds.), Sage Handbook of Qualitative Research. Thousand Oaks, CA: Sage.

Chawla, R. (1990). The distribution of wealth in Canada and the United States. Perspectives on Labour and Income, 2(1).

Chawla, R. (2011). The distribution of mortgage debt in Canada. Perspectives on Labour and Income, 23(2).

Choi, J., Laibson, D. \& Madrian, B. (2004). Plan design and 401(k) savings outcomes. National Tax Journal, 57(2), 275-298.

Chrétien, J. (1978). The budget. The Debates of the House of Commons. June 19.

Cocco, J. (2004). Portfolio choice in the presence of housing. The Review of Financial Studies, 18(2), 535-567.

Cohen, M., Franken, H., \& Maser, K. (2001). Methodology for estimating the value of employer pension plan benefits. Ottawa, ON: Statistics Canada.

Conley, D. (2001). Capital for college: Parental assets and postsecondary schooling. Sociology of Education, 74(1), 59-72.

Copps, S. (1986). The budget. The Debates of the House of Commons. January 15.

Coward, S., Gellaty, G. \& Moussaly, K. (2012). The income of Canadian: 1981 to 2001. Economic Insights, 15, Statistics Canada.

Crawford, T. (1981, May 25). Banking on higher education. The Toronto Star, p.C1. 
CST Foundation (2012). Annual report. Retrieved from www.cst.org.

Currie, S., Leonard, D., Robson, J. \& Hunter, H. (2009). Post-secondary access and retention strategies: Literature review. Ottawa, ON: Social Research and Demonstration Corporation.

Curry, B. (2011, October 21). The Finance Minister, the disability assistance plan and a flood of tears. The Globe and Mail. Retrieved from www.theglobeandmail.com

Daly, M. \& Naquib, F. (1985). Designing and non-distortionary personal tax system for Canada. Economic Letters, 18(2-3), 209-212.

Daniels, R. \& Trebilcock, M. (2005). Rethinking the welfare state: Government by voucher. New York, NW: Routledge.

Davies, J. (2009). Efficiency and effectiveness of savings instruments design. Research paper. Ottawa: Department of Finance. Retrieved from http://www.fin.gc.ca/activty/pubs/pension/riar-narr-eng.asp

Davey, C. (1957, March 15). Exemption of flat $\$ 100$ aids many. The Globe and Mail, p.1.

Delacourt, S. (2004). Juggernaut: Paul Martin's campaign for Jean Chrétien's crown. Toronto, ON: McLelland and Stewart.

DellaVigna, S. (2009). Psychology and economics: Evidence from the field. Journal of Economic Literature, 47(2), 315-372.

Denzin, N. \& Lincoln, Y. (2005). The Sage Handbook of Qualitative Research. Thousand Oaks, CA:Sage Publications.

Dimmock, S. \& Kouwenberg, R. (2010). Loss-aversion and household portfolio choice. Journal of Empirical Finance, 17(3), 441-459.

DiPasquale, D. \& Glaeser, E. (1999). Incentives and social capital: Are homeowners better citizens? Journal of Urban Economics, 45, 354-384.

Dodge, J. (2012). Deconstructing Haig-Simons income and reconstructing it as objective ability-to-pay income. Research paper, Florida State University College of Law, Business and Economics, May 2012.

Duguay, L. (1986). The budget. The Debates of the House of Commons. January 21.

Dunn, W. (2003). Public policy analysis: An introduction, third edition. Upper Saddle River, NJ: Prentice Hall. 
Dunn, W. (2012). Public policy analysis: An introduction [PowerPoint Slides]. Retrieved from http://www.slideshare.net/nida19/public-policy-analysisdunn.

Dye, T. (1995). Understanding public policy, eighth edition. Upper Saddle River, NJ: Prentice Hall.

Ebbinghaus, B (2012). Comparing welfare state regimes: Are typologies an ideal or realistic strategy? Draft paper, European Social Policy Analysis Network Conference, Edinburgh, UK, September.

Echevin, D. (2013). Wealth Tax Experiments in France. Paper presented at the Canadian Economics Association Annual Meeting, Montreal, QC, May.

Economic Council of Canada (1987). The taxation of savings and investment. Research report. Ottawa, ON.

Engeland, J., Lewis, R. \& Shillington, R. (2006). Household income, net worth and housing affordability in Canada. Research highlights, Socio-economic Series 06003, Ottawa, ON: Canada Mortgage and Housing Corporation.

Engen, E., Gale, W. \& Scholz, J. (1996). The effects of tax-based saving incentives on saving and wealth. NBER working paper No. 5759, National Bureau of Economic Research, Inc. Retrieved from http://ideas.repec.org/e/pga40.html.

Esping-Andersen, G. (1990). The three worlds of welfare capitalism. Princeton, NJ: Princeton University Press.

Esping-Andersen, G. (2006). Three worlds of welfare capitalism. In Pierson, C. \& Castles, F. (Eds.). The welfare state reader, second edition. Cambridge, UK: Polity Press.

Esping-Andersen, G. (2009). The welfare state and redistribution. In Salverda, W., Nolan, B. \& Smeeding, T. (Eds.). The oxford handbook of economic inequality. London, UK: Oxford University Press.

Esping-Andersen, G. \& Myles, J. (2011). Economic inequality and the welfare state. In Salverda, W. \& Smeeding, T. (Eds.)., The Oxford Handbook of Economic Inequality. Oxford, UK: Oxford University Press.

Fairclough, E. (1956). National revenue. The Debates of the House of Commons, June 14.

Finance Alberta (2013). Budget documents. Retrieved from www.finance.alberta.ca.

Finance Canada (1972). Amendments to the Income Tax Act. Press release. October 15. 
Finance Canada (1974). Federal budget documents. Notice of ways and means motions. Retrieved from http://www.budget.gc.ca/pdfarch/index-eng.html.

Finance Canada (1985). Federal budget documents. Retrieved from http://www.budget.gc.ca/pdfarch/index-eng.html.

Finance Canada (1995). Tax expenditures and evaluations 1995. Retrieved from http://www.fin.gc.ca/purl/taxexp-eng.asp.

Finance Canada (1996). Budget documents. Retrieved from http://www.budget.gc.ca/pdfarch/index-eng.html.

Finance Canada (1997a). Tax expenditures and evaluations 1997. Retrieved from http://www.fin.gc.ca/purl/taxexp-eng.asp.

Finance Canada (1997b). Budget documents. Retrieved from http://www.budget.gc.ca/pdfarch/index-eng.html.

Finance Canada (1998a). Tax expenditures and evaluations 1998. Retrieved from http://www.fin.gc.ca/purl/taxexp-eng.asp.

Finance Canada (1998b). Budget documents. Retrieved from http://www.budget.gc.ca/pdfarch/index-eng.html.

Finance Canada (1999). Tax expenditures and evaluations 1999. Retrieved from http://www.fin.gc.ca/purl/taxexp-eng.asp.

Finance Canada (2000). Tax expenditures and evaluations 2000. Retrieved from http://www.fin.gc.ca/purl/taxexp-eng.asp.

Finance Canada (2001). Tax expenditures and evaluations 2001. Retrieved from http://www.fin.gc.ca/purl/taxexp-eng.asp.

Finance Canada (2002). Tax expenditures and evaluations 2002. Retrieved from http://www.fin.gc.ca/purl/taxexp-eng.asp.

Finance Canada (2003a). Tax expenditures and evaluations 2003. Retrieved from http://www.fin.gc.ca/purl/taxexp-eng.asp.

Finance Canada (2003b). Budget documents. Retrieved from http://www.budget.gc.ca/pdfarch/index-eng.html.

Finance Canada (2004). Tax expenditures and evaluations 2004. Retrieved from http://www.fin.gc.ca/purl/taxexp-eng.asp. 
Finance Canada (2005). Tax expenditures and evaluations 2005. Retrieved from http://www.fin.gc.ca/purl/taxexp-eng.asp.

Finance Canada (2006b). Tax expenditures and evaluations 2006. Retrieved from http://www.fin.gc.ca/purl/taxexp-eng.asp.

Finance Canada (2006b). Budget documents. Retrieved from http://www.budget.gc.ca/pdfarch/index-eng.html.

Finance Canada (2006c). Report of the Minister's expert panel on financial security for children with disabilities. Retrieved from www.fin.gc.ca.

Finance Canada (2007). Tax expenditures and evaluations 2007. Retrieved from http://www.fin.gc.ca/purl/taxexp-eng.asp.

Finance Canada (2008). Tax expenditures and evaluations 2008. Retrieved from http://www.fin.gc.ca/purl/taxexp-eng.asp.

Finance Canada (2009). Tax expenditures and evaluations 2009. Retrieved from http://www.fin.gc.ca/purl/taxexp-eng.asp.

Finance Canada (2010). Tax expenditures and evaluations 2010. Retrieved from http://www.fin.gc.ca/purl/taxexp-eng.asp.

Finance Canada (2011a). Tax expenditures and evaluations 2011. Retrieved from http://www.fin.gc.ca/purl/taxexp-eng.asp.

Finance Canada (2011b). Budget documents. Retrieved from http://www.budget.gc.ca/pdfarch/index-eng.html.

Finance Canada (2012a). Tax expenditures and evaluations 2012. Retrieved from http://www.fin.gc.ca/purl/taxexp-eng.asp.

Finance Canada (2012b). Budget documents. Retrieved from http://www.budget.gc.ca/pdfarch/index-eng.html.

Finance Canada (2013). Personal communication with Director General, Evaluation and Research Group, Tax Policy Branch. Spring 2013.

Finnie, A. \& Davies, S. (2011). Towards a nation of savers: Understanding and overcoming the challenges to saving on a lower income. Personal Finance Research Centre, University of Bristol.

Flaherty, J. (2006). Federal Accountability Act. The Debates of the House of Commons. April 26. 
Flaherty, J. (2008). The budget. The Debates of the House of Commons. February 26.

Frenette, M., Green, D. \& Milligan, K. (2009). Taxes, transfers and Canadian income inequality. Canadian Public Policy, 35(4), 389-411.

Friedman, M. (1957). The permanent income hypothesis. NBER chapters, in: A theory of the consumption function, pages 20-37, National Bureau of Economic Research, Inc. Retrieved from http://ideas.repec.org/b/nbr/nberbk/frie 57-1.html

Forest, Y. (1970). Written questions. The Debates of the House of Commons. April 13.

Gale, W. \& Scholz, J. (1992). IRAs and household saving. Paper 9244, Center for Economic Research. http://ideas.repec.org/e/pga40.html

Gallup Canada Inc. (1998). National poll. March 1998.

Garman, T. (1997). Personal finance education for employees: Evidence on the bottomline benefits. Journal of Financial Counseling and Planning, 8, 1-6.

Garrison, R. (2004). Overconsumption and forced saving in the Mises-Hayek theory of the business cycle. History of Political Economy, 36(2).

Girdharry, K., Simonova, E. \& Lefebvre, R. (2010). Registered education savings plans Valuable opportunities for the students of tomorrow. Research report. Certified General Accountants of Canada. Retrieved from http://www.cga-canada.org/enca/ResearchReports/ca_rep_2010-06_RESP.pdf

Globe and Mail (1940, November 28). Editorial, p.6.

Globe and Mail (1941, October 6). Editorial, p.6.

Gormley, J. (1986). The budget. The Debates of the House of Commons. January 21.

Goss, E. \& Phillips, J. (1997). The effect of state economic development agency spending on state income and employment growth. Economic Development Quarterly, 11, 88-96.

Grinstein-Weiss, M., Sherraden, M., Rohe, W. M., Gale, W., Schreiner, M., \& Key, C. (2012). Long-term follow-up of Individual Development Accounts: Evidence from the ADD experiment, (CSD Report 12-43). St. Louis, MO: Center for Social Development, Washington University.

Guest, D. (1991). The emergence of social security in Canada. Vancouver, BC: University of British Columbia Press. 
Guilmette, S. (2011). Competing priorities-Education and retirement saving behaviours of Canadian families. Education Matters: Insights on Education, Learning and Training in Canada, 8(1).

Gurley, T. \& Bruce, D. (2005). The effects of car access on employment outcomes for welfare recipients. Journal of Urban Economics, 58, 250-272.

Hale, G. (2002). The politics of taxation in Canada. Peterborough, ON: Broadview Press.

Hamilton, M. (2009) Comments on tax-free savings accounts. Cited in Chevreau, J. Making TFSA room retroactive to make up for 2008 losses. Blog post. April 2009. Retrieved from http://opinion.financialpost.com/category/wealthy-boomer/

Hansard (1942). Federal budget papers. The Debates of the House of Commons, June 23.

Harnish, T. (2009). State early commitment programs: A contract for college success? Policy brief, American Association of State Colleges and Universities, May.

Harris, W. (1957a). The budget. The Debates of the House of Commons, March 14.

Harris, W. (1957b). The budget. The Debates of the House of Commons, April 2.

Hayek, F. (1933). Monetary theory and the trade cycle. Retrieved from http://mises.org/daily/3121

Helleyer, P. (1969). Report of the federal task force on housing and urban development. Ottawa, ON: Queen's Printer for Canada.

Higgins, B. (1944). Canada's financial system in war, National Bureau of Economic Research.

Hogg, M. A., \& Smith, J. R. (2007). Attitudes in social context: A social identity perspective. European Review of Social Psychology, 18, 89-131.

Holden, S., Ireland, K., Leonard-Chambers, V. \& Bogdan, M. (2005). The individual retirement account at age 30: A retrospective. Perspective, 11(1).

Hole, L. (2004). Alberta Speech from the Throne. Debates of the Alberta Legislature, February 17.

Horner, K. (1983). Savings incentives and the retirement income system. (Doctoral dissertation). Retrieved from Dissertation Abstracts International (Accession number NK65771). 
Horner, K. (2005). The disability savings plan: Contribution estimates and policy issues. Ottawa, ON: The Caledon Institute. Retrieved from www.thecaledoninst.org.

Hou, F. (2010). Homeownership over the life course of Canadians: Evidence from Canadian censuses of population. Research paper. Ottawa, ON: Statistics Canada.

Howard, C. (2007). The welfare state nobody knows: Debunking myths about U.S. social policy. Princeton, NJ: Princeton University Press.

HM Revenue and Customs (2013). Individual savings accounts: Annual statistics. Retrieved from www.hmrc.gov.uk/

Hubbard, R. (1985). Personal taxation, pension wealth, and portfolio composition. The Review of Economics and Statistics, 67(1), 53-60.

Hubbard, R., Skinner, J., \& Zeldes, S. (1995). Precautionary saving and social insurance. Journal of Political Economy, 103(2), 360-399.

Hulchanski, D. (2001).

Human Resources and Skills Development Canada (2009). Formative evaluation of the additional education savings grant and the Canada learning bond. Retrieved from www.hrsdc.gc.ca.

Human Resources and Skills Development Canada (2009b). Canada education savings program annual statistical review. Retrieved from www.hrsdc.gc.ca.

Human Resources and Skills Development Canada (2010). Federal disability report. Retrieved from www.hrsdc.gc.ca

Human Resources and Skills Development Canada (2011). Departmental performance report. Retrieved from http://www.tbs-sct.gc.ca.

Human Resources and Skills Development Canada (2013). Federal disability report. Retrieved from www.hrsdc.gc.ca

Human Resources and Skills Development Canada (2013b). Canada education savings program annual statistical review. Retrieved from www.hrsdc.gc.ca.

Hunter, G. \& Miazdyck, D. (2004). Current issues surrounding poverty and welfare programming in Canada: Two reviews. Research paper. Canadian Centre for Policy Alternatives.

Ibbitson, J. \& Taber, J. (2003, May 10) True grit. The Globe and Mail, p.F7. 
Ilsely, J. (1943). The budget. The Debates of the House of Commons, March 2.

Ilseley, J. (1944). The budget. The Debates of the House of Commons, June 26.

Internal Revenue Service (2012). Individual retirement arrangements. Publication 590. Retrieved from www.irs.gov.

Internal Revenue Service (2013). Take credit for your retirement. Tax tip, 2013-27. Retrieved from www.irs.gov.

Jackman, H. (1944). The budget. The Debates of the House of Commons, June 26.

Japelli, T. \& Pistaferi, L. (2007). Do people respond to tax incentives? An analysis of the Italian reform of the deductibility of home mortgage interests. European Economic Review, 51, 247-271.

Johnson-Cartee, K. \& Copeland, G. (2004). Strategic political communication: Rethinking social influence, persuasion, and propaganda. Lanham, MD: Rowman and Littlefield.

Joulfaian, D. (2013). Household debt and capital gains taxation. Paper presented at the Canadian Economics Association Annual Meetings, Montreal, QC, May.

Kahneman, D., Knetch, J. \& Thaler, R. (1990). Experimental tests of the endowment effect and the coase theorem. Journal of Political Economy, 86(4), 1325-1348.

Kato, J. (2003). Regressive taxation and the welfare state: Path dependence and policy diffusion. Cambridge, UK: Cambridge University Press.

Katz, M. (1989). The undeserving poor: From the war on poverty to the war on welfare. New York, NY: Pantheon Books.

Kempson, E., Collard, S. \& Moore, N. (2005). Measuring financial capability. Research paper. London, UK: Financial Services Authority.

Kempson, E., Finney, A., \& Davies, S. (2011). The Child Trust Fund - Findings from the wave 2 evaluation. London, UK: HM Revenue \& Customs.

Kesselman, J. (2012). Expanding the tax-free savings account: Requisite companion reforms. Canadian Tax Journal, 60(2), 375-389.

Keynes, J.M. (1930). Treatise on money. New York, NY: Harcourt, Brace and Company.

Keynes, J.M. (1936). General theory. New York, NY: Harcourt, Brace and Company. Retrieved from http://www.marxists.org/reference/subject/economics/keynes/general-theory/ 
Keynes, J. M. (1962). Collected writings. London, UK: Macmillan.

Kerstetter, S. (2002). Rags and riches: Wealth inequality in Canada. Research paper, Canadian Centre for Policy Alternatives.

Kesselman, J. (1988). Direct expenditures vs. tax expenditures for economic and social policy. In Bruce, N. (Ed.). Tax expenditures and government policy, Kingston, ON: John Deutsche Institute for the Study of Economic Policy.

Kesselman, J. \& Poschmann, F. (2001). Expanding the recognition of personal savings in the Canadian tax system. Canadian Tax Journal, 49(1), 40-101.

Kesselman, J. (2009). Policy forum: Tax-free savings accounts in a consumption-based personal tax. Canadian Tax Journal, 57(3): 533-562.

Kesselman, J. (2012). Policy forum: Expanding the tax-free savings account—Requisite companion reforms. Canadian Tax Journal, 60(2), 375-89.

Kingston, P. \& Fries, J. (1994). Having a stake in the system: The sociopolitical ramifications of business and homeownership. Social Science Quarterly, 75, 679686.

Klyuev, V. \& Mills, P. (2007). Is housing wealth an 'ATM'? The relationship between household wealth, home equity withdrawal and saving rates. IMF Staff Papers, 54(3), 539-561.

Knetch, J. (2010). Remarks to the task force on financial literacy. Ottawa, ON.

Knight, B., Waslander, B. \& Wortsman, A. (2008). Review of registered educations savings plan industry practices - Final report. Research report prepared for Human Resources and Skills Development Canada, Ottawa, ON. Retrieved from http://publications.gc.ca/site/eng/334301/publication.html

Knighton, T., Hujaleh, F. \& Iacampo, J. (2009). Lifelong learning among Canadians aged 18 to 64 years: First results from the 2008 Access and Support to Education and Training Survey. Ottawa, ON: Statistics Canada.

Knowles, S. (1978). The budget. The Debates of the House of Commons. June 19.

Kosters, M. (1992). Personal saving, consumption, and tax policy. Lanham, MD: Rowman and Littlefield.

Lambert, M. (1974) The budget. The Debates of the House of Commons. May 6. 
Laurin, A. \& Poschman, F. (2010). Saver's choice: Comparing the marginal effective tax burdens on RRSPs and TFSAs. Discussion paper. Toronto, ON: C.D. Howe Institute. Retrieved from http://www.cdhowe.org/savers-choice-comparing-themarginal-effective-tax-burdens-on-rrsps-and-tfsas-2/11852

Leckie, N., Shek-Wai Hui,T., Tattrie, D., Robson, J. \& Voyer, JP. (2010). Learning to save, saving to learn: Final report of the learn\$ave individual development accounts project. Ottawa, ON: Social Research and Demonstration Corporation.

Lefebvre, S. (2004). Saving for post-secondary education. Perspectives on Labour and Income, Autumn.

Lester, J. (2012). Managing tax expenditures and government program spending: Proposals for reform. University of Calgary, School of Public Policy Research paper, 5(35). Retrieved from www.policyschool.ucalgary.ca/sites/default/files/research/tax-expenditureslester.pdf

Lerman, R. \& McKernan, S. (2008). The effects of holding assets on social and economic outcomes of families: A review of theory and evidence. The Urban Institute. Retrieved from http://aspe.hhs.gov/hsp/07/poorfinances/Effects/report.pdf

Lewis, D. (1974). The budget. The Debates of the House of Commons. May 7.

Lewis, P. (2004). Testimony on RESPs. Standing Committee on Human Resources, House of Commons. Journals, Hansard. November 2.

Lipmann, D. (1942a, April 14). Opinion column. The Globe and Mail, p.6.

Lipmann, D. (1942b, April 30). Opinion column. The Globe and Mail, p.6.

List, J. (2004). Young, selfish, and male: Field evidence of social preferences. Economic Journal, 114(492), 121-149.

Lusardi, A. (2003). Saving and the effectiveness of financial education. Pension Research Council working paper 2003-14.

MacDaniel, C. (1998). Marketing Research Essentials. New York, NY: Taylor and Francis.

MacDonald, D. (1976a). The budget. The Debates of the House of Commons, December 2.

MacDonald, D. (1976b). The Income Tax Act. The Debates of the House of Commons, December 15. 
MacDonald, D. (1977). The budget. The Debates of the House of Commons, March 31.

MacPherson, C.B. (1999). Property: mainstream and critical positions. Toronto, ON: University of Toronto Press.

Mahoney, M. (1997). Psychotherapists' personal problems and self-care patterns. Professional Psychology: Research and practice, 28(1), 14-16.

Manning, P. (2009). The semiotics of brand. Annual Review of Anthropology, 39, 39-49.

Marchildon, G. (1996). Profits and politics: Beaverbrook and the gilded age of Canadian finance. Toronto, ON: University of Toronto Press.

Marks, G., Headley, B. \& Wooden, M. (2005). Household wealth in Australia: Its components, distribution and correlates. Journal of Sociology, 41(1), 47-68.

Martin, P. (1999). Testimony to the Standing Committee on Finance. Journals, Hansard. November 2, 1999.

Martin, P. (2008). Hell or high water: My life in and out of politics. Toronto, ON: Douglas Gibson Books.

Maslove, A. (1978). The other side of public spending: Tax expenditures in Canada. In Doern, G. \& Maslove, A. (Eds.). The Public Evaluation of Government Spending. Montreal, QC: Institute for Research on Public Policy.

Mazankowski, D. (1992). The budget. The Debates of the House of Commons. December 2.

McCaughey, G. (2013). Remarks to National Summit on Pension Reform. Toronto, ON: Canadian Imperial Bank of Commerce.

McCloskey, D. (2006). The prehistory of American thrift. In Yates, J. (Ed.). Thrift in America. Retrieved from http://www.deirdremccloskey.com/docs/prehist.pdf

McDonnough, A. (2004). Statements on RESPs. Standing Committee on Human Resources, House of Commons. Journals, Hansard. October 21 and November 2.

McFeat, T. (2011, December 30). Disabled ill informed about registered savings. $C B C$ News. Retrieved from www.cbc.ca.

McLister, R. (2013). Disappointing new stats on the RRSP home buyer's plan. Canadian Mortgage Trends. Posted online February 5, 2013. Retrieved from www.canadianmortgagetrends.com. 
McKay, S. \& Kempson, E. (2003). Savings and life events. Research paper. Personal Finance Research Centre, Bristol University.

McKnight, A. (2011). Estimates of the asset-effect: The search for a causal effect of assets on adult health and employment outcomes. Working paper 149. London, UK: Centre for Analysis of Social Exclusion.

Meh, C., Terajima, Y., Chen, D. \& Carter, T. (2009). Household debt, assets, and income in Canada: A micro-data study. Discussion Paper No. 2009-7. Ottawa, ON: Bank of Canada.

Meltz, N. (1983). Historical statistics of Canada. Ottawa, ON: Statistics Canada.

Michener, D. (1956). Retirement savings and self-employment. The Debates of the House of Commons, July 30.

Midgley, J. (2005). Asset-based policy in historical and international perspective. In Sherraden, M. (Ed.). Inclusion in the American dream: Assets, poverty and public policy. New York: Oxford University Press.

Miller, J., \& Montalto, C. (1998). Comparison of economic status of elderly households: Non metropolitan versus metropolitan. Family Economics and Nutrition Review, 11 (4).

Milligan, K. (2003). How do contribution limits affect contributions to tax-preferred savings accounts? Journal of Public Economics, 87(2), 253-281.

Milligan, K. (2004). Life-cycle asset accumulation and allocation in Canada. NBER working paper No.10860, National Bureau of Economic Research, Inc. Retrieved from http://ideas.repec.org/e/pmi14.html

Milligan, K. (2012). Policy forum: The tax-free savings account-Introduction and simulations of potential revenue costs. Canadian Tax Journal, 60(2), 355-360.

Mink, G. \& O'Connor, M. (2004). Poverty in the United States: An encyclopedia of history, politics and poverty. Santa Barbara, CA: ABC-CLIO.

Mintz, J. (2001). Taxing future consumption. In Grady, P. \& Sharpe, A. (Eds.)., The State of Economics in Canada: Festschrift in Honour of David Slater. Ottawa, ON: Centre for the Study of Living Standards.

Mintz, J. (2009). Summary report on retirement income adequacy research. Ottawa, ON: Department of Finance. Retrieved from http://www.fin.gc.ca/activty/pubs/pension/riar-narr-eng.asp 
Mintz, J. \& Wilson, T. (2013). Reform proposals for replenishing retirement savings. Discussion paper. University of Calgary.

Mises, L. (1966). Human action, fourth edition. Retrieved from http://mises.org/books/humanaction.pdf

Mkandawire, T. (2005). Targeting and universalism in poverty reduction. Social Policy and Development Programme Paper No. 23, United National Research Institute for Social Development.

Modigliani, F. (1986). Life cycle, individual thrift, and the wealth of nations. The American Economic Review, 76(3), 297-313.

Mont, O. \& Plepys, A. (2008). Sustainable consumption progress: Should we be proud or alarmed? Journal of Cleaner Production, 16 (4), 531-537.

Morissette, R., Zhang, X. \& Drolet, M. (2002). Wealth inequality. Perspectives on Labour and Income, February.

Morissette, R. \& Ostrovsky, Y. (2005). The instability of family earnings and family income in Canada, 1986 to 1991 and 1996 to 2001. Research paper No 265. Ottawa, ON: Statistics Canada.

Morissette, R. \& Zhang, X. (2006). Revisiting wealth inequality. Perspectives on Labour and Income, 7(12), 5-16.

Morrison, W. \& Oxoby, R. (2011). Economic research using laboratory experiments to investigate behavioural aspects of savings decisions. Research paper prepared for the Task Force on Financial Literacy.

Moscovitch, A. \& Albert, J. (1987). The "benevolent" state: The growth of welfare in Canada. Toronto, ON: Garamond Press.

Moussaly, K. (2010). Participation in private retirement savings plans, 1997-2008. Research paper. Ottawa, ON: Statistics Canada.

Mullainathan, S. \& Shafir, E. (2009). Savings policy and decision-making in low-income households. In Barr, M. \& Blank, R. (Eds.). Insufficient funds: Savings, assets, credit and banking among low-income households. New York, NY: Russell Sage Foundation Press.

Munroe, D. (2013). Mansion tax: The effect of transfer taxes on the residential real estate market. Paper presented at the Canadian Economics Association Annual Meeting, Montreal, QC, May. 
Myles, J. (1998). How to design a liberal welfare state: A comparison of Canada and the United States. Social Policy and Administration, 32, 341-364.

Myles, J. \& Picot, G. (2000). Social transfers, earnings and low-income intensity among children, 1981-96: Highlighting recent developments in low-income measurement. Branch research paper series, No. 144. Ottawa, ON: Statistics Canada.

National Anti-Poverty Organization (2004). Testimony on RESPs. Standing Committee on Human Resources, House of Commons. Journals, Hansard. October 21 November 2.

National Council of Welfare (2010). Welfare Incomes in Canada. Ottawa, ON.

National War Finance Committee (1942). Briefing paper on projected federal budget. Retrieved from Library and Archives Canada.

National War Finance Committee (1942). Pamphlet on compulsory savings. August 1942. Retrieved from Library and Archives Canada.

Nayar Consulting (2013). SmartSaver: Final evaluation report. Toronto, ON: Omega Foundation.

New Economics Foundation (2005). Behavioural economics: Seven principles for policymakers. Discussion paper London, UK:NEF.

Nishiyama, S. (2011). The budgetary and welfare effects of tax-deferred retirement savings accounts. Journal of Public Economics, 95, 1561-1578.

Oliver, M. and Shapiro, T. (1995). Black wealth/White wealth. New York, NY: Routledge.

Organization for Economic Cooperation and Development (2007). Encouraging savings through tax-preferred accounts. Tax policy study No.15. Retrieved from www.oecd.org.

Organization for Economic Cooperation and Development (2011). How's life?: Measuring well-being. Retrieved from www.oecd.org.

Organization for Economic Cooperation and Development (2013). Guidelines for micro statistics on household wealth. Paris, France: OECD. Retrieved from www.oecd.org.

Orlikow, D. (1978). The budget. The Debates of the House of Commons. June 21. 
Parliamentary Budget Office (2011). Federal tax expenditures: Use, reporting and review. Library of Parliament. Retrieved from http://www.pbodpb.gc.ca/files/files/Publications/Tax_Expenditures_Note_EN.pdf.

Paxton. W. \& White, S. (2006). The Citizen's Stake: Exploring the Future of Universal Asset Policies. Bristol: Policy Press.

Pelletier, R. \& Thomas, T. (1998). Financing university education in Canada. Ottawa, ON: Statistics Canada. Retrieved from http://www.statcan.gc.ca/pub/11-516x/sectionw/4147445-eng.htm\#3

Perry, H. (1951). Taxation in Canada. Toronto, ON: The Canadian Tax Foundation.

Perry, H. (1989). A fiscal history of Canada: The postwar years. Toronto, ON: The Canadian Tax Foundation.

Planned Lifetime Advocacy Networks (2003). Submission to the Technical Advisory Committee on Tax Measures for Persons with Disabilities. Vancouver, BC.

Planned Lifetime Advocacy Networks (2011). Submission to the three year review of the RDSP. Vancouver, BC.

Poschmann, F. (2012). Why we should not fear expansion of tax-free savings accounts. Canadian Tax Journal, 60(2), 391-399.

Poschman, F. \& Robson, W. (2004). Saving's grace: A framework to promote financial independence for low-income Canadians. Backgrounder 86. Toronto, ON: C.D. Howe Institute.

Poterba, J., Venti, S. \& Wise, D. (1995). Do 401(k) contributions crowd out other personal saving? Journal of Public Economics, 58(1), 1-32.

Poterba, J. \& Samwick, A. (2002). Taxation and household portfolio composition: US evidence from the 1980s and 1990s. Journal of Public Economics, Elsevier, 87(1), 5-38.

Poterba, J. (2011). Introduction: Economic analysis of tax expendtures. National Tax Journal, 64, 451-457.

Prince, M. (2007). Soft craft, hard choices, altered context: Reflections on twenty-five years of policy advice in Canada. In Dobuzinskis, L, Howlett, M. \& Laycock, D. (Eds.). Policy analysis in Canada. Toronto, ON: University of Toronto Press, 163-185.

Privy Council Office (1945). Royal commission on taxation of annuities and family corporations. Ottawa, ON. Retrieved from http://www.pco- 
$\underline{\text { bcp.gc.ca/index.asp?lang }=\text { eng \&page }=\text { information } \& s u b=\text { commissions } \& d o c=\operatorname{archi}}$ ves/comm-eng.htm\#I

Privy Council Office (1957). Cabinet record of decision. Undated, 1957. Ottawa, ON. Retrieved from Library and Archives Canada.

Privy Council Office (1966). Royal commission on taxation. Ottawa, ON. Retrieved from http://www.pcobcp.gc.ca/index.asp?lang=eng\&page $=$ information $\&$ sub $=$ commissions\&doc $=a \operatorname{archi}$ ves/comm-eng.htm\#I

Privy Council Office (1976). Cabinet record of decision. August 5. Ottawa, ON. Retrieved from Library and Archives Canada.

Quinn (1973). Quinn v Canada. Federal Court, case 73, DTC 5215. April 16.

Quebec Portal (2013). QESI [webpage]. Retrieved from www.gouv.qc.ca/eng/.

Rabin, M. (1998). Psychology and economics. Journal of Economic Literature, 36(1), 11-46.

Ragan, C. (1994). Progressive incomes taxes and the substitution effect of RRSPs. Canadian Journal of Economics, 27, 43-57.

Ragan, C. (1995). RRSPs and national saving in Canada. Prepared under contract for the Department of Finance, Ottawa, ON, December.

Ragan, C. (1997, January 30). Abolish RRSPs? Yes! The Ottawa Citizen. Retrieved from http://people.mcgill.ca/files/christopher.ragan/oped0.pdf.

Raphael, S. \& Rice, L. (2002). Car ownership, employment, and earnings. Journal of Urban Economics 52, 109-130.

Rauflaud, T. (2006). Canada student loans program. Background paper. Ottawa, ON: Library of Parliament.

Robinson, A. \& Cutt, J. (1973). Public finance in Canada: Selected readings. Toronto, ON: Methuen.

Robson, J. (2004). Testimony on RESPs. Standing Committee on Human Resources, House of Commons. Journals, Hansard. November 2.

Robson, J. (2008). Wealth, low-wage work and welfare: The unintended costs of provincial needs-tests. Research report. Toronto, ON: Social and Enterprise Development Innovations. 
Rohe, W. \& Stewart, L. (1996). Home ownership and neighborhood stability. Housing Policy Debate, 9, 37-81.

Rowlingson, K. \& McKay, S. (2012). Wealth and the wealthy: Exploring and tackling inequalities between rich and poor. Bristol, UK: The Policy Press.

Ryley, A. (1970). Let to plan members. Toronto: ON: Canadian Scholarship Trust Foundation.

Ryley, A. (1971). Let to plan members. Toronto: ON: Canadian Scholarship Trust Foundation.

Ryley, A. (1972). Let to plan members. Toronto: ON: Canadian Scholarship Trust Foundation.

Ryley, A. (1973). Let to plan members. Toronto: ON: Canadian Scholarship Trust Foundation.

Ryley, A. (1974). Let to plan members. Toronto: ON: Canadian Scholarship Trust Foundation.

Ryley, A. (1975). Let to plan members. Toronto: ON: Canadian Scholarship Trust Foundation.

Saarimaa, T. (2010). Tax incentives and demand for mortgage debt: Evidence from the Finnish 1993 tax reform. International Journal of Housing Policy, 10(1), 19-40.

Savoie, D. (1999). Governing from the Centre: The concentration of power in Canada. Toronto, ON: University of Toronto Press.

Scanlon, E. \& Page-Adams, E. (2001). Effects of asset-holding on neighborhoods, Families, and Children: A Review of Research. In Boshard, R. (Ed.). Building assets - A report on the asset-development and IDA field. Washington, DC: Center for Economic Development.

Scarlat, M. \& Lefebvre, R. (2009). Tax-free savings accounts - Shifting opportunity. Research report. Certified General Accountants of Canada.

Schellenberg, G. \& Ostrovsky, Y. (2010). Retirement-related highlights from the 2009 Canadian Financial Capability Survey. Insights on the Canadian Economy 2010026e. Statistics Canada.

Schick, A. (2007). The federal budget: Politics, policy, process. Washington, DC: Brookings Institute Press. 
Schwartz, S. \& Ben-Ishai, S. (2012). Access to personal financial services in Canada. Research report for Human Resources and Skills Development Canada, Ottawa, ON.

Shaviro, D. (2004). Replacing the income tax with a progressive consumption tax. Tax Notes, April 5.

Sherraden, M. (1991). Assets and the poor: A new American welfare policy. Armonk, NY: M.E. Sharpe Inc.

Sherraden, M. (2005). Inclusion in the American dream: Assets, poverty and public policy. New York, NY: Oxford University Press.

Sherraden, M. (2008). IDAs and asset-building policy: Lessons and directions. Working Paper 08-12, Center for Social Development, Washington University.

Shillington, R. (2003). New poverty traps: Means-testing and modest-income seniors. Backgrounder \#65. Toronto, ON: C.D. Howe Institute.

Shillington, R. (2004). Testimony on RESPs. Standing Committee on Human Resources, House of Commons. Journals, Hansard. November 2.

Shillington, R. (2005). The disability savings plan: Policy milieu and model development. Ottawa, ON: The Caledon Institute. Retrieved from www.caledoneinst.org.

Shipley, L., Ouellette, S. \& Cartwright, F. (2003). Planning and preparations: First results from the Survey of Approaches to Educational Planning. Research paper. Statistics Canada.

Skinner, B. F. (1953). Science and human behavior. New York, NY: Macmillan.

Skinner, B.F. (1978). Reflections on behaviorism and society. New Jersey: Prentice Hall.

Smiles, S. (1876). Thrift. Retrieved from Project Gutenberg. http://www.gutenberg.org/ebooks/14418

Social and Enterprise Development Innovations (2010). Submission to the Canadian Securities Administrators. June 21. Retrieved from www.sedi.org.

Sofaer, S. (1999). Qualitative methods: What are they and why use them? Journal of Health Services Research, 34(5), 1101-1118.

Soman, D. (2011). The trouble with consumer credit: Literacy consideration and policy implications. Research report prepared for the Task Force on Financial Literacy, Ottawa, ON. 
Sørensen, P. (2007). The Nordic dual income tax: Principles, practices, and relevance for Canada. Canadian Tax Journal, 55(3), 557-602.

Spaargarn, G (2003). Sustainable consumption: A theoretical and environmental policy perspective. Society and Natural Resources, 16, 687-701.

Stapleton, J. \& Shillington, R. (2008). No strings attached: How the tax-free savings account can help lower-income Canadians get ahead. Policy brief. Toronto, ON: C.D. Howe Institute.

Stapleton, J. (2009). Why don't we want the poor to own anything? Research report. Toronto, ON: Metcalfe Foundation.

Stapleton, J. (2013). Stop wondering about under-subscription of benefits. Blog post, January 22. Retrieved from www.openpolicyontario.com.

Statistics Canada (2009). Canadian Survey of Financial Capability. Author's calculations. Retrieved from www.odesi.ca.

Statistics Canada (2010). Survey of Financial Security: Microdata user's guide. Ottawa, $\mathrm{ON}$.

Steele, M. (2007). The Canadian home buyers' plan: Tax benefit, tax expenditure, and policy assessment. The Canadian Tax Journal, 55(1), 1-30.

Steinberger, P. (1981). Political participation and community: A cultural/interpersonal approach. Rural sociology, 46, 17-19.

Stevanovic, P. \& Rupert, P. (2004). Career-sustaining behaviors, satisfactions and stresses of professional psychologists. Psychotherapy: Theory, research, practice, training, 41(3), 301-309.

Stoesz, D. (2007). Bootstrap capitalism: Sequel to welfare reform. Families in Society, 88(3), 375-378.

Surrey, S. (1967). The U.S. income tax system: The need for a full accounting. Speech before the Money Marketers, November 15, 1967. Cited in Toder, E. (2005). Tax Expenditures and Tax Reform: Issues and analysis. Paper presented at the National Tax Association Meetings, Miami, Florida, November 19, 2005. Retrieved from http://www.taxpolicycenter.org

Sussman, A. \& Shafir, E. (2012). On assets and debt in the psychology of perceived wealth. Psychological Science, 23(1), 101-108.

Tax Review Board (1972). Quinn v. Canada. Case 72, DTC 1413. May 30. 
Templin, M. (2004). Panic fiction: Women's responses to Antebellum economic crisis. Legacy, 21(1), 1-16.

Thaler, R. \& Shefrin, H. (1981). An economic theory of self-control. Journal of Political Economy, 89(2), 392-406.

Thaler, R. (1990). Saving, fungibility, and mental accounts, Journal of Economic Perspectives, 4(1), 193-205.

Thaler, R. (1994). Psychology and savings policies. American Economic Review, 84(2), $186-92$.

Thaler, R. (1999). Mental accounting matters. Journal of Behavioral Decision Making, 12. 183-206.

Thaler, R. (2000). From homo economicus to homo sapiens. Journal of Economic Perspectives, 14(1), 133-141.

Thaler, R. \& Sunstein, C. (2008). Nudge. New York, NY: Penguin Books.

Thaler, R. (2010). Presentation to the Task Force on Financial Literacy. Toronto.

The Calgary Herald (2008, March 8). RESP proposal called 'bizarre'. Retrieved from www.canada.com.

Titmus, R. (1962). Income distribution and social change. London, UK: Allen and Unwin.

Toder, E. (2005). Tax expenditures and tax reform. Working paper. Tax Policy Center, Washington, DC. Retrieved from http://www.taxpolicycenter.org/UploadedPDF/411371_tax_expenditures.pdf.

Toder, E., Harris, B. \& Lim, K. (2011). Distributional effects of tax expenditures. Working Paper. Tax policy Center. Washington, DC. Retrieved from http://www.taxpolicycenter.org/UploadedPDF/411922_expenditures.pdf.

Toussaint, J. (2011). Housing assets as a potential solution for financial hardship. Housing Theory and Society, 28(4), 320-341.

Turner, T. \& Luea, H. (2009). Homeownership, wealth accumulation and income status. Journal of Housing Economics, 18, 104-114.

Tversky, A. \& Kahneman, D. (1991). Loss aversion in riskless choice: A referencedependent model. The Quarterly Journal of Economics, 106(4), 1039-61. 
University of British Columbia (2013). Dataset. Sauder Business School. Centre for Urban Economics and Real Estate, Vancouver, BC.

VanLoan, P. (2004). Statements on RESPs. Standing Committee on Human Resources, House of Commons. Journals, Hansard. November 2.

van Rooij, M., Lusardi, A., \& Alessie, R. (2011). Financial literacy and retirement planning in the Netherlands. Journal of Economic Psychology, 32(4), 593-608.

Veall, M. (2001). Did tax flattening affect RRSP contributions? Canadian Journal of Economics, 34(1), 120-131.

Venti, S. \& Wise, D. (1986). Tax-deferred accounts, constrained choice and estimation of individual saving. Review of Economic Studies, 53(4), 579-601.

Wardhaugh, R. (2010). Behind the scenes: The life and work of W.C. Clark. Toronto, ON: University of Toronto Press.

Warland, P. (1999) "Consumer perception: ISAs and image", speech to the Money Marketing Conference, London, UK, November.

Wasco, S., Campbell, R., Clark, M. (2002). A multiple case study of rape victim advocates' self care routines. American Journal of Community Psychology, 30(5), 731-760.

Watson, J. B. (1924). Behaviorism. New York, NY: Norton.

Wawro, G. \& Katznelson, I. (2010). Political science and history: Enhancing the methodological repertoire. Working paper. Retrieved from www.columbia.edu/ gjw10/polisci_history.8_20_10.pdf

Weber, M. (1905). The protestant ethic and the spirit of capitalism. Reprinted online 2005. Retrieved from https://www.marxists.org/reference/archive/weber/protestant-ethic/index.htm

Wells, P. (2006). Right side up: The fall of Paul Martin and the rise of Stephen Harper's new conservatism. Toronto, ON: McLelland and Stewart.

White, D. (2003). Personal communication. London, UK, Fall 2003.

Whyley, C. \& Kempson, E. (2000). Understanding small savers: Saving behaviour amongst low-to-middle income groups. Personal Finance Research Centre, Bristol University. Retrieved from http://www.bristol.ac.uk/geography/research/pfrc/themes/psa/ 
Wilkinson, R. \& Pickett, K. (2009). The Spirit Level: Why more equal societies almost always do better. London, UK: Bloomsbury Press.

Wilson, M. (1985a). The budget. The Debates of the House of Commons. May 23.

Wilson, M. (1985b). The budget. The Debates of the House of Commons. December 11.

Wisenthal, M. (1983). Historical statistics of Canada. Ottawa, ON: Statistics Canada. Retrieved from: http://www.statcan.gc.ca/pub/11-516-x/sectionw/4147445eng.htm\#3

Wright, P. (1962). Letter to plan members. Toronto: ON: Canadian Scholarship Trust Foundation.

Wright, P. (1963). Letter to plan members. Toronto: ON: Canadian Scholarship Trust Foundation.

Wright, P. (1964). Letter to plan members. Toronto: ON: Canadian Scholarship Trust Foundation.

Wright, P. (1965). Letter to plan members. Toronto: ON: Canadian Scholarship Trust Foundation.

Wright, P. (1966). Letter to plan members. Toronto: ON: Canadian Scholarship Trust Foundation.

Wright, P. (1967). Letter to plan members. Toronto: ON: Canadian Scholarship Trust Foundation.

Wright, P. (1968). Letter to plan members. Toronto: ON: Canadian Scholarship Trust Foundation.

Wright, P. (1969). Letter to plan members. Toronto: ON: Canadian Scholarship Trust Foundation.

Wong, M. (2010). SmartSAVER. Conference presentation. Fear of Finance, Financial Literacy and Planning for Post-secondary education. Higher Education Quality Council of Ontario, Toronto, ON.

Woo, L., Schweke, W. \& Buccholz, D. (2004). Hidden in plain sight: A look at the \$335 billion federal asset-building budget. Research report. Washington, DC: Corporation for Enterprise Development.

Yermo, J. (2001). Private annuity contracts in OECD countries. Private Pensions Series No. 3. Paris, France: OECD. 
Yin, R. (2011). Qualitative Research from Start to Finish. New York, NY: Guilford Press.

Zhou, J. (2009). The asset location puzzle: Taxes matter. Journal of Economic Dynamics and Control, 33, 955-969.

Zuberi, D. (2004). Transfers matter most: How changes in transfer systems of Canada and the United States explain the divergence in household poverty levels from 1974-1994. International Journal of Comparative Sociology, 45(1-2), 87-110.

Zyblock, M., Webber, M., Sheilds, M. \& Maser, K. (1997). Towards a new Canadian asset and debt survey: A content discussion paper. Ottawa, ON: Statistics Canada. 